\title{
Connecting conversations: experienced quality of care from the resident's perspective
}

Citation for published version (APA):

Sion, K. Y. J. (2021). Connecting conversations: experienced quality of care from the resident's perspective: a narrative method for nursing homes . [Doctoral Thesis, Maastricht University]. Maastricht University. https://doi.org/10.26481/dis.20210317ks

Document status and date:

Published: 01/01/2021

DOI:

$10.26481 / \mathrm{dis} .20210317 \mathrm{ks}$

Document Version:

Publisher's PDF, also known as Version of record

\section{Please check the document version of this publication:}

- A submitted manuscript is the version of the article upon submission and before peer-review. There can be important differences between the submitted version and the official published version of record.

People interested in the research are advised to contact the author for the final version of the publication, or visit the DOI to the publisher's website.

- The final author version and the galley proof are versions of the publication after peer review.

- The final published version features the final layout of the paper including the volume, issue and page numbers.

Link to publication

\footnotetext{
General rights rights.

- You may freely distribute the URL identifying the publication in the public portal. please follow below link for the End User Agreement:

www.umlib.nl/taverne-license

Take down policy

If you believe that this document breaches copyright please contact us at:

repository@maastrichtuniversity.nl

providing details and we will investigate your claim.
}

Copyright and moral rights for the publications made accessible in the public portal are retained by the authors and/or other copyright owners and it is a condition of accessing publications that users recognise and abide by the legal requirements associated with these

- Users may download and print one copy of any publication from the public portal for the purpose of private study or research.

- You may not further distribute the material or use it for any profit-making activity or commercial gain

If the publication is distributed under the terms of Article $25 \mathrm{fa}$ of the Dutch Copyright Act, indicated by the "Taverne" license above, 


\section{Connecting Conversations}

Experienced quality of care from the resident's perspective:

a narrative method for nursing homes

Katya Yolanda Jeannette Sion 
The research presented in this thesis was conducted at CAPHRI Care and Public Health Research Institute, Department of Health Services Research, Maastricht University. CAPHRI participates in the Netherlands School of Public Health and Care Research CaRe. The research was funded by the seven long-term care organizations belonging to the Living Lab in Ageing and Long-Term Care: Meandergroep Zuid-Limburg, Sevagram, Envida, Cicero Zorggroep, Zuyderland, Mosae Zorggroep and Vivantes, and the health insurance company CZ (grant number 201600132). This work was co-supported bij Limburg Meet (LiMe).

Printing: Gildeprint

Cover design: Marijn Berg

(C) Copyright Katya Sion, Maastricht 2021

All rights are reserved. No part of this book may be reproduced or transmitted in any form or by any means, without the written permission from the author or, where appropriate, from the publishers of the publications. 


\section{Connecting Conversations}

Experienced quality of care from the resident's perspective: a narrative method for nursing homes

\section{PROEFSCHRIFT}

Ter verkrijging van de graad van doctor aan de Universiteit Maastricht, op gezag van Rector Magnificus, Prof. Dr. Rianne M. Letschert, volgens het besluit van het College van decanen, in het openbaar te verdedigen op woensdag 17 maart 2021 om 13.00u

door

Katya Yolanda Jeannette Sion 


\section{Promotores}

Prof. Dr. JPH Hamers

Prof. Dr. H Verbeek

Prof. Dr. GJ Odekerken-Schröder

Prof. Dr. JMGA Schols

Beoordelingscommissie

Prof. dr. FRJ Verhey (voorzitter)

Prof. dr. D Mahr

Prof. dr. AMWJ Schols

Prof. dr. K Spilsbury (University of Leeds, UK)

Prof. dr. GJ Westerhof (University of Twente) 
Dedicated to Daddy \& Mama 



\section{CONTENTS}

CHAPTER 1 General Introduction 9

CHAPTER 2 Themes Related to Experienced Quality of Care in Nursing Homes

From the Resident's Perspective: A Systematic Literature Review and Thematic Synthesis

Gerontology \& Geriatric Medicine, 2020

CHAPTER 3 Experienced Quality of Post-Acute and Long-Term Care From the

Care Recipient's Perspective - A Conceptual Framework

Journal of the American Medical Directors Association, 2019

CHAPTER 4 How to Assess Experienced Quality of Care in Nursing Homes From the Client's Perspective: Results of a Qualitative Study

BMC Geriatrics, 2020

CHAPTER 5 The Feasibility of Connecting Conversations: A Narrative Method to Assess Experienced Quality of Care in Nursing Homes From the Resident's Perspective

International Journal of Environmental Research and Public Health, 2020

CHAPTER 6 The Validity of Connecting Conversations: A Narrative Method to Assess Experienced Quality of Care in Nursing Homes From the Resident's Perspective

International Journal of Environmental Research and Public Health, 2020

CHAPTER 7 Listen, Look, Link and Learn: a Stepwise Approach to Analyze

Narrative Quality Data within Resident-Family-Nursing Staff Triads in Nursing Homes

Submitted for publication

CHAPTER 8 General Discussion

Summary

Samenvatting

Impact

Dankwoord

About the Author

Scientific Publications 



\section{CHAPTER 1}

General Introduction 

Recently, Mr and Mrs Hill went away for the weekend to Maastricht. After having used the lavatory facilities in a shopping mall, Mr Hill was - while washing his hands - asked by a sign to evaluate his overall experience of the cleanliness of the lavatory, by pressing a green, orange or red smiley face. They continued to their spa appointments, where the couple waited for a whole hour before they were met by a staff member. After their mud bath, they were asked for an additional 5 minutes of their time, to fill out a form on their experience with the provided service. They then proceeded to their pre-booked dinner at a highly recommended restaurant. The restaurant kindly asked them to leave an online review of their dining experience. The next morning, shortly after checking out of the hotel, Mrs. Hill received an email, asking how she and her husband had experienced their overnight stay at the hotel, and if they would recommend it to their friends and family.

The story above shows how people are continuously part of different service encounters, and are being asked to evaluate how they have experienced these. It is important to structurally assess quality of services, to assure a high quality standard, and alignment between consumers' expectations and the service delivered. ${ }^{1,2}$ Service delivery (for example in restaurants or hotels) has many similarities with long-term care provision (for example in nursing homes). Both are complex service networks characterized as intangible, heterogeneous, perishable, interactive, and multifaceted. ${ }^{3-5}$ They are dependent on the interactions between people involved, for example between the resident and the professional caregiver in a nursing home, and cannot be judged in advance. In addition, they cannot be provided with uniformity, as they are dependent on their location and timing. ${ }^{3,4}$

However, the nursing home setting is unique compared to these other services, as the nursing home is the resident's home. A resident's customer journey is a continuous ongoing journey as long as the resident lives in the nursing home, making it more extensive and complex than when receiving a standard service. It includes many different stakeholders who the resident has to rely on, due to his or her frailty and continuous need of support. In addition, a resident receiving care is dependent on others for (instrumental) activities of daily living and often has limited choice regarding which nursing home to live in and who provides the care services. It encompasses someone's full daily life and therefore, assessing quality of care in nursing homes is even more complex than assessing quality of more standard services.

The studies in this dissertation focus on discovering how to define and assess quality of care in nursing homes from the resident's perspective. This chapter will introduce the nursing home setting, the concept of quality of care in this setting, and how quality of care in nursing homes is currently assessed. The final paragraph will present the aims and the outline of this dissertation. 


\section{NURSING HOMES IN THE NETHERLANDS}

Worldwide, 703 million people were aged 65+ (9\%) in 2019 and this number is expected to increase to 1.5 billion (16\%) in $2050 .{ }^{6}$ In the Netherlands, approximately 3.3 million people were aged $65+(19 \%)$ in $2019 .{ }^{7}$ Dutch policy stimulates people to live at home as long as possible and nursing homes are provided as an alternative only for the most frail group of people in our society. ${ }^{8}$ Currently, more than 115.000 people in the Netherlands are living in a nursing home. ${ }^{9}$ Nursing homes are institutions that provide 24-hour care for people who are vulnerable and have complex health needs, requiring assistance with (instrumental) activities of daily living. ${ }^{10}$ There are three different types of nursing home wards: somatic wards for residents with physical disabilities, psychogeriatric wards for residents with cognitive impairments (such as dementia) and rehabilitation wards for residents in need of short-term care. ${ }^{11} \mathrm{~A}$ majority of Dutch nursing home residents are women (73\%), have a mean age of 85 years and most are diagnosed with memory problems, severe physical impairments and/or comorbidities. ${ }^{12}$ There is a wide variety in nursing home residents and therefore the average stay in nursing homes varies with averages of 3 months up to 18 months. ${ }^{13}$ Caregivers working in nursing homes are mostly certified nurse assistants (verzorgenden), nurse assistants (helpenden), registered nurses (MBO-verpleegkundigen), and bachelor-educated registered nurses (HBO-verpleegkundigen), and most Dutch nursing homes work with self-employed elderly care physicians, a unique role in Dutch nursing homes. ${ }^{14}$ In addition, allied health professionals are part of nursing staff, including psychologists, occupational therapists, dieticians and physiotherapists amongst others.

Worldwide, nursing homes used to be perceived quite negatively by society and the media, emphasizing that the work pressure is too high and that residents are being neglected. ${ }^{15}$ Moving to a nursing home has been related to negative effects including loneliness, isolation from loved ones and loss of privacy and identity. ${ }^{16,17}$ Residents have expressed frustrations regarding their lack of independence and decision-making, and how they are spoken to in disparagement by staff. ${ }^{18,19}$ In addition, nursing staff have experienced high levels of burden and time pressure, challenging relationships with family members, and feelings of guilt about the quality of care they can provide. ${ }^{20,21}$

In 2014, the Dutch Health Care Inspectorate identified a need to improve good care delivery in nursing homes. ${ }^{22}$ In response to all this negativity and the urgent need for improvement, the Dutch government introduced a new program in 2015 'Waardigheid en Trots' (Dignity and Pride), the key elements of loving care for our elderly. This program aims to achieve good care for residents living in nursing homes by maximizing self-esteem and quality of life. Dignity entails care provision that matches the wishes and possibilities of the resident, with the warm involvement and pleasure of motivated informal and formal caregivers. This care should be provided with (professional) pride, because it meets professional standards delivered in a protected residential environment. ${ }^{23}$ In 2017, this program was accompanied by a new quality framework on how to maintain and improve quality of care in nursing homes. ${ }^{24}$ This policy emphasizes the importance of person- and relationship-centred care, 
well-being, safety, and learning and collaborating. It states residents should determine how caregivers and organisations can optimally contribute to their quality of life and that they are the ones who should also evaluate this. In other countries similar developments are occurring. ${ }^{25,26}$ Gradually the views on nursing homes are changing accompanied by more positive news, for example a recent report revealed six out of ten residents feel (extremely) happy living in the nursing home and family and residents are becoming more positive about nursing homes. ${ }^{8,27}$

In line with these developments, there is an ongoing culture change from task-oriented to person-centred and relationship-centred care in nursing homes. Whereas task-oriented care focusses more on the medical tasks that need to be performed, such as activities of daily living; person-centred care is more holistic and incorporates residents' needs, preferences and relationships; and relationship-centred care incorporates the needs of everyone involved in the care experiences. ${ }^{28-32}$ Currently, person-centred care is most commonly strived for in nursing homes and different definitions have emerged over the past decades. What they have in common is that person-centeredness aims to identify each resident as an individual by (1) understanding the person, (2) engaging them in decision-making, and (3) promoting their care relationships. ${ }^{33}$ Ideally, staff strive to make it possible for residents living in nursing homes to continue living their lives as they did before they moved into the nursing home, and know who they are as an individual person. ${ }^{34}$ However, this has shown to be challenging to achieve in practice. ${ }^{35}$ The culture change has also enhanced the debate regarding what is considered to be good quality of care.

\section{DEFINING QUALITY OF CARE IN NURSING HOMES}

A philosopher recently said defining quality of care is problematic, as it is a concept about how people appreciate things, which is constantly changing, very personal and actually only exists once people talk about it together. ${ }^{36}$ This is reflected in the variety of definitions that exist for quality. In service sciences for example, service quality has been defined as the extent to which an organization meets or exceeds customers' expectations. ${ }^{1}$ In health sciences, Donabedian defined quality of care as a reflection of values and goals within the care system and society. ${ }^{37}$ Building on this, the Institute of Medicine specified quality of care as 'the degree to which health services for individuals and populations increase the likelihood of desired health outcomes and are consistent with current professional knowledge'. Many definitions of quality of care are also being fragmented into dimensions such as being safe, effective, person-centred, timely, efficient, equitable, accessible and affordable. ${ }^{38-40}$

These generic definitions of quality of care are frequently used as a foundation to operationalize quality of care to a specific setting and from a specific perspective. When focussing specifically on care for older people for example, a study discovered that quality of care received by older people is influenced by: (1) respecting the personhood of the care recipients i.e. being perceived as an individual, (2) valuing the interdependence in the relationship, and (3) investing in caregiving as a choice or personal decision. ${ }^{41}$ For nursing 
homes specifically, in the late 90s a multidimensional theoretical model was developed in which residents and their families are at the core surrounded by six dimensions: interactions between staff and residents, milieu and community, environment e.g. cleanliness and space, individualized care i.e. staff know and meet individual resident needs, staff skills, and safety. ${ }^{42}$ Currently, person-centred care is considered a model that reflects high quality of care in nursing homes, as it has shown to positively influence residents' quality of life and satisfaction. ${ }^{43,44}$ This fits within the setting, because living in a nursing home is more than receiving medical care; it is someone's home. ${ }^{45}$ The culture change has also resulted in an increased focus on care experiences, defined as the sum of interactions across the care process, influencing residents' perceptions within the nursing home culture. ${ }^{46}$

In addition, different perspectives value different aspects of quality of care in nursing homes. Residents have expressed the importance of feeling alive, including the need for a home-like environment, person-centred care tailored to residents' wishes, and receiving autonomy. ${ }^{47}$ Family members have expressed they value that a nursing home pays attention to the resident's physical appearance, personal preferences and how the resident's life was at home. ${ }^{45,48} \mathrm{~A}$ recent study showed nurses value their working environment, not just in terms of adequate resources and staffing, but also regarding education opportunities and effective leadership..$^{49}$ On a different level, the health insurer for example seeks for high quality of care for the lowest possible costs. ${ }^{50}$ Henceforth, the choice of perspective influences the definition and assessment of quality of care.

\section{ASSESSING QUALITY OF CARE IN NURSING HOMES}

Assessing quality of care in nursing homes is important for improvement of individual and organizational quality of care, accountability and transparency. ${ }^{25}$ On an operational level, information on quality of care is indispensable to learn from and improve direct care provision for residents. On a tactical level, this information can be used to improve organizational processes within the nursing home and within care teams, and on a strategic level, it can be used for transparency and accountability purposes. ${ }^{51,52}$ Each level requires a specific type of information, and therefore it is challenging to assess quality of care from the resident's perspective on all three levels with one assessment method. To stay close to the residents and incorporate their views into quality of care cycles, the research in this dissertation was performed with the operational level as its starting point which ideally will ultimately allow for aggregation on a tactical and strategic level.

Assessing quality of care in nursing homes is complex, as this is dependent on the definition of what to assess, for which purpose, from which perspective and who to involve in these assessments. For service delivery, many methods exist to evaluate how consumers experienced a service, by means of for example short surveys, green-orange-red smileys, or the Net Promotor Score (NPS). ${ }^{53}$ In the health care sector, these methods of evaluation are also being used more frequently, for example in hospital care. ${ }^{54}$ However, in nursing homes this is more challenging, as residents can find it more difficult to evaluate care services due 
to their cognitive deteriorations, their care dependent position, and the nursing home is where they live, it is not just a temporary service encounter. ${ }^{55}$ Additionally, the complexity of the concept of quality of care makes it challenging to assess.

Therefore, in health care, quality indicators are frequently used to operationalize quality of care and make it more tangible and measurable. ${ }^{56}$ Donabedian's structure, process and outcomes model helps to define and operationalize quality indicators. ${ }^{57}$ Examples of these indicators are staff-mix (structure), the placement of safety protocols (process), and the prevalence of pressure ulcers or malnutrition (outcomes). ${ }^{56-58}$ The downside of using quality indicators however is that multiple indicators need to be assessed to capture the full construct of quality of care, and the choice of indicators is dependent on the definition of quality and the purpose of the measurement. ${ }^{52}$ In addition, most indicators focus on the outcomes and often remain quite clinical, because these aspects are easier to assess. Social aspects, such as engagement in daily life, and emotional aspects, such as satisfaction, are often underrepresented, and other people in the caring environment are often not included in the assessments. ${ }^{56,59,60}$ Henceforth, a complete portrait of quality of care remains absent. This is more in line with the professional or regulatory agency perspective, instead of representing the values and needs of what residents and their families find most important. ${ }^{31,61,62}$ This often results in improvement initiatives focusing on the wrong aspects to achieve a higher quality of care and quality of life for residents.

The increasing focus on the resident's needs, preferences and relationships, has led to the development of quality indicators that can be assessed by residents themselves with patient reported outcome measures (PROMs), such as 'severity of pain' assessed with a VAS-scale, and patient-reported experience measures (PREMs), such as 'feeling heard' assessed with the Consumer-Quality Index (CQ-Index). ${ }^{63,64}$ Additionally, satisfaction is considered an important outcome of the resident's perspective. ${ }^{65}$ Whereas PROMS, PREMS and satisfaction measures are useful quality indicators, they do not capture sufficient information on an operational level to fully understand and improve an individual's quality of care. ${ }^{66}$ In the Netherlands, assessments of quality of care from the resident's perspective with a mandatory standardized questionnaire was abolished, as this data was used more on a strategic level than on an operational and tactical level. It provided insufficient guidance to reflect on and actually improve quality of care based on these quantitative findings. ${ }^{67}$ The new policy guideline has provided nursing homes with more freedom to assess quality of care from the resident's perspective as they wish, with the minimum requirement of a yearly NPS measure which can be supplemented with any other assessment method deemed suitable. ${ }^{68}$ These evolvements show the growing need to focus more on residents' views on their full care experiences in quality assessments. ${ }^{46,69,70}$ However, the question remains how quality of care in nursing homes from the resident's perspective should be assessed, in order to be useable for quality improvement initiatives on an operational level. Therefore, the research presented in this dissertation has been performed. 


\section{AIM AND OUTLINE}

Aim

The aim of this dissertation is to develop an innovative method to assess quality of care in nursing homes from the resident's perspective. The steps undertaken to develop this assessment method are based on the five steps to develop a measurement instrument: defining the construct, development of items and response options, pilot-testing, fieldtesting, and evaluation of measurement properties. ${ }^{71}$ More specifically, this dissertation has multiple aims:

1. To gain insight into the definition of quality of care in nursing homes from the resident's perspective (defining the construct, chapters 2 and 3 )

2. To gain insight into how quality of care in nursing homes from the resident's perspective should be assessed according to stakeholders (development of item and response options, chapter 4)

3. To develop and test a method that assesses quality of care in nursing homes from the resident's perspective (pilot- and field-testing, chapter 5)

4. To evaluate the validity and value of the assessment method (evaluation of measurement properties, chapters 6 and 7)

\section{Outline}

The outline is presented in Figure 1. Chapter two reveals themes related to residents' experiences in nursing homes identified in a systematic literature review and thematic synthesis. Chapter three develops a conceptual framework that defines experienced quality of long-term care from the resident's perspective. Chapter four identifies how quality of care in nursing homes should be assessed according to client representatives and nursing home staff in a qualitative study. Chapter five creates the content and evaluates the feasibility of the narrative instrument 'Connecting Conversations' that assesses experienced quality of care in nursing homes. Chapter six analyses the face, content and construct validity of Connecting Conversations in a psychometric study. Chapter seven explores how the narrative data collected with Connecting Conversations can be used to learn from and improve with. In chapter eight the main findings of all studies are summarized followed by methodological and theoretical considerations, resulting in recommendations for further research and practice. 


\section{Defining the construct, item and response options}

2. Literature review

3. Theoretical framework

4. Needs assessment

\section{Instrument development}

5. Pilot \& field-testing including feasibility

\section{Evaluation of measurement properties}

6. Validity

7. Value

Figure 1. 'Quality of care: what is it truly about?' 


\section{REFERENCES}

1. Parasuraman A, ZeithamI VA, Berry LL. SERVQUAL: A multiple-item scale for measuring customer perceptions of service quality. . Journal of Retailing. 1988;6(41):12-40.

2. Gronroos C. Service quality: The six criteria of good perceived service. Review of business. 1988;9(3):10.

3. Parasuraman A, ZeithamI VA, Berry LL. A Conceptual Model of Service Quality and Its Implications for Future Research. Journal of Marketing. 1985;49(4):41-50.

4. Goffin K, Mitchell R. Innovation Management: Effective strategy and implementation: Macmillan Education UK; 2016.

5. Verleye K, Jaakkola E, Hodgkinson IR, Jun GT, Odekerken-Schröder G, Quist J. What causes imbalance in complex service networks? Evidence from a public health service. Journal of Service Management. 2017.

6. United Nations DoE, Affairs S. World Population Ageing, 2019. 2019.

7. CBS. Bevolking; geslacht, leeftijd en viercijferige postcode, 1 januari. StatLine; 2020.

8. Van Campen C, Verbeek-Oudijk D. Gelukkig in een verpleeghuis? Ervaren kwaliteit vanleven en zorg van ouderen in verpleeghuizen en verzorgingshuizen. Den Haag, NL: Sociaal en Cultureel Planbureau, 2017.

9. Centraal Bureau Statistiek. Aantal bewoners van verzorgings- en verpleeghuizen 20192020 [updated 25 March 202011 May 2020]. Available from: https://www.cbs.nl/nlnl/maatwerk/2020/13/aantal-bewoners-van-verzorgings-en-verpleeghuizen-2019.

10. Sanford AM, Orrell M, Tolson D, Abbatecola AM, Arai H, Bauer JM, et al. An international definition for "nursing home". J Am Med Dir Assoc. 2015;16(3):181-4.

11. Huls M, Rooij SE, Diepstraten A, Koopmans R, Helmich E. Learning to care for older patients: hospitals and nursing homes as learning environments. Medical Education. 2015;49(3):332-9.

12. Verbeek-Oudijk D, Van Campen C. Ouderen in verpleeghuizen en verzorgingshuizen: landelijk overzicht van hun leefstiuatie in 2015-2016. Den Haag, NL: Sociaal en Cultureel Planbureau, 2017.

13. Kiers B. Sterftecijfer verpleeghuis stijgt met kwart: Zorgvisie; 2018. Available from: https://www.zorgvisie.nl/sterftecijfer-verpleeghuis-stijgt-met-kwart/.

14. Schols JM, Crebolder HF, van Weel C. Nursing home and nursing home physician: the Dutch experience. J Am Med Dir Assoc. 2004;5(3):207-12.

15. Vegter F, Gijsberts L, Voorn M. Verpleeghuiszorg in Nederland. Belevingsonderzoek onder Nederlands publiek, professionals en bestuurders. 2016.

16. Townsend $P$. The last refuge: a survey of residential institutions and homes for the aged in England and Wales: London, Routledge; 1962.

17. Theurer K, Mortenson WB, Stone R, Suto M, Timonen V, Rozanova J. The need for a social revolution in residential care. Journal of Aging Studies. 2015;35:201-10.

18. Timonen V, O'Dwyer C. Living in institutional care: residents' experiences and coping strategies. Soc Work Health Care. 2009;48(6):597-613.

19. Baur VE, Abma TA. Resident councils between lifeworld and system: Is there room for communicative action? Journal of Aging Studies. 2011;25(4):390-6.

20. Zimmerman S, Williams CS, Reed PS, Boustani M, Preisser JS, Heck E, et al. Attitudes, stress, and satisfaction of staff who care for residents with dementia. Gerontologist. 2005;45 Spec No 1(1):96105.

21. Gallego-Alberto L, Losada A, Vara C, Olazarán J, Muñiz R, Pillemer K. Psychosocial Predictors of Anxiety in Nursing Home Staff. Clin Gerontol. 2018;41(4):282-92. 
22. Inspectie voor de Gezondheidszorg. Verbetering van de kwaliteit van de ouderenzorg gaat langzaam: Intensivering toezichtbezoeken aan verpleeg- en verzorgingshuizen in deperiode 2011 en 2012. Den Haag, Nederland: 2014.

23. Van Rijn MJ. Waardigheid en Trots, liefdevolle zorg voor onze ouderen. Ministerie van Volksgezondheid, Welzijn en Sport; 2015. p. 1-21.

24. Zorginstituut Nederland. Kwaliteitskader Verpleeghuiszorg Samen leren en verbeteren: Zorginstituut Nederland; 2017. 1-41 p.

25. OECD/EU. A Good Life in Old Age? Paris: OECD Publishing; 2013.

26. Tolson D, Rolland Y, Andrieu S, Aquino J-P, Beard J, Benetos A, et al. International Association of Gerontology and Geriatrics: A Global Agenda for Clinical Research and Quality of Care in Nursing Homes. Journal of the American Medical Directors Association. 2011;12(3):184-9.

27. Patiëntenfederatie Nederland. 70.000 verpleeghuisbewners aan het word: eindrapportage waarderingen binnen de verpleeghuiszorg 2015-2018. Utrecht, Nederland: 2018.

28. Brownie S, Nancarrow S. Effects of person-centered care on residents and staff in aged-care facilities: a systematic review. Clinical Interventions in Aging. 2013;8:1-10.

29. Rosher RB, Robinson S. Impact of the Eden Alternative on family satisfaction. Journal of the American Medical Directors Association. 2005;6(3):189-93.

30. Kazemi A, Kajonius P. User-oriented elderly care: a validation study in two different settings using observational data. Quality in Ageing and Older Adults. 2015;16(3):140-52.

31. Koren MJ. Person-centered care for nursing home residents: the culture-change movement. Health Aff (Millwood). 2010;29(2):312-7.

32. Pew-Fetzer TaskForce. Relationship-centered care: San Francisco: Pew Health Professions Commission; 1994.

33. Wilberforce M, Challis D, Davies L, Kelly MP, Roberts C, Clarkson P. Person-centredness in the community care of older people: A literature-based concept synthesis. International Journal of Social Welfare. 2017;26(1):86-98.

34. Verbeek H. Inclusion and Support of Family Members in Nursing Homes. In: Schüssler S, Lohrmann C, editors. Dementia in Nursing Homes. Cham: Springer International Publishing; 2017. p. 67-76.

35. Rosemond CA, Hanson LC, Ennett ST, Schenck AP, Weiner BJ. Implementing person-centered care in nursing homes. Health care management review. 2012;37(3):257-66.

36. Kremer J, Koksma J. Kwaliteit meten is een moreel oordeel vellen. Medisch Contact. 2017.

37. Donabedian A. Evaluating the quality of medical care. The Milbank memorial fund quarterly. 1966;44(3):166-206.

38. Donabedian A. The Definition of Quality and Approaches to Its Assesment: Health Administration Press; 1980.

39. Institute of Medicine Committee on Quality of Health Care in America. Crossing the Quality Chasm: A New Health System for the 21st Century. Washington (DC): National Academies Press (US); 2001.

40. Department of Health. The new NHS; modern .dependable. London: The Stationary Office; 1997.

41. Mulrooney CP. The competencies of formal caregivers needed to enhance elders' quality of life: The utility of the person- and relationship-centered caregiving trait. . The 16th World Congress of Gerontology, International Association of Gerontology and Geriatrics; August 1997; Adelaide, Australia1997.

42. Rantz MJ, Mehr DR, Popejoy L, Zwygart-Stauffacher M, Hicks LL, Grando V, et al. Nursing home care quality: a multidimensional theoretical model. J Nurs Care Qual. 1998;12(3):30-46; quiz 69-70.

43. Chou S-C, Boldy DP, Lee AH. Resident satisfaction and its components in residential aged care. Gerontologist. 2002;42(2):188-98.

44. McCormack B, McCance T. Person-centred nursing: theory and practice: John Wiley \& Sons; 2011. 
45. van Hoof J, Verbeek H, Janssen BM, Eijkelenboom A, Molony SL, Felix E, et al. A three perspective study of the sense of home of nursing home residents: the views of residents, care professionals and relatives. BMC Geriatr. 2016;16(1):169.

46. Wolf JA, Niederhauser V, Marshburn D, LaVela SL. Defining Patient Experience. Patient Experience Journal. 2014;1(1):7.

47. Vaismoradi M, Wang IL, Turunen H, Bondas T. Older people's experiences of care in nursing homes: a meta-synthesis. Int Nurs Rev. 2016;63(1):111-21.

48. Ryan EB, Byrne K, Spykerman H, Orange J. Evidencing Kitwood's personhood strategies: Conversation as care in dementia. Alzheimer Talk, Text and Context: Springer; 2005. p. 18-36.

49. White EM, Aiken LH, Sloane DM, McHugh MD. Nursing home work environment, care quality, registered nurse burnout and job dissatisfaction. Geriatric Nursing. 2020;41(2):158-64.

50. Alders P, Schut FT. The 2015 long-term care reform in the Netherlands: Getting the financial incentives right? Health Policy. 2019;123(3):312-6.

51. Anderson RA, Issel LM, McDaniel RR, Jr. Nursing homes as complex adaptive systems: relationship between management practice and resident outcomes. Nurs Res. 2003;52(1):12-21.

52. Quentin W, Partanen V-M, Brownwood I, Klazinga N. 3 Measuring healthcare quality. Improving healthcare quality in Europe. 2019:31.

53. Patti CH, van Dessel MM, Hartley SW. Reimagining customer service through journey mapping and measurement. European Journal of Marketing. 2020.

54. Beattie M, Murphy DJ, Atherton I, Lauder W. Instruments to measure patient experience of healthcare quality in hospitals: a systematic review. Systematic reviews. 2015;4(1):97.

55. Gaudet Hefele J. Nursing home quality: what matters to patients. BMJ Quality \&amp; Safety. 2020;29(5):401-4.

56. Castle NG, Ferguson JC. What Is Nursing Home Quality and How Is It Measured? Gerontologist. 2010;50(4):426-42.

57. Donabedian A. The quality of care. How can it be assessed? Jama. 1988;260(12):1743-8.

58. van Nie-Visser NC, Schols JM, Meesterberends E, Lohrmann C, Meijers JM, Halfens RJ. An international prevalence measurement of care problems: study protocol. J Adv Nurs. 2013;69(9):e18-e29.

59. Huber M, Knottnerus JA, Green L, Horst Hvd, Jadad AR, Kromhout D, et al. How should we define health? Bmj. 2011;343.

60. Huber M, van Vliet M, Giezenberg M, Winkens B, Heerkens Y, Dagnelie PC, et al. Towards a 'patientcentred' operationalisation of the new dynamic concept of health: a mixed methods study. BMJ Open. 2016;6(1):e010091.

61. Nakrem S. Understanding organizational and cultural premises for quality of care in nursing homes: an ethnographic study. BMC Health Serv Res. 2015;15:508.

62. Berwick DM. Era 3 for medicine and health care. Jama. 2016;315(13):1329-30.

63. Triemstra M, Winters S, Kool RB, Wiegers TA. Measuring client experiences in long-term care in the Netherlands: a pilot study with the Consumer Quality Index Long-term Care. BMC Health Serv Res. 2010;10:95.

64. Weldring T, Smith SM. Article Commentary: Patient-Reported Outcomes (PROs) and PatientReported Outcome Measures (PROMs). Health Serv Insights. 2013;6:HSI. S11093.

65. Castle NG. A review of satisfaction instruments used in long-term care settings. J Aging Soc Policy. 2007;19(2):9-41.

66. Voorhees CM, Fombelle PW, Gregoire Y, Bone S, Gustafsson A, Sousa R, et al. Service encounters, experiences and the customer journey: Defining the field and a call to expand our lens. Journal of Business Research. 2017;79:269-80. 
67. Van den Elsen W. Doek valt voor CQ-index in ouderenzorg 2015 [updated 29 June 201528 May 2020]. Available from: https://www.zorgvisie.nl/doek-valt-voor-cq-index-in-ouderenzorg$1783689 \mathrm{w} /$.

68. Zorginstituut Nederland. Kwaliteitskader Verpleeghuiszorg Samen leren en verbeteren.: Zorginstituut Nederland; 2017. 1-41 p.

69. LaVela SL, Gallan AS. Evaluation and measurement of patient experience. Patient Experience Journal. 2014;1(28):36.

70. OECD. Ministerial Statement: the Next Generation of Health Reforms. Paris: OECD Publishing; 2017.

71. De Vet HCW, Terwee CB, Mokkink LB, Knol DL. Measurement in Medicine: A Practical Guide. Cambridge: Cambridge University Press; 2011. 



\section{CHAPTER 2}

\section{Themes Related to Experienced Quality of Care in Nursing Homes from the Resident's Perspective: A Systematic Literature Review and Thematic Synthesis}

This chapter was published as:

Sion KYJ, Verbeek H, Zwakhalen SMG, Odekerken-Schröder GJ, Schols JMGA, Hamers $\mathrm{JPH}$. Themes Related to Experienced Quality of Care in Nursing Homes from the Resident's Perspective: A Systematic Literature Review and Thematic Synthesis. Gerontology \& Geriatric Medicine, 2020; 5:1-16

https://doi.org/10.1177/2333721420931964 
ABSTRACT

Background: The culture change from task-centered care to person- and relationshipcentered care has resulted in the resident's voice gaining importance when assessing experienced quality of care in nursing homes. This review aimed to identify which factors contribute to experienced quality of care in nursing homes worldwide from the resident's perspective.

Method: A systematic literature review and thematic data synthesis were performed. The databases PubMed, Cumulative Index to Nursing and Allied Health Literature (CINAHL), PsychInfo and Business Source Complete were searched to identify qualitative studies aimed at retrieving factors related to residents' experienced quality of care in nursing homes. Only studies in which residents themselves were interviewed were included.

Results: This literature review included 27 publications covering 14 countries. Thematic analysis revealed three overarching themes related to residents' care experiences: (a) The nursing home environment consisted of the physical environment and caring environment, (b) individual aspects of living in the nursing home consisted of personhood and coping with change, and (c) social engagement consisted of meaningful relationships and care provision.

Discussion: To achieve high experienced quality of care in nursing homes, residents' care experiences need to be assessed and used in quality management. 


\section{BACKGROUND}

Worldwide there is an increase in the number of older adults (60+ years) paired with an increasing demand for long-term care services. ${ }^{1,2}$ Nursing homes aim to care for the most frail and dependent older adults in society, by providing 24-hr functional support and care for people with complex health needs, increased vulnerability, and who need support with activities of daily living. ${ }^{3}$ Nursing home characteristics differ between and within countries, for example, some only provide long-term care, whereas others may also provide short-term rehabilitation care.

There is a wide variety in the quality of care between nursing homes. ${ }^{4}$ This can partially be explained by the strain on resources due to an increase in aging population, increasing complexity of residents' care needs and challenges in staff composition and funding. ${ }^{5-9}$ However, in addition, residents have different expectations of living in a nursing home due to the culture change from task-oriented to person- and relationship-centered care. ${ }^{10}$ Person-centered care focusses on residents being unique with their own needs, preferences and relationships, which henceforth contributes to quality of care. ${ }^{10,11}$

Whereas quality of care in nursing homes is traditionally assessed with clinical indicators, such as falling incidents or pressure ulcers, the culture shift has resulted in the need to assess social and emotional indicators of care too, such as perceived care experiences and resident satisfaction. ${ }^{6,12}$ These outcomes are usually assessed with closed-ended questionnaires that are often completed by residents' proxies if residents have cognitive impairment and difficulty communicating; however, proxies do not always know what matters most to their loved ones. ${ }^{13-15}$ To assess and improve quality of care, there is a need to understand residents' care experiences by having in-depth conversations with the residents themselves. ${ }^{16,17}$

Previous qualitative research has focused on specific residents' experiences such as transitions to the nursing home or the mealtime experience. ${ }^{18,19} \mathrm{~A}$ recent review identified seven qualitative studies of residents' experiences of being cared for in nursing homes. ${ }^{20}$ The main findings related to residents wanting to retain the meaning of being alive in a homelike place that delivers person-centered care. This review was narrowed to the concept "being cared for" and recommended future reviews on residents' experiences to include a broader spectrum of concepts as experienced quality of care is a process that can be influenced by multiple concepts. Therefore, the aim of this systematic review was to identify which factors contribute to experienced quality of care in nursing homes worldwide from the resident's perspective.

\section{METHOD}

This systematic review and synthesis of qualitative research was reported according to the Enhancing Transparency in Reporting the Synthesis of Qualitative Research (ENTREQ) statement. ${ }^{21}$ 


\section{Databases and search strategy}

In April 2019, PubMed, Cumulative Index to Nursing and Allied Health Literature (CINAHL), PsychInfo and Business Source Complete were searched and snowballing was performed by checking reference lists of key articles. The search strategy combined three key terms and their synonyms: "experienced quality of care" AND "resident perspective" AND "nursing home". The search string for PubMed (Box 1) was adapted accordingly for each database (full searches are available on request). A predefined filter for qualitative studies and filters for scientific articles published in English or Dutch were added. ${ }^{22,23}$

Box 1. Search string PubMed
((Quality AND Care) OR (Experience*) OR (Perception*) OR (Perceive*) OR (View*) OR (Opinion*) OR (Satisfaction) OR (Quality Indicators, Health Care[MESH]) OR (Narrative Medicine[MESH]) OR (Patient Satisfaction[MESH[) OR (Perception[MESH]) OR ("Process Assessment (Health Care)[MESH])) AND ((Resident) OR (Residents) OR (Client) OR (Clients) OR (Patient) OR (Patients) OR (Elderly) OR (Senior) OR (Seniors) OR (Aged[MESH])) AND ((Nursing Home*) OR (Residential Facilit*) OR (Long Term Care) OR (Assisted Living) OR (Residential Care) OR (Housing for the Elderly) OR (Care Home*) OR (Institutional*) OR (Homes for the Aged) OR (Special Care Unit*) OR (Residential Facilities[MESH])))

\section{Eligibility criteria and study selection}

Table 1 presents the predefined selection criteria. Qualitative studies reporting themes related to experienced quality of care in nursing homes, from the resident's perspective were eligible for inclusion. Themes needed to be identified bottom-up from the collected data. Studies focusing on only one factor of experienced quality of care such as the transition to the nursing home or the mealtime experience were excluded, as these studies go into too little detail about the overall experienced quality of care.

All titles and abstracts were screened by one researcher and a second researcher independently screened $10 \%$ to confirm consistency and refine the selection criteria ( $96 \%$ agreement). Full texts were screened by two researchers and discrepancies were solved by discussing with a third researcher to reach consensus.

Table 1. Selection criteria

\begin{tabular}{lll}
\hline \hline Reason & Include & Exclude \\
\hline \hline Population & $\begin{array}{l}\text { Residents living in } \\
\text { institutionalized long-term care } \\
\text { settings for older people }\end{array}$ & Children, adults aged <65 \\
\hline Perspective & Resident & Family, caregiver, organizational \\
\hline & $\begin{array}{l}\text { Long-term care settings for older } \\
\text { adults receiving 24-hr care, }\end{array}$ & Hospital care, home care, mental care, acute \\
Context & $\begin{array}{l}\text { including public and private } \\
\text { nursing homes, residential care } \\
\text { settings, assisted-living }\end{array}$ & care, short-term care \\
& & \\
\end{tabular}




\begin{tabular}{lll}
\hline Topic & $\begin{array}{l}\text { Experiences } \\
\text { Quality of care }\end{array}$ & $\begin{array}{l}\text { Specific concept related to experiences or } \\
\text { quality of care, that is, mealtimes, dignity, } \\
\text { palliative care, quality of dying, transitions, } \\
\text { quality of life, experiences of having a specific } \\
\text { disease, and so on. Interventions }\end{array}$ \\
\hline \multirow{3}{*}{ Study design } & Qualitative studies & $\begin{array}{l}\text { Instrument validation, comments, editorials, } \\
\text { briefs, theoretical, secondary data analyses, } \\
\text { reviews }\end{array}$ \\
\hline \multirow{2}{*}{ Outcomes } & $\begin{array}{l}\text { Themes related to experiences } \\
\text { or quality of care emerging from } \\
\text { the data through bottom-up } \\
\text { analysis. }\end{array}$ & $\begin{array}{l}\text { Data analyzed and presented with predefined } \\
\text { themes (top-down). } \\
\text { combined for multiple perspectives, not } \\
\text { reporting resident perspective separately }\end{array}$ \\
\hline Unretrievable & - & Full text articles that could not be accessed \\
\hline \hline
\end{tabular}

\section{Data extraction and quality appraisal}

Data extraction and quality appraisal were performed by one researcher and checked by a second researcher. The following information was extracted from the studies in a predeveloped template: the aim, population description, sample size and selection, setting, data collection and analysis methods, and the themes in the results. Included articles were critically appraised using a checklist to assess qualitative studies. ${ }^{24}$ Articles were scored sufficient $=1$ or insufficient $=0$ on eight criteria, the total score ranging from 0 to 8 . These criteria are (a) scope and purpose (clear statement of the research question), (b) design and method (appropriate use of qualitative methods), (c) sample (clear description of sample), (d) data collection (adequate description of data collection methods), (e) analysis (analytic methods are made explicit), (f) reliability and validity (presents how categories/themes are developed), (g) generalizability (limits for generalizability clearly stated), and(h) credibility and plausibility (results and conclusions are supported by evidence). ${ }^{25}$ The research team decided to only include studies with a quality appraisal score $\geq 4$ for data synthesis as the quality of the findings may otherwise be unreliable.

\section{Data synthesis}

Thematic synthesis was used to analyze the results from each identified study. ${ }^{26}$ This threestep inductive approach identifies common data elements across a variety of studies. ${ }^{27}$ First, the results section from each study was openly coded line by line, enabling the researchers to translate concepts from one study to another. The themes identified by the authors and quotations from the original studies presented in the result sections were considered as data. Second, these codes were categorized into descriptive themes from which a tree structure emerged. Finally, the descriptive themes were translated into the final analytical themes, subthemes and categories to answer the research question. Supportive quotes were added to clarify each subtheme. Analyses were performed in MAXQDA by two researchers. ${ }^{28}$ 


\section{RESULTS}

The literature search identified 3,151 publications, of which 2,561 were reviewed based on title and abstract, and 207 on full text. As a result, 25 publications were included and two additional publications were identified through snowballing, a technique for reference review. Therefore, this literature review included 27 relevant publications covering 26 original studies for data extraction and quality appraisal (Figure 1).

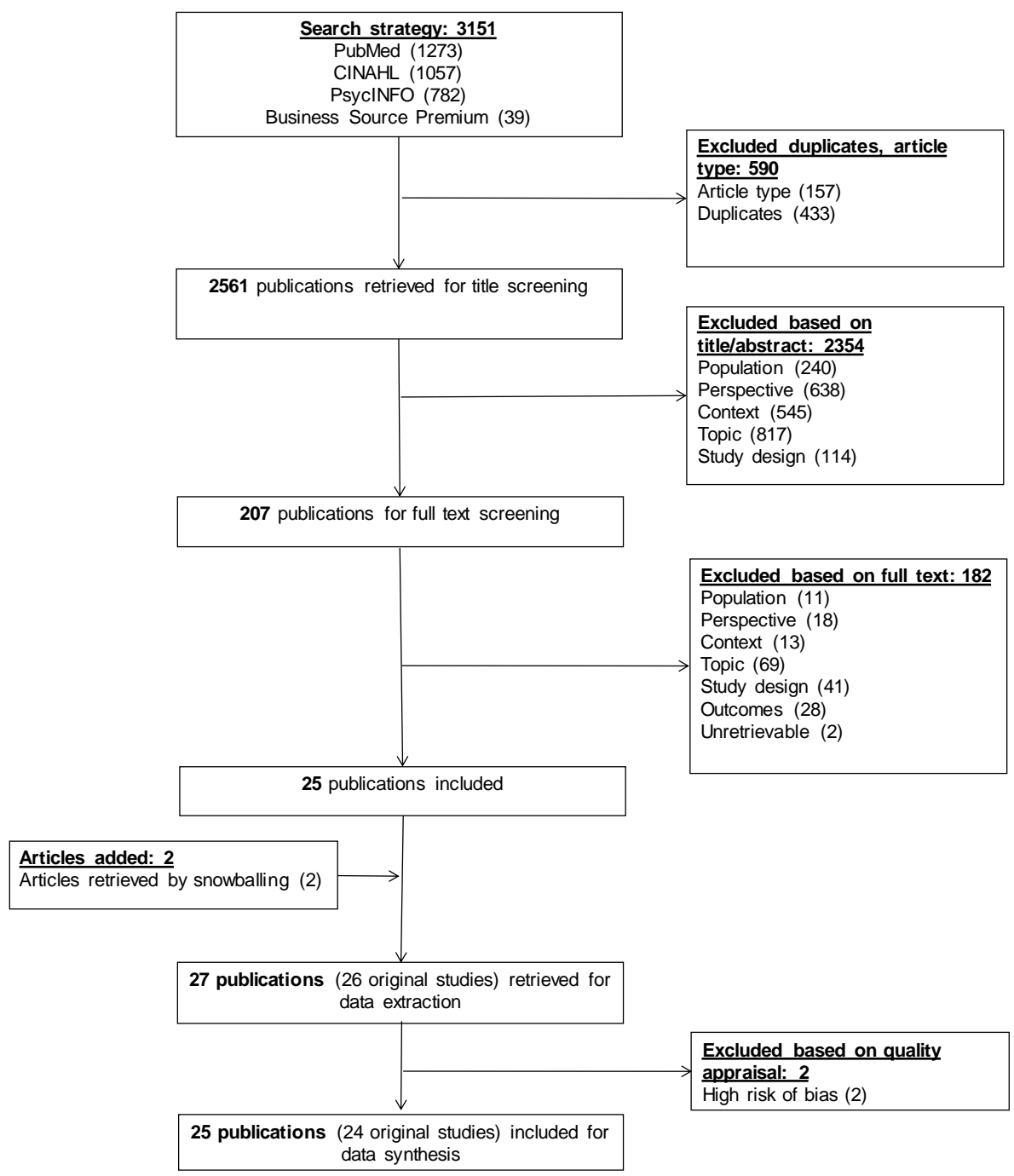

Figure 1. Flow-chart study selection 


\section{Study design and quality appraisal}

This review includes the experiences of 578 residents living in 93 nursing homes in 14 countries. Table 2 presents the characteristics of the included studies. One study was reported in two publications with a different focus. ${ }^{7,} 29$ Studies were performed in Europe (eight studies), Asia (eight studies), North America (six studies), Australia (three studies), and South America (one study). Studies ranged from five to 96 participants living in one (eight studies) to 19 (one study) long-term care facilities. Each study aimed to explore residents' experiences and views on quality of care and/or needs. All studies performed interviews with residents and some performed additional observations (seven studies) or group interviews (two studies). Most only included residents who were cognitively capable to be interviewed (16 studies), a few deliberately included residents with cognitive impairment (three studies), and some were unclear about this (seven studies). A majority of the studies were of high quality, scoring 6 to 8 points ( 20 studies). Two scored 3 points ${ }^{30,31}$ and were excluded from the thematic synthesis. Supplement Table 1 presents the detailed results of the quality appraisal.

\section{Thematic synthesis}

Across the 25 publications (24 studies), analysis revealed three overarching themes related to residents' care experiences: the nursing home environment, the individual aspects of living in the nursing home and social engagement. These themes were divided into six subthemes that covered 17 categories as presented in Table 3.

\section{The nursing home environment}

The nursing home environment consisted of the physical environment (19 studies) and the caring environment (24 studies). In the physical environment, nursing home characteristics (13 studies) such as space, noise, odor and cleanliness, and the availability of facilities such as on-site shops and a restaurant were mentioned repeatedly and a few studies mentioned accessibility and affordability. In addition, sufficient resources (14 studies) were considered a prerequisite for a good care experience. Residents specifically stressed having sufficient staff with low turnover rates and staff having enough time to attend to residents' needs in a timely manner.

In the caring environment, the residents' needs for feeling at home (14 studies), receiving privacy (14 studies), feeling safe (14 studies) and having a daily routine (22 studies) were reported. Some studies highlighted the challenges of residents living together in a public facility. Residents stressed the importance of making the nursing home a home in which they could feel comfortable. Having access to their own personally, furnished and decorated rooms contributed to this as residents receive the option to withdraw from the communal setting to their own space. Residents also specifically mentioned their need for privacy. Some reported a loss of privacy in the nursing home, whereas others reported accepting the lack 
of privacy as it enhanced their feelings of security. In half the studies, residents addressed the importance of their sense of security. This was accomplished by assuring residents that $24 / 7$ help is available and providing them the opportunity to lock their doors, to avoid people stealing from them or other residents entering when not being welcome. Many studies addressed daily routines, either as residents having the freedom to structure their days as they wished or experiencing monotony in their days and feeling limited by rules and regulations. Meaningful activities tailored to residents' preferences were considered very important to decrease boredom and enhance residents' sense of purpose. Some specific activities mentioned were religious/spiritual activities, outings outside of the nursing home, mealtimes and visits from loved ones.

\section{Individual aspects of living in the nursing home}

The individual aspects of living in the nursing home consisted of personhood ( 25 studies) and coping with change (20 studies). Personhood was addressed in all studies as maintaining identity, maintaining dignity and/or having self-determination. Residents valued being able to maintain their identity and being treated as individuals with their own preferences and needs (13 studies). Maintaining dignity by being respected and valued was also considered important (22 studies). In addition, gaining self-determination and autonomy in the nursing home contributed to personhood by providing residents with choice and involving them in decision-making (23 studies). Residents also struggled with becoming more dependent on others.

Studies reported that residents were coping with getting older and living in the nursing home (17 studies). Whereas many residents experienced deteriorating health and some expressed wanting this to improve, most accepted the situation and some even experienced improved health since living in the nursing home. A few studies touched upon the topic of coping with end-of-life (eight studies) and that living in the nursing home felt as waiting for the end. Some addressed specific aspects, including fear of death, reflection on life, funeral arrangements and coping with death of other residents.

\section{Social engagement}

Social engagement consisted of having meaningful relationships (24 studies) and how care is provided by staff ( 23 studies). In their relationships with staff ( 22 studies), some residents preferred a family-oriented approach going beyond care and towards friendship, whereas others preferred a service-oriented approach focused on receiving proper care. Some studies stressed residents did not want to be considered as a burden to staff and henceforth making themselves subservient. Studies reporting on relationships with friends and family (17 studies) mostly mentioned residents' desires to maintain long-term relationships and have meaningful social interactions that contribute to their sense of belonging. Some experienced difficulty maintaining their relationships or even felt neglected by their relatives. Forming 
friendships with other residents (16 studies) and having valuable meaningful social interactions added to feelings of self-worth and identity according to multiple studies. Some, however, mentioned the lack of meaningful social interactions, because of the challenges of interacting with people with cognitive impairments and the lack of choice who resides in the nursing home.

Care provision is an interactive and reciprocal act. Studies reporting on the care provided by staff highlighted the importance of a tailored care approach adapted to the care needs of each individual resident (14 studies). Many residents expected staff to possess the right technical skills to provide proper care (17 studies). Equally important for the care experience were staff's emotional skills (17 studies), such as caring skills (trust, engagement and encouragement), emotional support, and adopting a good attitude towards the residents. 
Table 2. Characteristics of included studies

\begin{tabular}{|c|c|c|c|c|c|}
\hline Source & Aim & Setting & Sample and size | selection & Data collection | analysis & Quality \\
\hline $\begin{array}{l}\text { Aggarwal, et al., } \\
2003^{32}\end{array}$ & $\begin{array}{l}\text { To explore how people with } \\
\text { dementia and their relatives } \\
\text { experience dementia and to find } \\
\text { out how they perceive and } \\
\text { receive care provision by directly } \\
\text { eliciting their views, experiences, } \\
\text { feelings and needs. } \\
\text { This review only presents } \\
\text { information from residents living } \\
\text { in residential care settings. }\end{array}$ & $\begin{array}{l}\text { Residential } \\
\text { care settings } \\
\text { UK }\end{array}$ & $\begin{array}{l}17 \text { residents, various dementia } \\
\text { stages. } \\
\text { Random }\end{array}$ & $\begin{array}{l}\text { Semi-structured } \\
\text { interviews with stimulus } \\
\text { materials } \\
\text { Passive participant } \\
\text { observation ( } 2000 \text { pages) } \\
\text { and video ( } 1 \text { wk) } \\
\text { Modified Quality of } \\
\text { Interactions scale and } \\
\text { qualitative analysis }\end{array}$ & $5 / 8$ \\
\hline $\begin{array}{l}\text { Anderberg and } \\
\text { Berglund, } \\
2010^{33}\end{array}$ & $\begin{array}{l}\text { To gain a deeper understanding of } \\
\text { elderly persons' experiences of } \\
\text { care and help, and how their lives } \\
\text { change in nursing homes. }\end{array}$ & $\begin{array}{l}4 \text { Nursing } \\
\text { homes } \\
\text { Sweden }\end{array}$ & $\begin{array}{l}15 \text { residents ( } 6 \text { male) aged } 73- \\
98, \geq 6 \text { months in nursing home, } \\
\text { able to participate in interview. } \\
\text { Selection by head nurse. }\end{array}$ & $\begin{array}{l}\text { In-depth interviews (30- } \\
70 \text { minutes) } \\
\text { The four life-world } \\
\text { existentials }\end{array}$ & $7 / 8$ \\
\hline $\begin{array}{l}\text { Bowers, et al., } \\
2001^{34}\end{array}$ & $\begin{array}{l}\text { To explore how nursing home } \\
\text { residents define quality of care } \\
\text { (QoC). }\end{array}$ & $\begin{array}{l}3 \text { Long-term } \\
\text { care facilities } \\
\text { USA }\end{array}$ & $\begin{array}{l}26 \text { residents (5 male), aged 64- } \\
104 . \text { Excluded: Residents too ill } \\
\text { or cognitively impaired for } \\
\text { interview. } \\
\text { All informed, first } 9 \text { residents/ } \\
\text { facility who expressed interest. }\end{array}$ & $\begin{array}{l}\text { Interviews conducted } \\
\text { twice (15-120 minutes) } \\
\text { Grounded dimensional } \\
\text { analysis }\end{array}$ & $5 / 8$ \\
\hline Chang, $2013^{35}$ & $\begin{array}{l}\text { To understand the meaning and } \\
\text { the essence of the experiences of } \\
\text { nursing home residents in this } \\
\text { specific situation deeply and } \\
\text { accurately }\end{array}$ & $\begin{array}{l}2 \text { Private } \\
\text { nursing homes } \\
\text { Korea }\end{array}$ & $\begin{array}{l}11 \text { residents ( } 3 \text { male), aged } 76- \\
96, \text { ability to express } \\
\text { themselves verbally, cognitively } \\
\text { intact, MMSE } \geq 24 \text {. } \\
\text { Purposeful }\end{array}$ & $\begin{array}{l}\text { Interviews conducted 2-4 } \\
\text { times (25-100 minutes) } \\
\text { Seven-stage Colaizzi } \\
\text { process }\end{array}$ & $8 / 8$ \\
\hline
\end{tabular}




\begin{tabular}{|c|c|c|c|c|c|}
\hline Source & Aim & Setting & "Sample and size | selection & Data collection | analysis & Quality \\
\hline $\begin{array}{l}\text { Chao and Roth, } \\
2005^{36}\end{array}$ & $\begin{array}{l}\text { To determine residents' } \\
\text { perceptions of QoC in nursing } \\
\text { homes in Taiwan }\end{array}$ & $\begin{array}{l}4 \text { Long-term } \\
\text { care } \\
\text { organizations } \\
\text { Taiwan }\end{array}$ & $\begin{array}{l}22 \text { residents ( } 10 \text { male), aged } \\
61-86, \text { MMSE-score }>24 \text {. } \\
\text { Convenience }\end{array}$ & $\begin{array}{l}\text { Semi-structured } \\
\text { interviews and } \\
\text { observation during the } \\
\text { interviews ( } 1 \text { hour) } \\
\text { Miles and Huberman } \\
(1994)^{37} \text { Inductive } \\
\text { process }\end{array}$ & $7 / 8$ \\
\hline $\begin{array}{l}\text { Cho, et al., } \\
201738\end{array}$ & $\begin{array}{l}\text { To explore older adults' } \\
\text { perceptions of their daily lives in } \\
\text { South Korean nursing homes. }\end{array}$ & $\begin{array}{l}5 \text { Nursing } \\
\text { homes } \\
\text { South Korea }\end{array}$ & $\begin{array}{l}21 \text { residents ( } 3 \text { male), aged } 65- \\
94, \geq 3 \text { month in nursing home. } \\
\text { Normal cognitive function, } \\
\text { ability to communicate, } \\
\text { understand and reiterate study } \\
\text { purpose. } \\
\text { Purposeful }\end{array}$ & $\begin{array}{l}\text { Semi-structured, in- } \\
\text { depth interviews (20-80 } \\
\text { minutes) } \\
\text { Braun and Clarke } \\
(2006)^{39} \text { six steps }\end{array}$ & $8 / 8$ \\
\hline $\begin{array}{l}\text { Chuang, et al., } \\
2015^{40}\end{array}$ & $\begin{array}{l}\text { To explore the older nursing } \\
\text { home residents' care needs from } \\
\text { their own perspectives. }\end{array}$ & $\begin{array}{l}2 \text { Nursing } \\
\text { Homes } \\
\text { Taiwan }\end{array}$ & $\begin{array}{l}18 \text { residents ( } 15 \text { male), age } \\
\text { mean }=80.7 \text { ( } S D=6.3 \text { ), } \geq 6 \text { month } \\
\text { in nursing home. Sufficient } \\
\text { mental functions to score } \\
\geq 20 / 30 \text { MMSE (mean } 24.6, S D \\
\text { 3.6). } \\
\text { Head nurse determined eligible } \\
\text { residents. }\end{array}$ & $\begin{array}{l}\text { In-depth interviews } \\
\text { conducted 1-5 times (22- } \\
99 \text { minutes) } \\
\text { Five step analysis: } \\
\text { (1) ordering and } \\
\text { organizing } \\
\text { (2) repeatedly reading } \\
\text { data } \\
\text { (3) labeling into codes } \\
\text { (4) create subcategories } \\
\text { (5) generate themes }\end{array}$ & $7 / 8$ \\
\hline
\end{tabular}




\begin{tabular}{|c|c|c|c|c|c|}
\hline Source & Aim & Setting & Sample and size | selection & Data collection | analysis & Quality \\
\hline $\begin{array}{l}\text { Coughlan and } \\
\text { Ward, } 2007^{41}\end{array}$ & $\begin{array}{l}\text { Assessment of residents' } \\
\text { experience in a new "state of the } \\
\text { art" long-term care facilities and } \\
\text { their understanding of QoC } \\
\text { shortly after relocation from two } \\
\text { older hospital style facilities. }\end{array}$ & $\begin{array}{l}1 \text { Long-term } \\
\text { care facility } \\
\text { Canada }\end{array}$ & $\begin{array}{l}18 \text { senior residents ( } 5 \text { male), } \\
\text { age mean }=84.35, \text { not severely } \\
\text { cognitively impaired. } \\
\text { All residents invited }\end{array}$ & $\begin{array}{l}\text { In-depth, semi- } \\
\text { structured interviews + } \\
\text { field note observations } \\
\text { Grounded theory }\end{array}$ & $6 / 8$ \\
\hline $\begin{array}{l}\text { Drageset, et al., } \\
2017^{42}\end{array}$ & $\begin{array}{l}\text { To identify and describe crucial } \\
\text { aspects promoting nursing home } \\
\text { residents' experience of meaning } \\
\text { and purpose in everyday life. }\end{array}$ & $\begin{array}{l}\text { Nursing home } \\
\text { Norway }\end{array}$ & $\begin{array}{l}18 \text { residents ( } 7 \text { male), aged } \\
65+, \geq 6 \text { months in nursing } \\
\text { home without dementia } \\
\text { (Clinical-Dementia-Rating } \leq 5 \text { ), } \\
\text { capable of having a } \\
\text { conversation. } \\
\text { NR }\end{array}$ & $\begin{array}{l}\text { Interviews conducted } \\
\text { once } \\
\text { Gadamer's } \\
\text { hermeneutical approach }\end{array}$ & $7 / 8$ \\
\hline $\begin{array}{l}\text { Eales, et al., } \\
2001^{43}\end{array}$ & $\begin{array}{l}\text { To better understand the } \\
\text { elements that residents } \\
\text { themselves felt were integral to } \\
\text { client-centered care. }\end{array}$ & $\begin{array}{l}1 \text { Adult family } \\
\text { living home } \\
1 \text { Assisted } \\
\text { living home } \\
\text { Canada }\end{array}$ & $\begin{array}{l}46 \text { residents ( } 12 \text { male), age } \\
\text { median=82, assisted }(n=16) \text { or } \\
\text { adult-family-living }(n=30) .70 \% \\
\text { had cognitive abilities within } \\
\text { normal limits. } \\
\text { All residents invited }\end{array}$ & $\begin{array}{l}\text { In-depth interviews (30- } \\
90 \text { minutes) } \\
\text { Miles and Huberman } \\
(1994)^{37}\end{array}$ & $6 / 8$ \\
\hline $\begin{array}{l}\text { Evangelista, } \\
2014^{31}\end{array}$ & $\begin{array}{l}\text { To analyze the perception of the } \\
\text { elderly on their living conditions } \\
\text { and the process of } \\
\text { institutionalization of a nursing } \\
\text { home. }\end{array}$ & $\begin{array}{l}1 \text { Nursing } \\
\text { home } \\
\text { Brazil }\end{array}$ & $\begin{array}{l}14 \text { elderly ( } 9 \text { male), aged 60-92, } \\
\text { MMSE-score } \geq 13 \text {. } \\
\text { All residents invited }\end{array}$ & $\begin{array}{l}\text { Semi-structured } \\
\text { interviews } \\
\text { Thematic content } \\
\text { analysis }\end{array}$ & $3 / 8$ \\
\hline
\end{tabular}




\begin{tabular}{|c|c|c|c|c|c|}
\hline Source & Aim & Setting & "Sample and size / selection & " Data collection | analysis & Q Quality \\
\hline Fiveash, $1998^{44}$ & $\begin{array}{l}\text { To describe, interpret, understand } \\
\text { and question the experiences of } \\
\text { nursing home residents + offer } \\
\text { them an opportunity to reflect on } \\
\text { their experiences and voice their } \\
\text { opinions about their } \\
\text { understanding of the situation. }\end{array}$ & $\begin{array}{l}2 \text { Private for } \\
\text { profit nursing } \\
\text { homes } \\
\text { Australia }\end{array}$ & $\begin{array}{l}8 \text { residents. } \\
\text { NR }\end{array}$ & $\begin{array}{l}\text { Participant observation } \\
\text { ( } 2 \text { hours, } 1 \text { /week } 6 \\
\text { months) } \\
\text { In-depth semi-structured } \\
\text { open-ended interviews } \\
2-3 \text { times ( } 1 \mathrm{hr}) \\
\text { Ethnographic }\end{array}$ & $4 / 8$ \\
\hline $\begin{array}{l}\text { Grant, et al., } \\
1996^{45}\end{array}$ & $\begin{array}{l}\text { A comprehensive identification of } \\
\text { indicators of quality of nursing } \\
\text { care as perceived by residents, } \\
\text { significant others and nursing } \\
\text { staff in long-term care facilities. }\end{array}$ & $\begin{array}{l}5 \text { Long-term } \\
\text { care centers } \\
\text { for the elderly } \\
\text { and disabled } \\
\text { Canada }\end{array}$ & $\begin{array}{l}52 \text { residents ( } 13 \text { male), aged } \\
\text { 25-99, mild cognitive } \\
\text { impairment ( } \geq 4 \text { Mental Status } \\
\text { Questionnaire) were } \\
\text { interviewed. } \\
\text { Random }\end{array}$ & $\begin{array}{l}\text { Critical incidence } \\
\text { technique (direct } \\
\text { observations) } \\
\text { Interviews (twice, } 929 \\
\text { incidents) } \\
\text { Content analysis }\end{array}$ & $7 / 8$ \\
\hline $\begin{array}{l}\text { Milte, et al., } \\
2016^{47}\end{array}$ & $\begin{array}{l}\text { To describe the meaning of } \\
\text { quality residential care from the } \\
\text { perspective of people with } \\
\text { cognitive impairment and their } \\
\text { family members.* }\end{array}$ & $\begin{array}{l}3 \text { Residential } \\
\text { aged care } \\
\text { facilities } \\
\text { Australia }\end{array}$ & $\begin{array}{l}15 \text { people (6 male), age } \\
\text { mean=79 }(S D=11) \text {, with mild to } \\
\text { severe cognitive impairment, } \\
\text { living in residential care }(n=12) \\
\text { or the community }(n=3) \text {. } \\
\text { Purposeful }\end{array}$ & $\begin{array}{l}\text { Semi-structured } \\
\text { interviews ( } \sim 30 \text { minutes) } \\
\text { Inductive, themes } \\
\text { generated from the data } \\
\text { itself }\end{array}$ & $6 / 8$ \\
\hline
\end{tabular}




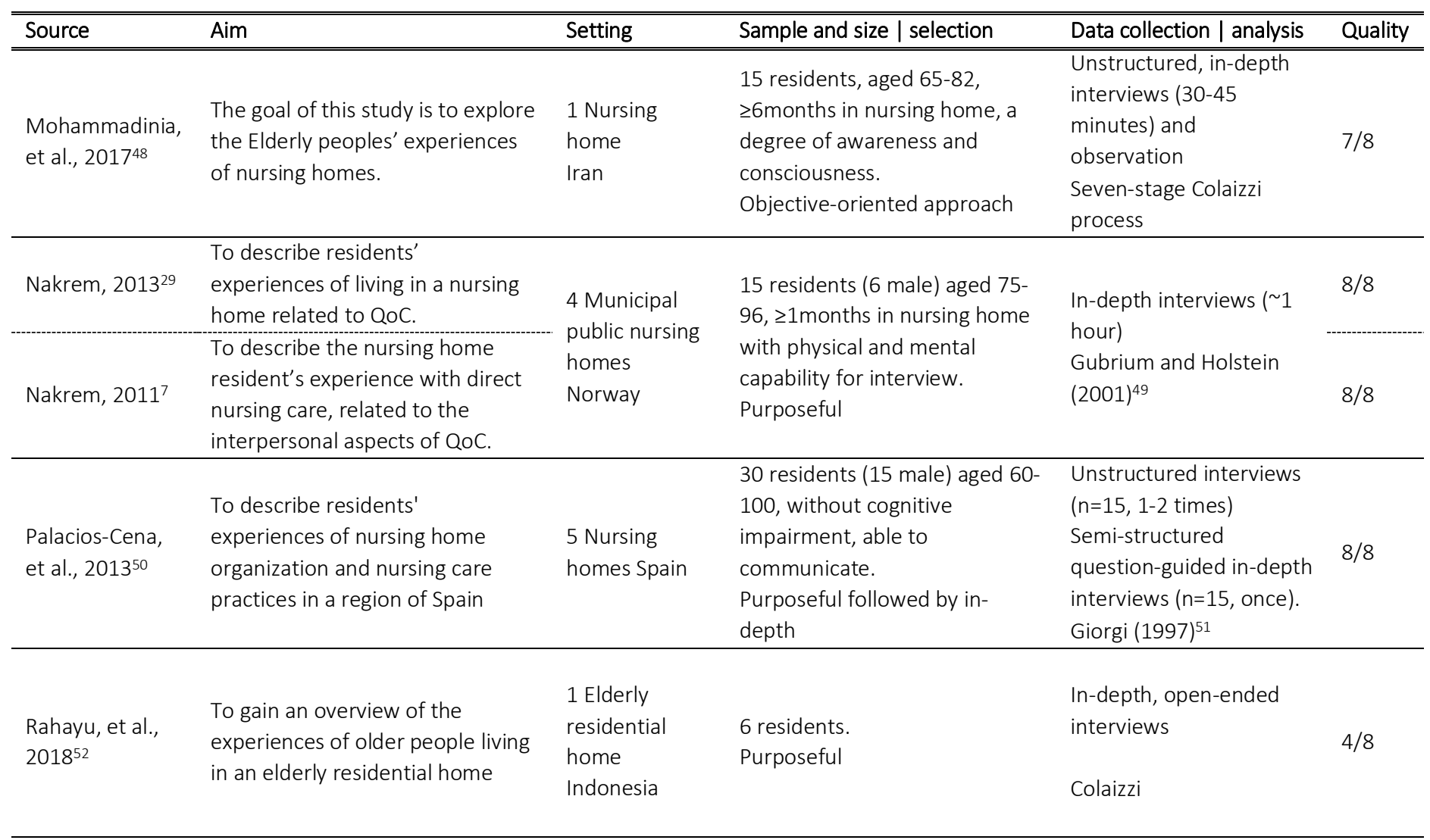




\begin{tabular}{|c|c|c|c|c|c|}
\hline Source & Aim & Setting & "Sample and size | selection & Data collection | analysis & Quality \\
\hline $\begin{array}{l}\text { Robinson, et al., } \\
2004^{53}\end{array}$ & $\begin{array}{l}\text { To advance the conceptualization } \\
\text { of resident satisfaction by } \\
\text { identifying essential content for } \\
\text { resident satisfaction surveys } \\
\text { synthesized from an analysis of } \\
\text { existing instruments (phase 1) } \\
\text { and open-ended interviews with a } \\
\text { diverse group of nursing home } \\
\text { residents (phase 2). This review } \\
\text { only presents phase } 2 \text { results. }\end{array}$ & $\begin{array}{l}3 \text { Nursing } \\
\text { homes } \\
\text { USA }\end{array}$ & $\begin{array}{l}15 \text { residents ( } 3 \text { male), aged } 48 \text { - } \\
102, \geq 4 \text { weeks in nursing home, } \\
\text { "independent" in the cognitive } \\
\text { skills for daily decision-making } \\
\text { (Minimum Data Set). } \\
\text { Purposeful (maximum } \\
\text { variation) }\end{array}$ & $\begin{array}{l}\text { Miller and Crabtree } \\
(1999)^{54} \text { template } \\
\text { organizing style of } \\
\text { qualitative data analysis }\end{array}$ & $6 / 8$ \\
\hline $\begin{array}{l}\text { Rodriguez, et } \\
\text { al., } 2013^{55}\end{array}$ & $\begin{array}{l}\text { To ascertain what QoC meant to } \\
\text { residents in nursing homes. }\end{array}$ & $\begin{array}{l}1 \text { Public } \\
\text { nursing home } \\
\text { Spain }\end{array}$ & $\begin{array}{l}20 \text { residents, aged 65+, without } \\
\text { cognitive impairment } \\
8 \text { proxy family members of } \\
\text { residents with cognitive } \\
\text { impairment. This review only } \\
\text { used resident data for analysis. } \\
\text { Theoretical }\end{array}$ & $\begin{array}{l}\text { In-depth interviews (50- } \\
120 \text { minutes) }\end{array}$ & $8 / 8$ \\
\hline Tappen, $2016^{56}$ & $\begin{array}{l}\text { To compare residents' } \\
\text { descriptions of their experiences } \\
\text { in the nursing home and } \\
\text { comparisons with their stay in the } \\
\text { hospital }\end{array}$ & $\begin{array}{l}19 \text { Nursing } \\
\text { homes } \\
\text { USA }\end{array}$ & $\begin{array}{l}96 \text { residents ( } 27 \text { male), aged } \\
47-99, \text { long-stay }(75 \%) \text {, short- } \\
\text { stay }(25 \%) \text {. } \\
\text { All residents were invited }\end{array}$ & $\begin{array}{l}\text { Interviews } \\
\text { Miles and Huberman } \\
(2013)^{57}\end{array}$ & $6 / 8$ \\
\hline $\begin{array}{l}\text { Timonen and } \\
\text { O'Dwyer, } \\
2009^{30}\end{array}$ & $\begin{array}{l}\text { To explore lives in institutional } \\
\text { care and make a contribution to } \\
\text { theorizing on the (met and } \\
\text { unmet) needs of institutional care } \\
\text { residents. }\end{array}$ & $\begin{array}{l}1 \text { Public-sector } \\
\text { residential } \\
\text { care setting } \\
\text { Ireland }\end{array}$ & $\begin{array}{l}12 \text { members of the residents' } \\
\text { council (11 residents, } 1 \\
\text { representative). } \\
\text { NR }\end{array}$ & $\begin{array}{l}\text { Group meetings } \\
\text { Semi-structured } \\
\text { interviews (1-2 times) } \\
\text { Manual coding, Nvivo }\end{array}$ & $3 / 8$ \\
\hline
\end{tabular}




\begin{tabular}{|c|c|c|c|c|c|}
\hline Source & Aim & Setting & "Sample and size | selection & "Data collection | analysis & Quality \\
\hline $\begin{array}{l}\text { Tsai and Tsai, } \\
2008^{58}\end{array}$ & $\begin{array}{l}\text { To explore the lived experiences } \\
\text { of older nursing home residents in } \\
\text { Taiwan. }\end{array}$ & $\begin{array}{l}8 \text { Nursing } \\
\text { homes } \\
\text { Taiwan }\end{array}$ & $\begin{array}{l}33 \text { residents (9 male), aged 65- } \\
97, \text { information-rich or likely to } \\
\text { talk openly about experiences. } \\
\text { Excluded: severe mental illness, } \\
\text { severe cognitive or language } \\
\text { deficits. } \\
\text { Purposeful }\end{array}$ & $\begin{array}{l}4 \text { focus groups followed } \\
\text { by } 52 \text { in-depth } \\
\text { interviews ( } 1 \text { hour) } \\
\text { Van Manen (1990) })^{59} \\
\text { steps of thematic } \\
\text { analysis }\end{array}$ & $6 / 8$ \\
\hline $\begin{array}{l}\text { Walker and } \\
\text { Paliadelis, } \\
2016^{60}\end{array}$ & $\begin{array}{l}\text { To add to what is known about } \\
\text { living in a residential aged care } \\
\text { facilities, and such associated } \\
\text { issues, from the perspectives of } \\
\text { those who are currently residents } \\
\text { in such facilities. }\end{array}$ & $\begin{array}{l}5 \text { Residential } \\
\text { aged care } \\
\text { facilities } \\
\text { Australia }\end{array}$ & $\begin{array}{l}18 \text { residents ( } 8 \text { male), aged } 77- \\
96, \geq 3 \text { months in facility. } \\
\text { Physically frail, cognitively able } \\
\text { to participate. Excluded: } \\
\text { moderate-advanced dementia, } \\
\text { unable to engage in interview. } \\
\text { Purposeful }\end{array}$ & $\begin{array}{l}\text { Semi-structured } \\
\text { interviews } \\
\text { Van Manen, thematically }\end{array}$ & $7 / 8$ \\
\hline $\begin{array}{l}\text { van Zadelhoff, } \\
\text { et al., } 2011^{61}\end{array}$ & $\begin{array}{l}\text { To investigate experiences of } \\
\text { residents, their family caregivers } \\
\text { and nursing staff in group living } \\
\text { homes for older people with } \\
\text { dementia and their perception of } \\
\text { the care process.* }\end{array}$ & $\begin{array}{l}2 \text { Group home } \\
\text { living units } \\
\text { Netherlands }\end{array}$ & $\begin{array}{l}5 \text { residents, aged 68-93; } \\
\text { MMSE-score mean=10 } \\
\text { (range }=0-14 \text { ) } \\
\text { NR }\end{array}$ & $\begin{array}{l}\text { Participant observation } \\
\text { ( } 8 \text { days, } 32 \text { hours): } \\
\text { watching, listening, } \\
\text { assisting with activities, } \\
\text { having conversations } \\
\text { In-depth interviews } \\
\text { Open 2-step coding }\end{array}$ & $8 / 8$ \\
\hline
\end{tabular}

MMSE: Mini-Mental State Examination, mins: minutes, NR: Not Reported; QoC: Quality of Care, SD: Standard Deviation

* This review only presents the information related to the residents. 
Table 3. Identified themes and categories related to residents' experiences in the nursing home

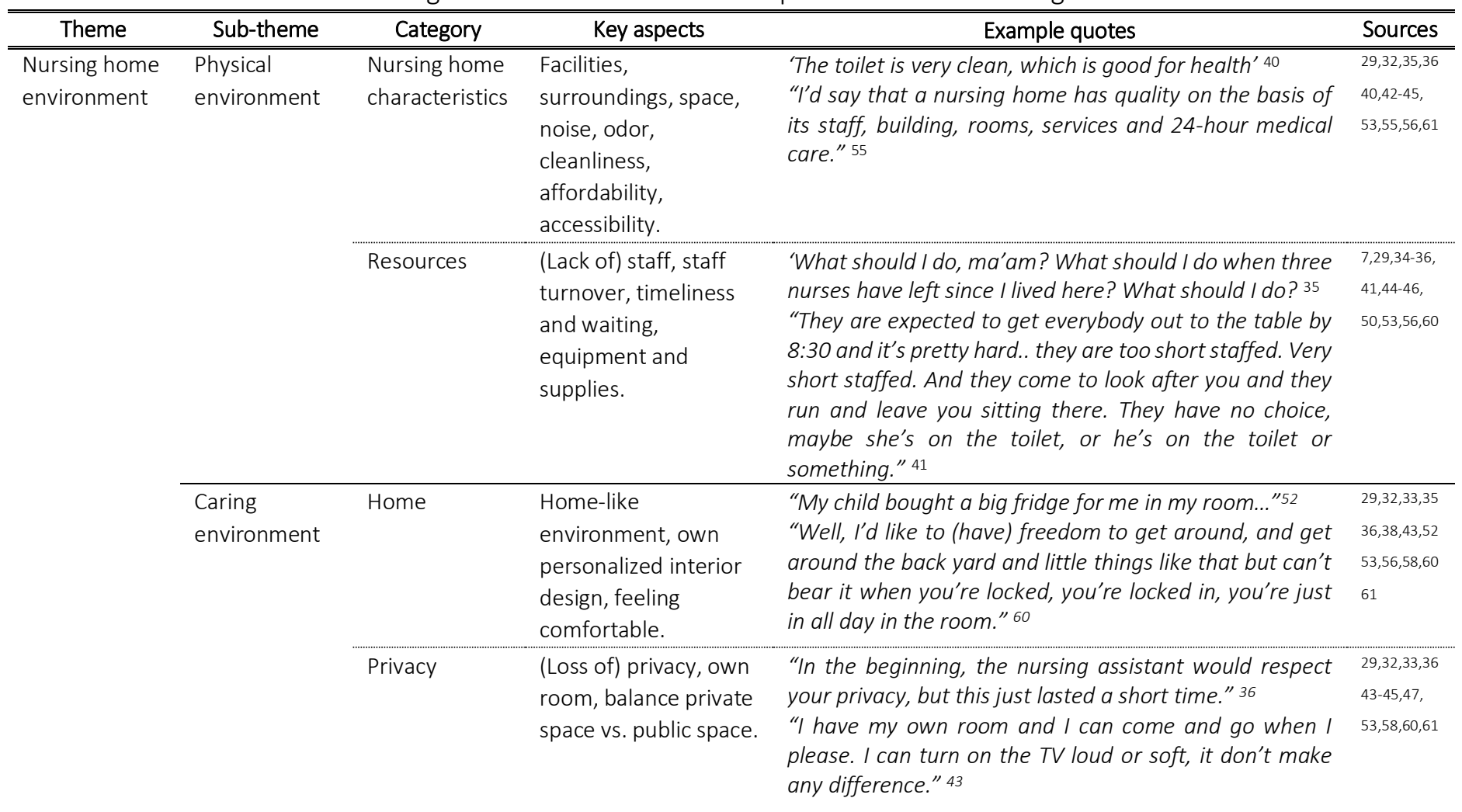




\begin{tabular}{|c|c|c|c|c|c|}
\hline Theme & Sub-theme & Category & Key aspects & Example quotes & Sources \\
\hline & & Safety & $\begin{array}{l}\text { Sense of security, } \\
\text { knowing help is } \\
\text { available } 24 / 7 \text {, } \\
\text { possessions being } \\
\text { safe. }\end{array}$ & $\begin{array}{l}\text { "I often wonder about safety here, and whether it is one } \\
\text { of the most important issues for the residents. One night, } \\
\text { I got up to go to the toilet. I fell down, but nobody knew } \\
\text { about this until next morning." } 36 \\
\text { "I was frightened. I awoke one night and this man was } \\
\text { standing at the end of my bed, looking at me. He had } \\
\text { scars and sores on his face, a bandage over his ear. I'd } \\
\text { never seen him before. I don't like to complain, but it's } \\
\text { very frightening." } 44\end{array}$ & $\begin{array}{l}7,29,33,35 \\
36,40,41 \\
43,44,47 \\
50,53,55,58\end{array}$ \\
\hline & & $\begin{array}{l}\text { Daily routines } \\
\text { and activities }\end{array}$ & $\begin{array}{l}\text { Daily routine, } \\
\text { monotony, rules and } \\
\text { regulations, boredom, } \\
\text { meaningful activities, } \\
\text { food (mealtimes), } \\
\text { visits from family. }\end{array}$ & $\begin{array}{l}\text { "Every day here is repetitive and exactly the same. I sit } \\
\text { on the chair and look around aimlessly, I do not even } \\
\text { think, and it will not work." } 62 \\
\text { "I have been here for a short period, but timetables and } \\
\text { rules... I do not know, it is like the army. If you ask for } \\
\text { anything out of the program, there are problems all } \\
\text { around." 50 }\end{array}$ & $\begin{array}{l}7,29,32,33, \\
35,36,38, \\
40-48,50, \\
52,53,55 \\
56,58,61\end{array}$ \\
\hline $\begin{array}{l}\text { Individual } \\
\text { aspects of } \\
\text { living in the } \\
\text { nursing home }\end{array}$ & Personhood & Identity & $\begin{array}{l}\text { Maintaining identity } \\
\text { vs. loss of identity. } \\
\text { Sense of belonging } \\
\text { and recognition. }\end{array}$ & $\begin{array}{l}\text { "You're pretty much just a number." } 43 \\
\text { "Well it makes you feel like somebody because normally } \\
\text { when you do these things yourself, that's the way you } \\
\text { would do it. I mean you wouldn't just start out to meet } \\
\text { others or even pass people on the street looking ragged. } \\
\text { I suppose it depends on the way you feel, but a lot of } \\
\text { people are daring, they don't care much but I like to look } \\
\text { at least neat and tidy if nothing else. If they can take a } \\
\text { minute to do that little thing, just quickly, it means a lot." } \\
45\end{array}$ & $\begin{array}{l}33,34,36, \\
41-43,45- \\
48,55,60,61\end{array}$ \\
\hline
\end{tabular}




\begin{tabular}{|c|c|c|c|c|c|}
\hline Theme & Sub-theme & Category & Key aspects & Example quotes & Sources \\
\hline & & Dignity & $\begin{array}{l}\text { Being valued and } \\
\text { respected vs. loss of } \\
\text { dignity. }\end{array}$ & $\begin{array}{l}\text { "... when one can manage something on one's own... } \\
\text { then you are not so... disregarded. . . you sort of get a } \\
\text { different worth for yourself" } 33 \\
\text { 'They treat us like children. Do what they want to do. . . } \\
\text { No respect. . . They need to be polite to older persons. } \\
\text { More polite. Respect us" } 40 \\
\text { "I feel pain in my heart when I see I am hungry yet I must } \\
\text { wait on the hour specified, to eat some food, or when I } \\
\text { become dirty and I canot take a bath unless it is at its } \\
\text { specified time, I get so embarrassed. } 48\end{array}$ & $\begin{array}{l}7,33-36,38, \\
40-42,44- \\
48,50,52,53 \\
55,56,58,60 \\
62\end{array}$ \\
\hline & & $\begin{array}{l}\text { Self- } \\
\text { determination }\end{array}$ & $\begin{array}{l}\text { (Loss of) autonomy, } \\
\text { decision-making, own } \\
\text { choice, own will, } \\
\text { independency vs. } \\
\text { dependency. }\end{array}$ & $\begin{array}{l}\text { "Much choice? Not a great deal of choice, but whatever } \\
\text { is given to me, I eat it." } 32 \\
\text { "I like to make my own decisions, so staff does not need } \\
\text { to make decisions for me." } 46 \\
\text { "...the shock in so far as losing your independence and, it } \\
\text { takes a heck of a time to get adjusted to it." } 60\end{array}$ & $\begin{array}{l}7,29,32-36, \\
38,40,42- \\
48,50,52,53 \\
55,58,60,61\end{array}$ \\
\hline & $\begin{array}{l}\text { Coping with } \\
\text { change }\end{array}$ & Getting older & $\begin{array}{l}\text { Acceptance of the } \\
\text { situation, } \\
\text { deteriorating health, } \\
\text { wanting to get better, } \\
\text { fear of what will } \\
\text { come. }\end{array}$ & $\begin{array}{l}\text { "They [people with dementia] don't recognize } \\
\text { themselves as either alive or dead... Whenever I see } \\
\text { them, I feel bad... I think it's like the end of life...If we get } \\
\text { older by } 5 \text { or } 6 \text { years, we can be like that, right? That can } \\
\text { be my figure... It will be awful to watch." } 35 \\
\text { "The distance that took } 5 \text { minutes for me to walk [before] } \\
\text { now takes } 10 \text { minutes, which makes me frustrated. I } \\
\text { don't have any confidence or hope. If there was any } \\
\text { chance of getting better, I might feel hopeful, but I'm just } \\
\text { getting worse, so I'm disappointed every time. }{ }^{38}\end{array}$ & $\begin{array}{l}7,29,32,33 \\
35,36,38,42 \\
-44,47,48 \\
52,53,58,60 \\
61\end{array}$ \\
\hline
\end{tabular}




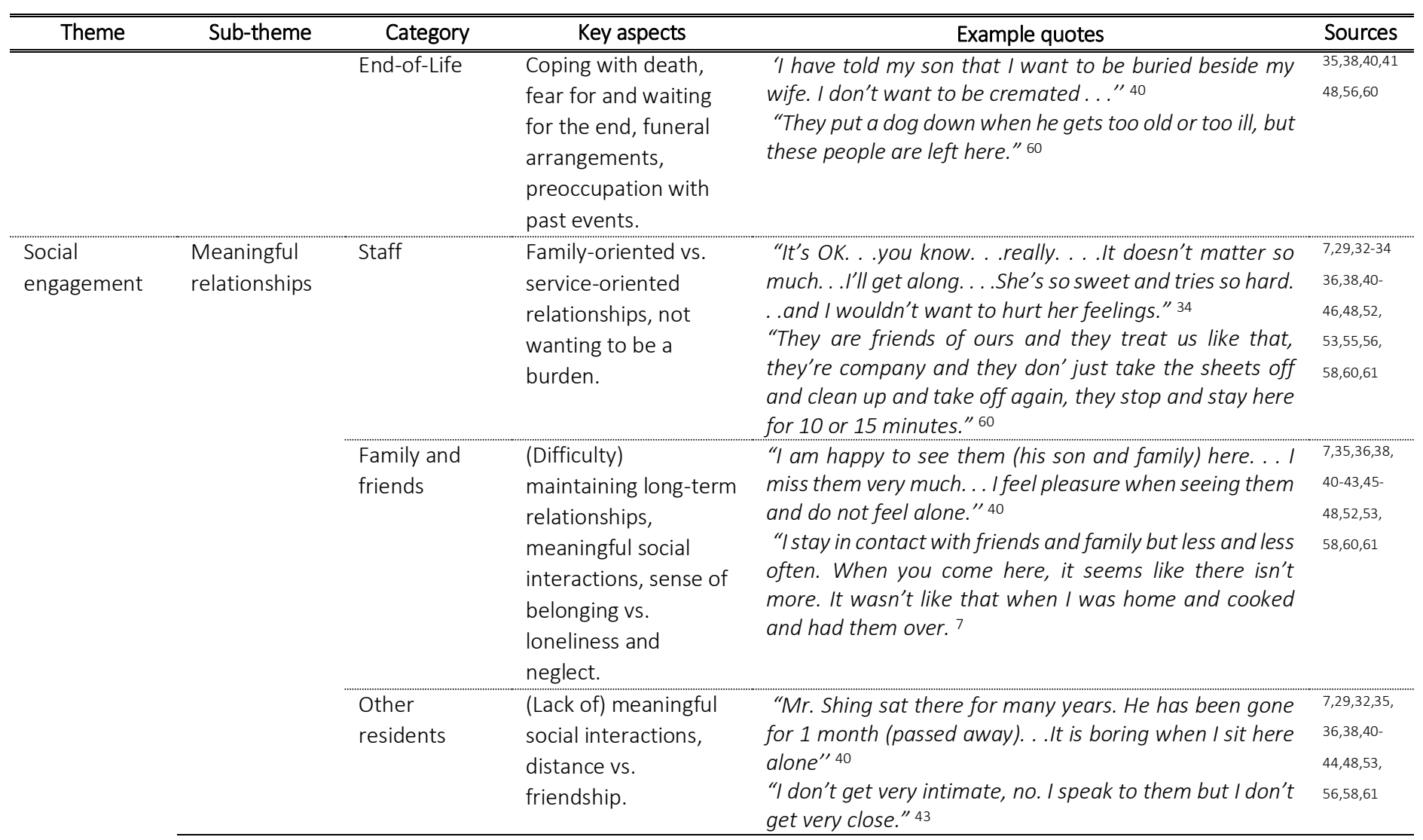




\begin{tabular}{|c|c|c|c|c|c|}
\hline Theme & Sub-theme & Category & Key aspects & Example quotes & Sources \\
\hline & Care provision & Tailored care & $\begin{array}{l}\text { (Lack of) care tailored } \\
\text { to the resident's } \\
\text { needs and } \\
\text { preferences. }\end{array}$ & $\begin{array}{l}\text { "I can't hold a spoon because my hand still is powerless. } \\
\text { They [staff] just left my meal [and did not help]." } \\
\text { "They have a plan laid out. I would assume that applies } \\
\text { to people who are sick differently one from another. And, } \\
\text { I know in my case, at a meeting and I was there. And it } \\
\text { was a matter of preparing for bed or getting up in the } \\
\text { morning. And I said: 'Well, I', I explained the things I can't } \\
\text { do and I would like covered. And they drew up a } \\
\text { statement from the R.N. to the effect that when you get } \\
\text { up in the morning you can wash your face and hands, } \\
\text { and they would bring the water to you." } 45\end{array}$ & $\begin{array}{l}7,29,32,34- \\
36,41,42,45 \\
46,50,53,55 \\
61\end{array}$ \\
\hline & & $\begin{array}{l}\text { Technical staff } \\
\text { skills }\end{array}$ & $\begin{array}{l}\text { Providing care well, } \\
\text { possessing the right } \\
\text { skills to provide care, } \\
\text { understanding care } \\
\text { needs. }\end{array}$ & $\begin{array}{l}\text { 'They are so good. They change my diaper regularly and } \\
\text { prevent my developing bed sores' } 36 \\
\text { "They should be skilled enough to transfer me safely." } 46\end{array}$ & $\begin{array}{l}7,32-34 \\
36,38,40,42 \\
44-47,50 \\
53,55,56,58\end{array}$ \\
\hline & & $\begin{array}{l}\text { Emotional } \\
\text { staff skills }\end{array}$ & $\begin{array}{l}\text { Caring skills, staff's } \\
\text { attitude, providing } \\
\text { emotional support. }\end{array}$ & $\begin{array}{l}\text { "when they say kind things about you, adjust the pillows } \\
\text { and ask if you are lying okay ... are polite ... and say "good } \\
\text { morning" and "good night". " } 42 \\
\text { "Since they have to do things, what I most value is that } \\
\text { they go about them with a good will" } 55\end{array}$ & $\begin{array}{l}29,33,34,36 \\
40-47,52 \\
53,55,56,58\end{array}$ \\
\hline
\end{tabular}




\section{DISCUSSION}

This review identified three main factors in each included study contributing to experienced quality of care in nursing homes from the resident's perspective: environment, individual aspects and social engagement. The nursing home environment consisted of both the physical environment and caring environment. Individual aspects of living in the nursing home consisted of residents wanting to maintain their personhood and personal self, and their need to cope with change. Social engagement consisted of residents wanting to have meaningful relationships and the way staff provides care.

Our findings that the nursing home environment contributes to experienced quality of care is in line with other research, emphasizing the importance of the physical environment on residents' behaviors and well-being. ${ }^{63}$ The sociocultural, professional, governmental and organizational environment can support maintaining personhood. ${ }^{64}$ This is achieved by residents feeling in control of their own life and feeling that they matter, by being recognized and valued as stated in the Senses Framework. ${ }^{65,66}$ To increase quality of care and personhood, professional caregivers need to develop meaningful relationships with residents, family members, and colleagues. ${ }^{67}$ The quality of care relationships are characterized on the resident level, professional level, interaction between resident and professional level, and contextual level and can be used to gain insight into how relationships influence care provision and the resident's personhood. 68,69

People with dementia should more often be included in studies about experiences. Only three studies explicitly included this population. People with dementia or aphasia may be limited to verbally express themselves or have challenges recalling on past experiences; however, future studies should adopt an inclusive design by using a tailored approach for this population by, for example, using supportive visuals or observations. ${ }^{70-75} \mathrm{~A}$ recent review explored self-reported needs and experiences of people with dementia in nursing homes. ${ }^{76}$ This is complementary to our review as it included qualitative and quantitative studies and focused on experiences, quality of life and well-being expressed by people with dementia. The identified themes were similar to our findings, focusing on tailored activities, meaningful relationships, choice, environment, end-of-life and reminiscence. Reminiscence, defined as opportunities to share memories with others, was not identified explicitly in the current review because it might be more related to well-being and quality of life.

Some methodological issues should be considered. The relatively high number of included studies performed in a variety of countries contributes to the 
generalizability of the findings from this review, especially as no major differences were identified between countries. This should, however, be done cautiously as there is a large variety in types of nursing homes and nursing home residents. ${ }^{77}$ Selection bias may be present as many studies excluded residents with cognitive impairment and only performed interviews with residents capable of this. Proxies were excluded to ensure only the resident's voice was included. This might have narrowed the findings; however, research has shown that proxies' expression of residents' needs can differ and this review explicitly focusses on the resident's perspective. ${ }^{78,79}$

Whereas the current review identified known themes from residents' reports, the voice of residents in informing quality management and improving daily practice is still insufficient. ${ }^{4}{ }^{12}$ Guidelines are more frequently stressing the importance of including the resident's voice when monitoring and improving quality of care. ${ }^{4,80,81}$ In the Netherlands, several methodologies are being developed that include narratives to assess quality of care from the resident's perspective. ${ }^{82}$ As demonstrated through this review, narratives provide residents the space to share their stories and specify what needs to be improved and how. ${ }^{83,84}$ In practice, this is, however, more complicated than surveys ${ }^{84}$ In addition, assessing the resident's voice is not enough; it needs to be translated to policy and practice.

To our knowledge, this review is one of the first to synthesize data from residents' experiences with quality of care in nursing homes. Our findings highlight the need for residents to express variation in their preferences regarding their physical environment, individual aspects and social engagement. ${ }^{85}$ Residents should receive enough space to share their care experiences in a way that they feel comfortable doing so. Focusing on meaningful care experiences as a whole can contribute to a new way of assessing experienced quality of care. ${ }^{16,17,86}$ This review presents the first steps into identifying what residents consider important. To achieve high experienced quality of care in nursing homes, future research should focus on how best to assess residents' experiences and how care teams can use these experiences for quality improvement. 


\section{REFERENCES}

1. World Health Organisation. Ageing and health: fact sheet $N^{\circ} 4042015$. Available from: http://www.who.int/mediacentre/factsheets/fs404/en/.

2. Smith DB, Feng Z. The accumulated challenges of long-term care. Health Affairs. 2010;29(1):29-34.

3. Sanford AM, Orrell M, Tolson D, Abbatecola AM, Arai H, Bauer JM, et al. An international definition for "nursing home". J Am Med Dir Assoc. 2015;16(3):181-4.

4. OECD/EU. A Good Life in Old Age? Paris: OECD Publishing; 2013.

5. Miller SC, Miller EA, Jung HY, Sterns S, Clark M, Mor V. Nursing home organizational change: the "Culture Change" movement as viewed by long-term care specialists. Med Care Res Rev. 2010;67(4 Suppl):65s-81s.

6. Zimmerman S, Shier V, Saliba D. Transforming nursing home culture: evidence for practice and policy. Gerontologist. 2014;54 Suppl 1:S1-5.

7. Nakrem S, Vinsnes AG, Seim A. Residents' experiences of interpersonal factors in nursing home care: a qualitative study. Int J Nurs Stud. 2011;48(11):1357-66.

8. Hicks LL, Rantz MJ, Petroski GF, Mukamel DB. Nursing home costs and quality of care outcomes. Nurs Econ. 2004;22(4):178-92, 5.

9. Comondore VR, Devereaux PJ, Zhou Q, Stone SB, Busse JW, Ravindran NC, et al. Quality of care in for-profit and not-for-profit nursing homes: systematic review and meta-analysis. Bmj. 2009;339:b2732.

10. Koren MJ. Person-centered care for nursing home residents: the culture-change movement. Health Aff (Millwood). 2010;29(2):312-7.

11. Nakrem S. Understanding organizational and cultural premises for quality of care in nursing homes: an ethnographic study. BMC Health Serv Res. 2015;15:508.

12. Castle N, Ferguson J. What is nursing home quality and how is it measured? Gerontologist. 2010;50(4):426-42.

13. Castle N. Are family members suitable proxies for transitional care unit residents when collecting satisfaction information? Int J Qual Health Care. 2005;17(5):439-45.

14. Reamy AM, Kim K, Zarit SH, Whitlatch CJ. Understanding discrepancy in perceptions of values: individuals with mild to moderate dementia and their family caregivers. Gerontologist. 2011;51(4):473-83.

15. Triemstra MW, S. Kool, R. B. Wiegers, T. A. Triemstra, Mattanja Winters, Sjenny Kool, Rudolf B. Wiegers, Therese A. Measuring client experiences in long-term care in the Netherlands: a pilot study with the Consumer Quality Index Long-term Care. BMC Health Serv Res. 2010;10:95-.

16. Wolf JA, Niederhauser V, Marshburn D, LaVela SL. Defining Patient Experience. Patient Experience Journal. 2014;1(1):7.

17. LaVela SL, Gallan AS. Evaluation and measurement of patient experience. Patient Experience Journal. 2014;1(28):36.

18. Watkins RG, V. A. Abbott, R. A. Backhouse, A. Moore, D. Tarrant, M. Attitudes, perceptions and experiences of mealtimes among residents and staff in care homes for older adults: A systematic review of the qualitative literature. Geriatr Nurs. 2017;38(4):325-33. 
19. Richards SH, Christina. "The experiences of older adults from moving into residential long term care. A systematic review of qualitative studies". JBI Library of Systematic Reviews. 2011;9:1-21.

20. Vaismoradi M, Wang IL, Turunen H, Bondas T. Older people's experiences of care in nursing homes: a meta-synthesis. Int Nurs Rev. 2016;63(1):111-21.

21. Tong A, Flemming K, McInnes E, Oliver S, Craig J. Enhancing transparency in reporting the synthesis of qualitative research: ENTREQ. BMC Med Res Methodol. 2012;12:181.

22. Health Sciences Library University of Washington. Finding Qualitative Research Articles Seattle, USA [updated 21 January 2019; cited 201914 April]. Available from: https://guides.lib.uw.edu/hsl/qualres.

23. Flemming $\mathrm{K}$, Briggs $\mathrm{M}$. Electronic searching to locate qualitative research: evaluation of three strategies. J Adv Nurs. 2007;57(1):95-100.

24. Bunn F, Dickinson A, Barnett-Page E, McInnes E, Horton K. A systematic review of older people's perceptions of facilitators and barriers to participation in falls-prevention interventions. Ageing and Society. 2008;28(4):449-72.

25. Bunn; F, Goodman C, Sworn K, Rait G, Brayne C, Robinson L, et al. Psychosocial factors that shape patient and carer experiences of dementia diagnosis and treatment: a systematic review of qualitative studies. PLoS Med. 2012;9(10):e1001331.

26. Thomas J, Harden A. Methods for the thematic synthesis of qualitative research in systematic reviews. BMC Med Res Methodol. 2008;8.

27. Lucas PJ, Baird J, Arai L, Law C, Roberts HM. Worked examples of alternative methods for the synthesis of qualitative and quantitative research in systematic reviews. BMC Med Res Methodol. 2007;7:4.

28. MAXQDA, software for qualitative data analysis. Berlin: VERBI Software - Consult Sozialforschung $\mathrm{GmbH}$; 1989-2020.

29. Nakrem S, Harkless A, Paulsen G, Arnfinn B. Ambiguities: residents' experience of 'nursing home as my home'. Int J Older People Nurs. 2013;8(3):226-35.

30. Timonen V, O'Dwyer C. Living in institutional care: residents' experiences and coping strategies. Soc Work Health Care. 2009;48(6):597-613.

31. Evangelista RA, Bueno Ade A, Castro PA, Nascimento JN, Araujo NT, Aires GP. Perceptions and experiences of elderly residents in a nursing home. Rev Esc Enferm USP. 2014;48 Spec No. 2:81-6.

32. Aggarwal N, Vass AA, Minardi HA, Ward R, Garfield C, Cybyk B. People with dementia and their relatives: personal experiences of Alzheimer's and of the provision of care. J Psychiatr Ment Health Nurs. 2003;10(2):187-97.

33. Anderberg $P$, Berglund A. Elderly persons' experiences of striving to receive care on their own terms in nursing homes. International Journal of Nursing Practice. 2010;16(1):64-8.

34. Bowers BJ, Fibich B, Jacobson N. Care-as-service, care-as-relating, care-as-comfort: understanding nursing home residents' definitions of quality. Gerontologist. 2001;41(4):539-45.

35. Chang SJ. Lived Experiences of Nursing Home Residents in Korea. Asian Nursing Research. 2013;7(2):83-90.

36. Chao S, Roth P. Dimensions of quality in long-term care facilities in Taiwan. J Adv Nurs. 2005;52(6):609-18. 
37. Miles MB, Huberman AM. Qualitative data analysis: An expanded sourcebook, 2nd ed. Thousand Oaks, CA, US: Sage Publications, Inc; 1994. xiv, 338-xiv, p.

38. Cho E, Kim H, Kim J, Lee K, Meghani SH, Chang SJ. Older Adult Residents' Perceptions of Daily Lives in Nursing Homes. J Nurs Scholarsh. 2017;49(5):495-503.

39. Braun V, Clarke V. Using thematic analysis in psychology. Qualitative Research in Psychology. 2006;3(2):77-101.

40. Chuang YH, Abbey JA, Yeh YC, Tseng IJ, Liu MF. As they see it: A qualitative study of how older residents in nursing homes perceive their care needs. Collegian. 2015;22(1):43-51.

41. Coughlan R, Ward L. Experiences of recently relocated residents of a long-term care facility in Ontario: assessing quality qualitatively. Int J Nurs Stud. 2007;44(1):47-57.

42. Drageset J, Haugan $G$, Tranvag $O$. Crucial aspects promoting meaning and purpose in life: perceptions of nursing home residents. BMC Geriatr. 2017;17(1):254.

43. Eales J, Keating N, Damsma A. Seniors' experiences of client-centred residential care. Ageing \& Society. 2001;21(3):279-96.

44. Fiveash B. The experience of nursing home life. Int J Nurs Pract. 1998;4(3):166-74.

45. Grant NK, Reimer M, Bannatyne J. Indicators of quality in long-term care facilities. Int J Nurs Stud. 1996;33(5):469-78.

46. Hwang HL, Hsieh PF, Wang HH. Taiwanese long-term care facility residents' experiences of caring: a qualitative study. Scand J Caring Sci. 2013;27(3):695-703.

47. Milte R, Shulver W, Killington M, Bradley C, Ratcliffe J, Crotty M. Quality in residential care from the perspective of people living with dementia: The importance of personhood. Arch Gerontol Geriatr. 2016;63:9-17.

48. Mohammadinia N, Rezaei MA, Atashzadeh-Shoorideh F. Elderly peoples' experiences of nursing homes in Bam city: A qualitative study. Electron Physician. 2017;9(8):5015-23.

49. Gubrium JF, Holstein JA. Handbook of Interview Research: SAGE Publications; 2001 2020/06/17.

50. Palacios-Cena D, Cachon-Perez JM, Gomez-Perez D, Gomez-Calero C, Brea-Rivero M, Fernandez DEL-PC. Is the influence of nurse care practices and nursing home organization understood? A qualitative study. J Nurs Manag. 2013;21(8):1044-52.

51. Giorgi A. The theory, practice, and evaluation of the phenomenological method as a qualitative research procedure. Journal of Phenomenological Psychology. 1997;28(2):23560.

52. Rahayu S, Catharina-Daulima NH, Eka-Putri YS. The experience of older people living in an elderly residential home (Panti Sosial Tresna Werdha): a phenomenology. Enferm Clin. 2018;28 Suppl 1:79-82.

53. Robinson JP, Lucas JA, Castle NG, Lowe TJ, Crystal S. Consumer Satisfaction in Nursing Homes: Current Practices and Resident Priorities. Res Aging. 2004;26(4):454-80.

54. Crabtree BF, Miller WL. Doing Qualitative Research: SAGE Publications; 1999.

55. Rodriguez M, B., Martinez A, M., Cervera M, B., Notario P, B., Martinez V, V. Perception of quality of care among residents of public nursing-homes in Spain: a grounded theory study. BMC Geriatr. 2013;13:65.

56. Tappen RM. They Know Me Here: Patients' Perspectives on Their Nursing Home Experiences. Online Journal of Issues in Nursing. 2016;21(1):13-.

57. Miles MB, Huberman AM, Saldana J. Qualitative Data Analysis: SAGE Publications; 2014. 
58. Tsai HH, Tsai YF. A temporary home to nurture health: lived experiences of older nursing home residents in Taiwan. J Clin Nurs. 2008;17(14):1915-22.

59. Van Manen M. Researching Lived Experience: Human Science for an Action Sensitive Pedagogy.[Albany NY]: State University of New York Press, 1990. Curriculum Inquiry. 1990;24(2):135-70.

60. Walker $\mathrm{H}$, Paliadelis $\mathrm{P}$. Older peoples' experiences of living in a residential aged care facility in Australia. Australasian Journal on Ageing. 2016;35(3):E6-E10.

61. van Zadelhoff E, Verbeek H, Widdershoven G, van Rossum E, Abma T. Good care in group home living for people with dementia. Experiences of residents, family and nursing staff. J Clin Nurs. 2011;20(17-18):2490-500.

62. Mohammad SM, Turney PD. Crowdsourcing a word-emotion association lexicon. Computational Intelligence. 2013;29(3):436-65.

63. Chaudhury H, Cooke HA, Cowie H, Razaghi L. The Influence of the Physical Environment on Residents With Dementia in Long-Term Care Settings: A Review of the Empirical Literature. Gerontologist. 2018;58(5):e325-e37.

64. Siegel $\mathrm{CH}, \mathrm{A}$. Dorner, T. E. Contributions of ambient assisted living for health and quality of life in the elderly and care services--a qualitative analysis from the experts' perspective of care service professionals. BMC Geriatr. 2014;14:112.

65. Oosterveld-Vlug MG, Pasman HRW, van Gennip IE, Willems DL, Onwuteaka-Philipsen BD. Changes in the personal dignity of nursing home residents: a longitudinal qualitative interview study. PloS one. 2013;8(9):e73822-e.

66. Nolan M, Brown J, Davies S, Nolan J, Keady J. The Senses Framework: improving care for older people through a relationship-centred approach. Getting Research into Practice (GRiP) Report No 2.: University of Sheffield.; 2006.

67. McCormack B, Roberts T, Meyer J, Morgan D, Boscart V. Appreciating the 'person' in longterm care. Int J Older People Nurs. 2012;7(4):284-94.

68. Scheffelaar A, Bos NH, van Dulmen M, Luijkx K. Determinants of the quality of care relationships in long-term care - a systematic review. BMC Health Serv Res. 2018;18(1):N.PAG-N.PAG.

69. Smebye KL, Kirkevold M. The influence of relationships on personhood in dementia care: a qualitative, hermeneutic study. BMC nursing. 2013;12(1):29.

70. Scheffelaar A, Hendriks M, Bos N, Luijkx K, van Dulmen S. Protocol for a participatory study for developing qualitative instruments measuring the quality of long-term care relationships. BMJ Open. 2018;8(11):e022895.

71. Alzheimer's Disease International. World Alzheimer Report 2015: The Global Impact of Dementia. London: Alzheimer's Disease International, 2015.

72. Stans SE, Dalemans R, de Witte L, Beurskens A. Challenges in the communication between 'communication vulnerable' people and their social environment: an exploratory qualitative study. Patient Educ Couns. 2013;92(3):302-12.

73. Whitlatch CJ. Including the person with dementia in family care-giving research. Aging Ment Health. 2001;5 Suppl 1:S20-2.

74. Curyto KJ, Van Haitsma K, Vriesman DK. Direct observation of behavior: a review of current measures for use with older adults with dementia. Res Gerontol Nurs. 2008;1(1):52-76.

75. Gardner H, Zurif EB, Berry T, Baker E. Visual communication in aphasia. Neuropsychologia. 1976;14(3):275-92. 
76. Shiells K, Pivodic L, Holmerova I, Van den Block L. Self-reported needs and experiences of people with dementia living in nursing homes: a scoping review. Aging Ment Health. 2019:1-16.

77. Schols JM, Crebolder HF, van Weel C. Nursing home and nursing home physician: the Dutch experience. J Am Med Dir Assoc. 2004;5(3):207-12.

78. Orrell M, Hancock GA, Liyanage KC, Woods B, Challis D, Hoe J. The needs of people with dementia in care homes: the perspectives of users, staff and family caregivers. Int Psychogeriatr. 2008;20(5):941-51.

79. Crespo M, Bernaldo de Quiros M, Gomez MM, Hornillos C. Quality of life of nursing home residents with dementia: a comparison of perspectives of residents, family, and staff. Gerontologist. 2012;52(1):56-65.

80. Zorginstituut Nederland. Kwaliteitskader Verpleeghuiszorg Samen leren en verbeteren.: Zorginstituut Nederland; 2017. 1-41 p.

81. Thomas KS, Wysocki A, Intrator O, Mor V. Finding Gertrude: The resident's voice in Minimum Data Set 3.0. Journal of the American Medical Directors Association. 2014;15(11):802-6.

82. Triemstra MF, A. Literatuurstudie en overzicht van instrumenten Kwaliteit van leven en zorg meten. . Utrecht: Ministerie van Volksgezondheid, Welzijn en Sport, 2017.

83. Martino SC, Shaller D, Schlesinger M, Parker AM, Rybowski L, Grob R, et al. CAHPS and Comments: How Closed-Ended Survey Questions and Narrative Accounts Interact in the Assessment of Patient Experience. J Patient Exp. 2017;4(1):37-45.

84. Schlesinger M, Grob R, Shaller D, Martino SC, Parker AM, Finucane ML, et al. Taking Patients' Narratives about Clinicians from Anecdote to Science. New England Journal of Medicine. 2015;373(7):675-9.

85. Edvardsson D, Baxter R, Corneliusson L, Anderson RA, Beeber A, Boas PV, et al. Advancing Long-Term Care Science Through Using Common Data Elements: Candidate Measures for Care Outcomes of Personhood, Well-Being, and Quality of Life. Gerontol Geriatr Med. 2019;5:2333721419842672.

86. Corazzini KN, Anderson RA, Bowers BJ, Chu CH, Edvardsson D, Fagertun A, et al. Toward Common Data Elements for International Research in Long-term Care Homes: Advancing Person-Centered Care. J Am Med Dir Assoc. 2019;20(5):598-603. 


\section{SUPPLEMENTS}

Supplement Table 1. Quality appraisal

\begin{tabular}{|c|c|c|c|c|c|c|c|c|c|}
\hline Source & $\begin{array}{l}\text { Scope/ } \\
\text { purpose }\end{array}$ & $\begin{array}{l}\text { Design/ } \\
\text { method }\end{array}$ & Sample & $\begin{array}{l}\text { Data } \\
\text { collection }\end{array}$ & Analysis & $\begin{array}{l}\text { Reliability } \\
\text { / validity }\end{array}$ & Generalizability & $\begin{array}{l}\text { Credibility / } \\
\text { plausibility }\end{array}$ & Total \\
\hline Aggarwal, $2003^{32}$ & + & + & - & + & + & - & - & + & $5 / 8$ \\
\hline $\begin{array}{l}\text { Anderberg and Berglund, } \\
2010^{33}\end{array}$ & + & - & + & + & + & + & + & + & $7 / 8$ \\
\hline Bowers, $2001^{34}$ & + & - & + & + & + & - & + & - & $5 / 8$ \\
\hline Chang, $2013^{35}$ & + & + & + & + & + & + & + & + & $8 / 8$ \\
\hline Chao and Roth, $2005^{36}$ & + & + & + & + & + & - & + & + & $7 / 8$ \\
\hline Cho, $2017^{38}$ & + & + & + & + & + & + & + & + & $8 / 8$ \\
\hline Chuang, $2015^{40}$ & + & - & + & + & + & + & + & + & $7 / 8$ \\
\hline Coughlan and Ward, $2007^{41}$ & + & - & + & + & + & + & - & + & $6 / 8$ \\
\hline Drageset, $2017^{42}$ & + & + & + & + & + & - & + & + & $7 / 8$ \\
\hline Eales, $2001^{43}$ & + & - & + & + & + & + & - & + & $6 / 8$ \\
\hline Evangelista, $2014^{31}$ & + & + & - & + & - & - & - & - & $3 / 8$ \\
\hline Fiveash, $1998^{44}$ & + & + & - & + & - & - & - & + & $4 / 8$ \\
\hline Grant, $1996^{45}$ & + & + & + & + & + & - & + & + & $7 / 8$ \\
\hline Hwang, $2013^{46}$ & + & + & + & + & + & + & + & + & $8 / 8$ \\
\hline Milte, $2016^{47}$ & + & - & + & + & + & + & - & + & $6 / 8$ \\
\hline
\end{tabular}




\begin{tabular}{|c|c|c|c|c|c|c|c|c|c|}
\hline Source & $\begin{array}{l}\text { Scope/ } \\
\text { purpose }\end{array}$ & $\begin{array}{l}\text { Design/ } \\
\text { method }\end{array}$ & Sample & $\begin{array}{l}\text { Data } \\
\text { collection }\end{array}$ & Analysis & $\begin{array}{l}\text { Reliability } \\
\text { / validity }\end{array}$ & Generalizability & $\begin{array}{l}\text { Credibility / } \\
\text { plausibility }\end{array}$ & Total \\
\hline Mohammadinia, $2017^{48}$ & + & - & + & + & + & + & + & + & $7 / 8$ \\
\hline Nakrem, $2013^{29}$ & + & + & + & + & + & + & + & + & $8 / 8$ \\
\hline Nakrem, $2011^{7}$ & + & + & + & + & + & + & + & + & $8 / 8$ \\
\hline Palacios-Cena, $2013^{50}$ & + & + & + & + & + & + & + & + & $8 / 8$ \\
\hline Rahayu, $2018^{52}$ & + & - & - & + & + & - & - & + & $4 / 8$ \\
\hline Robinson, $2004^{53}$ & + & - & + & + & + & - & + & + & $6 / 8$ \\
\hline Rodriguez, $2013^{55}$ & + & + & + & + & + & + & + & + & $8 / 8$ \\
\hline Tappen, $2016^{56}$ & + & - & + & + & + & + & - & + & $6 / 8$ \\
\hline Timonen. 2009. & + & - & - & - & + & - & + & - & $3 / 8$ \\
\hline Tsai. 2008. & + & - & + & + & + & + & - & + & $6 / 8$ \\
\hline Walker. 2016. & + & + & + & + & + & - & + & + & $7 / 8$ \\
\hline Van Zadelhoff. 2011. & + & + & + & + & + & + & + & + & $8 / 8$ \\
\hline
\end{tabular}




\section{CHAPTER}

\section{Experienced Quality of Post-Acute and Long-Term Care from the Care Recipient's Perspective-A Conceptual Framework}

This chapter was published as:

Sion KYJ, Haex R, Verbeek H, Zwakhalen SMG, Odekerken-Schröder GJ, Schols JMGA, Hamers JPH. Experienced Quality of Post-Acute and Long-Term Care from the Care Recipient's Perspective-A Conceptual Framework. JAMDA, 2019; 20(11):1386-1390

https://doi.org/10.1016/j.jamda.2019.03.028 


\section{ABSTRACT}

This article aims to conceptualize experienced quality of post-acute and long-term care for older people (LTC) as perceived by care recipients. An iterative literature review and consultations with stakeholders led to the development of the INDividually Experienced QUAlity of Long-term care (INDEXQUAL) framework. INDEXQUAL presents the process of an individual care experience consisting of a pre (expectations), during (experiences), and post (assessment) phase. Expectations are formed prior to an experience by personal needs, past experiences and word-of-mouth. An experience follows, which consists of interactions between the actors in the caring relationships. Lastly, this experience is assessed by addressing what happened and how it happened (perceived care services), how this influenced the care recipient's health status (perceived care outcomes) and how this made the care recipient feel (satisfaction). INDEXQUAL can serve as a framework to select or develop methods to assess experienced quality of LTC. It can provide a framework for quality monitoring, improvement and transparency. 
Long-term care (LTC) comprises a range of services to maintain or improve the functional and health outcomes of frail, chronically ill, and physically or cognitively disabled older people. ${ }^{1}$ LTC has been defined as "the activities undertaken by others to ensure that people with or at risk of a significant ongoing loss of intrinsic capacity can maintain a level of functional ability consistent with their basic rights, fundamental freedoms and human dignity," portraying the importance of relationships within this type of care delivery. ${ }^{2}$ LTC provision used to be considered a task-oriented, profession-driven service focused on safety and efficiency. ${ }^{3}$ Over the past decades, there has been an ongoing culture change striving towards a more holistic approach to care provision, incorporating not only the professional, but also the care recipient's perspective, thus allowing more focus on the care recipient's preferences, autonomy, and self-determination. ${ }^{4-7}$ This has resulted in the emerging need to define and assess quality of LTC as experienced by the care recipient.

In the mid-1960s, Donabedian already touched on the complexity of defining and assessing quality of care. ${ }^{8}$ He portrayed quality as a reflection of values and goals within the care system and society. Building on this, the Institure of Medicine 9 defined quality of care as "the degree to which health services for individuals and populations increase the likelihood of desired health outcomes and are consistent with current professional knowledge." As quality of care consists of many aspects, it is challenging to assess and, therefore, indicators are often used to operationalize quality of care with Donabedian's structure-process-outcomes model, ${ }^{10}$ such as the prevalence of fall incidents, malnutrition or pressure ulcers. ${ }^{11}$ Indicators however, often focus on the physical aspects of care (ie, pressure ulcers), while underrepresenting the social (ie, engagement in daily life) and emotional aspects (ie, satisfaction) and ignoring others in the caring environment. ${ }^{11-13}$ This is more in line with the professional or regulatory agency perspective, instead of representing the values and needs of what care recipients and their families find most important. ${ }^{1,14}$ This increasing focus on the care recipient's perspective has led to the development of quality indicators that can be assessed by the care recipients themselves by means of patient-reported outcome measures, including severity of pain and patientreported experience measures such as the Consumer-Quality Index. ${ }^{15,} 16$ Patientreported outcome measures and patient-reported experience measures do not capture the care recipient's journey, which is important for establishing the experienced quality of care for an older person. ${ }^{17}$

Furthermore, from a service science perspective, care service delivery has certain characteristics that complicate the assessment of the experienced quality of care from the recipient's perspective. Care service delivery is characterized as being 
intangible, heterogeneous, perishable, interactive, and multifaceted. ${ }^{18,19}$ This means that the experience of care provision is built on interactions between people involved in a value-creating process, and, therefore, its quality cannot be judged in advance (intangible), it cannot be provided with uniformity (heterogeneous) and it cannot be stored; thus, the location and timing influence the experiences as well (perishability). Care provision is usually achieved during interactions between the care recipient and the care provider (interactive), and it is considered a complex service (multifaceted quality). The complexity of care services in combination with the more holistic view on (health) care and the increasing importance of the care recipient's perspective have resulted in the need for a clear understanding of the meaning of experienced quality of LTC.

\section{CONCEPTUALIZATION OF EXPERIENCED QUALITY OF LTC}

To conceptualize experienced quality of care, we performed multiple actions. The literature within the service sciences and health sciences was reviewed to identify models and frameworks defining the process of service quality from the user's perspective, and care quality from the care recipient's perspective. Iterative searches were performed in PubMed, Psyclnfo and EBSCO Business Source Complete, and by means of snowballing. We used search terms including "quality of care," "experienced quality," and "service quality." Based on identified relevant articles, we added search terms including "expectations," "perceived quality," "patient reported," and "satisfaction," We considered articles relevant if they presented a model, framework, concept, or theory related to experienced quality of LTC from the care recipient's perspective. Studies focused on the evaluation of an intervention or validation of an instrument were considered out of scope. In addition, the grey literature was searched to assure key publications were identified. Appendix 1 presents additional information on the article selection.

The identified models and frameworks were reviewed, compared with each other, and combined into a conceptual framework because existing models and frameworks did not fully fulfill the research aim to conceptualize experienced quality of LTC from the care recipient's perspective. This was an iterative process, during which results were reviewed, discussed and adjusted in the research team. The research team consisted of a professor in care of older persons, a professor in old age medicine, a professor in nursing science, a professor in customer centric service science, an associate professor in LTC design, and 2 researchers with a background in psychology and health sciences. In addition, a panel of experts was assembled and gathered 3 times to reflect on the framework. This panel consisted of representatives from 
multiple national stakeholders in the Netherlands specialized in LTC policy, including the Ministry of Health $(n=2)$, the National Health Care Institute $(n=2)$, the National Client Council $(n=1)$, the Professional Association of Nurses $(n=2)$, the Health and Youth Care Inspectorate $(n=2)$ and Nursing Home Organizations $(n=4)$. When consensus could not be reached within the research team, the topic of discussion was presented to the panel of experts. Eventually, these iterative steps have resulted in the development of the INDividually EXperienced QUAlity of Long-term care (INDEXQUAL) framework (Figure 1, Table 1).

INDEXQUAL aims to provide a framework describing the process of experienced quality of LTC by focusing on the care recipient's experiences with care services and factors occurring prior to, during, and after this experience, within a certain context. The framework presents a process that starts with a personal need and ends after an experience. In the after experience, a differentiation could be made between a variety of care recipient groups, including moving out of one particular long-term care setting (eg, nursing home) to another type of care setting (eg, home care), remaining in the long-term care setting, or passing away. The framework is a global representation that allows for adaptation to a specific long-term care setting, timing and population.

Two principles underlie the development of INDEXQUAL. First, INDEXQUAL assumes that care provision is a form of service delivery and therefore, a process that consists of a before, during and after phase. ${ }^{17}$ Second, INDEXQUAL places relationshipcentered care at the core of care experiences, emphasizing that all relationships within the caring process need to be considered and not solely the care recipients. ${ }^{20}$, ${ }^{21}$ It assumes that care experiences are mainly influenced by the interactions throughout the caring process, especially within LTC provision, which is more often focused on care and less on cure. ${ }^{22}$ 


\section{Context}

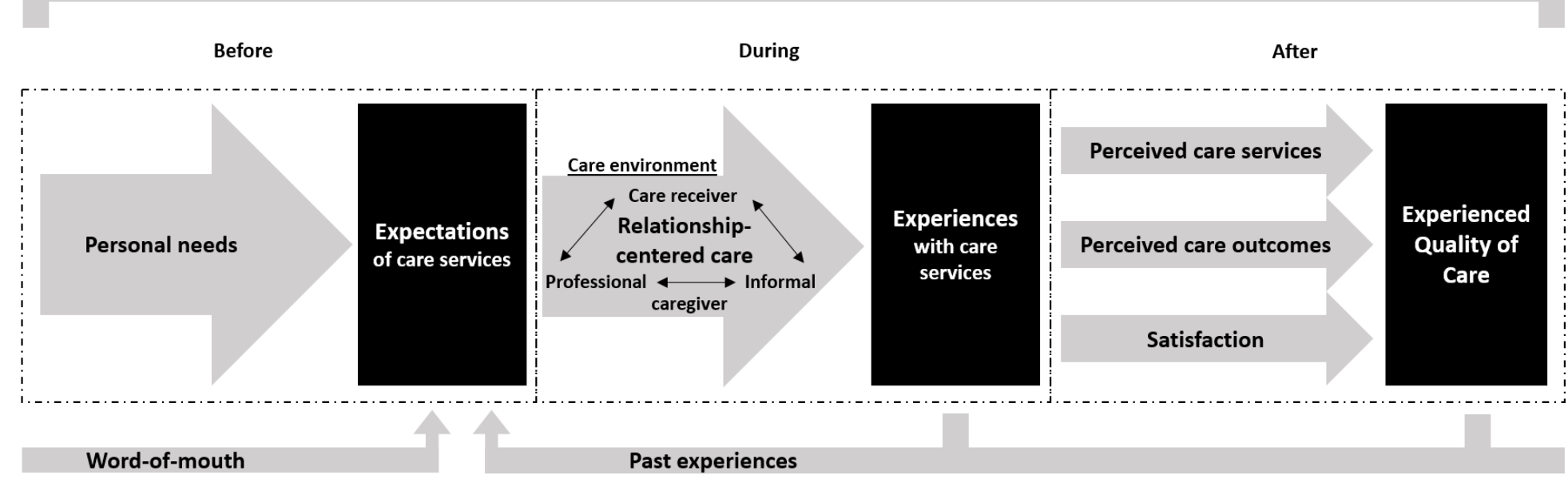

Figure 1. A framework of INDividually EXperienced QUAlity of Long-term care (INDEXQUAL) 
Table 1. Overview and definitions of individual components from the INDEXQUAL framework

Concept Description Examples of themes, indicators and/or tools to assess

Context Care receiver characteristics and the setting in which care is delivered. ${ }^{23,24}$

- Interpersonal environment: description of care recipient (ie, age, sex, ethnicity, health status)

- Organizational environment i.e. type of care organization (nursing home, home care, rehabilitation care); size; skill mix; available facilities and supportive organizational systems

\section{Expected care services}

- Security - to feel safe physically, psychologically, existentially

- Belonging - to feel part of a valued group, to maintain or form important relationships

Personal care needs

the long-term care setting, care needs can be place into Nolan's senses framework: security, continuity, belonging, significance, purpose and fulfilment. ${ }^{25}$

The client's previous exposure to a care service that is

Past experience relevant to the current service, and can shape predictions and desires. ${ }^{2}$

Personal and sometimes non-personal statements made by parties other than the care organization or care receivers themselves. They convey to care

Word of mouth receivers what the service will be like (i.e. what they can expect). It is perceived as unbiased and tends to be quite important in care services, because services are difficult for care receivers to evaluate prior to purchasing and directly experiencing them. ${ }^{28}$
- $\quad$ Continuity - to be able to make links between the past, present and future

- Purpose - to enjoy meaningful activity, to have valued goals

- Achievement - to reach valued goals to satisfaction of self and/or others

- $\quad$ Significance - to feel that you 'matter' and are accorded value and status Factors related to the experience of care transition between different care services, such as experiencing changes of significant relationships, moving from familiar to unknown environments and cultures, being prepared for transfer and achieving responsibility. ${ }^{27}$

All information received from experts about the type of care delivery, including reviews from other care receivers, friends and family, such as reviews on Yelp. ${ }^{26,29}$ 


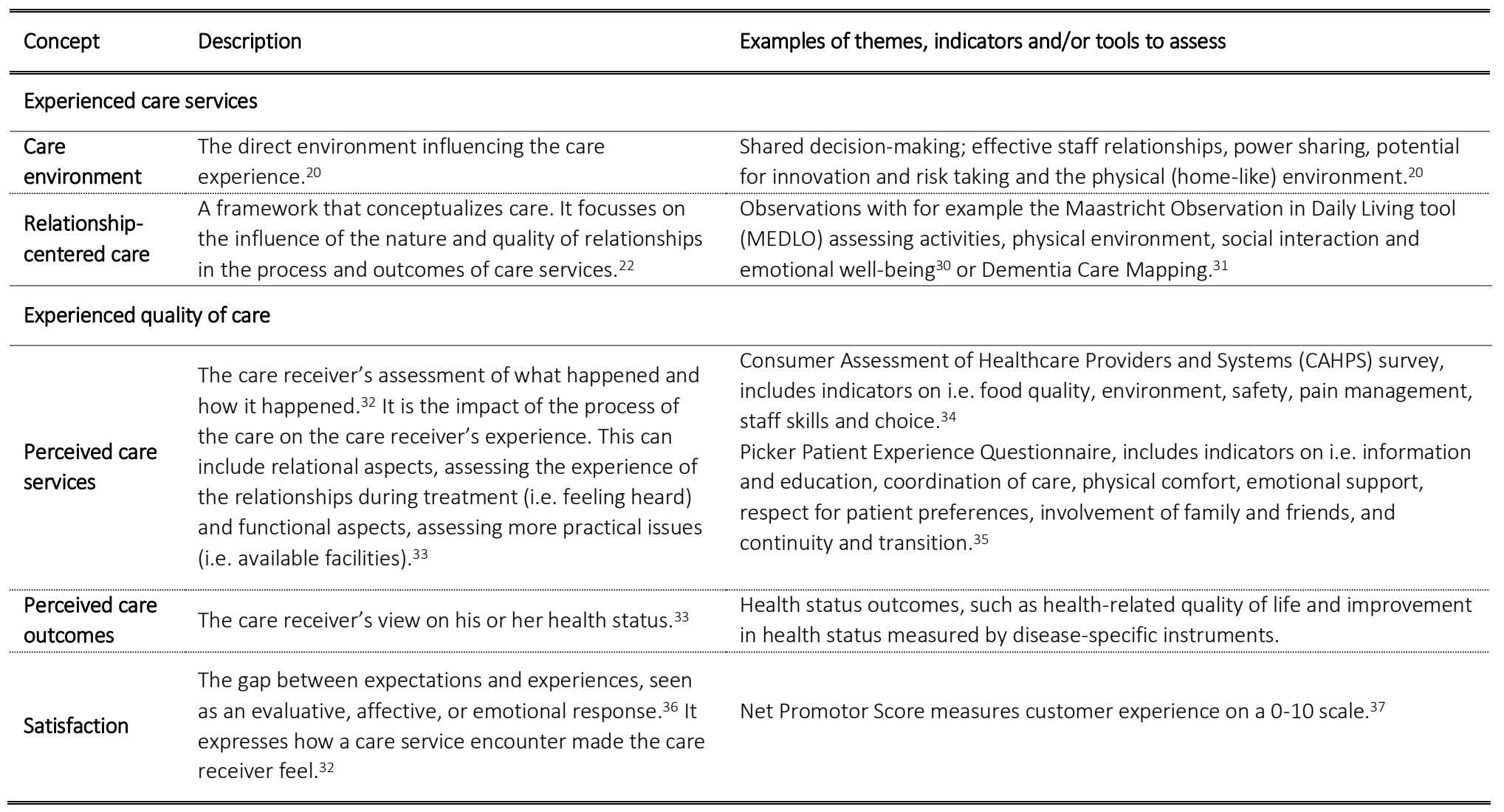




\section{Expectations (before)}

There are 2 types of expectations: adequate and desired. Adequate expectations are what is likely to happen and what a care recipient considers to be acceptable. Desired expectations are the services a care recipient hopes and desires to receive, in other words, what they feel a service should offer. ${ }^{26}$ The range between an adequate and desired expectation of LTC services is formed by 3 influences: personal needs, past experiences, and word of mouth, as adopted from the Service Quality (SERVQUAL) model. ${ }^{18}$ This is the most widely known model in the field of service sciences, describing experienced service quality from the customer's perspective. ${ }^{18}$ It recognizes the difference between expected services and perceived services, known as the gap representing customer satisfaction. ${ }^{26,38}$

Experienced quality of care starts with the occurrence of a personal need. Everyone has basic personal needs, and within relationship-centered care these are defined as the 6 basic senses: security, continuity, belonging, significance, purpose, and fulfilment. ${ }^{25}$ Underlying any care service, there is a need related to 1 or multiple of these senses. For example, the need to receive competent care can be placed in the sense of security, or the need to form meaningful and interactive relationships can be placed in the sense of belonging. Past experiences are the care recipient's previous exposures to a care service that are relevant to the current service and can shape predictions and desires. ${ }^{26}$ They can have a direct impact on what someone expects from a care service. Other people's past experiences can influence a care recipient's expectations by word of mouth. ${ }^{18}$ These are personal and sometimes nonpersonal statements made by parties other than the organization, such as care recipient reviews, friends and family. ${ }^{28}$ They express what the service will be like to care recipients (ie, what they can expect). Word of mouth is perceived as unbiased and has shown to be quite important in care services because services are difficult for consumers to evaluate prior to purchasing and directly experiencing them. ${ }^{28}$

\section{Experiences (during)}

Experiences with care services are defined as the sum of interactions across the care process, influencing the care recipient's perception within the organizational culture. ${ }^{39}$ The care environment influences the care experience, for example, by means of shared decisionmaking and the physical aspects of the environment, such as a home-like atmosphere, privacy, noise and cleanliness. ${ }^{20,40,41}$ During the actual experience with a care service in the care environment, interactions within the caring relationships can influence the experience. Caring relationships are defined as "human interactions grounded in caring processes, incorporating physical work (doing), interactions (being with), and relationships (knowing each other)." ${ }^{23}$ They are deemed necessary to provide high quality of care. ${ }^{23}$ How care is delivered and received is dependent on how we define ourselves and others within a network of relationships and social circumstances. ${ }^{22}$ In service sciences, this is portrayed as balanced centricity, implying that value is co-created by all involved stakeholders who each deserve 
satisfaction of their needs and wants. ${ }^{42}$ Relationships are the medium of care that should be based upon mutual respect, equity and shared understanding. ${ }^{43}$ Family is considered an important player in LTC, as their involvement can influence the care recipient's experiences by means of, for example choice, community connection, and quality of life. ${ }^{44}$ Figure 1 presents the relationships in a triangle consisting of the care recipient, professional caregivers, and informal caregivers. This network of relationships can differ for each individual care recipient; however, the simplified visualization in the framework portrays the emphasis on the relationships between the involved players. Players in the caring relationships can each have a view on the experienced quality of care process from the care recipient's perspective because they are part of the experience. For example, a family member also has certain expectations and experiences with the care provided to their loved one, and this can influence the experienced quality of care results.

\section{Experienced quality of LTC (after)}

After the experience, the care recipient makes a conscious or unconscious assessment by comparing his or her expectations with the actual experience, taking into consideration the gap between the experience and the reported experience. ${ }^{45}$ This leads to an evaluation of 3 aspects: perceived care services, perceived care outcomes, and satisfaction. ${ }^{32},{ }^{33}$ Within perceived care services, the process of the experience is evaluated by answering questions such as what happened and how it happened. ${ }^{32}$ This can include relational aspects, assessing the experience of the care relationships (ie, feeling heard) and functional aspects, assessing more practical issues (ie, allocated caregiving time). ${ }^{33}$ Within perceived care outcomes, the care recipient's health status is assessed, such as (health-related) quality of life, levels of pain, and other changes in the care recipient's health outcomes. ${ }^{33}$ Within satisfaction, the care recipient attaches an emotional response to the experience, expressing how the experience made him or her feel. ${ }^{32}$ It is considered to be the gap between expectations and experiences, seen as an evaluative, affective, or emotional response. ${ }^{36}$ Eventually the sum of these evaluations contributes to the assessment of the overall experienced quality of LTC.

\section{Context}

Considering the framework presents the process of experiences from an individual care recipient's perspective, it needs to be taken into account that each individual within the care process has his or her own personal characteristics, such as age, sex, education, ethnicity and social class. ${ }^{45,46}$ The framework has been developed within the LTC setting for older people. ${ }^{1}$ The individual characteristics and the LTC setting for older people in which care is delivered (ie, at home or in a nursing home) shape the context of an experience. ${ }^{23,24}$

\section{Example}

INDEXQUAL can be adapted to different settings, timings, and populations. For example, the framework can be adapted to people with dementia living in nursing homes for the 
remainder of their lives. In this case, the framework can focus on assessing the entire experience of living in the nursing home for a longer period of time. The method to assess the experience might be by means of observations as care recipients cannot always express themselves anymore. ${ }^{30,31}$ In addition, the position of the family in the triangle may gain more importance in this setting to support and voice the needs of the care recipient.

\section{IMPLICATIONS FOR PRACTICE, POLICY AND/OR RESEARCH}

INDEXQUAL presents a framework of a care recipient's journey, including the expectations, experiences and assessment of quality of LTC in terms of perceived care services, care outcomes, and satisfaction. INDEXQUAL has been based on theory and the next step is to validate it in practice. The framework was developed for the LTC setting for older people, however, it may be applicable for other LTC settings as well. Currently, there is an occurring trend focused on the importance of relationships within care delivery. ${ }^{47}$ INDEXQUAL can provide insight into the care process as experienced within these relationships (care recipient, professional caregiver, and informal caregiver). It can be used as a framework to select existing methods or develop a new method to assess how LTC provision is experienced.

The INDEXQUAL framework differs from existing frameworks and models because it incorporates knowledge from healthcare literature and service sciences literature from the care recipient's perspective. It is a dynamic framework presenting the process of experienced quality of care, highlighting the importance of relationships within this experience. The framework presents an overarching representation allowing flexibility to adapt to specific LTC settings, timing, and population. In addition, INDEXQUAL addresses quality of LTC not only from the physical, but also from the social and emotional, aspects of care. This is in line with the growing focus on assessing more than standardized quality indicators and assessing the care recipient's experiences as well. Perceived care processes assess what happened and how it happened, perceived care outcomes assess the care recipient's self-reported health status, and satisfaction assesses how the experience made the care recipient feel. ${ }^{26,32,48}$ The sum of these results provide a more holistic view on how care provision is experienced. INDEXQUAL can serve as a framework for quality monitoring, improvement, and transparency. 


\section{REFERENCES}

1. OECD/EU. A Good Life in Old Age? Paris: OECD Publishing; 2013.

2. World Health Organisation. World report on ageing and health. Luxembourgh: World Health Organisation, 2015.

3. Rosher RB, Robinson S. Impact of the Eden Alternative on family satisfaction. Journal of the American Medical Directors Association. 2005;6(3):189-93.

4. Brownie S, Nancarrow S. Effects of person-centered care on residents and staff in aged-care facilities: a systematic review. Clinical Interventions in Aging. 2013;8:1-10.

5. Snoeren MM, Janssen BM, Niessen TJ, Abma TA. Nurturing cultural change in care for older people: Seeing the cherry tree blossom. Health Care Analysis. 2016;24(4):349-73.

6. McColl-Kennedy JR, Snyder H, Lars Witell ME, Helkkula A, Hogan SJ, Anderson L. The changing role of the health care customer: review, synthesis and research agenda. Journal of Service Management. 2017;28(1):2-33.

7. Shura R, Siders RA, Dannefer D. Culture Change in Long-term Care: Participatory Action Research and the Role of the Resident. Gerontologist. 2011;51(2):212-25.

8. Donabedian A. Evaluating the quality of medical care. The Milbank memorial fund quarterly. 1966;44(3):166-206.

9. Institute of Medicine. Chapter 1. Health, Health Care, and Quality of Care. In: Lohr KN, editor. Medicare: A Strategy for Quality Assurance: Volume 1. Washington (DC): National Academies Press (US) 1990.

10. Donabedian A. The quality of care. How can it be assessed? Jama. 1988;260(12):1743-8.

11. Castle NG, Ferguson JC. What Is Nursing Home Quality and How Is It Measured? Gerontologist. 2010;50(4):426-42.

12. Huber M, Knottnerus JA, Green L, Horst Hvd, Jadad AR, Kromhout D, et al. How should we define health? Bmj. 2011;343.

13. Huber M, van Vliet M, Giezenberg M, Winkens B, Heerkens Y, Dagnelie PC, et al. Towards a 'patientcentred' operationalisation of the new dynamic concept of health: a mixed methods study. BMJ Open. 2016;6(1):e010091.

14. Berwick DM. Medical associations: guilds or leaders? Either play the role of victim or actively work to improve healthcare systems. 1997;314(7094):1564.

15. Triemstra M, Winters S, Kool RB, Wiegers TA. Measuring client experiences in long-term care in the Netherlands: a pilot study with the Consumer Quality Index Long-term Care. BMC Health Serv Res. 2010;10:95.

16. Weldring T, Smith SM. Article Commentary: Patient-Reported Outcomes (PROs) and PatientReported Outcome Measures (PROMs). Health Serv Insights. 2013;6:HSI. S11093.

17. Voorhees CM, Fombelle PW, Gregoire Y, Bone S, Gustafsson A, Sousa R, et al. Service encounters, experiences and the customer journey: Defining the field and a call to expand our lens. Journal of Business Research. 2017;79:269-80.

18. Parasuraman A, ZeithamI VA, Berry LL. A Conceptual Model of Service Quality and Its Implications for Future Research. Journal of Marketing. 1985;49(4):41-50.

19. Goffin K, Mitchell R. Innovation Management: Effective strategy and implementation: Macmillan Education UK; 2016.

20. McCormack B, Roberts T, Meyer J, Morgan D, Boscart V. Appreciating the 'person' in long-term care. Int J Older People Nurs. 2012;7(4):284-94.

21. Pew-Fetzer Task Force \& Tresolini CP. Health professions education and relationship-centered care : report: Pew Health Professions Commission, UCSF Center for the Health Professions; 1994. 
22. Soklaridis S, Ravitz P, Nevo GA, Lieff S. Relationship-centred care in health: A 20-year scoping review. Patient Experience Journal. 2016;3(1):130-45.

23. Duffy JR, Hoskins LM. The Quality-Caring Model: blending dual paradigms. ANS Adv Nurs Sci. 2003;26(1):77-88.

24. McCormack B, McCance TV. Development of a framework for person-centred nursing. J Adv Nurs. 2006;56(5):472-9.

25. Nolan M, Brown J, Davies S, Nolan J, Keady J. The Senses Framework: improving care for older people through a relationship-centred approach. Getting Research into Practice (GRiP) Report No 2.: University of Sheffield.; 2006.

26. Parasuraman A, ZeithamI VA, Berry LL. SERVQUAL: A multiple-item scale for measuring customer perceptions of service quality. . Journal of Retailing. 1988;6(41):12-40.

27. Fegran L, Hall EOC, Uhrenfeldt L, Aagaard H, Ludvigsen MS. Adolescents' and young adults' transition experiences when transferring from paediatric to adult care: A qualitative metasynthesis. Int J Nurs Stud. 2014;51(1):123-35.

28. ZeithamI VA, Berry LL, Parasuraman A. The nature and determinants of customer expectations of service. Journal of the Academy of Marketing Science. 1993;21(1):1-12.

29. Johari K, Kellogg C, Vazquez K, Cardenas V, Zhu Y, Enguidanos S, et al. What Consumers Say About Nursing Homes in Online Reviews. Gerontologist. 2018;58(4):e273-e80.

30. de Boer B, Beerens HC, Zwakhalen SM, Tan FE, Hamers JP, Verbeek H. Daily lives of residents with dementia in nursing homes: development of the Maastricht electronic daily life observation tool. Int Psychogeriatr. 2016;28(8):1333-43.

31. Brooker DJ, Surr C. Dementia Care Mapping (DCM): initial validation of DCM 8 in UK field trials. Int J Geriatr Psychiatry. 2006;21(11):1018-25.

32. LaVela SL, Gallan AS. Evaluation and measurement of patient experience. Patient Experience Journal. 2014;1(28):36.

33. Kingsley C, Patel S. Patient-reported outcome measures and patient-reported experience measures. BJA Education. 2017;17(4):137-44.

34. Agency for Healthcare Research and Quality. CAHPS: Consumer Assessment of Healthcare Providers and Systems. [cited 201921 February 2019]. Available from: http://www.cahps.ahrq.gov.

35. Jenkinson C, Coulter A, Bruster S, Richards N, Chandola T. Patients' experiences and satisfaction with health care: results of a questionnaire study of specific aspects of care. Qual Saf Health Care. 2002;11(4):335-9.

36. Oliver RL, DeSARBO WS. Processing of the satisfaction response in consumption: a suggested framework and research propositions. Journal of Consumer Satisfaction, Dissatisfaction and Complaining Behavior. 1989;2(1):1-16.

37. Reichheld FF. The one number you need to grow. Harv Bus Rev. 2003;81(12):46-54, 124.

38. Kulašin D, Fortuny-Santos J, editors. Review of the SERVQUAL concept. The 4th Research/expert Conference with International Participation, In Macau; 2005.

39. Wolf JA, Niederhauser V, Marshburn D, LaVela SL. Defining Patient Experience. Patient Experience Journal. 2014;1(1):7.

40. Chan J, Beard RL, Lyons W, Kris AE, Schell E, Kayser-Jones J. Factors That Influence End-of-Life Care in Nursing Homes: The Physical Environment, Inadequate Staffing, and Lack of Supervision. The Gerontologist. 2003;43(suppl_2):76-84.

41. Mahmood A, Chaudhury H, Valente M. Nurses' perceptions of how physical environment affects medication errors in acute care settings. Applied Nursing Research. 2011;24(4):229-37. 
42. Gummesson E. Extending the service-dominant logic: from customer centricity to balanced centricity. Journal of the Academy of Marketing Science. 2008;36(1):15-7.

43. Adams T, Clarke CL. Dementia care: Developing partnerships in practice: Bailliere Tindall Limited; 1999.

44. Gaugler JE. Family involvement in residential long-term care: A synthesis and critical review. Aging \& Mental Health. 2005;9(2):105-18.

45. Sandager M, Freil M, Knudsen JL. Please tick the appropriate box: Perspectives on patient reported experience. Patient Experience Journal. 2016;3(1):63-79.

46. Chow A, Mayer EK, Darzi AW, Athanasiou T. Patient-reported outcome measures: The importance of patient satisfaction in surgery. Surgery. 2009;146(3):435-43.

47. McCormack B, van Dulmen S, Eide H, Skovdahl K, Eide T. Person-Centred Healthcare Research: Wiley; 2017.

48. Cronin JJ, Taylor SA. Measuring Service Quality: A Reexamination and Extension. Journal of Marketing. 1992;56(3):55-68. 


\section{APPENDICES}

Appendix 1. Additional literature used in model development but not cited

The special article presents the final selection of core publications that were used to compose the INDEXQUAL framework. Behind the development of this framework lies a broad literature review of experienced quality of care from the care recipient's perspective. There is a secondary list of articles that contributed to the insights in this special article, but were not the primary contributors to the final framework. ${ }^{1-55}$ Reasons for exclusion were that these articles (1) did not focus on the care receiver's perspective; (2) focused on quality of life instead of quality of care; (3) presented specific outcomes or themes related to a specific setting or construct; (4) presented an adaptation of an existing model; or (5) did not present a model, framework or theory of quality of care or care experiences.

1. Alonazi WB, Thomas SA. Quality of care and quality of life: convergence or divergence? Health Serv Insights. 2014;7:1-12.

2. Babakus E, Mangold WG. Adapting the SERVQUAL scale to hospital services: an empirical investigation. Health Services Research. 1992;26(6):767-86.

3. Beach MC, Inui T. Relationship-centered care. A constructive reframing. J Gen Intern Med. 2006;21 Suppl 1:S3-8.

4. Beattie M, Murphy DJ, Atherton I, Lauder W. Instruments to measure patient experience of healthcare quality in hospitals: a systematic review. Systematic reviews. 2015;4(1):97.

5. Beerens HC. Adding life to years : quality of life of people with dementia receiving long-term care. Maastricht: Hanneke Beerens; 20162016.

6. Bird M, Anderson K, MacPherson S, Blair A. Do interventions with staff in long-term residential facilities improve quality of care or quality for life people with dementia? A systematic review of the evidence. Int Psychogeriatr. 2016;28(12):1937-63.

7. Bjerregaard K, Haslam SA, Mewse A, Morton T. The shared experience of caring: a study of careworkers' motivations and identifications at work. Ageing \& Society. 2017;37(1):113-38.

8. Bjertnaes OA, Sjetne IS, Iversen HH. Overall patient satisfaction with hospitals: effects of patientreported experiences and fulfilment of expectations. BMJ Qual Saf. 2012;21(1):39-46.

9. Bradshaw SA, Playford ED, Riazi A. Living well in care homes: a systematic review of qualitative studies. Age Ageing. 2012;41(4):429-40.

10. Brod M, Stewart AL, Sands L, Walton P. Conceptualization and measurement of quality of life in dementia: the dementia quality of life instrument (DQoL). Gerontologist. 1999;39(1):25-35.

11. Brooker D. Person-Centred Dementia Care: Making Services Better: Jessica Kingsley Publishers; 2006.

12. Brownie S, Nancarrow S. Effects of person-centered care on residents and staff in aged-care facilities: a systematic review. Clinical Interventions in Aging. 2013;8:1-10.

13. Campbell SM, Roland MO, Buetow SA. Defining quality of care. Soc Sci Med. 2000;51(11):1611-25.

14. Care Alliance Ireland. Literature review on the relationship between family carers and home care support workers. 2014.

15. Carr AJ, Gibson B, Robinson PG. Measuring quality of life: Is quality of life determined by expectations or experience? Bmj. 2001;322(7296):1240-3.

16. Carr AJ, Higginson IJ. Are quality of life measures patient centred? Bmj. 2001;322(7298):1357-60. 
17. Chow A, Mayer EK, Darzi AW, Athanasiou T. Patient-reported outcome measures: The importance of patient satisfaction in surgery. Surgery. 2009;146(3):435-43.

18. Cooney A, Murphy K, O'Shea E. Resident perspectives of the determinants of quality of life in residential care in Ireland. J Adv Nurs. 2009;65(5):1029-38.

19. Cossette S, Cara C, Ricard N, Pepin J. Assessing nurse-patient interactions from a caring perspective: report of the development and preliminary psychometric testing of the Caring Nurse--Patient Interactions Scale. Int J Nurs Stud. 2005;42(6):673-86.

20. Cronin JJ, Taylor SA. Measuring Service Quality: A Reexamination and Extension. Journal of Marketing. 1992;56(3):55-68.

21. D'Astous V, Abrams R, Vandrevala T, Samsi K, Manthorpe J. Gaps in understanding the experiences of homecare workers providing care for people with dementia up to the end of life: A systematic review. Dementia.0(0):1471301217699354.

22. Dewar B, Nolan M. Caring about caring: developing a model to implement compassionate relationship centred care in an older people care setting. Int J Nurs Stud. 2013;50(9):1247-58.

23. Garvin DA. What Does "Product Quality" Really Mean? Sloan Management Review. 1984;26(1):2543.

24. Gerteis M. Through the patient's eyes: understanding and promoting patient-centered care. 1993.

25. Glass AP. Nursing home quality: a framework for analysis. J Appl Gerontol. 1991;10(1):5-18.

26. Griffiths P. State of the art metrics for nursing: a rapid appraisal. London: National Nursing Research Unit, King's College London; 2008.

27. Gronroos C. Service quality: The six criteria of good perceived service. Review of business. 1988;9(3):10.

28. Gummesson E. Extending the service-dominant logic: from customer centricity to balanced centricity. Journal of the Academy of Marketing Science. 2008;36(1):15-7.

29. Hudon C, Fortin M, Haggerty JL, Lambert M, Poitras ME. Measuring patients' perceptions of patientcentered care: a systematic review of tools for family medicine. Ann Fam Med. 2011;9(2):155-64.

30. Jenkinson C, Coulter A, Bruster S, Richards N, Chandola T. Patients' experiences and satisfaction with health care: results of a questionnaire study of specific aspects of care. Qual Saf Health Care. 2002;11(4):335-9.

31. Kane RA. Long-term care and a good quality of life: bringing them closer together. Gerontologist. 2001;41(3):293-304.

32. Kane RA, Kling KC, Bershadsky B, Kane RL, Giles K, Degenholtz HB, et al. Quality of life measures for nursing home residents. J Gerontol A Biol Sci Med Sci. 2003;58(3):240-8.

33. Kobayashi $\mathrm{H}$, Takemura $\mathrm{Y}$, Kanda K. Patient perception of nursing service quality; an applied model of Donabedian's structure-process-outcome approach theory. Scand J Caring Sci. 2011;25(3):41925.

34. Kuis EE, Hesselink G, Goossensen A. Can quality from a care ethical perspective be assessed? A review. Nurs Ethics. 2014;21(7):774-93.

35. Kulašin D, Fortuny-Santos J, editors. Review of the SERVQUAL concept. The 4th Research/expert Conference with International Participation, In Macau; 2005.

36. Lee D. HEALTHQUAL: a multi-item scale for assessing healthcare service quality. Service Business. 2017;11(3):491-516.

37. Marcoen A. Filial maturity of middle-aged adult children in the context of parent care: Model and measures. Journal of Adult Development. 1995;2(2):125-36.

38. McColl-Kennedy JR, Snyder H, Lars Witell ME, Helkkula A, Hogan SJ, Anderson L. The changing role of the health care customer: review, synthesis and research agenda. Journal of Service Management. 2017;28(1):2-33. 
39. Mead N, Bower P. Patient-centredness: a conceptual framework and review of the empirical literature. Soc Sci Med. 2000;51(7):1087-110.

40. Miller D, Gray CS, Kuluski K, Cott C. Patient-centered care and patient-reported measures: let's look before we leap. The Patient-Patient-Centered Outcomes Research. 2015;8(4):293-9.

41. Morgan S, Yoder LH. A concept analysis of person-centered care. J Holist Nurs. 2012;30(1):6-15.

42. Oliver RL, Swan JE. Consumer Perceptions of Interpersonal Equity and Satisfaction in Transactions: A Field Survey Approach. Journal of Marketing. 1989;53(2):21-35.

43. Oliver RL. Cognitive, affective, and attribute bases of the satisfaction response. Journal of consumer research. 1993;20(3):418-30.

44. Oliver RL. Customer Satisfaction. Wiley International Encyclopedia of Marketing: John Wiley \& Sons, Ltd; 2010.

45. Pascoe GC. Patient satisfaction in primary health care: a literature review and analysis. Evaluation and program planning. 1983;6(3-4):185-210.

46. Rantz MJ, Mehr DR, Popejoy L, Zwygart-Stauffacher M, Hicks LL, Grando V, et al. Nursing home care quality: a multidimensional theoretical model. J Nurs Care Qual. 1998;12(3):30-46; quiz 69-70.

47. de Rooij AH, Luijkx KG, Spruytte N, Emmerink PM, Schols JM, Declercq AG. Family caregiver perspectives on social relations of elderly residents with dementia in small-scale versus traditional long-term care settings in the Netherlands and Belgium. Journal of clinical nursing. 2012;21(2122):3106-16.

48. Rosher RB, Robinson S. Impact of the Eden Alternative on family satisfaction. Journal of the American Medical Directors Association. 2005;6(3):189-93.

49. Shah DR, Roland T. ; Parasuraman, Ananthanarayanan ; Staelin, Richard ; Day, George S. The Path to Customer Centricity. Journal of Service Research. 2006;9(2):113-24.

50. Shippee TP, Henning-Smith C, Kane RL, Lewis T. Resident- and Facility-Level Predictors of Quality of Life in Long-Term Care. Gerontologist. 2015;55(4):643-55.

51. Spreng RA, Mackoy RD. An empirical examination of a model of perceived service quality and satisfaction. Journal of Retailing. 1996;72(2):201-14.

52. Tronto JC. Moral Boundaries: A Political Argument for an Ethic of Care: Routledge; 1993.

53. Uman GC, Urman HN. Measuring consumer satisfaction in nursing home residents. Nutrition. 1997;13(7-8):705-7.

54. De Waele I, Van Loon J, Van Hove G, Schalock RL. Quality of Life Versus Quality of Care: Implications for People and Programs. Journal of Policy and Practice in Intellectual Disabilities. 2005;2(3-4):22939.

55. Zubritsky C, Abbott KM, Hirschman KB, Bowles KH, Foust JB, Naylor MD. Health-related quality of life: expanding a conceptual framework to include older adults who receive long-term services and supports. Gerontologist. 2013;53(2):205-10. 



\section{CHAPTER 4}

How to Assess Experienced Quality of Care in Nursing Homes from the Client's Perspective: Results of a Qualitative Study

This chapter was published as:

Sion KYJ, Verbeek H, De Boer B, Zwakhalen SMG, Odekerken-Schröder GJ, Schols JMGA, Hamers JPH. How to assess experienced quality of care in nursing homes from the client's perspective: results of a qualitative study. BMC Geriatrics, 2020; 20(67):1-12

https://doi.org/10.1186/s12877-020-1466-7 


\section{ABSTRACT}

Background: The culture shift in nursing homes from task-oriented to person-centered care has created a need to assess clients' experienced quality of care (QoC), as this corresponds best with what matters to them. This study aimed to gain insight into how to assess experienced QoC in nursing homes from the client's perspective.

Method: A qualitative study was performed consisting of a focus group with client representatives $(n=10)$, a focus group with nursing home staff $(n=9)$ and a world café with client representatives and staff recruited from the Living Lab in Ageing \& Long-Term Care $(n=24)$. Three questions about assessing experienced QoC from the client's perspective were addressed during data collection: 1) what content needs to be assessed? 2) What assessment procedures are needed? and, 3) who needs to be involved in the assessment? Semistructured questions, photo elicitation and creative writing were used to answer these questions. Conventional content analysis was used to analyze the data.

Results: Participants indicated that experienced QoC mostly occurs within the interactions between the clients, family and staff, highlighting the impact of relationships. They suggested assessments should focus on three aspects: 1) knowledge about the client, 2) a responsive approach, and 3) a caring environment. These can be assessed by having conversations with clients, their families and staff, and additionally observing the clients in their living environments. Sufficient time and resources are prerequisites for this. Additionally, the person performing the quality assessments needs to possess certain communication and empathy skills.

Conclusion: It is important to include the perspectives of the client, family and staff when assessing experienced $\mathrm{QoC}$, in line with the principles underlying relationship-centered care. In order to be feasible it is recommended to incorporate quality assessments into the nursing homes' daily routines. Further research with clients, family and staff in nursing homes is needed to develop a feasible, reliable and valid method that assesses experienced QoC from the client's perspective. 


\section{BACKGROUND}

Currently, Western countries are struggling to consistently improve quality of care (QoC) in nursing homes. ${ }^{1}$ Reasons for this are changing expectations of what nursing homes should offer, an increase in the aging population, and high staff shortages and turnover. ${ }^{2,3}$ Many definitions of QoC exist and most relate to the Institute of Medicine's criteria stating that care needs to be safe, effective, patient-centered, timely, efficient and equitable. ${ }^{4-6}$ However, there has been a culture change from task-oriented to person-centered care, putting clients' needs, wants, preferences and relationships more centrally in care provision in order to achieve high QoC in nursing homes. ${ }^{7-10}$ Consequently, it has become more important to include the client's perspective when assessing QoC and focus on what matters most to clients, i.e. the client's experienced QoC. ${ }^{11}$ Research has shown that clients' and families' experiences offer less tangible information on QoC, such as the importance of feeling at home, being empowered and maintaining dignity. ${ }^{12,13}$ These insights have resulted in the need to incorporate these perspectives when assessing experienced QoC in nursing homes. ${ }^{11,}{ }^{14-16}$ In the Netherlands, nursing home clients can live in three types of wards: somatic for those with physical deteriorations; psychogeriatric for those with cognitive impairment; and rehabilitations for those who are recovering from temporary physical impairment. ${ }^{17}$ In 2016, the Dutch government introduced an updated policy on how to maintain and improve QoC in nursing homes. ${ }^{18}$ This policy focusses on person-centered care and relationships, well-being, safety and learning from each other. In other countries similar developments are occurring. ${ }^{19}$

The Individually Experienced Quality of Post-Acute and Long-Term Care (INDEXQUAL) framework presents experienced QoC from the client's perspective as a process, consisting of a before (expectations), during (experiences) and after (assessment) phase within a certain context. ${ }^{20}$ It acknowledges that care experiences occur mostly within interactions between the client, family and staff, in line with the principles of relationship-centered care and defines experienced QoC as the sum of perceived care services, perceived health outcomes and satisfaction. Many instruments have been identified that assess QoC in nursing homes. ${ }^{21}$ However, research on experienced QoC has mainly focused on satisfaction, which is defined as the subjective evaluation of the gap between a health care recipient's expectations and experiences with care. ${ }^{22,}{ }^{23}$ Other instruments address perceived health outcomes, which assess the client's views on his or her health status. ${ }^{24}$

Currently, there is growing interest to assess perceived care services, focused on relationships and practical issues, assessed with patient-reported experience measures. ${ }^{24} \mathrm{~A}$ majority of these instruments are quantitative and give a rating on specific pre-defined topics, lacking information that explains why a certain rating is given and what can be done to improve it. ${ }^{21,24}$ These questionnaires limit the opportunity for respondents to divert beyond their pre-defined topics and address what may actually be of even more value to 
them. Whilst the results are useful for transparency and accountability purposes, there is a growing need to also monitor and improve the client's individually experienced Qoc. ${ }^{22,25}$ In line with these developments, qualitative approaches to assess experienced QoC are being developed and used more frequently. However, a majority of these instruments have not been developed according to the steps in the development and evaluation of a measurement instrument, starting with clearly defining the construct. ${ }^{26}$ This has resulted in them also not having been sufficiently tested regarding their validity, reliability, ability to contribute to quality improvements and user-friendliness. ${ }^{21,26}$ Therefore, the aim of this study was to discover how to assess experienced QoC in nursing homes from the client's perspective according to client representatives' and nursing home staffs' views. These insights will support the future development of a method to assess experienced QoC in nursing homes from the client's perspective.

\section{METHOD}

\section{Study design}

This was a qualitative study consisting of two focus groups and a world café. A focus group is a specific type of group interview in which group interaction is an explicit part of the method and participants' thoughts can be explored. ${ }^{27}$ The world café method is a specific type of group conversation in which a mix of participants share their knowledge and build further on each other's ideas. ${ }^{28}$

\section{Participants}

For the first focus group, policy officers and nurses employed in a nursing home organization were invited to represent the nursing home staff's perspective (hereafter referred to as staff). For the second focus group, client council representatives were invited to represent the voice of the clients (hereafter referred to as client representatives). Both focus groups consisted of homogenous groups to create a comfortable and safe environment for discussions. ${ }^{27}$ For the world café, heterogeneous groups were formed to enhance the discussions and give participants the opportunity to learn from each other and create new ideas together. ${ }^{27,} 28$ Policy officers, formal caregivers (such as nurses or physiotherapists), family, and client council representatives were invited to participate (hereafter referred to as world café participants). The difference between family and client council representatives is that family represent one client's voice, whereas client council representatives have a position within the nursing home to represent the voice of all clients without having to be directly connected to one specific client. This study planned to include clients living in nursing homes as well; however this was considered challenging as many clients in nursing homes suffer from cognitive decline. ${ }^{17}$ After having performed two pilot interviews with clients living in somatic wards, without cognitive impairment, it became apparent that this was not 
feasible. Whilst clients were able to talk about how they perceived the care they received they were not able to distinguish this from how they believed this should be assessed.

Whilst purposive sampling was used to select the main groups of participants directly involved in nursing homes; convenience sampling was used to select the participants within these groups. Staff engaged with QoC policy assurance were selected as they were considered most knowledgeable about the developments in the nursing home setting, and client representatives were selected as they were closely involved with clients and considered knowledgeable about what is important to clients. Participants were recruited from seven nursing home organizations within the Living Lab in Ageing \& Long-Term Care South Limburg (the Netherlands), via an information letter providing information about the aim of the study, a description of the participants, the location and date, confidentiality and how to participate. ${ }^{29}$ The information letters were distributed by the contact persons within the organizations. Participants could register by informing the contact person or the lead researcher of the study by phone or e-mail. For each focus group the aim was to include 8 to 12 participants ${ }^{30}$, and for the world café the aim was to include 20 to 28 participants. ${ }^{28}$ All participants provided written informed consent and could sign up for a newsletter to stay informed on the results of the research.

\section{Data collection}

Data collection took place between May and July 2017 at the university. The focus group with staff was performed first to position the need for a new method of assessing experienced QoC. This was followed by the world café in which participants could brainstorm, share ideas and discuss together. The focus group with client representatives was performed last, in order to gain more in-depth knowledge about the clients' needs. The research team established data saturation was reached after the last focus group. ${ }^{31}$

All discussions were focused on the content to assess, the procedure of the assessment and who to involve during the assessment. Table 1 shows the main characteristics and interview guide for each group discussion. The interview guide was specifically developed for this study. All participants were asked to complete a brief questionnaire on their age, gender and professional background. 
Table 1. Overview of data collection methods

\begin{tabular}{|c|c|c|c|}
\hline & $\begin{array}{l}\text { Data } \\
\text { collection }\end{array}$ & Question(s) & $\begin{array}{l}\text { Duration / } \\
\text { Researchers }\end{array}$ \\
\hline \multirow{4}{*}{$\begin{array}{l}\text { Focus group } \\
\text { staff }\end{array}$} & \multirow{4}{*}{$\begin{array}{l}\text { Semi- } \\
\text { structured } \\
\text { questions }\end{array}$} & $\begin{array}{l}\text { 1. Without any restrictions, how would } \\
\text { you assess how clients experience the } \\
\text { quality of care they receive in nursing } \\
\text { homes? }\end{array}$ & \multirow{4}{*}{$\begin{array}{l}1 \text { hour / } \\
\text { Health Scientist } \\
\text { (first author) and } \\
\text { Associate } \\
\text { Professor in Long- } \\
\text { Term Care Design }\end{array}$} \\
\hline & & $\begin{array}{l}\text { 2. Which topics need to be discussed } \\
\text { during the quality assessment? }\end{array}$ & \\
\hline & & $\begin{array}{l}\text { 3. What assessment procedures are } \\
\text { needed? }\end{array}$ & \\
\hline & & $\begin{array}{l}\text { 4. Who needs to be involved in the } \\
\text { assessment? }\end{array}$ & \\
\hline \multirow[b]{2}{*}{$\begin{array}{l}\text { Focus group } \\
\text { client } \\
\text { representatives }\end{array}$} & \multirow[b]{2}{*}{$\begin{array}{l}\text { Photo } \\
\text { elicitation }\end{array}$} & \multirow[b]{2}{*}{$\begin{array}{l}\text { 1. Please select an image that represents } \\
\text { how quality of care in nursing homes } \\
\text { should be assessed from the client's } \\
\text { perspective }\end{array}$} & 1 hour / \\
\hline & & & $\begin{array}{l}\text { Health Scientist } \\
\text { (first author) and } \\
\text { Professor in Care } \\
\text { of Older Persons }\end{array}$ \\
\hline \multirow{5}{*}{ World café } & \multirow{5}{*}{$\begin{array}{l}\text { Photo } \\
\text { elicitation } \\
\text { Post-its and } \\
\text { writing } \\
\text { material }\end{array}$} & $\begin{array}{l}\text { 1. Please select an image which } \\
\text { represents your expectations of care in a } \\
\text { nursing home from the client's } \\
\text { perspective? }\end{array}$ & \multirow{5}{*}{$\begin{array}{l}2,5 \text { hours } \\
\text { Health Scientist } \\
\text { (first author) and } \\
\text { Associate } \\
\text { Professor in Long- } \\
\text { Term Care Design } \\
\text { and } 4 \text { researchers } \\
\text { in aging } \\
\text { (moderators). }\end{array}$} \\
\hline & & \multirow{2}{*}{$\begin{array}{l}\text { 2. Please select an image which } \\
\text { represents your experiences of care in a } \\
\text { nursing home from the client's } \\
\text { perspective? }\end{array}$} & \\
\hline & & & \\
\hline & & $\begin{array}{l}\text { 3. Please select an image which } \\
\text { represents how quality of care in nursing } \\
\text { homes should be assessed from the } \\
\text { client's perspective? }\end{array}$ & \\
\hline & & 4. Who is involved in a client's network? & \\
\hline
\end{tabular}

Focus groups

The one-hour focus group with staff was guided by semi-structured questions; as they were considered to already have thoughts on the topic. The one-hour focus group with client representatives used photo elicitation in order to trigger discussions. ${ }^{32}$ As the research question was considered quite broad, images were used to support participants to structure their thoughts. ${ }^{33}$ Photo elicitation can stimulate a deeper layer of a person's consciousness and unveil participants' underlying views and beliefs. ${ }^{32}$ This study used the My Home Life Scotland (C) image pack consisting of approximately 100 different images, varying from two people holding hands, to an image of puzzle pieces. ${ }^{34}$ The focus group started by inviting client representatives to select an image that best captured how they felt experienced QoC in nursing homes should be measured. Hereafter, participants explained why they chose a 
specific image and this was followed up by in-depth questions facilitating further discussion. Both focus groups were led by one researcher and supported by another researcher from the research team. Discussions were audio recorded and field notes were taken. Preliminary results were presented to both groups for interpretation and discussion.

\section{World café}

The world café method covered four themes, each focusing on a specific question (Table 1). Questions 1, 2 and 3 used photo elicitation with the My Home Life Scotland (C images to stimulate discussion. Question 4 used post-its and colored pens to create an overview of all stakeholders in a client's network. First, participants were informed about the definition of experienced QoC in nursing homes from the client's perspective, to assure discussions would focus on personal experiences and not on standardized quantitative outcomes such as the prevalence of pressure ulcers or malnutrition. Second, participants were invited to take a random seat at one of the four tables representing a question. In three consecutive 30minute rounds, separate groups consisting of 4 to 8 participants were encouraged to discuss the question. After each round, participants swapped seats and continued a discussion about another theme at a different table. A moderator remained seated at the table to introduce the new theme and explain what the previous group had discussed. ${ }^{28}$ The moderators had experience in guiding groups and world cafés, and received a 1-hour training. During this training the lead researcher provided information on the aim of the world café, and how to stimulate and capture discussions. Additionally, moderators were assigned to their research question and were provided with the opportunity to ask questions. Discussions were written down in keywords on sheets of paper covering the tables, and subsequently summarized. Participants started each round by writing down their thoughts on post-its and laying these onto the table sheet. After the three sessions, there was a plenary session in which each group presented the results of the specific theme, and field notes were taken by the researcher. All moderators provided the lead researcher with a summary of the three rounds including explanations for each of the chosen images for the questions using elicitation. After interpreting these summaries, the lead researcher had conversations with all moderators to confirm that the interpretations of the results were correct.

\section{Data-analysis}

Conventional content analysis was used to analyse the collected data. ${ }^{30,}{ }^{35}$ First, audio recordings from both focus groups were transcribed, and the extensive summaries and table sheets from the world cafe were prepared for analysis. Then, the first author familiarised with this data and gained a deeper understanding by reading all transcripts and summaries multiple times. Hereafter, the first author identified key thoughts and concepts by means of open coding. Concepts such as knowing the client, expectations, methods of assessing QoC, prerequisites for assessments, and perspectives were coded and a code tree emerged. A topdown approach was used to create overarching categories which were based on the main 
content, procedure and who to involve themes that guided data collection. A second researcher validated the code tree, by coding sections of the transcript with the same code tree. This was compared with the first author's coding to identify similarities and differences. Differences were resolved with the research team and adjusted throughout the entire coding process. Data were analysed with MAXQDA version 18.0.3 software. $^{36}$

\section{Trustworthiness}

Multiple actions were involved to enlarge the trustworthiness of this study. ${ }^{37-39}$ Participants were invited from seven long-term care organizations in the region, which contributed to the credibility of this study. Method triangulation was apparent as two focus groups and a world café were performed with the same aim. ${ }^{40}$ Data triangulation was apparent as participants with different roles in the nursing home setting participated. ${ }^{40}$ Furthermore, the research team engaged in reflexivity acknowledging and discussing their views on QoC assessments and the impact of their views and backgrounds on the research process. ${ }^{40}$ Data analysis was performed by two researchers, known as investigator triangulation. ${ }^{40}$ In order to enhance dependability, the procedures followed in this study were described in detail, and to increase the confirmability, the main results were summarized at the end of both focus groups and the world café ${ }^{39}$ Participants were encouraged to further explain their thoughts, and correct or add information when necessary. Detailed descriptions of the findings have been supported with quotes from both focus groups and the world café, increasing the transferability of the presented findings in this study. ${ }^{38}$ Additionally, a group of experts involved in national long-term care policy making was consulted after data collection to discuss and validate the findings.

\section{Ethics approval}

The study protocol was approved by the medical ethics committee of Zuyderland (17-N-86). Information about the aim of the study and the expected burden of the focus group or world café session was provided to all participants in advance by e-mail. Participation was strictly voluntarily for all participants. Before the start of each gathering, written informed consent to contribute to the study was given by all participants. Participants were allowed to withdraw from the study at any moment. In order to guarantee privacy and anonymity of participants, no names or institutions were documented.

\section{RESULTS}

A total of 38 stakeholders participated in this study as presented in Table 2. 
Table 2. Characteristics of participants

\begin{tabular}{|c|c|c|c|}
\hline & $\begin{array}{l}\begin{array}{l}\text { Focus group staff } \\
(n=10)\end{array}\end{array}$ & $\begin{array}{l}\text { Focus group client } \\
\text { representatives }(n=9)\end{array}$ & World café $(n=24)$ \\
\hline $\begin{array}{l}\text { Gender } \% \quad(n) \\
\text { female }\end{array}$ & $100 \%(10)$ & $33 \%(3)$ & $92 \%(22)$ \\
\hline $\begin{array}{l}\text { Age years } \\
\text { mean [min; max] }\end{array}$ & $42[27 ; 54]$ & $71[61 ; 83]$ & $43[22 ; 68]^{a}$ \\
\hline Participants $(n)^{b}$ & $\begin{array}{l}\text { Staff: } \\
\text { Policy officerc ( } 8) \\
\text { Formal caregivers } \\
\text { (2) } \\
\text {-Nurses (2) }\end{array}$ & $\begin{array}{l}\text { Client representatives: } \\
\text { Client council } \\
\text { representatives (9) }\end{array}$ & $\begin{array}{l}\text { Staff: } \\
\text { Policy officerc (7) } \\
\text { Formal caregivers (12) } \\
\text {-Nurses (8) } \\
\text {-Physiotherapists (2) } \\
\text {-Occupational therapists (2) } \\
\text { Client representatives: } \\
\text { Family (3) } \\
\text { Client council } \\
\text { representatives (2) }\end{array}$ \\
\hline
\end{tabular}

a $n=23$, data from one participant is missing

$\mathrm{b}$ three policy officers and two client council representatives participated in both a focus group and the world café

c policy officers were employed at a nursing home organization and were occupied with quality assurance within their organization

Figure 1 provides an overview of the topics that were discussed by the participants. All emphasized the importance of relationships for care experiences and their assessments. They reflected that a great part of experienced QoC occurs within the interactions between the clients, family and staff. The following sections will present participants' views on the content, procedure and who to involve, and the importance of relationships when assessing experienced $\mathrm{QoC}$ in nursing homes from the client's perspective.

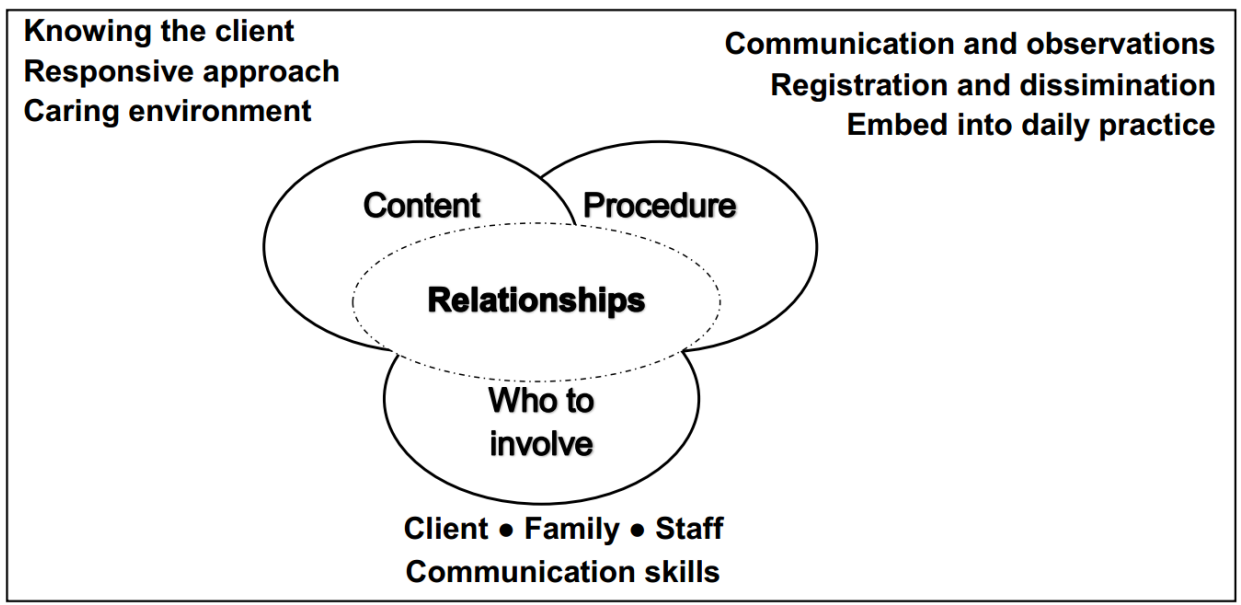

Figure 1. Identified topics on how to assess experienced QoC in nursing homes 


\section{Relationships}

One overarching topic occurred in the content, procedure and who to involve sections: the importance of relationships. Participants in each group believed that taking time to establish a relationship with the client and show genuine interest is essential for meaningful conversations. It is important to explore and experience the client's life together and adopt a tailored approach during these conversations. Staff viewed experienced QoC to be highly influenced by relationships between clients and their formal caregivers. Client representatives added family to this equation, as they are often involved in expressing the clients' preferences and needs. Additionally, the relationship between the client and the person assessing experienced QoC can affect the outcome of QoC assessments. According to client representatives, true commitment, trust, empathy, openness, attention for what is being said, and a level of understanding are needed within relationships. Speaking the same language could contribute according to staff and world café participants. For example, speaking a specific dialect or approaching someone with the title or name they prefer. In conclusion, relationships were seen as the pillars of experiencing and assessing experienced QoC.

"Quality of care is related to emotions and experiences in all phases of the disease. To be able to measure that, you must be able to experience and feel this, which requires a continuous professional relationship." (Client representative)

\section{Content of the quality assessment}

Participants in all groups suggested assessments should focus on three aspects: 1) knowing the client, 2) adopting a personal approach for each client, and 3) creating a caring environment.

\section{Knowing the client}

Participants in all groups mentioned it is important to get to know the clients and their expectations, wishes and needs in order to make them feel at home. This already starts when a client has not moved to the nursing home yet, as this can contribute to a smooth move. For clients and their family it can be a big step to move to an unfamiliar place, which might feel threatening, and therefore prior to moving to the nursing home it was considered beneficial for the experience, to already know who the client is. Client representatives and world café participants added that it is important to know a client's history, even though a client's demands and expectations can shift and change during the disease process. Nursing homes are expected to know what clients and their families expect, and clients and families are expected to know what they can expect from the nursing home. Everyone's norms and values differ, and therefore participants expressed the importance of tailored care. By discovering what a client finds pleasant, values will become visible and care can be tailored. 
Both staff and client representatives acknowledged the importance of relationships to achieve this.

\section{Responsive approach}

Participants mentioned that it is especially important when agreements have been made, that these are fulfilled within a reasonable timeframe. As experienced QoC was approached as a subjective concept, what to assess differs between clients, and therefore client representatives recommended to decide on this together with the client. Client representatives approached $\mathrm{QoC}$ as a personal experience related to less tangible concepts such as emotions and quality of life. They stated clients are seeking for closeness, affection, compassion, attention, and relationships, regardless of the severity of their physical and/or cognitive disabilities. Therefore, when assessing experienced QoC it is important to consider these aspects. It was suggested to assess if clients can organize their daily routines as they wish, and whether the nursing home is adhering to these wishes and fulfilling the client's needs.

"It's in the small things. When a client calls that, he needs to go to the toilet for example. And the nurse replies [agitated] she'll be right there. He does not feel taken seriously" (Staff)

\section{Caring environment}

Participants discussed the importance of creating a safe and caring environment in which clients can rest, feel at home and feel secure. World café participants explained that a safe environment consists of more than alarm systems and locks, but actually touches upon the feeling of being safe at "home". Staff mentioned there are countless possibilities to make someone feel more at home, however they also touched upon the fact that there is a certain limit, and sometimes nursing homes may not be able to meet the client's expectations. This conflicting interest in wanting to provide to the individual's needs, whilst simultaneously seeing countless limitations is a constant struggle. When assessing experienced QoC, it is important to acknowledge the client's environment as well.

"I think we [the nursing home] also need to stay honest. We try to match the home situation. We can decorate the home nicely with your [the client's] own furniture and TV and photos and all, but it is no longer $100 \%$ like at home. I think you should always be realistic about that. We try to do everything as homely as possible and respect other's values as much as possible. And yet there are certain limits." (Staff) 


\section{Procedure of the quality assessment}

Participants addressed the following aspects that need to be taken into account when assessing QoC from the client's perspective: conversations and observations to measure, registration and dissemination of information, and embedding the assessment into practice with sufficient time and resources.

\section{Conversations and observations}

Participants in all groups clearly indicated that whilst they did not know in detail what the best procedure would be to assess experienced $\mathrm{QoC}$, in their opinions existing standardized questionnaires do not sufficiently capture experienced QoC. Reasons for this were that they trigger socially desirable answers, lack the space to capture feelings, are considered too difficult, and focus too much on specific pre-defined topics. Staff emphasized the importance of the story behind a quantitative rating. Participants did mention numerous examples of possibly feasible methods to measure experienced QoC, however not providing details on what these procedures would exactly entail. The most frequently mentioned method was to have regular conversations addressing questions such as "What is important to the client?" or "What does the client expect from the nursing home?". World café participants highlighted the importance of proper communication, especially between clients, family and staff. This requires actual sincerity during conversations, providing each other with time, space and attention. Additionally, they suggested a positive approach could support these conversations. Focus on what is going well and how to do more of this, and thinking in possibilities instead of limitations.

"Have regular 10 minute conversations with the client, even when it seems there is nothing to discuss. Take a seat, sympathize and have a cup of coffee together [during daily care]."(Client representative)

Participants indicated that not all clients might be capable of having conversations, because of their decline in health status and cognitive abilities. However, client representatives specifically stressed the importance of always trying to communicate with the client first. Observations were suggested to be of added value. Client representatives more specifically mentioned that facial expressions give away a lot of information, whereas world café participants focused more on participated observations in which the observer experiences the care environment. In line with observations, several world café participants highlighted the value of assessing QoC by combining speaking (i.e. conversations), hearing (i.e. listening), seeing (i.e. observing), smelling (i.e. cleanliness) and feeling (i.e. the atmosphere), which portrays a more complete picture of the actual daily experiences and interactions.

Both staff and client representatives mentioned the smiley method to roughly monitor how a situation is experienced, however acknowledging it is not sufficient to capture the full spectrum of experienced QoC. This method captures green (happy), orange (neutral) and red 
(unhappy) emotions. After an experience, the client or family member can evaluate by selecting the emotion that corresponds best to how they felt at that specific moment.

\section{Registration and dissemination of collected information}

Participants highlighted the importance that something is done with the information and that the client and family can see that (reciprocity); however, there was no agreement on how to achieve this. World café participants mentioned that a substantial amount of knowledge about the clients is present within the nursing home, however not registered and/or disseminated in a proper way. This could result in important knowledge about a client not reaching all caregivers. It was considered challenging to register information objectively and to the point. Staff suggested the use of grades from for example 1 to 10, however also immediately realized these do not provide information on what exactly is going well and what needs improving. Both a staff member and a client representative gave a similar example of the one page profile, in which a short list of essential client preferences and needs is portrayed in the client's room.

"Unfortunately, many promises are often made but few actions are undertaken." (Participant in world café at table topic 2)

Additionally, participants appeared to have different reasons to assess experienced QoC. Whilst staff highlighted the need for a proper balance of providing clients the space to tell what is important to them, and providing the nursing home constructive information that can be used to identify trends and improve the experienced QoC; client representatives aimed at assessing experienced QoC to improve the client's individual care experience. These differences in aims support the complexity of how best to assess, register and disseminate experienced QoC information.

\section{Embedding into daily practice}

A majority of the participants recommended to assess continuously, as one assessment captures only a snapshot of reality, and therefore it was suggested to measure at multiple moments. Client representatives mentioned measurements should not be seen as big official moments. Whilst challenging, they recommended for measurements to have a low-threshold and be embedded into daily practice. Staff were more specifically discussing the need for a fixed frequency in the quality measurement, whilst keeping it feasible.

Participants indicated that nursing homes need to provide sufficient resources for quality measurements. Some considered the use of conversations and observations to be time consuming, whereas others noted that the conversations might be able to replace the content of the conversations that are already being held. Staff were searching for a balance between standardized checklists for benchmarking versus regular and tailor-made conversations. 
"Everything revolves around time. Time to be there, to listen, to take care of, to fill out forms. Time to let the client live his or her own life and if this becomes challenging, take time for that. Create time when needed. Time is also a precondition for staff." (Participant in world café at table topic 2)

\section{Who to involve in the quality assessment}

Participants agreed it would be beneficial to include multiple perspectives in the quality measurement, to get a better overall view of experienced QoC. Most important, include the client, even when he or she might suffer from a cognitive decline. Whereas others also tend to have knowledge about the client, it was considered important to not surpass the client when measuring QoC from the client's perspective. Clients are quite often still capable to express their wants and dislikes, and incorporating this perspective was considered crucial. Client representatives emphasized the importance of not making assumptions of what clients want or think, but to always ask them.

"What strikes me is that people with dementia are often underestimated. They often can indicate what they like and don't like... For example, people with dementia can also indicate: I want to go for a walk more often, I am just sitting inside and there is no one for me." (Staff)

Participants mentioned the family perspective can provide additional information about experienced QoC, however they do not always have the same views and preferences as the client. Participants indicated that when in doubt, preferences expressed by the client outweigh the family's opinion. It was considered to be of added value to include the family's own expectations and experiences, as these also influence the relationships and experienced QoC. Therefore, staff recommended to ask family what they think and feel, instead of asking them as a proxy on behalf of the client.

"That is also a part of being attentive. Just asking a client or family member:' how are you doing?" (Staff)

Additionally participants mentioned that formal caregivers have plenty of knowledge about the client too. However, it is important they do not only reason from their medical background, but also from their knowledge of who the client is. World café participants mentioned formal caregivers, just like family, have their own expectations and experiences which can influence their assessment of experienced QoC.

"Enter into conversations with different groups; the client, family members and caregivers." (Participant in world café at table topic 3)

Participants were not sure who needs to perform the quality measurement. On the one hand someone close to the client, because of the established relationship and the convenience of 
immediately solving problems. On the other hand, someone from outside might be better at objectively capturing experienced QoC, and allow clients to express themselves without being in a care dependent position. Dependency could result in clients and families not being completely open and honest, because they fear negative consequences for the client's daily care. Participants did agree whoever performs the assessment needs to possess certain communicative skills and be motivated to get to the core. Staff and client representatives mentioned caregivers are doers, and therefore it is important to show them how to have these meaningful conversations and coach them on the job.

"Family members often asked me [policy officer]: 'Do you work for the nursing home organization? I don't want dad or mum to be the victim of what I am saying'." (Staff)

\section{DISCUSSION}

The aim of this study was to discover the main needs regarding how to assess experienced QoC in nursing homes from the client's perspective. The main findings related to the content, procedure and who to involve in the experienced QoC assessments, all implied that relationships form an important aspect of how care delivery is experienced and how it can be assessed. It became apparent that assessing experienced QoC is complex and no one has the perfect solution as to how this should be done. Participants provided pros and cons for most themes that were discussed. Results did show assessments should address if staff knows the client, responds to the client's needs and has created a caring environment for the client, by having meaningful conversations with clients, their family and staff, as they are all part of the care experience. These conversations can be supported by observations and should be embedded into the existing care routines.

Findings in this study confirmed the importance of relationships when receiving and assessing care. Caring relationships have been defined as human interactions grounded in caring processes, incorporating physical work (doing), interaction (being with), and relationship (knowing each other)' ${ }^{41}$ Relationship-centered care emphasizes the necessity of caring relationships in order to achieve quality health care outcomes. ${ }^{42,}{ }^{43}$ This implies that care experiences occur during the interactions between the clients, family and staff, who all have their own ideas on what high QoC in nursing homes is. ${ }^{44}$

This study confirms that what is assessed should reflect what matters most to the client. ${ }^{22}$ The outcome of a client's QoC assessment depends on whether the nursing home has met the client's expectations and fulfilled his or her needs. ${ }^{45} \mathrm{~A}$ recent meta-synthesis of older people's experiences of care concluded a client's main goal is to retain the meaning of being alive. ${ }^{13}$ It is important to meet a client's priorities; however, there is a gap between a nursing home as a corporate culture and what clients perceive as good QoC. ${ }^{45}$ Additionally, there is a gap in client and family quality ratings, as family is satisfied when the environment, staff 
and meals meet their standards ${ }^{46-48}$; whereas clients are satisfied when they feel at home and can retain their meaning of being alive. ${ }^{13,45}$ These differences confirm the importance of being cautious when family members assess quality as a proxy. They do not always know how the client feels and how services are being delivered. ${ }^{16,47}$ Therefore in order to increase the validity of quality results, it is essential that not only the client, but also family and staff are asked how they are experiencing the care process. ${ }^{45,49,50}$

In order to identify the needs, feelings and experiences from the different perspectives, our findings suggest re-occurring meaningful conversations. Research has confirmed that standardized questionnaires are not sufficient to fully capture experienced QoC, and that qualitative data from conversations are very valuable to give care recipients a voice and get in-depth information on experienced QoC. ${ }^{22,45,51,52}$ Observations are considered of additional value to capture experienced $\mathrm{QoC}$ in nursing homes, as it can sometimes be challenging for clients to verbally express themselves. ${ }^{53}$ This is however considered timeconsuming and therefore sufficient time and resources are a prerequisite. ${ }^{49}$ Additionally, it needs to be considered that clients and their families are dependent on staff, and may fear retribution when being completely honest about their experiences. ${ }^{54}$ Therefore, it is important that the right person has conversations about experienced QoC. Whilst it remains unclear who this person should be, space needs to be created to form a trusting relationship, to be able to have meaningful conversations. This has been confirmed by others, who also perform research in the nursing home setting based on the relationship-centered care principles. ${ }^{55}$ An advantage of having the formal caregiver perform the QoC conversations, is that they can immediately take action to improve QoC. These conversations could be incorporated in the daily care processes and the nursing home's culture. In order to disseminate information, the content of daily work meetings could for example be changed. Instead of using these to discuss everyday processes, they could be used to discuss the client's needs and wishes. In order for this to be successful, formal caregivers will need to improve how they reflect on the care provided and on their own competencies. ${ }^{56,57}$ It could be beneficial to adopt an appreciative inquiry approach, because whilst traditionally quality monitoring and improvements focus on identifying and solving problems, appreciative inquiry focusses on what is already working and how this can be done more frequently. ${ }^{58}$ Adopting this positive approach has been proven to work motivating, encouraging and improve QoC in nursing homes. ${ }^{59,60}$

Furthermore, results confirmed that different groups have different reasons to assess experienced QoC. ${ }^{1}$ Regulators want information for benchmarking purposes and local authorities use information for resource allocation decision-making. Whereas formal caregivers use quality information for internal quality improvement and learning from each other, clients and their family use quality information to select their providers, and to provide information about their experiences. ${ }^{1}$ The output of quality results may differ depending on the purpose of the quality assessment, for example aggregated results on 
nursing home or organization level may be used for benchmarking, whereas individual or ward level results may be used for quality improvements. Therefore, it is important to define for what purpose experienced $\mathrm{QoC}$ is being assessed, prior to performing the assessment.

\section{Strengths and limitations}

Some methodological considerations had to be made in this study. Clients in nursing homes were not directly participants during data collection. The set-up of this study, using many interactive and group discussions, may not have been a suitable method for clients living in nursing homes, due to their frailty and often cognitive impairments. We recommend future studies to adopt an inclusive approach by amending study designs to clients' needs and capabilities. Research has shown that supportive approaches, such as visualization materials and simplified language can support the inclusion of this important population. ${ }^{61-63}$ To assure the client's voice was represented in the current study, client representatives were invited, as this is their main task within their position and they represent the voice of many more clients at the same time. They were considered to have a helicopter view of what issues are important to clients as they interact with a large variety of nursing home clients on a frequent basis.

An advantage of this study is that different methods were used to collect data, making it possible to personalize data collection to the needs of the stakeholders involved. Whilst it was expected that staff would be able to have meaningful discussions about the topics by means of supportive semi-structured questions; client representatives received visual stimuli to support them in answering the research question. For the heterogeneous group, the world café with supporting stimuli was used in order to create a comfortable environment with no visible hierarchy. A disadvantage of using different methods is that it was more challenging to compare and analyze the collected data, as this was collected with different questions and recorded with different resources such as audio and field notes. Whilst the world café method is an acknowledged research method, it is challenging to capture the findings without audio recordings in this deliberately created informal setting. ${ }^{28,64}$ To overcome this challenge, we used moderators that had sufficient knowledge on the topic, in order to assure they were capable of understanding and extensively summarizing the main findings.

Other studies have investigated which themes are considered important to client's regarding their experienced QoC in nursing homes. ${ }^{13,65,66}$ However, these studies mainly focused on what is important to clients, and not on how this needs to be assessed and who should be involved. To our knowledge, this is the first study that has combined different qualitative research methods and included client representatives' and staffs' views in the nursing home setting to find answers to these main questions. 


\section{CONCLUSION}

The findings of this study show that focusing on caring relationships is fundamental when assessing experienced $\mathrm{QoC}$ in nursing homes from the client's perspective. In order to identify what really matters most to clients, there is a need for meaningful conversations with the client, family and staff about their experienced $\mathrm{QoC}$ and interactions with each other, supported by observations. Prerequisites for successful assessments are that the person performing these assessments need to possess certain communicative skills and the assessments should be embedded into daily practice, for example during the client's yearly multidisciplinary consultation. Additionally, the results of the measurement need to be used to visibly improve the experienced $\mathrm{QoC}$, as measuring needs to be done with a clear purpose. Adopting a positive, appreciative inquiry, culture could enhance nursing homes' support, involvement and implementation of a new method to assess experienced QoC. The findings of this study can be used to develop a user-friendly, feasible, reliable and valid method that assesses experienced QOC from the client's perspective. Further research should be performed in close collaboration with clients, their families and staff in nursing homes to ensure the developed method will meet everyone's needs. 


\section{REFERENCES}

1. OECD/EU. A Good Life in Old Age? Paris: OECD Publishing; 2013.

2. Miller SC, Miller EA, Jung HY, Sterns S, Clark M, Mor V. Nursing home organizational change: the "Culture Change" movement as viewed by long-term care specialists. Med Care Res Rev. 2010;67(4 Suppl):65s-81s.

3. Nakrem S, Vinsnes AG, Seim A. Residents' experiences of interpersonal factors in nursing home care: a qualitative study. Int J Nurs Stud. 2011;48(11):1357-66.

4. Donabedian A. The Definition of Quality and Approaches to Its Assesment: Health Administration Press; 1980.

5. Institute of Medicine Committee on Quality of Health Care in America. Crossing the Quality Chasm: A New Health System for the 21st Century. Washington (DC): National Academies Press (US); 2001.

6. Department of Health. The new NHS; modern .dependable. London: The Stationary Office; 1997.

7. Brownie S, Nancarrow S. Effects of person-centered care on residents and staff in aged-care facilities: a systematic review. Clinical Interventions in Aging. 2013;8:1-10.

8. Rosher RB, Robinson S. Impact of the Eden Alternative on family satisfaction. Journal of the American Medical Directors Association. 2005;6(3):189-93.

9. Kazemi A, Kajonius P. User-oriented elderly care: a validation study in two different settings using observational data. Quality in Ageing and Older Adults. 2015;16(3):140-52.

10. Koren MJ. Person-centered care for nursing home residents: the culture-change movement. Health Aff (Millwood). 2010;29(2):312-7.

11. OECD. Ministerial Statement: the Next Generation of Health Reforms. Paris: OECD Publishing; 2017.

12. Nadash P, Hefele J, Wang J, Barooah A. NURSING HOME SATISFACTION MEASURES: WHAT IS THEIR RELATIONSHIP TO QUALITY? Innovation in Aging. 2017;1(suppl_1):542-.

13. Vaismoradi $\mathrm{M}$, Wang IL, Turunen $\mathrm{H}$, Bondas T. Older people's experiences of care in nursing homes: a meta-synthesis. Int Nurs Rev. 2016;63(1):111-21.

14. Saliba D, Schnelle JF. Indicators of the quality of nursing home residential care. J Am Geriatr Soc. 2002;50(8):1421-30.

15. Johansson $\mathrm{P}$, Oleni $\mathrm{M}$, Fridlund $\mathrm{B}$. Patient satisfaction with nursing care in the context of health care: a literature study. Scand J Caring Sci. 2002;16(4):337-44.

16. Rodriguez-Martin B, Martinez-Andres M, Cervera-Monteagudo B, Notario-Pacheco B, MartinezVizcaino V. Perception of quality of care among residents of public nursing-homes in Spain: a grounded theory study. BMC Geriatr. 2013;13:65.

17. Schols JM, Crebolder HF, van Weel C. Nursing home and nursing home physician: the Dutch experience. J Am Med Dir Assoc. 2004;5(3):207-12.

18. Zorginstituut Nederland. Kwaliteitskader Verpleeghuiszorg Samen leren en verbeteren: Zorginstituut Nederland; 2017. 1-41 p.

19. Fujisawa R, Klazinga NS. Measuring patient experiences (PREMS): Progress made by the OECD and its member countries between 2006 and 2016: OECD Health Working Papers, No. 102. Paris: 2017.

20. Sion KYJ, Haex R, Verbeek H, Zwakhalen SMG, Odekerken-Schröder G, Schols JMGA, et al. Experienced Quality of Post-Acute and Long-Term Care From the Care Recipient's Perspective-A Conceptual Framework. Journal of the American Medical Directors Association. 2019;20(11):138690.e1.

21. Triemstra MF, A. Literatuurstudie en overzicht van instrumenten Kwaliteit van leven en zorg meten. . Utrecht: Ministerie van Volksgezondheid, Welzijn en Sport, 2017.

22. LaVela SL, Gallan AS. Evaluation and measurement of patient experience. Patient Experience Journal. 2014;1(28):36. 
23. Pascoe GC. Patient satisfaction in primary health care: A literature review and analysis. Evaluation and Program Planning. 1983;6(3-4):185-210.

24. Kingsley C, Patel S. Patient-reported outcome measures and patient-reported experience measures. BJA Education. 2017;17(4):137-44.

25. Zuidgeest M, Delnoij DMJ, Luijkx KG, de Boer D, Westert GP. Patients' experiences of the quality of long-term care among the elderly: comparing scores over time. BMC Health Serv Res. 2012;12:26.

26. De Vet HCW, Terwee CB, Mokkink LB, Knol DL. Measurement in Medicine: A Practical Guide. Cambridge: Cambridge University Press; 2011.

27. Kitzinger J. Qualitative Research: Introducing focus groups. Bmj. 1995;311(7000):299-302.

28. Brown J. The World Café: A Resource Guide for Hosting Conversations That Matter. California: Whole Systems Associates; 2002.

29. Verbeek H, Zwakhalen SM, Schols JM, Hamers JP. Keys to successfully embedding scientific research in nursing homes: a win-win perspective. J Am Med Dir Assoc. 2013;14(12):855-7.

30. Boeije HR. Analyseren in kwalitatief onderzoek : denken en doen. Amsterdam: Boom onderwijs; 2014.

31. Baarda B. Basisboek kwalitatief onderzoek. Groningen: Noordhof Uitgevers; 2013.

32. Harper D. Talking about pictures: A case for photo elicitation. Visual Studies. 2002;17(1):13-26.

33. Craig C. Imagined futures: designing future environments for the care of older people. The Design Journal. 2017;20(sup1):S2336-S47.

34. University of the West of Scotland. My Home Life Visual Inquiry Cards. Scotland: My Home Life.

35. Hsieh HF, Shannon SE. Three approaches to qualitative content analysis. Qual Health Res. 2005;15(9):1277-88.

36. MAXQDA, software for qualitative data analysis. Berlin: VERBI Software - Consult - Sozialforschung $\mathrm{GmbH} ; 1989-2020$.

37. Polit DF, Beck CT. Nursing research : generating and assessing evidence for nursing practice. Philadelphia: Wolters Kluwer Health/Lippincott Williams \& Wilkins; 2012.

38. Korstjens I, Moser A. Series: Practical guidance to qualitative research. Part 4: Trustworthiness and publishing. Eur J Gen Pract. 2018;24(1):120-4.

39. Lincoln YS, Guba YSLEG, Guba EG. Naturalistic Inquiry: SAGE Publications; 1985.

40. Sim J, Sharp K. A critical appraisal of the role of triangulation in nursing research. Int J Nurs Stud. 1998;35(1-2):23-31.

41. Duffy JR, Hoskins LM. The Quality-Caring Model: blending dual paradigms. ANS Adv Nurs Sci. 2003;26(1):77-88.

42. Beach MC, Inui T. Relationship-centered care. A constructive reframing. J Gen Intern Med. 2006;21 Suppl 1:S3-8.

43. Soklaridis S, Ravitz P, Nevo GA, Lieff S. Relationship-centred care in health: A 20-year scoping review. Patient Experience Journal. 2016;3(1):130-45.

44. Sion KYJ, Haex R, Verbeek H, Zwakhalen SMG, Odekerken-Schröder G, Schols JMGA, et al. Experienced Quality of Post-Acute and Long-Term Care From the Care Recipient's Perspective: A Conceptual Framework. Journal of the American Medical Directors Association. 2019: [Epub ahead of print].

45. Nakrem S. Understanding organizational and cultural premises for quality of care in nursing homes: an ethnographic study. BMC Health Serv Res. 2015;15:508.

46. Shippee TP, Henning-Smith C, Gaugler JE, Held R, Kane RL. Family Satisfaction With Nursing Home Care. Res Aging. 2017;39(3):418-42. 
47. Aggarwal N, Vass AA, Minardi HA, Ward R, Garfield C, Cybyk B. People with dementia and their relatives: personal experiences of Alzheimer's and of the provision of care. J Psychiatr Ment Health Nurs. 2003;10(2):187-97.

48. Williams AS, Jane K. Applebaum, Robert. The Nursing Home Five Star Rating: How Does It Compare to Resident and Family Views of Care? Gerontologist. 2016;56(2):234-42.

49. Curyto KJ, Van Haitsma K, Vriesman DK. Direct observation of behavior: a review of current measures for use with older adults with dementia. Res Gerontol Nurs. 2008;1(1):52-76.

50. Nakrem S, Vinsnes AG, Harkless GE, Paulsen B, Seim A. Nursing sensitive quality indicators for nursing home care: international review of literature, policy and practice. Int J Nurs Stud. 2009;46(6):848-57.

51. Martino SC, Shaller D, Schlesinger M, Parker AM, Rybowski L, Grob R, et al. CAHPS and Comments: How Closed-Ended Survey Questions and Narrative Accounts Interact in the Assessment of Patient Experience. J Patient Exp. 2017;4(1):37-45.

52. Wolf JA, Niederhauser V, Marshburn D, LaVela SL. Defining Patient Experience. Patient Experience Journal. 2014;1(1):7.

53. Lawton MP, Van Haitsma K, Klapper J. Observed Affect in Nursing Home Residents with Alzheimer's Disease. The Journals of Gerontology: Series B. 1996;51B(1):P3-P14.

54. Li Y, Li Q, Tang Y. Associations Between Family Ratings on Experience With Care and Clinical Qualityof-Care Measures for Nursing Home Residents. Med Care Res Rev. 2016;73(1):62-84.

55. Nolan M, Brown J, Davies S, Nolan J, Keady J. The Senses Framework: improving care for older people through a relationship-centred approach. Getting Research into Practice (GRiP) Report No 2.: University of Sheffield.; 2006.

56. Mauk KL. Gerontological Nursing Competencies for Care: Jones \& Bartlett Learning; 2017.

57. Görel H, Mona K. Carers' reflections about their video-recorded interactions with patients suffering from severe dementia. Journal of clinical nursing. 2001;10(6):737-47.

58. Cooperrider DL, Whitney DK, Stavros JM. Appreciative Inquiry Handbook: Lakeshore Communications; 2003.

59. Watkins S, Dewar B, Kennedy C. Appreciative Inquiry as an intervention to change nursing practice in in-patient settings: An integrative review. Int J Nurs Stud. 2016;60:179-90.

60. Dewar B. Editorial: Appreciative inquiry. Int J Older People Nurs. 2010;5(4):290-1.

61. Whitlatch CJ. Including the person with dementia in family care-giving research. Aging Ment Health. 2001;5 Suppl 1:S20-2.

62. Alzheimer's Disease International. World Alzheimer Report 2015: The Global Impact of Dementia. London: Alzheimer's Disease International, 2015.

63. Stans SE, Dalemans R, de Witte L, Beurskens A. Challenges in the communication between 'communication vulnerable' people and their social environment: an exploratory qualitative study. Patient Educ Couns. 2013;92(3):302-12.

64. Sanders EBN, Stappers PJ. Co-creation and the new landscapes of design. CoDesign. 2008;4(1):518.

65. Mor V. Defining and Measuring Quality Outcomes in Long-Term Care. Journal of the American Medical Directors Association. 2007;8(3, Supplement 2):e129-e37.

66. Sangl J, Buchanan J, Cosenza C, Bernard S, Keller S, Mitchell N, et al. The development of a CAHPS instrument for Nursing Home Residents (NHCAHPS). J Aging Soc Policy. 2007;19(2):63-82. 



\section{CHAPTER}

\section{The Feasibility of Connecting Conversations: A Narrative Method to Assess Experienced Quality of Care in Nursing Homes from the Resident's Perspective}

This chapter was published as:

Sion KYJ, Verbeek H, De Vries E, Zwakhalen SMG, Odekerken-Schröder GJ, Schols JMGA, Hamers JPH. The Feasibility of Connecting Conversations: A Narrative Method to Assess Experienced Quality of Care in Nursing Homes from the Resident's Perspective. International Journal of Environmental Research and Public Health, 2020; 17(14):5118

https://doi.org/10.3390/ijerph17145118 


\begin{abstract}
Currently, residents living in nursing homes and their caring relationships are being placed more central in the care experience. Experienced quality of care is influenced by the interactions between residents, family and caregivers, who each have their own experiences and needs. Connecting Conversations is a narrative method aimed at assessing experienced quality of care in nursing homes from the resident's perspective by having separate conversations with residents, family and caregivers (triads), adopting an appreciative inquiry approach. This study presents how to use Connecting Conversations and its feasibility. Feasibility was assessed as performance completeness, protocol adherence and interviewers' experience. Conversations were conducted by trained nursing home staff $(n=35)$ who performed 275 Connecting Conversations in another nursing home than where they were employed (learning network). Findings show it is feasible to perform separate appreciative conversations with resident-family-caregiver triads by an interviewer employed in another nursing home, however protocol adherence was sometimes challenging in conversations with residents. Interviewers valued the appreciative approach, the learning network and the depth of the separate conversations. Challenges were experienced with scheduling conversations and receiving time and support to perform the conversations. Stakeholders should continue collaboration to embed Connecting Conversations into daily practice in nursing homes.
\end{abstract}




\section{INTRODUCTION}

The proportion of people over 60 years is expected to almost double from $12 \%$ (2015) to $22 \%(2050) .{ }^{1}$ The aging population has resulted in an increasing number of older people with chronic diseases requiring long-term care. ${ }^{2}$ The most vulnerable people with complex health needs live in nursing homes in which they receive $24-\mathrm{h}$ care and functional support. ${ }^{3}$ Nursing homes are struggling to maintain and improve their quality of care due to the increase in aging population and strain on resources, the complexity of residents' needs, the changes in residents' expectations and the challenges in staff-mix. ${ }^{4-7}$ According to the Institute of Medicine, a component of the US National Academy of Sciences, quality of care needs to be safe, effective, efficient, timely, patient-centered and equitable. ${ }^{8}$ It is challenging to fully operationalize these generic concepts to the nursing home setting and therefore quality indicators are often used. ${ }^{9}$ To assess these quality indicators, such as the prevalence of pressure ulcers or malnutrition, standardized quantitative methods are used, such as the nursing home minimum data set (MDS) or the national prevalence measurement of quality of care (LPZ). ${ }^{10,11}$ More recently, initiatives such as the Worldwide Elements to Harmonize Research in Long-term Care Living Environments (WE-THRIVE) have occurred, aiming to achieve global common data elements for quality of care to enhance standardized assessments in long-term care..$^{12}$ Additionally, specific areas of health care, for example palliative care, have identified their own indicators for quality of care. ${ }^{13}$ Stakeholders use quality of care data for different purposes, for example, professional caregivers may use them to learn, reflect and improve care provision, nursing home managers to monitor and improve their performance, and policy makers for transparency and accountability. ${ }^{14,15}$

In service science, quality is often defined as the comparison of the consumer's expectations and the actually delivered service, assessed with the outcome 'satisfaction' ${ }^{16}$ Care provision in nursing homes can be considered a type of service delivery in which the resident's expectations and experiences gain a much more important role than in the more traditional quality of care definitions. Evaluations of care services more frequently are trying to fully recognize residents' needs and experiences with the complete service experience before, during and after receiving care. ${ }^{17}$ This means evaluation does not only focus on the actual activity, but also incorporates, for example, how the resident was approached during this activity. By mapping the full customer journey, the sum of all experiences (touchpoints) can be described and moments of truth can be identified that can positively or negatively influence an experience..$^{18}$ This holistic view can help care organizations to sustain caring relationships and retention, and receive positive word-of-mouth. ${ }^{17}$ 
In line with this service science perspective, residents and their caring relationships are being placed more centrally in the care experience, as can be seen in care models such as person-centered care and relationship-centered care. ${ }^{19,20}$ Person-centered care focusses on residents as each being unique human beings with their own needs and wishes, and relationship-centered care goes one step further by focusing on all people involved in the residents' care experiences, including family, and the impact of their reciprocal relationships. ${ }^{21-23}$ This concept is known as balanced centricity in service sciences, implying that experiences are created by multiple stakeholders whose needs deserve to be acknowledged. ${ }^{24}$ Residents, family and caregivers each have their own experiences and needs and by including all involved stakeholders when assessing quality of care, quality improvement initiatives can focus more on what matters most from a holistic perspective. ${ }^{25-28}$ Additionally, this contributes to a resident's quality of life and well-being, families feeling valued by making a useful contribution and caregivers' job satisfaction. ${ }^{29,} 30$ In line with this holistic view on quality of care, the Dutch policy guidelines for quality of care in nursing homes have been revised to focus more on person- and relationship-centered care, well-being, safety and learning together with and from each other's practices, highlighting the importance of assessing quality of care from the resident's perspective. ${ }^{31}$

Studies have revealed the complementary value of assessing quality of care by having conversations with residents, their families and professional caregivers, as each have their own needs and stories. ${ }^{25,32}$ The addition of the story behind quality rating is often missing when resident experiences and outcomes are only assessed with quantitative patient-reported experience (PREMs), patient-reported outcome (PROMs) and satisfaction measures. ${ }^{33-35}$ Stories about experiences, so-called narratives, help people to make sense of their world, relationships and themselves, and can support nursing homes to focus on what really matters. ${ }^{35,36}$ They can help to identify what is most important to residents and can support quality improvement initiatives for individual residents. ${ }^{37}$ Narratives are able to capture an experience that is enriched by incorporating emotions, explaining logic and providing details about the caring relationships. ${ }^{38}$ As quality of care is a complex concept, there is a need to assess multiple quantitative and qualitative indicators, and this information should be used in continuous quality improvement cycles. ${ }^{14}$

Narratives are already being used as methods to assess for example children's speech $^{39}$ or perform mental health research with young children ${ }^{40}$ and in nursing homes as interventions, such as life reviews, to improve residents' life satisfaction. ${ }^{41}$, 42 However, the use of narratives as a method to structurally assess elements of quality of care in long-term care is relatively new. This is gradually occurring more 
frequently; however, little is known about how to use them and their feasibility in practice. ${ }^{43,}{ }^{44}$ Recently, the narrative method Connecting Conversations has been developed aimed at assessing experienced quality of care in nursing homes from the resident's perspective. It was developed according to the steps in the development and evaluation of a measurement method by De Vet ${ }^{43}$, including defining the construct to be measured ${ }^{45}$, mapping the needs of key stakeholders ${ }^{46}$, one cycle of pilot-testing and two cycles of field-testing. This study aimed to present how to use the narrative method 'Connecting Conversations' in practice and its feasibility. Validity findings have been published separately in this special issue of IJERPH as well. ${ }^{47}$

\section{Theoretical Foundation}

Quality of care from the resident's perspective, i.e., experienced quality of care, is a process in which expectations occur prior to receiving care, interactions occur during the care experience and an assessment is given after the care experience within a certain context, as defined by the Individually Experienced Quality of Post-Acute and Long-Term Care (INDEXQUAL) framework. ${ }^{45}$ Relationship-centered care and caring relationships, individual needs of the resident, family and caregiver (a triad) and their interactions are considered to be at the core of a care experience. ${ }^{22,48,49}$ Therefore, to assess experienced quality of care, it is important to ask not only residents, but also family and caregivers how the resident experiences the quality of care, by performing separate conversations. ${ }^{46}$ Additionally, the resident's full customer journey should be considered during quality assessments, as stories, experiences and preferences between residents differ. ${ }^{12,28}$

It could be beneficial to adopt a positive approach when performing these conversations, as nursing homes often adopt a problem-focused approach magnifying what is not going well; whereas focusing on what is working best and how to build on this can be more rewarding. ${ }^{46,50}$ Appreciative inquiry is a positive approach identified as the opposite of problem-solving and helps participants to really engage and focus on discovery (appreciate the best of what is), dream (imagine what could be), design (determine what should be) and destiny (create what will be) ${ }^{51}$. This approach has proven to have positive outcomes on the nursing home culture and interactions by care staff. ${ }^{50,52,53}$ The INDEXQUAL framework, relationshipcentered care and appreciative inquiry are the theoretical foundation of Connecting Conversations. 


\section{MATERIALS AND METHODS}

The study used a cross-sectional design and data collection was performed in two cycles of field-testing: (1) October 2018 to February 2019 and (2) October 2019 to January 2020. First, a description of the content of Connecting Conversations is provided, followed by the operationalization of feasibility, details of the participants, data-collection and data-analysis used to assess feasibility.

\section{Connecting Conversations}

The narrative method Connecting Conversations aims to assess experienced quality of care in nursing homes from the resident's perspective. Figure 1 presents the structure of 'Connecting Conversations'. The content of each blue element is performed by a trained interviewer. The orange elements are currently performed by the research team, as these are still under development. Separate conversations are performed with a resident, family member and professional caregiver of that resident, a so-called care triad. These conversations are registered in an app on a tablet. Interviewers follow a mandatory three-day training to be able to perform the conversations in another nursing home than where they are employed, facilitating a learning network. The research team analyses and reports back the data to the nursing homes. All elements are described in detail in Appendix A. Table 1 provides a brief description of each element.

\section{Interpretation and Operationalization of Feasibility for Connecting Conversations}

To determine to what extent it is feasible to use Connecting Conversations in practice, feasibility has been defined as the extent to which Connecting Conversations was conducted as planned and how interviewers experienced Connecting Conversations. This definition has been operationalized into three elements: completeness, protocol adherence and interviewer experiences as presented in Table 2. Feasibility analyses only focused on the Connecting Conversations elements performed by the interviewer: conversations, registration, training and learning network. 


\section{Connecting Conversations}

INDEXQUAL Framework | Appreciative Inquiry
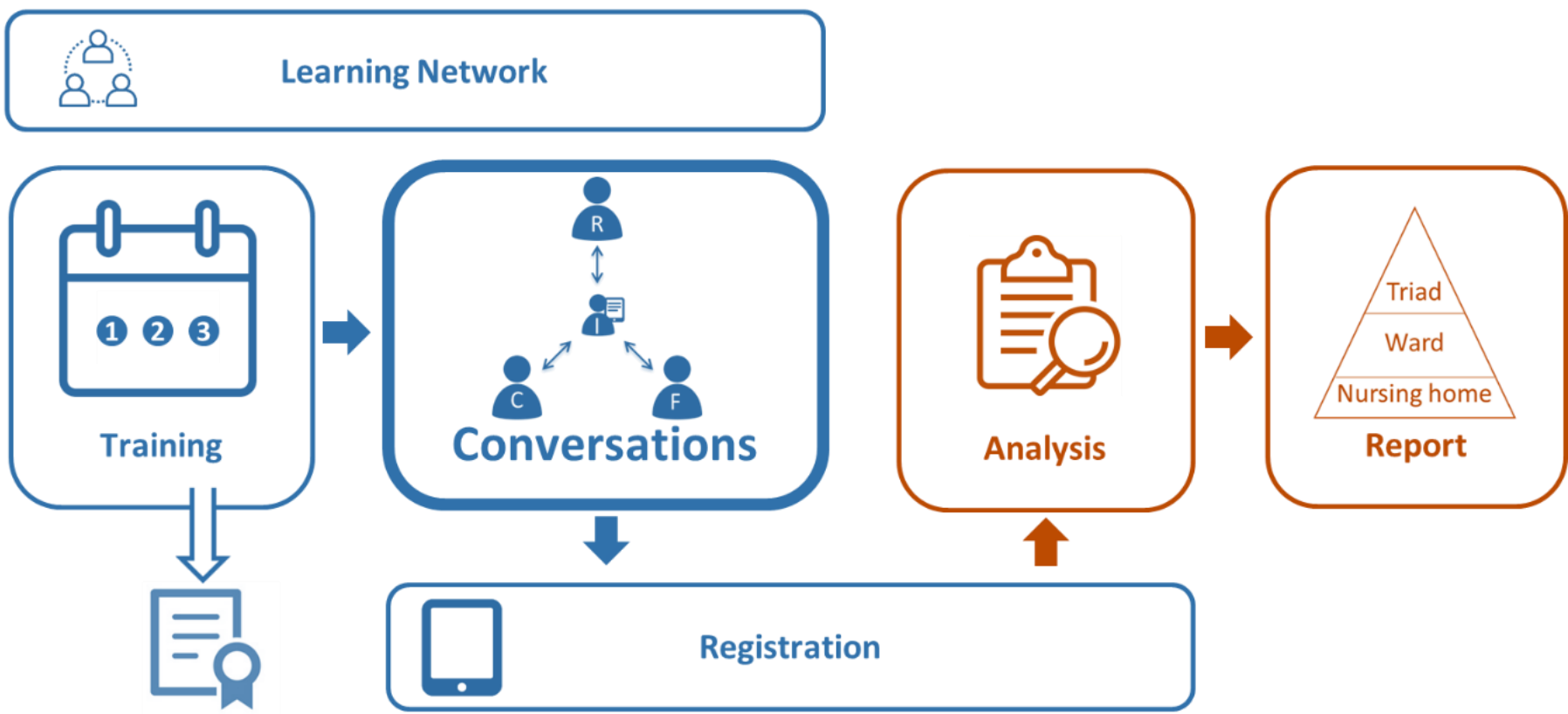

- Interviewers

- Connecting conversations analysts

C: caregiver, F: family, I: interviewer, INDEXQUAL: individually Experienced Quality of Long-term Care, R: resident

Icons made by Freepik and Font Awesome from www.flaticon.com

Figure 1. Connecting Conversations 
Table 1. A summarized description of the Connecting Conversations elements

Element Main Description

Interviewers need to follow a mandatory three-day (3 h/day) training to assure the quality and reliability of performing and registering

Training Connecting Conversations. The training focusses on connecting, practicing and sharing experiences, and has adopted an appreciative inquiry approach. Successful attendance results in a certificate.

Semi-structured questions are asked in separate conversation with a resident, family member and professional caregiver of that resident, who each answer from the resident's perspective. Questions are based on the INDEXQUAL framework and are formulated from an

Conversations appreciative inquiry approach.

Main topics: resident's life, satisfaction with care provision, most positive experience, description of an average day in the nursing home and relationships between the resident, family and caregiver.

Registration The Connecting Conversations app supports interviewers to perform, register and view the conversations. Main features app: documenting informed consent, participant demographics, summative answers, audio recording and viewing collected data.

The learning network provides a platform for interviewers in which they can learn from and with each other through continuous

Learning interaction ${ }^{54}$. Interviewers from different care organizations follow the training together and perform conversations in each other's care
network interviewers to learn from daily practices in another nursing home environment.

\begin{tabular}{ll}
\hline Analysis & The written texts, as reported in the app, are analyzed by two researchers with content analysis 55. \\
\hline Report & $\begin{array}{l}\text { The analyzed data are presented on ward level in a factsheet with supporting 'quotes'. Additional reports on triad and nursing home level } \\
\text { can be delivered upon request. }\end{array}$ \\
\hline \hline
\end{tabular}


Table 2. Feasibility definitions, operationalization and analyses for Connecting Conversations

\begin{tabular}{|c|c|c|}
\hline $\begin{array}{l}\text { Feasibility } \\
\text { Concept }\end{array}$ & Definition & $\begin{array}{l}\text { Operationalization for Connecting Conversations } \\
\text { - Element analyzed }\end{array}$ \\
\hline
\end{tabular}

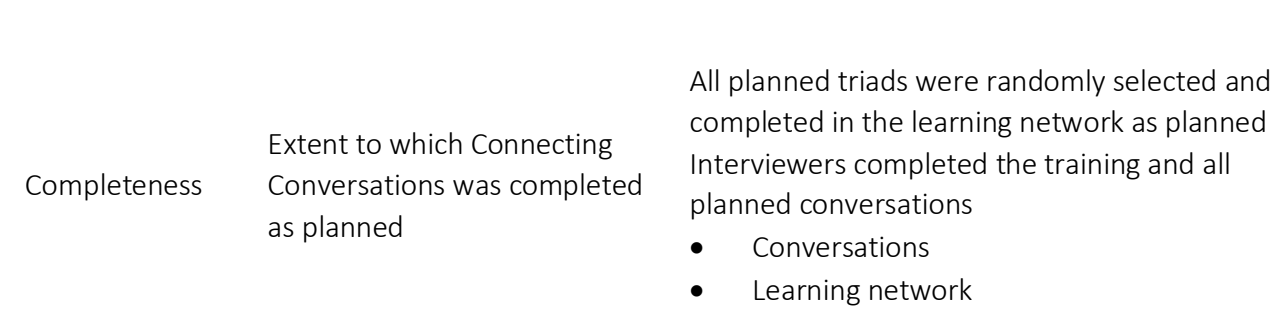

\begin{tabular}{lll}
\hline & & \\
& & All interviewers followed the Connecting \\
Protocol & Extent to which the & Conversations' protocol as taught during the \\
adherence & conversations were & training. \\
& performed as planned & - Conversations \\
& &
\end{tabular}

\begin{tabular}{ll}
\hline & \\
Interviewers' satisfaction with \\
experiences & $\begin{array}{l}\text { Connecting Conversations and } \\
\text { experienced facilitators and } \\
\text { barriers }\end{array}$
\end{tabular}

All interviewers evaluated all components of Connecting Conversations: training, scheduling conversations, performing conversations and registering conversations.

- Conversations

- Registration

- Training

- Learning network

\section{Analysis}

- Description of successes and challenges of random selection of triads on a ward and the learning network

- Completed conversations rate*, including documentation of incomplete and missing triads, and the duration of the conversations

- Description of recruited interviewers and attendance rate* training

- $\quad$ All six questions were asked as formulated in the protocol*

- Per conversation at least one probing question and one time paraphrasing was used $^{*}$

- The respondent talked more than the interviewer*

Deductive coding of interviewer experiences, categorized into elements that were appreciated and that were considered challenging

*Interpret as total percentage of participants: $<60 \%$ not acceptable, $60 \%-80 \%$ acceptable, $>80 \%$ good 


\section{Setting and Participants}

This study was performed within the Living-Lab in Ageing and Long-Term Care. The living-lab is a collaboration between seven long-term care organizations and four educational institutes, all located in the southern part of the Netherlands ${ }^{56}$.

\section{Care Triads}

Each of the seven care organizations selected one somatic (for people with physical deterioration) and one psychogeriatric (for people with cognitive decline) ward. Within the selected wards, random selection of residents was necessary to increase the reliability and validity of the assessment and avoid biased selection of only the most well-spoken and satisfied residents with closely involved families. Residents were randomly selected from the nursing home ward by generating a random sequence list of all residents' room numbers of the selected wards. The contact person of the ward approached residents of the first five (cycle 1) or six (cycle 2) randomly generated room numbers to participate. When a resident refused, the next was approached until the total number of triads was recruited. A family member and professional caregiver closely involved with the selected residents daily care provision were invited, once the resident agreed to participate. Triads were included as dyads if a resident was unable to have the Connecting Conversations because of cognitive impairment (family-professional caregiver dyad) or if no family was available or unwilling to participate (resident-professional caregiver dyad). To provide all residents the opportunity to have a conversation, conversations were attempted with each resident. Only when the resident did not respond at all or merely mumbled answers that could not be understood, the results of the conversation were not included for that triad.

\section{Interviewers}

Any interested staff member employed at one of the seven care organizations within the living-lab was invited to apply and each care organization's management performed final selection. There were three main selection criteria for interviewers: (1) familiar with the nursing home environment, either by providing hands-on care, such as nurses or recreational coaches, or more managerial, such as ward managers or policy makers; (2) good communication skills and natural empathetic abilities; and, (3) involved in or a strong interest in quality assurance. Selection aimed at including two interviewers per care organization per cycle. Additionally, researchers in geriatric nursing science employed the university, such as health scientists or psychologists, were allowed to participate as well. A minimum of 14 interviewers (two per care organization) and a maximum of 20 interviewers could participate, as this was the maximum attendance to ensure involvement and interaction during the training. The interviewers attended the training and performed the conversations during their working hours, and did not receive any additional incentives. 


\section{Data-Collection and Procedure}

\section{Connecting Conversations}

Appendix A presents the interview guide of questions asked during the separate conversations. Family and professional caregivers were asked to answer the questions, as they believed the resident would. Interviewers were provided a list of probing questions and supportive visuals for the questions asking for a grade to support them during the conversations.

\section{Procedure}

The research team assigned interviewers to another care organization than where they were employed, considering travel distance, to enhance the learning network. This prevents confirmation bias, as the interviewer has no prior knowledge of the resident or the performance of the nursing home ${ }^{57}$. Interviewers scheduled five (cycle 1 ) or three (cycle 2) full triads with a contact person in their assigned care organization. Multiple conversations could be performed a day, estimated at one hour per conversation. Family members could be interviewed by phone, if scheduling a face-to-face conversation was not possible.

\section{Completeness}

For completeness, data from cycle 1 and 2 were collected by documenting the number and duration of performed conversations. Interviewer characteristics were collected at the start of training day 1 with a survey: age in years, sex, job title and years of working experience in the nursing home setting.

\section{Protocol Adherence}

Data from cycle 1 were used to assess protocol adherence. The data were collected by audio recording performed conversations with a tablet.

\section{Interviewer Experiences}

Interviewers from cycle 1 and 2 were invited to informally evaluate Connecting Conversations at the end of each training day. The trainer asked if interviewers were satisfied with the content, felt engaged, felt confident and if anything should be done differently. After completing all conversations, interviewers were invited to complete a written customer journey about Connecting Conversations, which described all touchpoints that the interviewer experienced during Connecting Conversations in a pre-developed format ${ }^{18}$. The five touchpoints in this journey were (1) the training, (2) scheduling conversations, (3) performing conversations, (4) documenting conversations and (5) miscellaneous for any other comments. Information was gathered adopting an appreciative inquiry approach, asking about what went well during these touchpoints, what could be improved and 
interviewers' overall satisfaction. To enhance understanding of what went well and what could be improved, interviewers were invited to attend a group interview or an individual interview, depending on their preference and availability.

\section{Data-Analysis}

\section{Completeness}

Descriptive statistics were used to calculate completeness of all performed conversations, mean duration of conversations and interviewers' characteristics.

\section{Protocol Adherence}

Interviewers' protocol adherence was evaluated for three elements: (1) the core theme of all six questions was asked; (2) the addressed conversation techniques 'probing questions' and 'paraphrasing' were applied at least once during each conversation; and, (3) respondents talked more than the interviewer, calculated by the total number of words spoken by the responder divided by the total number of words in the full transcript ${ }^{58}$. These analyses were performed for all conversations of which audio recordings were available (cycle 1). All audio recordings were transcribed verbatim and two researchers scored the transcripts independently. Discrepancies between both researchers regarding if a protocol element was adhered to or not were discussed with a third member of the research team until consensus was reached.

\section{Interviewer Experiences}

Interviewers' evaluations of Connecting Conversations were analyzed and summarized by one researcher with the computer software MAXQDA v20.0.7 ${ }^{59}$. Findings were evaluated with another researcher during two face-to-face discussions. During these discussions, the findings were interpreted and focus was on which elements interviewers appreciated and which were considered challenging. Points for improvement provided during field testing cycle 1 were implemented prior to the start of field-testing cycle 2. The main findings of the evaluations were presented back to the interviewers for validation.

\section{Ethical Considerations}

The medical ethics committee of Zuyderland, the Netherlands, approved the study protocol (17-N-86) and concluded that the study was not subject to the Medical Research Involving Human Subjects Act. Information about the study was provided to all interviewers, residents, family members and caregivers in advance by letter. All participants provided written informed consent to contribute to the study and residents with legal representatives gave informed assent themselves before and during the conversations, and their legal representatives gave written informed consent ${ }^{60}$. Participation was strictly voluntarily and 
participants could withdraw from the study at any moment. Anonymity of participants was guaranteed and therefore no names or organizations were documented, unless participants provided consent to share their individual data with the nursing staff for quality improvement initiatives.

\section{RESULTS}

In total, 35 interviewers attended the training and performed 275 Connecting Conversations (89 residents, 83 family members, 103 caregivers) in 18 different nursing homes (8 psychogeriatric, 9 somatic and 1 acquired brain injury). When residents refused to participate, the most common reason was that they considered this to be too intensive or they were not interested.

\section{Completeness}

Random selection of residents' room numbers was performed successfully in 14 of the 18 nursing homes. The exchange of interviewers between nursing homes, i.e., the learning network, was deemed feasible, as each interviewer performed at least three conversations in their assigned nursing home. Reasons for unsuccessful random selection and challenges with the learning network were organizational challenges in the nursing home. These consisted of a lack of a designated contact person to manage the selection and scheduling of the conversations, a lack of staff and high time pressure, and a lack of understanding of the added value of the conversations and random selection. During cycle 2, the research team made some improvements to the execution of the study compared to cycle 1 . They started recruitment earlier and in a more structured manner, with a standardized protocol, a central e-mail address for questions, clearer instructions and timely follow-up to guide the process more thoroughly. Table 3 presents details on the completeness of collected data and interviewer characteristics in total, and separately for field-testing cycles 1 and 2.

Completeness was $76 \%$ of all planned triads/dyads. For $10 \%(n=14)$ of the conversations, the resident was not able to communicate and for $15 \%(n=20)$ of the conversations, family was not willing or available to participate. Additionally, $24 \%(n=32)$ of the triads could not be recruited due to insufficient triads willing to participate on the ward or challenges scheduling conversations with the visiting interviewer. During cycle 2, completeness rates were notably higher than during cycle 1 ( $84 \%$ and $71 \%$, respectively). Median duration of conversations was 17 minutes. 
Table 3. Connecting Conversations' care triads and interviewer demographics

\begin{tabular}{|c|c|c|c|}
\hline Care triads & Total & $\begin{array}{c}\text { Field-Testing } \\
\text { Cycle } 1\end{array}$ & $\begin{array}{c}\text { Field-Testing } \\
\text { Cycle } 2\end{array}$ \\
\hline \multicolumn{4}{|l|}{ Planned conversations $\mathrm{n}$} \\
\hline Total & 405 & 240 & 165 \\
\hline Triads R-F-C & 135 & 80 & 55 \\
\hline \multicolumn{4}{|l|}{ Performed conversations n (\%) } \\
\hline Total & $275(68)^{3}$ & $149(62)^{5}$ & $126(76)^{7}$ \\
\hline Resident (R) & $89(66)$ & $46(58)$ & $43(78)$ \\
\hline Family (F) & $83(61)$ & $46(58)$ & $37(67)$ \\
\hline Caregiver (C) & $103(76)$ & $57(71)$ & $46(84)$ \\
\hline Total triads/dyads & $103(76)$ & $57(71)$ & $46(84)$ \\
\hline Full triads R-F-C & $68(50)^{4}$ & $34(43)^{6}$ & $34(60)^{8}$ \\
\hline F-C combination ${ }^{1}$ & $14(10)$ & $11(14)$ & $3(5)$ \\
\hline $\mathrm{R}-\mathrm{C}$ combination & $20(15)$ & $11(14)$ & $9(16)$ \\
\hline Full triads missing & $32(24)$ & $23(29)$ & $9(16)$ \\
\hline \multicolumn{4}{|l|}{ Mean/Median minutes conversations (range) } \\
\hline Total & 19/17 (3-79) & $18 / 15(3-54)$ & $21 / 18(4-79)$ \\
\hline Resident (R) & $21 / 17(4-79)$ & $18 / 14(6-54)$ & $24 / 22(4-79)$ \\
\hline Family (F) & $21 / 19(6-48)$ & $21 / 22(6-39)$ & $21 / 18(7-48)$ \\
\hline Caregiver $(\mathrm{C})$ & $17 / 14(3-55)$ & $15 / 14(3-41)$ & $19 / 16(4-55)$ \\
\hline \multicolumn{4}{|l|}{ Interviewers' characteristics } \\
\hline Total interviewers $n$ & 35 & 16 & 19 \\
\hline Mean age in years (SD) & $40(11)$ & $40(11)$ & $42(11)$ \\
\hline Females (\%) & $31(89)$ & $14(88)$ & $17(89)$ \\
\hline \multicolumn{4}{|l|}{ Occupation n (\%) } \\
\hline Nurse & $10(29)$ & $6(38)$ & $4(21)$ \\
\hline Baccalaureate-educated nurse & $9(26)$ & $4(25)$ & $5(26)$ \\
\hline Policy advisor & $5(14)$ & $3(19)$ & $2(11)$ \\
\hline Care manager & $2(6)$ & 0 & $2(11)$ \\
\hline Recreational coach & $2(6)$ & 0 & $2(11)$ \\
\hline Psychologist ${ }^{2}$ & $3(9)$ & $1(6)$ & $2(11)$ \\
\hline Health scientist ${ }^{2}$ & $2(6)$ & $1(6)$ & $1(5)$ \\
\hline Nurse aid & $1(3)$ & $1(6)$ & 0 \\
\hline Complaints officer & $1(3)$ & 0 & $1(5)$ \\
\hline Mean contracted hours per week (SD) & $32.4(5.2)$ & $32.3(5.2)$ & $32.6(5.3)$ \\
\hline Mean years working experience (SD) & $13.1(11.0)$ & $13.8(9.7)$ & $12.4(12.1)$ \\
\hline Training attendance all 3 days $n(\%)$ & $30(86)$ & $13(81)$ & $17(89)$ \\
\hline Training attendance 2 out of 3 days $n(\%)$ & $5(14)$ & $3(19)$ & $2(11)$ \\
\hline
\end{tabular}

${ }_{1}^{1}$ Residents missing because on psychogeriatric ward and not cognitively capable to have the conversation. ${ }^{2}$ Not employed at the nursing home, but at the university. ${ }^{3}$ Of which 241 with audio recordings. ${ }^{4}$ Of which 52 with audio recordings. ${ }^{5}$ Of which 125 with audio recordings. ${ }^{6}$ Of which 24 with audio recordings. ${ }^{7}$ Of which 116 with audio recordings. ${ }^{8}$ Of which 28 with audio recordings. 


\section{Protocol Adherence}

Table 4 presents the results of the protocol adherence analysis of 125 transcripts performed by 15 interviewers during field-testing cycle 1 (one interviewer had no successful audio recordings).

Table 4. Protocol adherence results ${ }^{1}$

\begin{tabular}{|c|c|c|c|c|}
\hline & $\begin{array}{c}\text { Total } \\
\mathrm{N}=125\end{array}$ & $\begin{array}{c}\text { Resident }(\mathrm{R}) \\
\mathrm{N}=36\end{array}$ & $\begin{array}{c}\text { Family (F) } \\
N=38\end{array}$ & $\begin{array}{c}\text { Caregiver (C) } \\
\quad N=51\end{array}$ \\
\hline Question 1 quality of life $n(\%)$ & $107(86)$ & $24(67)$ & $36(95)$ & $47(92)$ \\
\hline Question 2 satisfaction caregivers $n(\%)$ & $113(90)$ & $29(81)$ & $34(89)$ & $50(98)$ \\
\hline Question 3 most positive $\mathrm{n}(\%)$ & $116(93)$ & $30(83)$ & $36(95)$ & $50(98)$ \\
\hline Question 4 average day $n$ (\%) & $113(90)$ & $26(72)$ & $37(97)$ & $50(98)$ \\
\hline Question 5 relationships $n(\%)^{2}$ & $102(82)$ & $24(67)$ & $34(89)$ & $44(86)$ \\
\hline Question 6 relationships $n(\%)^{3}$ & $106(85)$ & $25(69)$ & $33(87)$ & $48(94)$ \\
\hline Average questions asked \% & 88 & 73 & 92 & 94 \\
\hline All six questions asked $\mathrm{n}(\%)$ & $79(63)$ & $14(39)$ & $28(74)$ & $37(73)$ \\
\hline Four or five questions asked $\mathrm{n}(\%)$ & $30(24)$ & $10(28)$ & $8(21)$ & $14(27)$ \\
\hline Less than four questions asked $\mathrm{n}(\%)$ & $14(11)$ & $12(33)$ & $2(5)^{4}$ & 0 \\
\hline Probing questions n (\%) & $124(99)$ & $36(100)$ & $37(97)$ & $51(100)$ \\
\hline Paraphrasing n (\%) & $86(69)$ & $22(61)$ & $29(76)$ & $35(69)$ \\
\hline$\geq 50 \%$ responder words spoken $n(\%)$ & $108(86)$ & $23(64)$ & $37(97)$ & $50(98)$ \\
\hline
\end{tabular}

1 Interpret as total percentage of participants: $<60 \%$ not acceptable, $60-80 \%$ acceptable, $>80 \%$ good.

2 Relationships: resident (resident-caregiver), family (family-caregiver), caregiver (caregiver-resident).

${ }^{3}$ Relationships: resident (resident-family), family (family-resident), caregiver (caregiver-family).

${ }^{4}$ This interview was performed by one interviewer that did not adhere to protocol.

Results show the questions were asked correctly for $88 \%$ of the cases (agreement rate $85 \%$ ). Compared to the resident group (73\%), the completeness of each separate question asked appears higher in the family (92\%) and caregiver group (94\%). Completeness of all six questions asked was 39\% for residents opposed to $74 \%$ and $73 \%$ for family and caregivers, respectively. Interviewers indicated that in some cases they went off protocol, because the resident had difficulties answering the open-ended questions. When less than four questions were asked correctly, this was because the resident was experiencing difficulties to have a conversation due to cognitive impairment. In almost all conversations, interviewers used at least one probing question (99\%) and in a majority of the conversations, paraphrasing was done (69\%). In $86 \%$ of the conversations, the responder spoke more than the interviewer did; for conversations with family and caregivers, this was almost always (97\%-98\%). 


\section{Interviewer Experiences}

Overall, interviewer experiences were very positive; however, they also experienced some challenges. Evaluations were mostly individual interviews $(n=29)$ and one group interview $(n=6)$ was performed. First, the valuable aspects interviewers experienced are presented followed by facilitators that can contribute to properly perform assessments with Connecting Conversations.

\section{In-Depth Attention}

"Real attention is given to someone". Interviewers were positive about the conversations, as became apparent from evaluations such as "I really enjoyed doing this" and "the conversations show a valuable overview of someone's experienced quality of care". Interviewers were surprised by the in-depth content of the conversations and found it "really special, the stories you hear and the directions they take". Registration with the app was considered a real asset, interviewers explained, and it was "so easy to use". Interviewers specifically valued the audio-recordings: "it was nice that audio recordings were made, so I could fully engage in the conversation without feeling the stress of needing to immediately write everything down".

\section{Narrative Appreciative Inquiry}

"Different from other conversations because of the questions being asked and the positive approach". Interviewers experienced the benefit of adopting an appreciative approach, as "often, in other conversations, only the negative side is addressed" and "the questions trigger to think positively". They also appreciated the positive nature of the training and showed this by being actively engaged and enthusiastic. Most were pleasantly surprised by the dynamic set-up of the training and felt they had really learned to perform appreciative conversations. They appreciated how the trainer created a safe environment, the "balance between theory and practice" and how they became "aware of their own listening skills".

\section{Three Perspectives}

"There is a clear difference between perspectives". Interviewers valued taking the time to have separate conversations with the resident, a family member and a caregiver of that resident and experienced that "the triad gives three different perspectives". They really encountered the differences and similarities between the perspectives and that it is important to hear each side to a story.

\section{Learning Network}

"Valuable to be in another organization". Interviewers enjoyed having the training together with colleagues from other care organizations and learning from each other. They also 
enjoyed performing the conversations in another care organization than where they were employed. Some were surprised by the openness of the responders, which was created by the interviewers' independent status within the nursing home: "I am a stranger to them who comes to interview them, and nevertheless they express themselves and theirfeelings to quite some extent". Interviewers also reflected on observations they made whilst visiting the other nursing home. For example, an interviewer shared she saw all caregivers taking their lunchbreak at the same time, leaving residents all alone in the living room. She realized in her ward they also do that, and has now installed an early and a late lunch shift.

\section{Commitment}

"I really enjoyed participating. My manager would really like to embed Connecting Conversations in the whole care organization". A majority of interviewers has remained engaged with Connecting Conversations after finalizing their conversations. For example, one interviewer had challenging experiences performing conversations as her assigned nursing home faced challenges to schedule conversations on multiple occasions. A follow-up session, however, kept her involved and motivated to stay engaged. Other interviewers have also positively shared their experiences with their managers and quality policy officers, resulting in an increasing demand for Connecting Conversations in care organizations.

\section{Scheduling}

"It was challenging to reach the contact person and to find suitable days for the conversations, also taking your own work schedule into consideration". Whereas the valuable aspects of Connecting Conversations are clearly visible, care organizations should be aware that it is a challenging process to implement this new way of assessing quality of care. There was a large variety between interviewers feeling supported or challenged to perform the conversations. This was mainly influenced by the support of one's own manager and the support of the care organization that was being visited. As interviewers performed conversations elsewhere, they were dependent on a contact person within the visiting care organization who facilitated recruitment of triads and scheduling of conversations. The contact person was considered a crucial element to successfully complete all conversations.

Based on all feasibility findings, Table 5 presents the facilitators that need to be considered when implementing Connecting Conversations. The elements have been formulated as facilitators, yet when absent, they will be experienced as barriers for successful implementation. First, organizations should adopt a clear vision in which they support this new way of assessing quality of care and provide resources for this. Second, several prerequisites are important to gather rich and valid stories: random selection of triads, external interviewers in the learning network, sufficient time and resources and a contact person on the ward. Last, when performing the conversations, it is important to be as inclusive as possible. 
Table 5. Facilitators to implement Connecting Conversations

\begin{tabular}{|c|c|c|}
\hline & Facilitators & Reason Why Important \\
\hline \multirow[t]{2}{*}{ Vision } & $\begin{array}{l}\text { Adopt an appreciative inquiry approach } \\
\text { when introducing, implementing and } \\
\text { embedding Connecting Conversations into } \\
\text { the nursing home }\end{array}$ & $\begin{array}{l}\text { To enhance commitment and } \\
\text { enthusiasm; and set an example } \\
\text { of the method's positive impact: } \\
\text { 'practice what you preach' }\end{array}$ \\
\hline & $\begin{array}{l}\text { Have a clear purpose for what the results will } \\
\text { be used }\end{array}$ & $\begin{array}{l}\text { To decide on the magnitude of } \\
\text { the assessment and the format of } \\
\text { the report(s) }\end{array}$ \\
\hline \multirow{4}{*}{ Prerequisites } & Random selection of triads on a ward & To avoid selection bias \\
\hline & $\begin{array}{l}\text { Assure interviewers have conversations } \\
\text { elsewhere than where they are employed } \\
\text { (external interviewers) }\end{array}$ & $\begin{array}{l}\text { To enhance the learning network } \\
\text { and provide respondents a safe } \\
\text { environment to share their stories }\end{array}$ \\
\hline & $\begin{array}{l}\text { Provide sufficient time for training, } \\
\text { conversations and the learning network }\end{array}$ & $\begin{array}{l}\text { To ensure quality of the } \\
\text { conducted conversations }\end{array}$ \\
\hline & $\begin{array}{l}\text { Assign a contact person in the nursing home } \\
\text { who is responsible for facilitating the visiting } \\
\text { interviewer (scheduling conversations; } \\
\text { informing residents, family and staff on the } \\
\text { ward) }\end{array}$ & $\begin{array}{l}\text { To enhance completeness and to } \\
\text { create a safe environment for the } \\
\text { visiting interviewer }\end{array}$ \\
\hline \multirow[b]{2}{*}{ Performance } & $\begin{array}{l}\text { Make an effort to have conversations with } \\
\text { each selected resident, regardless of his or } \\
\text { her (cognitive) health status }\end{array}$ & $\begin{array}{l}\text { To embrace an inclusive } \\
\text { approach, in which residents are } \\
\text { provided with self-determination }\end{array}$ \\
\hline & $\begin{array}{l}\text { Think in solutions when scheduling } \\
\text { conversations, for example by allowing full- } \\
\text { time employed family to have the } \\
\text { conversation by phone or during evening } \\
\text { hours }\end{array}$ & $\begin{array}{l}\text { To embrace an inclusive and } \\
\text { appreciative approach }\end{array}$ \\
\hline
\end{tabular}

\section{DISCUSSION}

Connecting Conversations assesses experienced quality of care in nursing homes from the resident's perspective. This article presented how to use the narrative method 'Connecting Conversations' and its feasibility. Main findings show it is feasible to perform separate appreciative conversations with a resident, family member and caregiver of that resident by a trained interviewer employed in another nursing home. Protocol adherence was sometimes considered challenging during conversations with residents, as residents did not always seem to understand the questions. Interviewers mostly valued the appreciative approach, the collaboration between care organizations in the learning network and the time they received for in-depth separate conversations with residents, family and caregivers. Challenges were experienced with scheduling the conversations and not all interviewers received the time and support from their care organizations to perform the conversations. 
Findings show it is possible to create a learning network in which care organizations exchange staff as interviewers, under the prerequisites that time and support is provided. Whereas it is often said that narratives are considered big time investments, ${ }^{61}$ our findings show a median duration of only 17 min per conversation and henceforth it is very feasible to perform these conversations. A successful learning network is characterized by sharing knowledge, balancing interests and self-development. ${ }^{62}$ This can contribute to the self-development and reflective learning of the interviewers, which henceforth can increase the quality of care in one's own nursing home. ${ }^{63}$ By integrating this appreciative manner of having conversations into the nursing staff's routines, focus can be shifted from time-based tasks for residents to continuously connecting with residents. ${ }^{61}$

Additionally, findings show appreciative inquiry is a useful approach to engage in conversations about quality of care. By adopting an appreciative evaluation of quality of care, a shift is made towards the positive, embracing caregivers to recognize valuable stories and use these positive insights in their future care provision. ${ }^{52}$ Appreciative inquiry has successfully been used in other nursing home initiatives too, for example in the implementation of the sensory garden in Norwegian nursing homes ${ }^{64}$ or the My Home Life program in the United Kingdom. ${ }^{65,66}$ To anchor an appreciative culture, management should reinforce communication and interactions between people, instead of standardized rules and procedures, on all levels of nursing home organizations: strategic, tactic and operational. ${ }^{67}$ Leadership could contribute to this, by, for example, assigning Connecting Conversation champions who adopt a key role in successfully developing and supporting quality improvement initiatives based on the collected narrative data. ${ }^{68}$. This, in turn, can contribute to increased quality of care and a positive psychosocial climate. ${ }^{69}$

Protocol adherence findings confirm the importance of a proper training for interviewers in which they learn how to adhere to the protocol and apply the appreciative approach and conversation techniques. Interviewers' skills, motivation, reliability, flexibility and productivity contribute in achieving completeness of planned triads. ${ }^{70}$ As interviewers are part of a narrative quality assessment method, they play a major role in the reliability of the quality data. ${ }^{71}$ Interviewers are not just recorders of the experiences, as they also have an experience of the shared experience. ${ }^{72}$ Therefore, to increase the richness of the collected quality of care experiences, it is recommended to invest in proper selection and training of interviewers.

This study shows that a majority of the randomly selected residents living in nursing homes are capable of having a conversation about their experiences. However, complete protocol adherence appeared to be challenging, as in more than half of the conversations, the interviewer was unable to ask all six questions according to protocol. Studies often exclude residents living in nursing homes with a certain degree of dementia or other cognitive declines. ${ }^{73-76}$ It is important to include the resident's voice and others have confirmed that in 
most cases, with well-trained interviewers and adapted questions, this is possible. ${ }^{77,78}$ For Connecting Conversations, it is recommended to adjust the protocol for residents with cognitive impairment, by for example reformulating the six overarching questions into multiple shorter and easier sub-questions. For an even more inclusive approach, it is recommended to perform additional observations when residents are indeed unable to have the conversation (i.e., very severe dementia or aphasia), to assure their experiences are also fully captured, for example with the Maastricht Electronic Daily Life Observation (MEDLO) tool. ${ }^{32,79}$ Other methods that exist for this include Dementia Care Mapping (DCM) or Person. Interaction. Environment. Care Experience in Dementia (PIECE-DEM). ${ }^{80,81}$ The challenges of these observation methods are that they are considered time-consuming and they have not been developed based on the principles of the INDEXQUAL framework of experienced quality of care, but on other theoretical frameworks.

Narratives are considered worth the time investment because they can have a positive impact on the caring relationships between residents, family and their caregivers, and residents' feelings of autonomy and well-being. ${ }^{61,82}$ However, for future implementation, there is room for improvement regarding analysis and reporting of the results. The stories from three perspectives provide rich information that can be used on multiple levels, and the forms of analysis and reporting are dependent on the reason why experienced quality of care is assessed. ${ }^{15,83}$ On an operational level, results can provide care teams with directories for continual learning and quality improvements for individual triads and teams. On a tactical level, managers need input on what is going well and what needs improvement within their ward or nursing home. To discover trends on an organization-wide strategic level, other analysis techniques could be more helpful, such as text mining, aimed at analyzing and identifying trends in large amounts of qualitative data. ${ }^{84}$ On all these levels, the model of relationship-centered organizations may be a fitting framework to adopt, as it focusses on the web of relationships between care professionals, their actions and cycles of reflection, which is supported by inquiry-centered leadership and a culture of continual learning. ${ }^{85}$

Findings show promising results for expanding the use of the narrative assessment method Connecting Conversations in practice. For successful implementation, there are many important determinants that need to be operationalized to the specific intervention and setting, including knowledge and cognition, attitude, routines, social influence, organizational characteristics and resources. ${ }^{86}$ Additionally, recent research has shown that developed interventions in the care sector are in need of self-sustaining business models and therefore it is important to develop a suitable business model for Connecting Conversations, keeping its contextual factors into consideration. ${ }^{87}$ For high completeness rates, it is important to clearly communicate with the participating interviewers and nursing homes, have clear protocols in place, follow-up in a timely manner and continuously be available to answer questions and provide support. 
The current study has not incorporated experiences of how respondents within the triads experienced the new way of assessing quality of care with Connecting Conversations. It is recommended for future research to ask them to describe their experiences with this new way of assessing quality of care from the resident's perspective, as they are considered the key players in the conversations. Additionally, future research should focus on evaluating Connecting Conversations' validity and reliability. Further development should combine research with practice and policy to focus on how the information from Connecting Conversations can be reported back to care organizations so the data can be used to improve quality of care in nursing homes. Stakeholders should collaborate to successfully and sustainably embed Connecting Conversations into daily practice in nursing homes.

\section{CONCLUSION}

To our knowledge, Connecting Conversations is one of the first narrative methods aimed at assessing experienced quality of care in nursing homes as a customer journey, within a triad, from the resident's perspective in an appreciative way. It would be useful for nursing homes to implement a full quality assessment formula in which clinical and safety indicators, staffs' job satisfaction and residents' experienced quality of care are structurally assessed to gain a holistic view on quality of care. This can contribute to providing and receiving the best possible care and working conditions for residents, family and staff. 


\section{APPENDIX A}

This appendix presents a full description of Connecting Conversations, as briefly presented in Figure 1 and Table 1. Connecting Conversations aims to assess experienced quality of care in nursing homes from the resident's perspective.

\section{Appendix A.1. Conversations}

Table A1 presents the semi-structured questions that are asked during Connecting Conversations, providing interviewers guidance throughout the conversations. Family and professional caregivers are asked to answer the questions, as they believe the resident would. Questions 1 to 4 replace "you" with "your loved one" for family and "resident's name" for caregivers. Questions 5 and 6 are adapted to reflect the respondents' relationships, thus family are asked about their contact with the resident and the caregivers; and caregivers are asked about their contact with the resident and the family.

Table A1. Connecting Conversations' Questions

\begin{tabular}{|c|c|}
\hline $1 \mathrm{a}$ & On a scale of 1 to 10 , how would you grade your life at this moment? \\
\hline $1 b$ & What is needed to make that a [grade +1$]$ ? \\
\hline $2 a$ & $\begin{array}{l}\text { On a scale of } 1 \text { to } 10 \text {, how would you grade the caregivers that are involved with your } \\
\text { daily care provision? }\end{array}$ \\
\hline $2 b$ & What is needed to make that a [grade +1 ]? \\
\hline 3 & What is the most positive experience you have experienced here? \\
\hline 4 & What does an average day look like for you? \\
\hline $5 a$ & What is pleasant about your contact with the caregivers here? \\
\hline $5 b$ & What could be different about your contact with the caregivers here? \\
\hline $6 a$ & What is pleasant about your contact with your family? \\
\hline $6 b$ & What could be different about your contact with the family here? \\
\hline $7 a$ & What goes well here? \\
\hline $7 \mathrm{~b}$ & What could be done more here? \\
\hline 8 & Is there anything left you would like to share that has not been addressed yet? \\
\hline \multirow{5}{*}{$\begin{array}{l}\text { Probing } \\
\text { questions }\end{array}$} & Why? \\
\hline & What is going well? \\
\hline & What could be done more? \\
\hline & How did that make you feel? \\
\hline & Can you give an example? \\
\hline
\end{tabular}

All questions are based on the elements of the INDEXQUAL framework, capture the resident's customer journey and are formulated from an appreciative inquiry approach. The 
critical incidence technique is applied in question 3 by asking explicitly about the most positive experience, aimed at identifying a critical incident. ${ }^{88} \mathrm{~A}$ critical incident combines cognitive, affective and behavioral dimensions by describing the experience itself, the behaviors of everyone involved and the result of these behaviors. ${ }^{89}$ Question 4 provides respondents the opportunity to fabricate their own customer journey, which contributes to understanding what is important to the resident, family and/or caregiver. ${ }^{18}$ Interviewers are provided with a list of probing questions, to support them during the conversations and supportive visuals for the questions asking for a grade (Figure A1).

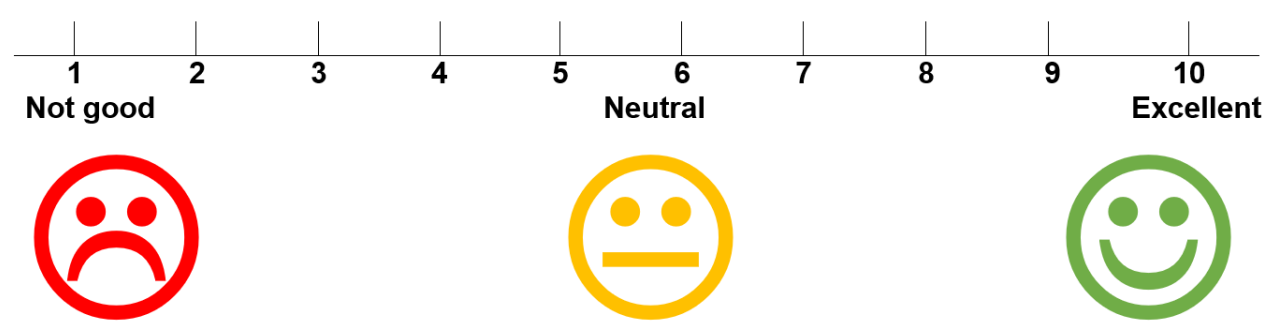

Figure A1. Supportive visual for Connecting Conversations

\section{Care Triads Recruitment}

On a ward consisting of 15-30 residents, six residents with their family and caregivers are randomly selected to participate by the research team. Care organizations are free to select the nursing home ward, however the research team randomly selects the six residents on the ward, to avoid selection bias. A random sequence list of all residents' room numbers of the selected wards is generated. When a resident refuses to participate, the next is approached until the total number of triads is recruited. A closely involved family member and professional caregiver are invited to participate, once the resident has agreed.

\section{Appendix A.2. Registration}

Connecting Conversations includes an app for tablets and computers. This app supports interviewers to perform, register and view their Connecting Conversations. The main features of the app are:

- $\quad$ signing informed consent;

- collecting participant demographics;

- $\quad$ presenting semi-structured questions and suggestions for probing questions;

- typing summative answers to each question;

- audio recording and replaying of conversations;

- viewing collected data through a web portal.

Replaying of audio and typing the summative answers can also be done on a computer or laptop by the interviewer, after having performed the conversation. On an online portal 
managed by the research team, new interviewers and nursing homes can be assigned and the data is securely stored. The raw data as entered into the app are also available for nursing homes upon request, if participants have provided consent for this as it may breach anonymity. Each interviewer has an own secured account in which triads can be created. The app is available in the app Store for tablets and interviewers receive login details during the first training day. Figure A2 presents two screen shots of the app: left shows the list of created triads and right shows the questions, answer fields and audio recording option for a conversation with a resident.

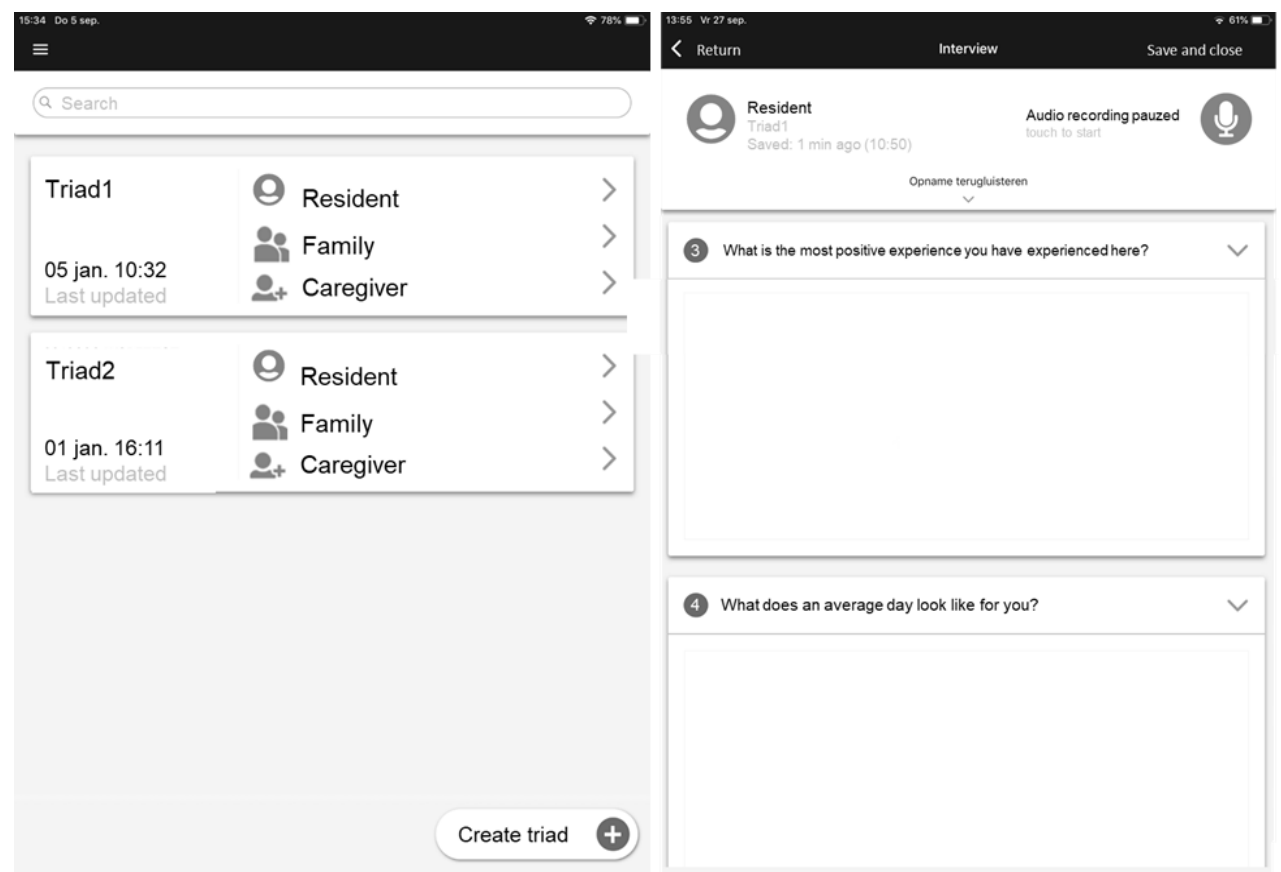

Figure A2. Screen shots from the Connecting Conversations app: triad list (left) and conversation with resident (right)

\section{Appendix A.3. Training}

In order to successfully perform and register Connecting Conversations, interviewers need to follow a mandatory three-day training. It aims to assure the quality and reliability of the conversations regardless which interviewer performs a conversation. The training teaches interviewers how to perform Connecting Conversations, focusing on both the theoretical foundations of INDEXQUAL, relationship-centered care, appreciative inquiry and the customer journey, and the practical aspects, such as how to use the app. The training consists of three 3-h sessions in a group of maximally 20 interviewers. Session 1 (day 1 ) is focused on engaging the group of interviewers, session 2 (day 8) on practicing conversations and session 3 (day 35 ) on evaluating and reflecting on each other's first experiences with the 
conversations. Interviewers are taught how to perform appreciative conversations with residents, family and caregivers, and how to ask probing questions, paraphrase and really listen without making assumptions.

The training is provided by an external company experienced in developing and providing innovative, scientific, tailor-made trainings, adopting an appreciative inquiry approach (in the Netherlands we collaborated with UMIO, an executive branch of Maastricht University). A holistic approach has been adopted, by applying the integral theory of consciousness focusing on intentional (I), behavioral (IT), cultural (WE) and social (ITS) quadrants. ${ }^{90}$ The training aims to tackle all four components, to achieve successful long-term change. Whereas standard trainings are often aimed at 'predict and control', this training uses a 'sense and respond' approach, providing the group space to adjust the content of the training to their personal needs, which enhances engagement and effective use of time. ${ }^{91}$

\section{Appendix A.4. Certificate}

Interviewers are rewarded with a certificate if they attend all three sessions and perform at least one triad in another nursing home than where they are employed. Interviewers, who are unable to attend one of the training sessions, receive the opportunity to hand in a compensation assignment. The certificate is valid for 1 years and can be extended after attending a celebration session. A celebration session is organized after all interviewers finalize their interviewers, to share experiences, enhance enthusiasm and future commitment, embrace the learning network, share feedback to further improve, and support interviewers to become Connecting Conversations champions within their organizations.

\section{Appendix A.5. Learning Network}

The learning network aims at contributing to sustainable success by providing a platform for interviewers in which they can learn from each other through continuous interaction. ${ }^{54}$ Interviewers from different care organizations follow the training together and perform conversations in each other's care organizations, thus not where they themselves are employed. This provides them the opportunity to interact with and learn from each other. Additionally, it supports responders in the triads to answer honestly, as the interviewer is independent and not related to the care organization. 


\section{Appendix A.6. Analysis}

The written texts as reported in the App, are analyzed by two researchers with content analysis. ${ }^{55}$ The texts are formatted in a table consisting of four columns allowing for comparison of answers within an individual triad (Table A2):

(1) the questions asked;

(2) summative answer resident;

(3) summative answer family;

(4) summative answer caregiver.

Table A2. Example answer output Connecting Conversations

\begin{tabular}{|c|c|c|c|}
\hline Question & Resident & Family & Caregiver \\
\hline $\begin{array}{l}\text { Q2. On a scale of } 1 \\
\text { to } 10, \text { how would } \\
\text { you grade the } \\
\text { caregivers that are } \\
\text { involved with your } \\
\text { daily care } \\
\text { provision? }\end{array}$ & $\begin{array}{l}\text { " } 9 \text {, because they do } \\
\text { everything they can. It's } \\
\text { just those girls have little } \\
\text { time. But they need to } \\
\text { see residents within a } \\
\text { certain time and cannot } \\
\text { just sit around with you." }\end{array}$ & $\begin{array}{l}\text { "Insufficient, because in } \\
\text { her opinion very many } \\
\text { care providers do not } \\
\text { treat her as a person, } \\
\text { but as a thing that needs } \\
\text { to be dressed quickly." }\end{array}$ & $\begin{array}{l}\text { " } 8 \text {, because the } \\
\text { wishes of the } \\
\text { client are met, for } \\
\text { example breakfast } \\
\text { in bed and care is } \\
\text { provided later." }\end{array}$ \\
\hline
\end{tabular}

First, researchers code meaningful segments per triad and label these as 'this is going well' (discover) or 'this needs to be done more frequently' (dream), adopting an appreciative inquiry approach. Second, they check to what extent the resident, family and caregiver expressed similar or different thoughts within a triad (relationship-centered care). Last, similarities and differences between triads are compared and aggregated into trends that are recognized as going well and that could be done more frequently on a ward, resulting in a report for the nursing home. Both researchers discuss their findings and conflicts with a third member of the research team. It is deemed unsustainable to analyze full transcripts for these large amounts of data, as this is very time-consuming and nursing homes want quick quality improvement cycles.

\section{Appendix A.7. Report}

The research team is responsible for reporting results back to the nursing homes. The analyzed data are presented on ward level in a factsheet with supporting 'quotes' by a researcher on location. Nursing homes can choose who attends this presentation, for example the ward manager, nursing home manager, quality policy officer of the nursing home and/or the care team. The presentation consists of eight sections presented from an appreciative inquiry approach and tailored to each ward's results presented in Table A3. 
Table A3. Outline of report

1. Core principles of Connecting Conversations

2. Details on how many conversations were performed in which ward

3. To what degree were there many similarities or differences between the resident, family and caregiver within each triad?

4. What is going well on the ward? (discover)

5. Quotes supporting results on section 4

6. What could be done more frequently on the ward? (dream)

7. Quotes supporting results on section 6

8. Discussion asking attendees what they think of the results, what they can learn from the results and what they are going to do with the results?

The ward manager is advised to share the results with the care team, family and residents; and to discuss if the results are familiar, how the team can learn from these results and what actions can be taken based on the findings (design and destiny). On request, nursing homes can ask for additional reports, such as a poster with the main results to share on the ward or a written report that can be used for accountability purposes. 


\section{REFERENCES}

1. World Health Organisation. Ageing and Health: key facts 2018 [updated 05/02/201806/07/2020]. Available from: https://www.who.int/news-room/fact-sheets/detail/ageing-and-health.

2. World Health Organisation. World report on ageing and health. Luxembourgh: World Health Organisation, 2015.

3. Sanford AM, Orrell M, Tolson D, Abbatecola AM, Arai H, Bauer JM, et al. An international definition for "nursing home". J Am Med Dir Assoc. 2015;16(3):181-4.

4. OECD/EU. A Good Life in Old Age? Paris: OECD Publishing; 2013.

5. Miller SC, Miller EA, Jung HY, Sterns S, Clark M, Mor V. Nursing home organizational change: the "Culture Change" movement as viewed by long-term care specialists. Med Care Res Rev. 2010;67(4 Suppl):65s-81s.

6. Zimmerman S, Shier V, Saliba D. Transforming nursing home culture: evidence for practice and policy. Gerontologist. 2014;54 Suppl 1:S1-5.

7. Nakrem S, Vinsnes AG, Seim A. Residents' experiences of interpersonal factors in nursing home care: a qualitative study. Int J Nurs Stud. 2011;48(11):1357-66.

8. Institute of Medicine Committee on Quality of Health Care in America. Crossing the Quality Chasm: A New Health System for the 21st Century. Washington (DC): National Academies Press (US); 2001.

9. Castle N, Ferguson J. What is nursing home quality and how is it measured? Gerontologist. 2010;50(4):426-42.

10. van Nie-Visser NC, Schols JM, Meesterberends E, Lohrmann C, Meijers JM, Halfens RJ. An international prevalence measurement of care problems: study protocol. J Adv Nurs. 2013;69(9):e18-e29.

11. Rahman AN, Applebaum RA. The Nursing Home Minimum Data Set Assessment Instrument: Manifest Functions and Unintended Consequences-Past, Present, and Future. Gerontologist. 2009;49(6):727-35.

12. Edvardsson D, Baxter R, Corneliusson L, Anderson RA, Beeber A, Boas PV, et al. Advancing LongTerm Care Science Through Using Common Data Elements: Candidate Measures for Care Outcomes of Personhood, Well-Being, and Quality of Life. Gerontol Geriatr Med. 2019;5:2333721419842672.

13. De Roo ML, Leemans K, Claessen SJJ, Cohen J, W. Pasman HR, Deliens L, et al. Quality Indicators for Palliative Care: Update of a Systematic Review. Journal of Pain and Symptom Management. 2013;46(4):556-72.

14. Mor V, Leone T, Maresso A. Regulating Long-Term Care Quality: An International Comparison. Cambridge: Cambridge University Press; 2014.

15. Clarke A, Rao M. Developing quality indicators to assess quality of care. Quality and Safety in Health Care. 2004;13(4):248-9.

16. Lewis RC, Booms BH. The marketing aspects of service quality. Emerging perspectives on services marketing. 1983;65(4):99-107.

17. Voorhees CM, Fombelle PW, Gregoire Y, Bone S, Gustafsson A, Sousa R, et al. Service encounters, experiences and the customer journey: Defining the field and a call to expand our lens. Journal of Business Research. 2017;79:269-80.

18. Lemon KN, Verhoef PC. Understanding Customer Experience Throughout the Customer Journey. Journal of Marketing. 2016;80(6):69-96.

19. McCormack B, Roberts T, Meyer J, Morgan D, Boscart V. Appreciating the 'person' in long-term care. Int J Older People Nurs. 2012;7(4):284-94. 
20. Wilberforce M, Challis D, Davies L, Kelly MP, Roberts C, Clarkson P. Person-centredness in the community care of older people: A literature-based concept synthesis. International Journal of Social Welfare. 2017;26(1):86-98.

21. Koren MJ. Person-centered care for nursing home residents: the culture-change movement. Health Aff (Millwood). 2010;29(2):312-7.

22. Duffy JR, Hoskins LM. The Quality-Caring Model: blending dual paradigms. ANS Adv Nurs Sci. 2003;26(1):77-88.

23. Beach MC, Inui T. Relationship-centered care. A constructive reframing. J Gen Intern Med. 2006;21 Suppl 1:S3-8.

24. Gummesson E. Extending the service-dominant logic: from customer centricity to balanced centricity. Journal of the Academy of Marketing Science. 2008;36(1):15-7.

25. Nolan M, Brown J, Davies S, Nolan J, Keady J. The Senses Framework: improving care for older people through a relationship-centred approach. Getting Research into Practice (GRiP) Report No 2.: University of Sheffield.; 2006.

26. OECD. Ministerial Statement: the Next Generation of Health Reforms. Paris: OECD Publishing; 2017.

27. Nadash P, Hefele J, Wang J, Barooah A. NURSING HOME SATISFACTION MEASURES: WHAT IS THEIR RELATIONSHIP TO QUALITY? Innovation in Aging. 2017;1(suppl_1):542-.

28. Corazzini KN, Anderson RA, Bowers BJ, Chu CH, Edvardsson D, Fagertun A, et al. Toward Common Data Elements for International Research in Long-term Care Homes: Advancing Person-Centered Care. J Am Med Dir Assoc. 2019;20(5):598-603.

29. Kellett U. Searching for new possibilities to care: A qualitative analysis of family caring involvement in nursing homes. Nursing Inquiry. 1999;6(1):9-16.

30. McGilton KS, Boscart VM. Close care provider-resident relationships in long-term care environments. J Clin Nurs. 2007;16(11):2149-57.

31. Zorginstituut Nederland. Kwaliteitskader Verpleeghuiszorg Samen leren en verbeteren.: Zorginstituut Nederland; 2017. 1-41 p.

32. Curyto KJ, Van Haitsma K, Vriesman DK. Direct observation of behavior: a review of current measures for use with older adults with dementia. Res Gerontol Nurs. 2008;1(1):52-76.

33. Weldring T, Smith SMS. Patient-Reported Outcomes (PROs) and Patient-Reported Outcome Measures (PROMs). Health services insights. 2013;6:61-8.

34. Zuidgeest M, Delnoij DMJ, Luijkx KG, de Boer D, Westert GP. Patients' experiences of the quality of long-term care among the elderly: comparing scores over time. BMC Health Serv Res. 2012;12:26.

35. LaVela SL, Gallan AS. Evaluation and measurement of patient experience. Patient Experience Journal. 2014;1(28):36.

36. Kenyon G, Randall W. Introduction. Journal of Aging Studies. 2015;34:143-5.

37. Heliker DM. A Narrative Approach to Quality Care in Long-Term Care Facilities. Journal of Holistic Nursing. 1997;15(1):68-81.

38. Finucane ML, Martino SC, Parker AM, Schlesinger M, Grob R, Cerully JL, et al. A framework for conceptualizing how narratives from health-care consumers might improve or impede the use of information about provider quality. Patient Experience Journal. 2018;5(1):15-26.

39. Beswick N. Determination of the inter-rater reliability of the Edmonton Narrative Norms Instrument. Unpublished project report, Dept of Speech Pathology and Audiology, University of Alberta. 2008.

40. Bettmann JE, Lundahl BW. Tell me a story: A review of narrative assessments for preschoolers. Child and Adolescent Social Work Journal. 2007;24(5):455-75. 
41. Hendriks L, Veerbeek MA, Volker D, Veenendaal L, Willemse BM. Life review therapy for older adults with depressive symptoms in general practice: results of a pilot evaluation. Int Psychogeriatr. 2019;31(12):1801-8.

42. Butler RN. The Life Review: An Interpretation of Reminiscence in the Aged. Psychiatry. 1963;26(1):65-76.

43. De Vet HCW, Terwee CB, Mokkink LB, Knol DL. Measurement in Medicine: A Practical Guide. Cambridge: Cambridge University Press; 2011.

44. Triemstra MF, A. Literatuurstudie en overzicht van instrumenten Kwaliteit van leven en zorg meten. . Utrecht: Ministerie van Volksgezondheid, Welzijn en Sport, 2017.

45. Sion KYJ, Haex R, Verbeek H, Zwakhalen SMG, Odekerken-Schröder G, Schols JMGA, et al. Experienced Quality of Post-Acute and Long-Term Care From the Care Recipient's Perspective-A Conceptual Framework. Journal of the American Medical Directors Association. 2019;20(11):138690.e1.

46. Sion KYJ, Verbeek H, de Boer B, Zwakhalen SMG, Odekerken-Schröder G, Schols JMGA, et al. How to assess experienced quality of care in nursing homes from the client's perspective: results of a qualitative study. BMC Geriatr. 2020;20(1):67.

47. Sion K, Verbeek H, Aarts S, Zwakhalen S, Odekerken-Schröder G, Schols J, et al. The Validity of Connecting Conversations: A Narrative Method to Assess Experienced Quality of Care in Nursing Homes from the Resident's Perspective. Int J Environ Res Public Health. 2020;17(14).

48. Soklaridis S, Ravitz P, Nevo GA, Lieff S. Relationship-centred care in health: A 20-year scoping review. Patient Experience Journal. 2016;3(1):130-45.

49. Nolan MR, Davies S, Brown J, Keady J, Nolan J. Beyond person-centred care: a new vision for gerontological nursing. Journal of clinical nursing. 2004;13(3a):45-53.

50. Cooperrider D, Srivastva S. Appreciative Inquiry in Organizational Life. Research in Organizational Change and Development. 1987;1:129-69.

51. Cooperrider DL, Whitney DK, Stavros JM. Appreciative Inquiry Handbook: Lakeshore Communications; 2003.

52. Dewar B, MacBride T. Developing caring conversations in care homes: An appreciative inquiry. Health \& social care in the community. 2017;25(4):1375-86.

53. Beauchamp JM, Glessner TM. Appreciative Inquiry Promotes Nursing Culture Change. Clinical Nurse Specialist. 2006;20(2):82.

54. Wenger E. Communities of Practice: Learning, Meaning, and Identity. Cambridge: Cambridge University Press; 1998.

55. Hsieh HF, Shannon SE. Three approaches to qualitative content analysis. Qual Health Res. 2005;15(9):1277-88.

56. Verbeek H, Zwakhalen SMG, Schols JMGA, Kempen GIJM, Hamers JPH. The Living Lab in Ageing and Long-Term Care: A Sustainable Model for Translational Research Improving Quality of Life, Quality of Care and Quality of Work. The journal of nutrition, health \& aging. 2019.

57. Nickerson RS. Confirmation Bias: A Ubiquitous Phenomenon in Many Guises. Review of General Psychology. 1998;2(2):175-220.

58. DeMarrais KB, Lapan SD. 4. Qualitative Interview Studies: Learning Through Experience. Foundations for Research: Methods of Inquiry in Education and the Social Sciences. New Jersey: L. Erlbaum Associates; 2004.

59. MAXQDA, software for qualitative data analysis. Berlin: VERBI Software - Consult - Sozialforschung $\mathrm{GmbH} ; 1989-2020$.

60. Black BS, Rabins PV, Sugarman J, Karlawish JH. Seeking assent and respecting dissent in dementia research. Am J Geriatr Psychiatry. 2010;18(1):77-85. 
61. Villar F, Serrat R. Changing the culture of long-term care through narrative care: Individual, interpersonal, and institutional dimensions. Journal of Aging Studies. 2017;40:44-8.

62. Meerveld Ev, Vos FSM, Bos EH, Jansen YJFM. Meerwaarde van een lerend netwerk, casus National Inzetbaarheidsplan. Hoofddorp: TNO, 2014 2014-01-01. Report No.

63. Boyd EM, Fales AW. Reflective Learning: Key to Learning from Experience. Journal of Humanistic Psychology. 1983;23(2):99-117.

64. Magnussen I-L, Alteren J, Bondas T. Appreciative inquiry in a Norwegian nursing home: a unifying and maturing process to forward new knowledge and new practice. International journal of qualitative studies on health and well-being. 2019;14(1):1559437-.

65. NCHR\&D. Quality of life in care homes: A review of the literature. London: Help the Aged; 2007.

66. Dewar B, Nolan M. Caring about caring: developing a model to implement compassionate relationship centred care in an older people care setting. Int J Nurs Stud. 2013;50(9):1247-58.

67. Anderson RA, Issel LM, McDaniel RR, Jr. Nursing homes as complex adaptive systems: relationship between management practice and resident outcomes. Nurs Res. 2003;52(1):12-21.

68. Woo K, Milworm G, Dowding D. Characteristics of quality improvement champions in nursing homes: A systematic review with implications for evidence-based practice. Worldviews on Evidence-Based Nursing. 2017;14(6):440-6.

69. Backman A, Sjögren K, Lindkvist M, Lövheim H, Edvardsson D. Towards person-centredness in aged care - exploring the impact of leadership. J Nurs Manag. 2016;24(6):766-74.

70. Stiegler A, Biedinger N. Interviewer Skills and Training. 2016.

71. Merriam SB. Qualitative Research and Case Study Applications in Education. Revised and Expanded from" Case Study Research in Education.": ERIC; 1998.

72. Clandinin DJ, Connelly FM. Narrative Inquiry: Experience and Story in Qualitative Research2000.

73. Chang SJ. Lived Experiences of Nursing Home Residents in Korea. Asian Nursing Research. 2013;7(2):83-90.

74. Chuang YH, Abbey JA, Yeh YC, Tseng IJ, Liu MF. As they see it: A qualitative study of how older residents in nursing homes perceive their care needs. Collegian. 2015;22(1):43-51.

75. Drageset J, Haugan G, Tranvag O. Crucial aspects promoting meaning and purpose in life: perceptions of nursing home residents. BMC Geriatr. 2017;17(1):254.

76. Walker $\mathrm{H}$, Paliadelis $\mathrm{P}$. Older peoples' experiences of living in a residential aged care facility in Australia. Australasian Journal on Ageing. 2016;35(3):E6-E10.

77. Applebaum R, Uman C, Straker J. Capturing the voices of consumers in long-term care: If you ask them they will tell. Consumer voice and choice in long-term care. 2006:127-40.

78. Milte R, Huynh E, Ratcliffe J. Assessing quality of care in nursing homes using discrete choice experiments: How does the level of cognitive functioning impact upon older people's preferences? Soc Sci Med. 2019;238:112466-.

79. de Boer B, Beerens HC, Zwakhalen SM, Tan FE, Hamers JP, Verbeek H. Daily lives of residents with dementia in nursing homes: development of the Maastricht electronic daily life observation tool. Int Psychogeriatr. 2016;28(8):1333-43.

80. Brooker D. Dementia Care Mapping. Principles and Practice of Geriatric Psychiatry2010.

81. Brooker D, La Fontaine J, De Vries K, Latham I, editors. The development of PIECE-dem: focussing on the experience of care for people living with advanced dementia. The British Psychological Society Clinical Psychology Forum; 2013: The British Psychological Society.

82. Bohlmeijer E, Kenyon G, Randall W. Toward a Narrative Turn in Health Care. Storying later life: Issues, investigations, and interventions in narrative gerontology: Oxford University Press; 2011.

83. Regulating Long-Term Care Quality: An International Comparison. Cambridge: Cambridge University Press; 2014. 
84. Usai A, Pironti M, Mital M, Mejri CA. Knowledge discovery out of text data: a systematic review via text mining. Journal of Knowledge Management. 2018.

85. Safran DG, Miller W, Beckman H. Organizational dimensions of relationship-centered care theory, evidence, and practice. J Gen Intern Med. 2006;21(1):9-15.

86. van Achterberg T, Schoonhoven L, Grol R. Nursing implementation science: how evidence-based nursing requires evidence-based implementation. J Nurs Scholarsh. 2008;40(4):302-10.

87. Christie HL, Martin JL, Connor J, Tange HJ, Verhey FRJ, de Vugt ME, et al. eHealth interventions to support caregivers of people with dementia may be proven effective, but are they implementationready? Internet Interventions. 2019;18:100260.

88. Flanagan JC. The critical incident technique. Psychological Bulletin. 1954;51(4):327-58.

89. Serrat O. The Critical Incident Technique. Knowledge Solutions: Tools, Methods, and Approaches to Drive Organizational Performance. Singapore: Springer Singapore; 2017. p. 1077-83.

90. Wilber K. An integral theory of consciousness. Journal of consciousness studies. 1997;4(1):71-92.

91. Bradley SP, Nolan RL. Sense and Respond: Capturing Value in the Network Era: Harvard Business School Press; 1998. 


\section{CHAPTER

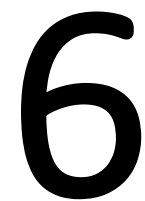

The Validity of Connecting Conversations: A Narrative Method to Assess Experienced Quality of Care in Nursing Homes from the Resident's Perspective

This chapter was published as:

Sion KYJ, Verbeek H, Aarts S, Zwakhalen SMG, Odekerken-Schröder GJ, Schols JMGA, Hamers JPH. The Validity of Connecting Conversations: A Narrative Method to Assess Experienced Quality of Care in Nursing Homes from the Resident's Perspective. International Journal of Environmental Research and Public Health, 2020; 17(14):5100

https://doi.org/10.3390/ijerph17145100 


\begin{abstract}
It is important to assess experienced quality of care in nursing homes as this portrays what is important to residents and helps identify what quality improvements should focus on. Connecting Conversations is a narrative method that assesses experienced quality of care from the resident's perspective in nursing homes by having separate conversations with residents, family and professional caregivers (triads) within a learning network. This study assessed the validity of performing the narrative method Connecting Conversations. Trained nursing home staff (interviewers) performed the conversations in another nursing home than where they were employed. In total, 149 conversations were performed in 10 nursing homes. Findings show that experts deemed the narrative assessment method appropriate and complete to assess experienced quality of care (face validity). The questions asked appeared to capture the full construct of experienced quality of care (content validity). Additionally, there was a range in how positive conversations were and first results indicated that a nursing home scoring higher on satisfaction had more positive conversations (construct validity). More data is needed to perform additional construct validity analyses. In conclusion, Connecting Conversations shows promising results to be used as a valid narrative method to assess experienced quality of care.
\end{abstract}




\section{INTRODUCTION}

Worldwide, there is an increase in older people and henceforth an increasing demand for long-term care services, such as nursing home care. ${ }^{1,2}$ Nursing homes are a type of LTC service with 24-hour care and functional support for the most vulnerable people in our society with complex health needs. ${ }^{3}$ The Institute of Medicine defined six domains to help define and assess quality of care: safety, effectiveness, efficiency, timeliness, patient-centeredness and equitability. ${ }^{4}$ It is challenging to assess quality of care, as providing care is a service that is characterized by its intangible, heterogeneous, multifaceted, perishable and interactive characteristics. ${ }^{5,6}$ Therefore, measures have been developed to assess a range of quality indicators, mostly focused on safety and effectiveness, such as the incidence of pressure ulcers. ${ }^{7}$ As the data collected with quality measures are used for quality improvement, policy-making, accountability and transparency, it is important to assure that the quality indicators truly measure the construct they aim to measure. ${ }^{8-}$ 10

Over the past decade, the nursing home culture has shifted from a mere medical approach to a more holistic person- and relationship-centered approach, acknowledging the resident's perspective, experiences and caring relationships. ${ }^{11-13}$ This holistic approach requires additional assessments of quality of care from the resident's perspective, as amongst others, this can help care teams to improve quality and it can support residents to enhance their quality of life in the nursing home. ${ }^{14,15}$ Quality of care from the resident's perspective is a process of care experiences with expectations before, care interactions during and an assessment of the experience afterwards in a certain context, as presented in the Individually Experienced Quality of Long-Term Care (INDEXQUAL) framework. ${ }^{16}$ Expectations are influenced by personal needs, previous experiences and word-of-mouth. ${ }^{5}$ The experiences in the caring environment are formed by the caring relationships between the resident, family and professional caregivers, and their interactions. ${ }^{17,18}$ Therefore, it is important to include the professional caregivers' and families' perspectives as well when assessing quality of care from the resident's perspective. ${ }^{19,20}$ After the experience, an assessment is given of what happened and how it happened (perceived care services), how this impacted the resident's health status (perceived care outcomes) and how this made the resident feel (satisfaction)..$^{21,22}$

Until now, the most common approach to assess residents' quality of care has been with quantitative satisfaction, patient-reported experience and patient-reported 
outcome measures, such as the Consumer Quality Index or the Net Promotor Score. ${ }^{7,22-26}$ These measures however are not sufficient to capture quality of care from the resident's perspective, as they only assess individual elements of care experiences and are lacking the meaning behind the response to these items. ${ }^{21,27}$ To capture the full process of residents' quality of care, it is valuable to use narratives, as these possess emotions, explain logic, provide information about the caring relationships and capture an experience. ${ }^{28}$ Narrative inquiry has been characterized by three dimensions: 1) personal and social (interaction) 2) past, present and future (continuity), and 3) place (situation), and respondents receive the opportunity to share their stories and elaborate on points for improvement. ${ }^{29,30}$ Therefore, narratives can help discover what is meaningful to residents and help to improve quality of care tailored to the individual. ${ }^{31}$ Research has shown that care staff can use narratives to evaluate and improve care services based on care recipients' stories. $^{32}$

The development of assessment methods is a step-wise approach in which the constructs and components are defined, the method is pilot- and field-tested and reliability and validity are assessed. ${ }^{10}$ Determining the reliability and validity of assessment methods is important to assure the quality of the method and the corresponding data, and to provide potential users transparency when selecting an appropriate assessment method. ${ }^{10}$ Reliability and validity of narratives are usually assessed with four key components related to trustworthiness: credibility, transferability, dependability and conformability, mainly focused on the process of data-collection and analysis. ${ }^{33}$ However, these components have been developed for qualitative research in general, not specifically for a qualitative assessment method. ${ }^{34}$

Reliability is a prerequisite of validity and has been defined as 'the degree to which measurement is free from measurement error'. ${ }^{35}$ For qualitative assessment methods, the data are in narrative form and subjective, and the interviewer is considered to be part of the method and can contribute to the reliability through training and practice. ${ }^{34,36,37}$ Therefore, reliability of narrative methods in terms of consistency can be analyzed by evaluating the procedures of how the assessments are performed. ${ }^{38}$

Validity has been defined as 'the degree to which an instrument truly measures the construct(s) it purports to measure'. ${ }^{35}$ It evaluates if an assessment method actually measures a construct and if the scores of the method are consistent with a theoretical framework of that construct. ${ }^{10}$ The question is how validity of narrative assessment methods should be evaluated and if the concepts of face, content and construct validity can be used, as these have been developed to evaluate quantitative 
assessment methods..$^{35}$ Valid methods assessing quality of care contribute to the credibility of the quality of care data. ${ }^{39,40}$

In the Netherlands, the use of narratives in nursing homes is occurring more frequently nowadays, as policy guidelines recommend the use of residents' experiences for quality monitoring and improvement. ${ }^{41}$ However to date, little research has been done on the reliability and validity of these narratives and if this has been addressed, this has usually been done by means of trustworthiness for qualitative research. ${ }^{10,42,43}$ The data collected with these narrative quality assessment methods are being used in daily nursing home practice for quality improvements and policy-making, and therefore it is inevitable to determine their validity.

Recently, the narrative method 'Connecting Conversations' was developed aimed at assessing the entire process of experienced quality of care in nursing homes from the resident's perspective. ${ }^{44}$ Connecting Conversations trains nursing home staff to perform separate conversations with a resident, family member and a professional caregiver of that resident (triad). Its theoretical foundation is based on relationshipcentered care and the full care experience as defined in the INDEXQUAL framework. 16,45 Connecting Conversations' feasibility has been assessed by evaluating the consistency of the procedure in terms of performance completeness, protocol adherence and satisfaction, and has been published elsewhere. ${ }^{44}$ This study aimed to evaluate the validity of performing the narrative method Connecting Conversations.

\section{MATERIALS AND METHODS}

The study used a mixed-methods cross-sectional design and data collection was performed from October 2018 to February 2019.

\section{Connecting Conversations}

Connecting Conversations is a narrative method that assesses experienced quality of care in nursing homes from the resident's perspective. Separate conversations are performed with the resident, a family member and a caregiver involved in the daily care of that resident (a triad) by a nursing home staff member (interviewer) employed in another care organization than where he or she performs the conversations. This provides for a learning network, creating the opportunity for interviewers to learn from each other and another environment, and it enhances an equal relationship between the participants in the triad and the interviewer. The method is based on appreciative inquiry, which focusses on what is going well and 
how this can be done more, instead of only focusing on problems and the negative [45].

The six main Connecting Conversations' questions are about the resident's life, satisfaction with care provision, most positive experience, description of an average day in the nursing home and relationships between the resident, family and caregiver, based on the INDEXQUAL framework [16]. Interviewers received simple visuals (green, yellow and red smiley) to support residents in answering the questions when needed. To assure interviewers have all the knowledge and skills to perform the conversations, a 3-day training is provided by UMIO, an executive branch of the university, in which interviewers learn to perform the conversations. During day 1 and 2 interviewers are taught that the questions in the protocol should be used to trigger respondents to share their stories and can be supported with conversation techniques, such as responding with probing questions, paraphrasing, and creating purposeful silences. Day 3 is focused on sharing experiences, reflecting and learning with and from each other. Specific details on the narrative method have been published elsewhere. ${ }^{44}$

\section{Interpretation and Operationalization of Validity for Connecting Conversations}

In total, three concepts were assessed for Connecting Conversations: 1) face validity, 2) content validity, and 3) construct validity. ${ }^{10}$ Table 1 presents the definitions of these concepts for a narrative method, the operationalization of these concepts for 'Connecting Conversations' and how they were translated to an analysis. ${ }^{35}$ 
Table 1. Validity definitions, operationalization and analyses for Connecting Conversations

\begin{tabular}{|c|c|c|c|}
\hline $\begin{array}{l}\text { Face } \\
\text { validity }\end{array}$ & $\begin{array}{l}\text { The degree to which a narrative assessment } \\
\text { method looks as though it is an adequate } \\
\text { reflection of the construct to be measured }{ }^{35}\end{array}$ & $\begin{array}{l}\text { The degree to which experts, interviewers } \\
\text { and client representatives judged Connecting } \\
\text { Conversations actually assesses residents' } \\
\text { experienced quality of care in nursing homes }\end{array}$ & $\begin{array}{l}\text { Three separate group discussions in } \\
\text { which evaluations by key stakeholders, } \\
\text { client representatives and trained } \\
\text { interviewers were interpreted }\end{array}$ \\
\hline \multirow{2}{*}{$\begin{array}{l}\text { Construct } \\
\text { validity }\end{array}$} & \multirow{2}{*}{$\begin{array}{l}\text { The degree to which the stories of a narrative } \\
\text { assessment method are consistent with } \\
\text { hypotheses, e.g. with regard to internal } \\
\text { relationships, relationships with scores of other } \\
\text { assessment methods or differences between } \\
\text { relevant groups }{ }^{35}\end{array}$} & $\begin{array}{l}\text { The degree to which data collected with } \\
\text { Connecting Conversations can be interpreted } \\
\text { as ratings of experience quality of care, } \\
\text { varying from negative to positive }\end{array}$ & $\begin{array}{l}\text { Analyzed the \%-positively coded } \\
\text { segments per transcript for one full triad } \\
\text { per interviewer. Hereafter, compared } \\
\% \text {-positive to the actors within a triad } \\
\text { and between triads }\end{array}$ \\
\hline & & $\begin{array}{l}\text { The degree to which results from Connecting } \\
\text { Conversations are similar to results from the } \\
\text { Net Promotor Score (NPS), assessing } \\
\text { residents' loyalty/satisfaction }\end{array}$ & $\begin{array}{l}\text { The \%-positive coded segments were } \\
\text { compared to the NPS score for all full } \\
\text { triads of one nursing home scoring high } \\
\text { and one scoring low on the NPS score }\end{array}$ \\
\hline
\end{tabular}




\section{Setting and Participants}

Care triads and interviewers were recruited from the nursing homes within the Living Lab in Ageing \& Long-Term Care South-Limburg. ${ }^{46}$

\section{Care Triads}

In the Netherlands, there are different types of nursing home wards that either offer longterm somatic care for residents with physical disabilities, long-term psychogeriatric care for residents with dementia or temporary rehabilitation care. ${ }^{47}$ This study included triads of residents living in both somatic and psychogeriatric wards. Ten nursing homes each selected one ward if 15 or more residents lived in a ward or two wards if less than 15 residents lived in a ward.

Within each ward, five triads (wards $<15$ residents) or ten triads (wards $>15$ residents) were recruited randomly by the research team in collaboration with a contact person of the ward. Random selection aimed to avoid selection bias and ensured a true sample of residents' experiences on the ward could be captured. One triad consisted of a nursing home resident, a family member and a caregiver of that resident. Inclusion criteria were that the resident was living in the nursing home and received long-term care at the time of the conversation; the family member was the nursing homes' first contact person for the resident; and the caregiver was involved in the residents' daily care provision at least one day a week.

Random selection of triads was performed by generating a random sequence list of all residents' room numbers in a specific ward. The contact person of the ward asked residents of the first 5 (or 10) randomized room numbers if they were interested in participating. When a resident refused, the next was approached until 5 (or 10) residents (and henceforth triads) were recruited. The reason to randomize all room numbers, prior to asking if participants would be interested to join was threefold. First, this assured all residents received an equal chance of being included for the conversations. There is risk of selection bias when recruiting residents for conversations, as well-spoken, more involved residents and families are more likely to respond to the recruitment call. This occurred during pilot testing of the narrative method. By randomizing all resident room numbers, each has an equal chance of being selected and invited to participate. Second, the opportunity to give the resident a voice was not limited by the willingness of the family member to participate. Third, once a participant has been randomly selected and is willing to participate, he or she will have the certainty that this will happen. This avoids getting their hopes up and eventually them not being selected for the conversations. Only once a resident agreed to participate, the family and professional caregiver were approached. If the resident was unable to have the Connecting Conversations because of cognitive impairment the triad was included as a dyad (family-professional caregiver). If no family member was available or the family did not want to participate, the triad was also included as a dyad (resident-professional caregiver). If a professional caregiver 
did not want to participate, he or she recommended another caregiver closely involved in the resident's care to participate.

\section{Interviewers}

Any staff member interested in becoming an interviewer could apply and managers selected interviewers based on their intrinsic motivation and involvement in quality assurance by providing hands-on care or within a policy position. Additionally, a health scientist and psychologist employed at the university attended the training and performed conversations as well. Selection aimed at including 12 to 20 interviewers, as this was a suitable group size for participation in the intensive, highly interactive training.

\section{Data-Collection and Procedure}

\section{Procedure}

Interviewers' demographic characteristics were collected at the start of training day 1 . These were age in years, sex, job title, and years of working experience in the nursing home setting. The research team assigned interviewers to another nursing home than where they were employed to perform Connecting Conversations. Each interviewer was instructed to perform conversations with five full triads on a ward. Interviewers scheduled their own conversations with a contact person in their assigned nursing homes. They could perform multiple onehour conversations a day. Family members who were unable to attend a face-to-face conversation were interviewed by phone. Interviewers audio recorded and documented a summary per question on a tablet.

\section{Face Validity}

Key stakeholders, client representatives and interviewers were invited to express to what degree they judged Connecting Conversations to be an appropriate method to assess experienced quality of care in nursing homes. Key stakeholders (up to two per institution) were from the Dutch Ministry of Health, the Dutch Health Care Institute, the Dutch Client Council, the Dutch Professional Association of Nurses, the Dutch Health and Youth Care Inspectorate and the board members of Nursing Homes. Up to three client representatives per care organization were invited through the seven care organizations within the LivingLab of Ageing and Long-Term Care. ${ }^{46}$

Two separate interactive group discussions were scheduled, one for key stakeholders and one for client representatives, which were documented in meeting minutes. Participants discussed two questions: 1) To what extent do you judge Connecting Conversations to be an appropriate method to assess quality of care in nursing homes from the resident's perspective? and 2) To what extent do you judge the questions asked with Connecting Conversations to fully cover the concept of experienced quality of care in nursing homes 
from the resident's perspective?. Interviewers evaluated during all three training days during which field notes were taken. First, information on the background and development of Connecting Conversations was presented. Hereafter, participants were invited to express their thoughts on the design of Connecting Conversations and provide the research team with constructive feedback.

\section{Content Validity}

To assess the degree to which Connecting Conversations has a sample of questions that covers the full concept of residents' experienced quality of care as defined by the INDEXQUAL framework, separate conversations with resident-family-caregiver triads were performed and audio-recorded, according to the Connecting Conversations protocol.

\section{Construct Validity}

In the Dutch national quality framework for nursing homes, the Net Promotor Score (NPS) is currently the minimally required assessment for residents' experiences in nursing homes. ${ }^{41}$ Therefore, all participating nursing homes were offered the choice if they wanted the NPS to be measured in their nursing homes alongside Connecting Conversations. The NPS is a oneitem measure that assesses loyalty, as a derivate for satisfaction, by asking residents one question: 'on a scale of $0-10$, would you recommend this nursing home to your family and friends?'. A score of 9 or 10 is a promotor, and scores of 6 or below are detractors. The final NPS score is a \% calculated as the different between the \% promotors and the \% detractors. ${ }^{26}$ In general, a more positive score $(>0)$ is considered good and a more negative score $(<0)$ is considered poor. The NPS was considered a suitable comparator to validate Connecting Conversations' data, as it also assesses the more subjective side of quality of care from the resident's perspective. It differs from Connecting Conversations as it only provides a basic one-score rating, without reaching the underlying explanation of why this score has been given.

\section{Data-Analysis}

\section{Face Validity}

Field notes and meeting minutes were formatted and analyzed by the first author. Data was categorized into two components: appropriateness and completeness. Within appropriateness, feedback on the appropriateness of the method was extracted, such as opinions on the choice for a narrative form or the three separate conversations. Within completeness, feedback on the number and content of questions was extracted, such as the formulation of the questions or missing topics. Two researchers evaluated the comments during two face-to-face discussions during which the categorized findings were interpreted. 
A sample of all collected data was selected for validity analysis to avoid overrepresentation of an interviewer or ward. One completed triad per interviewer, which was audio recorded, was randomly selected. The random sample of transcripts was coded with the 15 themes from the INDEXQUAL framework, as this framework covers the themes of experienced quality of long-term care. Directed content analysis was performed. ${ }^{48}$ Both researchers independently coded the transcripts with the sub-themes from the INDEXUQAL framework. ${ }^{16}$ Coding was supported with a code tree that defined each INDEXQUAL theme (Table 2). The INDEXQUAL framework consists of four main themes divided into 15 sub-themes. For each sub-theme a question was formulated that enhanced the coders understanding of the code tree. If a section was unrelated to the INDEXQUAL sub-themes, it was left un-coded. Discrepancies between both researchers regarding the assignment of a code were discussed with the research team until consensus was reached.

\section{Construct Validity}

On a scale of 1 (bad) to 10 (perfect), responders are known to give a range of answers between 1 and 10 . When using narratives, the range in answers provided is less standardized. Therefore, transcripts were coded with two codes: positive and negative, by two researchers independently. Segments were only coded if a clear emotional value was provided, for example positive segments included words such as 'satisfied', 'happy', 'great' and negative such as 'unfortunate', 'frustrating', 'angry'. Neutral segments such as 'she reads a lot' were not coded. Per transcript, the total number of positive coded segments was calculated as a percentage of the total number of coded segments: e.g. if 50 segments were coded, of which 30 were positive and 20 were negative, the \%-positive would be $60 \%$. For each triad, the \%positive was plotted into a graph to visualize the range in \%-positive between the different conversations (resident-family-caregiver) and different triads. Additionally, the \%-positive of triads performed in a participating nursing home with a high NPS $(>0)$ in 2018, and a nursing home with a low NPS $(<0)$ in 2018 were compared. Both NPS scores were compared to the nursing homes' \%-positive. Validity was apparent if the \%-positive was lower in the nursing home with the lower NPS score compared to the \%-positive of the nursing home with the high NPS score. This analysis was performed on all full triads available for both nursing homes. Qualitative data was analyzed with MAXQDA version 18.1.1. and quantitative descriptive data with SPSS version $25 .{ }^{49,50}$

Table 2. Code tree INDEXQUAL

\begin{tabular}{lll}
\hline \hline Theme & Sub-theme & Interpretation \\
\hline \hline \multirow{2}{*}{ Context } & Nursing home & What are the characteristics of the nursing home? \\
\cline { 2 - 3 } & Person & Who was and who is the resident? \\
\hline \multirow{3}{*}{ Expectations } & Expectations & What did the R-F-C expect from the nursing home care? \\
\cline { 2 - 3 } & $\begin{array}{l}\text { Word-of-mouth } \\
\text { Care? }\end{array}$ & $\begin{array}{l}\text { What did the R-F-C hear from others about nursing home } \\
\text { call }\end{array}$
\end{tabular}




\begin{tabular}{|c|c|c|}
\hline Theme & Sub-theme & Interpretation \\
\hline & Personal needs & $\begin{array}{l}\text { What needs does the resident have? (sense of security, } \\
\text { belonging, continuity, purpose, achievement, significance) }\end{array}$ \\
\hline & Past experiences & What prior experiences did the $\mathrm{R}-\mathrm{F}-\mathrm{C}$ have with care? \\
\hline \multirow{6}{*}{ Experiences } & $\begin{array}{l}\text { Experiences (daily } \\
\text { routine) }\end{array}$ & What does an average day of the resident look like? \\
\hline & $\begin{array}{l}\text { Relationship- } \\
\text { centered care }\end{array}$ & $\begin{array}{l}\text { How are the relationships in the nursing home? (more } \\
\text { general than themes below) }\end{array}$ \\
\hline & $\begin{array}{l}-\quad \text { Resident- } \\
\text { Family }\end{array}$ & How is the relationship between $\mathrm{R}-\mathrm{F}$ ? \\
\hline & $\begin{array}{l}-\quad \text { Resident- } \\
\text { Caregiver }\end{array}$ & How is the relationship between $\mathrm{R}-\mathrm{C}$ ? \\
\hline & $\begin{array}{l}-\quad \text { Family- } \\
\quad \text { Caregiver }\end{array}$ & How is the relationship between $\mathrm{F}-\mathrm{C}$ ? \\
\hline & Care environment & $\begin{array}{l}\text { How is the subjective nursing home environment } \\
\text { experienced? }\end{array}$ \\
\hline \multirow{3}{*}{$\begin{array}{l}\text { Experienced } \\
\text { quality of care }\end{array}$} & $\begin{array}{l}\text { Perceived care } \\
\text { services }\end{array}$ & What happened during a specific experience? \\
\hline & $\begin{array}{l}\text { Perceived care } \\
\text { outcomes }\end{array}$ & How is the resident's health status? \\
\hline & Satisfaction & How did it make the R-F-C feel? \\
\hline
\end{tabular}

R: resident, F: family, C: caregiver.

\section{Ethical Considerations}

The study protocol was approved by the medical ethics committee of the regional medical center Zuyderland (17-N-86). Information about the aim of the study, the expected burden of the conversations and confidentiality was provided to all residents, family members and caregivers in the triads in advance by letter. Before the start of each conversation, written informed consent was provided by all participants. Residents with legal representatives gave informed assent themselves before and during the conversations, and their legal representatives gave written informed consent. ${ }^{51}$ Participation was strictly voluntarily and participants were allowed to withdraw from the study at any moment. To guarantee privacy and anonymity of participants, no names or organizations were documented.

\section{RESULTS}

In 2018, 16 interviewers attended the training and performed 149 Connecting Conversations (46 residents, 46 family members, 57 caregivers) in 10 different nursing homes (4 psychogeriatric, 5 somatic, 1 acquired brain injury $<65$ years). In total 34 full triads were performed, 11 family-caregiver dyads and 11 resident-caregiver dyads. Of these conversations, 125 were successfully audio recorded and 21 were not due to technical failure $(n=17)$, or participants refusal to audio record the conversation $(n=4)$. All interviewers attended the first two training days and 13 (81\%) attended the third evaluation training day. Interviewers' demographics are presented in Table 3. 
Table 3. Interviewer demographics and data collection

\begin{tabular}{lc}
\hline \hline Interviewers (N=16) & \\
\hline \hline Mean age in years (SD) & $40(11)$ \\
\% Female & $14(88)$ \\
Occupation & $10(63)$ \\
$\quad$ Nurse (\%) & $3(19)$ \\
Policy advisor (\%) & $1(6)$ \\
Nurse aid (\%) & $1(6)$ \\
Psychologist (\%) & $1(6)$ \\
Health scientist (\%) & $32.3(5.2)$ \\
Mean contracted hours per week (SD) & $13.8(9.7)$ \\
Mean years working experience (SD)
\end{tabular}

${ }^{*}$ Not employed in the nursing home, but at the university.

Interviewers had planned to perform five completed triads each; however, multiple triads were not completed. Reasons for an incomplete triad included: cognitive inability of the resident to participate in the conversation $(n=11)$, unavailability of a family member to participate ( $n=11)$ and challenges recruiting triads within a ward due to scheduling issues and lack of time ( $n=23$ triads). Table 4 presents a summary of the main findings for the validity analyses.

Table 4. Main findings face, content and construct validity

\begin{tabular}{|c|c|c|}
\hline Concept & Interpretation Connecting Conversations & Main findings \\
\hline $\begin{array}{l}\text { Face } \\
\text { validity }\end{array}$ & $\begin{array}{l}\text { The degree to which experts, interviewers } \\
\text { and client representatives judged } \\
\text { Connecting Conversations truly assesses } \\
\text { residents' experienced quality of care in } \\
\text { nursing homes }\end{array}$ & $\begin{array}{l}\text { Key stakeholders }(n=7) \text {, interviewers } \\
(n=16) \text { and client representatives }(n=10) \\
\text { evaluated the design of and questions } \\
\text { asked with Connecting Conversations to } \\
\text { be the right formula to assess } \\
\text { experienced quality of care in nursing } \\
\text { homes from the resident's perspective. }\end{array}$ \\
\hline $\begin{array}{l}\text { Content } \\
\text { validity }\end{array}$ & $\begin{array}{l}\text { The degree to which Connecting } \\
\text { Conversations has an appropriate sample } \\
\text { of questions to cover the full concept of } \\
\text { residents' experienced quality of care as } \\
\text { defined by the INDEXQUAL framework }\end{array}$ & $\begin{array}{l}\text { All themes and sub-themes from the } \\
\text { INDEXQUAL framework were present in } \\
\text { the } 11 \text { randomly selected triads. Word- } \\
\text { of-mouth was seldom identified }\end{array}$ \\
\hline \multirow{2}{*}{$\begin{array}{l}\text { Construct } \\
\text { validity }\end{array}$} & $\begin{array}{l}\text { The degree to which data collected with } \\
\text { Connecting Conversations can be } \\
\text { interpreted as true ratings of experience } \\
\text { quality of care. Henceforth, there is a } \\
\text { variety in conversations from being not } \\
\text { positive to very positive }\end{array}$ & $\begin{array}{l}\text { \%-positive ranged between and within } \\
\text { triads } \\
\text { - } \quad \text { Residents, } 6 \% * \text { to } 100 \% \text { positive } \\
\text { - } \quad \text { Family, } 23 \% \text { to } 100 \% \text { positive } \\
\text { - Caregivers, } 31 \% \text { to } 100 \% \text {. } \\
\text { *6\% positive means } 94 \% \text { negative coded } \\
\text { segments }\end{array}$ \\
\hline & $\begin{array}{l}\text { The degree to which results from } \\
\text { Connecting Conversations are similar to } \\
\text { results from the Net Promotor Score } \\
\text { (NPS), assessing residents' } \\
\text { loyalty/satisfaction }\end{array}$ & $\begin{array}{l}\text { A nursing home scoring low on the NPS } \\
\text { also scored a lower \%-positive compared } \\
\text { to a nursing home scoring high on the } \\
\text { NPS, showing a general tendency } \\
\text { There was insufficient data for a } \\
\text { correlation analysis }\end{array}$ \\
\hline
\end{tabular}




\section{Face Validity}

Key stakeholders $(n=7)$, interviewers $(n=16)$ and client representatives $(n=10)$ evaluated if the design of and questions asked with Connecting Conversations were fitting to assess experienced quality of care in nursing homes from the resident's perspective. All expressed the importance of taking time to perform conversations and the benefit of having three separate conversations. Additionally, key stakeholders highlighted the strength of the method being based on the INDEXQUAL framework: "it is important to include the resident's experiences, but also the families' and caregivers' experiences" and client representatives confirmed, "to a large extent, the relationship with a resident determines the experienced quality of care". Interviewers were able to reflect on the questions after having performed conversations and evaluated that "they are the correct questions to ask and very clear". The main concern by key stakeholders and interviewers was if residents with cognitive impairment would be capable to have these conversations; client representatives however did not express this concern. Interviewers for example suggested it would be good to "receive some more guidance and supportive tools".

\section{Content Validity}

Of the 16 interviewers, 11 completed at least one full triad with audio recordings. The 11 triads were performed in somatic wards for older people $(n=5)$, psychogeriatric wards for older people $(n=5)$ and an acquired brain injury ward for people $<65$ years old $(n=1)$.

Table 5 presents how often each INDEXQUAL sub-theme was coded with the INDEXQUAL framework. The larger the grey circle, the higher the number of coded segments. Additionally, Table 5 presents quotes for each sub-theme to enhance understanding of how the data fit the framework. Analysis showed that all themes and almost all sub-themes from the INDEXQUAL framework were present in the random selection of triads. These findings suggest that the six Connecting Conversations questions cover the full concept of experienced quality of care. Word-of-mouth is the only sub-theme that rarely occurs. Residents did not address the relationship between their family and professional caregivers, which makes sense, as they are not directly asked about this. Perceived care services, perceived care outcomes and satisfaction were identified the most; in line with the INDEXQUAL framework that places these themes in the after 'assessment' phase. Numerically less segments were coded for residents $(n=404)$ compared to family members $(n=636)$ and caregivers $(n=621)$. 
Table 5. Connecting Conversations content validity coded with INDEXQUAL themes

\begin{tabular}{|c|c|c|c|}
\hline Theme & Sub-theme & $R-F-C$ & Quote \\
\hline \multirow[b]{2}{*}{ Context } & Nursing home & - & "It is eventually small-scale living" (F) \\
\hline & Person & & $\begin{array}{l}\text { "She always enjoys to talk" (C) } \\
\text { "I am used to speaking dialect and that is what I } \\
\text { feel comfortable with." (R) }\end{array}$ \\
\hline \multirow{4}{*}{ Expectations } & Expectations & $\circ$ & $\begin{array}{l}\text { "What is being organized here, I have been } \\
\text { totally amazed. I did not expect that." (F) }\end{array}$ \\
\hline & $\begin{array}{l}\text { Word-of- } \\
\text { mouth }\end{array}$ & 0 & $\begin{array}{l}\text { "Her husband also has that. They all think it is } \\
\text { too busy." (F) }\end{array}$ \\
\hline & Personal need & & $\begin{array}{l}\text { "But, close by, That is precisely what I long for. } \\
\text { That I really live in my own village. And that is } \\
\text { very important to me." (R) }\end{array}$ \\
\hline & $\begin{array}{l}\text { Past } \\
\text { experiences }\end{array}$ & - & $\begin{array}{l}\text { "I also think through the years, she used to live } \\
\text { elsewhere. The family therefore has certain } \\
\text { expectations of care that cannot always be } \\
\text { achieved." (C) }\end{array}$ \\
\hline \multirow{6}{*}{ Experiences } & $\begin{array}{l}\text { Experiences } \\
\text { (daily routine) }\end{array}$ & $\bigcirc \bigcirc$ & $\begin{array}{l}\text { "In the evening she usually goes to bed on time, } \\
\text { because she has dialysis and then she has to be } \\
\text { downstairs at } 7.30 \text { a.m." (F) }\end{array}$ \\
\hline & $\begin{array}{l}\text { Relationship- } \\
\text { centered care }\end{array}$ & O & $\begin{array}{l}\text { "The contact with the people from the other } \\
\text { neighborhood here...she really misses that } \\
\text { connection." (C) }\end{array}$ \\
\hline & $\begin{array}{l}\text { Resident- } \\
\text { Family }\end{array}$ & - & "It's nice every time they visit" (R) \\
\hline & $\begin{array}{l}\text { Resident- } \\
\text { Caregiver }\end{array}$ & $0 \bigcirc$ & "She likes all staff, so a 10 " (F) \\
\hline & $\begin{array}{l}\text { Family- } \\
\text { Caregiver }\end{array}$ & 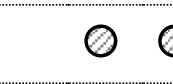 & $\begin{array}{l}\text { "Yes, actually good too; the daughter is also the } \\
\text { first contact person." (C) }\end{array}$ \\
\hline & $\begin{array}{l}\text { Care } \\
\text { environment }\end{array}$ & $\therefore$ & $\begin{array}{l}\text { "Because, they don't always have time for us." } \\
\text { (R) }\end{array}$ \\
\hline \multirow{2}{*}{$\begin{array}{l}\text { Experienced } \\
\text { quality of care }\end{array}$} & $\begin{array}{l}\text { Perceived care } \\
\text { services }\end{array}$ & & $\begin{array}{l}\text { "Yes you are looked after, but that is all. You } \\
\text { have to nag the entire week because you don't } \\
\text { have absorbent products and then suddenly } \\
\text { there are six packs on the rack." (R) }\end{array}$ \\
\hline & $\begin{array}{l}\text { Perceived care } \\
\text { outcomes }\end{array}$ & & $\begin{array}{l}\text { "She always used to love to read, but reading is } \\
\text { not possible anymore." (F) }\end{array}$ \\
\hline
\end{tabular}

C: Caregiver, F: Family, R: Resident. The larger the colored circle, the higher the number of coded segments (calculated based on 20 percentiles). • 1-7 | 8-26 | $\bigcirc 27-37 \mid$ 38-62। 63-150 coded segments.

\section{Construct Validity}

For each transcript within a triad, both positive and negative segments could be identified and coded. An example of a positive and a negative segment are presented below: 
- Positive segment Resident-Caregiver (triad 008) - Interviewer: "How is the contact between you and Mister Johnson?" Caregiver: "Actually, it is very good. I experience it as being pleasant. He is very grateful that I am there for him and help him."

- Negative segment Care environment (triad 002) - Interviewer: "Is there anything that could be better?" Resident: "Yes, the care provision. They are busy. They see everything but yeah... And the music is loud. I cannot stand that. Then I often ask if it can be softer."

Figure 1 presents the range in quality ratings between conversations and triads. Each row represents a different triad and portrays the \%-positively coded segments of the resident, family and caregiver in that triad and the ' $x$ ' shows each triads' mean \%-positive. For residents, \%-positive ranged from $6 \%$ to $100 \%$, for family it ranged from $23 \%$ to $100 \%$ and for caregivers it ranged from $31 \%$ to $100 \%$. These findings indicate that Connecting Conversations' data capture a large variety in scores range from low \%-positive to high \%positive. The median \%-positive over the 11 triads is 54\% and caregivers (64\%) seemed more positive than residents (46\%) and family members (53\%).

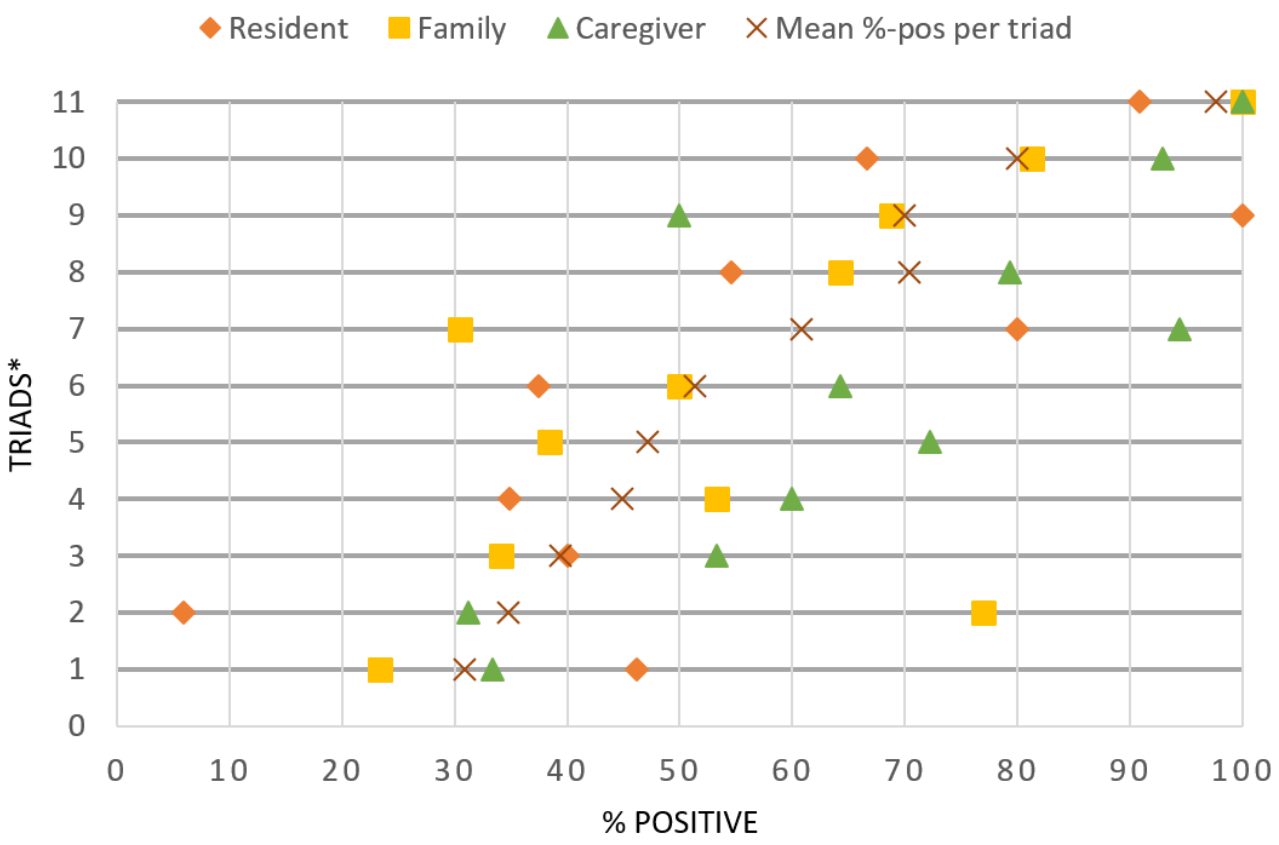

Figure 1. \%-Positive coded segments of each resident, family and caregiver per triad

* Each row represents one completed Connecting Conversation triad, presenting the \%-positive for the resident, family, caregiver and the mean \%-positive for these three.

We compared \%-positives to the NPS-score for two nursing homes (Table 6). Nursing home A scored highly above average on the NPS score (34) and shows that this nursing home scored a higher \%-positive coded segments (72\%). Nursing home B scored greatly below 
average on the NPS score (-50) accompanied with a lower \%-positive (57\%). This indicates that there is a convergence between resident satisfaction measured on a one-item scale (NPS) and the qualitative data (\%-positive) collected with Connecting Conversations. There was insufficient data to perform a correlation analysis.

Table 6. NPS score and Connecting Conversations \%-positive

\begin{tabular}{lllll}
\hline \hline & \multicolumn{2}{c}{ Nursing Home A } & \multicolumn{2}{c}{ Nursing Home B } \\
\cline { 2 - 5 } & Score & $n$ & Score & $n$ \\
\hline \hline NPS score (residents) & 34 & 38 & -50 & 16 \\
\% Positive Connecting Conversations (residents) & $62 \%$ & 4 & $49 \%$ & 3 \\
\% Positive Connecting Conversations (triads R-F-C) & $72 \%$ & 12 & $57 \%$ & 9 \\
\hline \hline
\end{tabular}

\section{DISCUSSION}

This study assessed the validity of performing the narrative method 'Connecting Conversations', which aims to assess experienced quality of care in nursing homes by performing separate conversations with a resident, family and professional caregiver of that resident. Results indicated that Connecting Conversations is a promising method to assess experienced quality of care in nursing homes from the resident's perspective and appears valid. Experts reported that both the design and questions asked were deemed appropriate and complete to assess experienced quality of care (face validity). Thematic content analysis showed the full construct of experienced quality of care appeared to be captured with the conversations (content validity). When addressing construct validity a range from negative to positive conversations became apparent. In addition, first results indicated a nursing home scoring low on satisfaction also scored a lower \%-positive coded segments compared to a nursing home scoring high on satisfaction (construct validity).

Our findings show that narratives can be used to evaluate care services, confirming the conclusion from another study. ${ }^{32}$ In nursing research, narratives are usually used to collect stories about someone's experiences in a certain context. ${ }^{52}$ However, stories collected with Connecting Conversations provided information on the full construct of experienced quality of care attached with a judgement of that quality, operationalized as \%-positive. Quality of care is a complex concept and therefore it is recommended to assess multiple components including resident experiences, clinical outcomes and employee satisfaction. For example, experienced quality of care assessed with Connecting Conversations, accompanied with the quantitative standardized quality indicators assessed with the National Prevalence Measurement of Quality of Care and employee satisfaction assessed with the single-item measure for overall job satisfaction. ${ }^{53-55}$ By combining quantitative and qualitative data we are able to capture a holistic view on quality of care.6,54 This can contribute to more tailored policy-making and quality improvement on nursing homes' operational (care triads), tactic (care teams) and strategic (care organization) level, aimed at achieving higher quality of care within a nursing home. ${ }^{56}$ 
Findings show residents living in nursing homes themselves are often capable of having conversations about their experienced quality of care, even when verbally challenged. The interpretation of stories shared by residents with moderate to severe cognitive impairment does need to be done cautiously. Research has shown this may be less valid, as residents may have difficulties correctly understanding questions and remembering past experiences. ${ }^{57}$ Connecting Conversations strengthened this by having three separate conversations, i.e. by including the families and caregivers stories as well, known as data triangulation. ${ }^{33}$ Findings show the benefit of including all three perspectives, as the \%-positive between actors in a triad often differed. Additionally, research has confirmed that with trained interviewers and clearly formulated questions residents with cognitive impairment can more often be included in the conversations. ${ }^{14,58-60}$ Interviewer may need to be provided with more support when conducting the conversations with the most vulnerable residents by means of more supportive questions and visuals, or by performing additional observations. ${ }^{61-63}$

For this study, several methodological considerations need to be addressed and some suggestions for future research. First, coding \%-positive was done binary (positive or negative). In practice, this range is larger as 'I am extremely happy' is interpreted as fully positive compared to 'I am quite happy', which is still positive, but to a lesser extent. We made no distinction between both types of positive quotes. Future research should focus on more in-depth analysis of the different intensities of positive and negative wordings, by means of for example text-mining. ${ }^{64,65}$ This can contribute to an even better understanding of the similarities and differences between experienced quality of care according to residents, their families and professional caregivers. Second, validity can only be present if an assessment method is reliable. ${ }^{66}$ For quantitative assessment methods, reliability analyses are usually focused on the outcome of the method in terms of consistency, stability and repeatability. ${ }^{10}$ Future research should explore possibilities to assess reliability of the outcome for narrative methods by means of for example inter-rater reliability or testretest. ${ }^{10}$ Third, there was insufficient data to perform a correlation analysis with satisfaction outcomes. Additional assessments should be performed to analyze this and other types of construct validity, such as the known-groups method, to explore if the method can distinguish nursing homes that are doing well compared to nursing homes that require more quality improvements. ${ }^{10}$ This is challenging as there is no standard evaluation available for narrative methods and existing evaluations will need to be adapted.

The current study introduced a different approach than trustworthiness to evaluate the validity of a narrative method that assesses quality of care with face, content and construct validity measures. It can be used by other researchers as a starting point to further explore validation of narrative assessment methods and can help to select appropriate qualitative methods that assess quality of care. When using the current study as an example, several steps should be taken into consideration. First, it is important to a-priori clearly define the construct to assess, as analyses on validity focusses on this. Second, a selection should be 
made of which concepts of validity will be assessed and how these will be assessed. Thirds, these concepts should be clearly defined and operationalized to the narrative method under study, as transparency supports the thoroughness of the research. ${ }^{67,68}$

\section{CONCLUSION}

The narrative method Connecting Conversations is deemed a promising method to assess experienced quality of care in nursing homes from the resident's perspective. Using validated narrative methods can contribute to credible quality assessments that can help determine what is going well and what needs to be improved when delivering care. It is important to use validated quality assessment methods, as the accuracy of the collected data is a first step towards more effective quality improvement initiatives and policy-making. Therefore, it would be beneficial to standardize the reliability and validity analysis of qualitative assessment methods. For Connecting Conversations, research should collaborate with practice and policy to explore how to embed the narrative assessment method in practice and how the data can be used to improve experienced quality of care in nursing homes. 


\section{REFERENCES}

1. World Health Organisation. Ageing and health: fact sheet $\mathrm{N}^{\circ} 404$ 2015. Available from: http://www.who.int/mediacentre/factsheets/fs404/en/.

2. Smith DB, Feng Z. The accumulated challenges of long-term care. Health Affairs. 2010;29(1):29-34.

3. Sanford AM, Orrell M, Tolson D, Abbatecola AM, Arai H, Bauer JM, et al. An international definition for "nursing home". J Am Med Dir Assoc. 2015;16(3):181-4.

4. Institute of Medicine Committee on Quality of Health Care in America. Crossing the Quality Chasm: A New Health System for the 21st Century. Washington (DC): National Academies Press (US); 2001.

5. Parasuraman A, ZeithamI VA, Berry LL. A Conceptual Model of Service Quality and Its Implications for Future Research. Journal of Marketing. 1985;49(4):41-50.

6. Goffin K, Mitchell R. Innovation Management: Effective strategy and implementation: Macmillan Education UK; 2016.

7. Castle N, Ferguson J. What is nursing home quality and how is it measured? Gerontologist. 2010;50(4):426-42.

8. OECD/EU. A Good Life in Old Age? Paris: OECD Publishing; 2013.

9. Burke RE, Werner RM. Quality measurement and nursing homes: measuring what matters. BMJ Quality \&amp; Safety. 2019;28(7):520-3.

10. De Vet HCW, Terwee CB, Mokkink LB, Knol DL. Measurement in Medicine: A Practical Guide. Cambridge: Cambridge University Press; 2011.

11. Koren MJ. Person-centered care for nursing home residents: the culture-change movement. Health Aff (Millwood). 2010;29(2):312-7.

12. McCormack B, Roberts T, Meyer J, Morgan D, Boscart V. Appreciating the 'person' in long-term care. Int J Older People Nurs. 2012;7(4):284-94.

13. Epp TD. Person-centred dementia care: A vision to be refined. The Canadian Alzheimer Disease Review. 2003;5(3):14-9.

14. Feinberg LF, Whitlatch CJ. Are persons with cognitive impairment able to state consistent choices? Gerontologist. 2001;41(3):374-82.

15. Lee H, Vlaev I, King D, Mayer E, Darzi A, Dolan P. Subjective well-being and the measurement of quality in healthcare. Soc Sci Med. 2013;99:27-34.

16. Sion KYJ, Haex R, Verbeek H, Zwakhalen SMG, Odekerken-Schröder G, Schols JMGA, et al. Experienced Quality of Post-Acute and Long-Term Care From the Care Recipient's Perspective-A Conceptual Framework. Journal of the American Medical Directors Association. 2019;20(11):138690.e1.

17. Duffy JR, Hoskins LM. The Quality-Caring Model: blending dual paradigms. ANS Adv Nurs Sci. 2003;26(1):77-88.

18. Soklaridis S, Ravitz P, Nevo GA, Lieff S. Relationship-centred care in health: A 20-year scoping review. Patient Experience Journal. 2016;3(1):130-45.

19. Sion KYJ, Verbeek H, de Boer B, Zwakhalen SMG, Odekerken-Schröder G, Schols JMGA, et al. How to assess experienced quality of care in nursing homes from the client's perspective: results of a qualitative study. BMC Geriatr. 2020;20(1):67.

20. Nolan MR, Davies S, Brown J, Keady J, Nolan J. Beyond person-centred care: a new vision for gerontological nursing. Journal of clinical nursing. 2004;13(3a):45-53.

21. LaVela SL, Gallan AS. Evaluation and measurement of patient experience. Patient Experience Journal. 2014;1(28):36.

22. Kingsley C, Patel S. Patient-reported outcome measures and patient-reported experience measures. BJA Education. 2017;17(4):137-44. 
23. Sangl J, Buchanan J, Cosenza C, Bernard S, Keller S, Mitchell N, et al. The development of a CAHPS instrument for Nursing Home Residents (NHCAHPS). J Aging Soc Policy. 2007;19(2):63-82.

24. Triemstra M, Winters S, Kool RB, Wiegers TA. Measuring client experiences in long-term care in the Netherlands: a pilot study with the Consumer Quality Index Long-term Care. BMC Health Serv Res. 2010;10:95.

25. Weldring T, Smith SM. Patient-reported outcomes (PROs) and patient-reported outcome measures (PROMs). Health Serv Insights. 2013;6:61.

26. Reichheld FF. The one number you need to grow. Harv Bus Rev. 2003;81(12):46-54, 124.

27. Bangerter LR, Abbott K, Heid A, Eshraghi K, Van Haitsma K. Using spontaneous commentary of nursing home residents to develop resident-centered measurement tools: A case study. Geriatr Nurs. 2017;38(6):548-50.

28. Finucane ML, Martino SC, Parker AM, Schlesinger M, Grob R, Cerully JL, et al. A framework for conceptualizing how narratives from health-care consumers might improve or impede the use of information about provider quality. Patient Experience Journal. 2018;5(1):15-26.

29. Martino SC, Shaller D, Schlesinger M, Parker AM, Rybowski L, Grob R, et al. CAHPS and Comments: How Closed-Ended Survey Questions and Narrative Accounts Interact in the Assessment of Patient Experience. J Patient Exp. 2017;4(1):37-45.

30. Schlesinger M, Grob R, Shaller D, Martino SC, Parker AM, Finucane ML, et al. Taking Patients' Narratives about Clinicians from Anecdote to Science. New England Journal of Medicine. 2015;373(7):675-9.

31. Heliker DM. A Narrative Approach to Quality Care in Long-Term Care Facilities. Journal of Holistic Nursing. 1997;15(1):68-81.

32. Hsu MY, McCormack B. Using narrative inquiry with older people to inform practice and service developments. J Clin Nurs. 2012;21(5-6):841-9.

33. Lincoln YS, Guba YSLEG, Guba EG. Naturalistic Inquiry: SAGE Publications; 1985.

34. Merriam SB. Qualitative Research and Case Study Applications in Education. Revised and Expanded from" Case Study Research in Education.": ERIC; 1998.

35. Mokkink LB, Terwee CB, Patrick DL, Alonso J, Stratford PW, Knol DL, et al. The COSMIN study reached international consensus on taxonomy, terminology, and definitions of measurement properties for health-related patient-reported outcomes. Journal of clinical epidemiology. 2010;63(7):737-45.

36. Zohrabi M. Mixed Method Research: Instruments, Validity, Reliability and Reporting Findings. Theory \& practice in language studies. 2013;3(2).

37. Clandinin DJ, Connelly FM. Narrative Inquiry: Experience and Story in Qualitative Research2000.

38. Overcash JA. Narrative research: a review of methodology and relevance to clinical practice. Critical Reviews in Oncology/Hematology. 2003;48(2):179-84.

39. Sitzia J. How valid and reliable are patient satisfaction data? An analysis of 195 studies. Int J Qual Health Care. 1999;11(4):319-28.

40. Kimberlin CL, Winterstein AG. Validity and reliability of measurement instruments used in research. American journal of health-system pharmacy. 2008;65(23):2276-84.

41. Zorginstituut Nederland. Kwaliteitskader Verpleeghuiszorg Samen leren en verbeteren.: Zorginstituut Nederland; 2017. 1-41 p.

42. Triemstra MF, A. Literatuurstudie en overzicht van instrumenten Kwaliteit van leven en zorg meten. . Utrecht: Ministerie van Volksgezondheid, Welzijn en Sport, 2017.

43. Schrieks M. Waaier cliëntervaringsninstrumenten 2017-2019. VGN, 2017. 
44. Sion K, Verbeek H, de Vries E, Zwakhalen S, Odekerken-Schröder G, Schols J, et al. The Feasibility of Connecting Conversations: A Narrative Method to Assess Experienced Quality of Care in Nursing Homes from the Resident's Perspective. Int J Environ Res Public Health. 2020;17(14).

45. Beach MC, Inui T. Relationship-centered care. A constructive reframing. J Gen Intern Med. 2006;21 Suppl 1:S3-8.

46. Verbeek H, Zwakhalen SMG, Schols J, Kempen G, Hamers JPH. The Living Lab In Ageing and LongTerm Care: A Sustainable Model for Translational Research Improving Quality of Life, Quality of Care and Quality of Work. J Nutr Health Aging. 2020;24(1):43-7.

47. Huls M, Rooij SE, Diepstraten A, Koopmans R, Helmich E. Learning to care for older patients: hospitals and nursing homes as learning environments. Medical Education. 2015;49(3):332-9.

48. Hsieh HF, Shannon SE. Three approaches to qualitative content analysis. Qual Health Res. 2005;15(9):1277-88.

49. MAXQDA, software for qualitative data analysis. Berlin: VERBI Software - Consult - Sozialforschung $\mathrm{GmbH} ; 1989-2020$.

50. Corp. I. IBM SPSS Statistics for Windows. Version 25.0. ed. Armonk, NY: IBM Corp.; Released 2017.

51. Black BS, Rabins PV, Sugarman J, Karlawish JH. Seeking assent and respecting dissent in dementia research. Am J Geriatr Psychiatry. 2010;18(1):77-85.

52. Holloway I, Freshwater D. Vulnerable story telling: Narrative research in nursing. Journal of Research in Nursing. 2007;12(6):703-11.

53. van Nie-Visser NC, Schols JM, Meesterberends E, Lohrmann C, Meijers JM, Halfens RJ. An international prevalence measurement of care problems: study protocol. J Adv Nurs. 2013;69(9):e18-e29.

54. Rahman AN, Applebaum RA. The Nursing Home Minimum Data Set Assessment Instrument: Manifest Functions and Unintended Consequences-Past, Present, and Future. Gerontologist. 2009;49(6):727-35.

55. Wanous JP, Reichers AE, Hudy MJ. Overall job satisfaction: how good are single-item measures? Journal of applied Psychology. 1997;82(2):247.

56. Anderson RA, Issel LM, McDaniel RR, Jr. Nursing homes as complex adaptive systems: relationship between management practice and resident outcomes. Nurs Res. 2003;52(1):12-21.

57. Bedard M, Squire L, Minthorn-Biggs M-B, Molloy DW, Dubois S, O'Donnell M, et al. Validity of SelfReports in Dementia Research. Clinical Gerontologist. 2003;26(3-4):155-63.

58. Applebaum R, Uman C, Straker J. Capturing the voices of consumers in long-term care: If you ask them they will tell. Consumer voice and choice in long-term care. 2006:127-40.

59. Milte R, Huynh E, Ratcliffe J. Assessing quality of care in nursing homes using discrete choice experiments: How does the level of cognitive functioning impact upon older people's preferences? Soc Sci Med. 2019;238:112466-.

60. Cahill S, Diaz-Ponce AM. 'I hate having nobody here. I'd like to know where they all are': Can qualitative research detect differences in quality of life among nursing home residents with different levels of cognitive impairment? Aging Ment Health. 2011;15(5):562-72.

61. Whitlatch CJ. Including the person with dementia in family care-giving research. Aging Ment Health. 2001;5 Suppl 1:S20-2.

62. Stans SE, Dalemans R, de Witte L, Beurskens A. Challenges in the communication between 'communication vulnerable' people and their social environment: an exploratory qualitative study. Patient Educ Couns. 2013;92(3):302-12.

63. Curyto KJ, Van Haitsma K, Vriesman DK. Direct observation of behavior: a review of current measures for use with older adults with dementia. Res Gerontol Nurs. 2008;1(1):52-76. 
64. Mohammad SM, Turney PD. Crowdsourcing a word-emotion association lexicon. Computational Intelligence. 2013;29(3):436-65.

65. De Smedt T, Daelemans W, editors. "Vreselijk mooi!"(terribly beautiful): A Subjectivity Lexicon for Dutch Adjectives. LREC; 2012.

66. Downing SM. Validity: on the meaningful interpretation of assessment data. Medical Education. 2003;37(9):830-7.

67. Altheide DL, Johnson JM. Criteria for assessing interpretive validity in qualitative research. Handbook of qualitative research. Thousand Oaks, CA, US: Sage Publications, Inc; 1994. p. 485-99.

68. Tuval-Mashiach R. Raising the curtain: The importance of transparency in qualitative research. Qualitative Psychology. 2017;4(2):126-38. 



\section{CHAPTER}

Listen, look, link and learn: a stepwise approach to use narrative quality data within resident-family-nursing staff triads in nursing homes for quality improvements

This chapter has been submitted for publication as:

Sion KYJ, Rutten JER, Verbeek H, De Vries E, Zwakhalen SMG, Odekerken-Schröder GJ, Schols JMGA, Hamers JPH. Listen, Look, Link and Learn: a Stepwise Approach to Use Narrative Quality data within resident-family-nursing staff triads in nursing homes for quality improvements 


\section{ABSTRACT}

Purpose: The use of qualitative data to assess quality of care in nursing homes from the resident's perspective has shown to be valuable, yet more research is needed to determine how this data can be used to gain insight into the quality of care within nursing homes. Whereas it is crucial to stay close to the stories that are the strength of qualitative data, an intermittent step to classify this data can support the interpretation and use. Therefore, this study introduces an approach that enables the use of narrative quality of care data to learn from and improve with.

Design: A cross-sectional mixed-methods study in which qualitative data was collected with the narrative quality assessment method Connecting Conversations and interpreted for analysis.

Methods: Connecting Conversations was used to collect narrative data about experienced quality of care in nursing homes according to residents, their families and nursing staff (triads). Data analysis consisted of coding positive/negative valences in each transcript.

Findings: A stepwise approach can support the use of narrative quality data consisting of four steps: (1) perform and transcribe the conversations (listen); (2) calculate a valence sore, defined as the mean \%-positive within a triad (look); (3) calculate an agreement score, defined as the level of agreement between resident-family-nursing staff (link); and (4) plot scores into a graph for interpretation and learning purposes with agreement score ( $x$-axis) and valence score (y-axis) (learn).

Conclusions: Narrative quality data can be interpreted as a valence and agreement score. These scores need to be related to the raw qualitative data to gain a rich understanding of what is going well and what needs to be improved. 


\section{INTRODUCTION}

Care provision in nursing homes has experienced a shift from being merely task-centered to being more relationship-centered, in which not only the resident's needs, but also family and nursing staffs' needs are considered. ${ }^{1-3}$ This has resulted in a new view towards quality of care in nursing homes known as experienced quality of care. Experienced quality of care is a process that is influenced by expectations; interactions and relationships between the resident, family and nursing staff; and an assessment afterwards. ${ }^{4}$ Residents, family and nursing staff in the care process each have their own needs and aspects they consider important regarding receiving and providing high quality of care, which can differ from each other. ${ }^{5,6}$ As service receivers, residents have expressed the importance of the nursing home environment, maintaining personhood; having and maintaining meaningful relationships with staff, family and other residents, and receiving tailored care. ${ }^{7}$ Residents and family have expressed the importance of feeling at home in a nursing home ${ }^{8}$. In addition, family values personalized attention for residents, recalling who they used to be, and receiving the opportunity to take some own responsibility in the care for the resident. ${ }^{5,9}$ As service providers, nursing staff often base their judgement of experienced quality of care on their task priorities, such as delivering personal individual care, creating a nice and friendly atmosphere and supporting residents emotionally. ${ }^{10}$ Furthermore, understanding residents' behaviors is important to them. ${ }^{5}$ By including these three different perspectives, discrepancies can be identified and a better understanding of the care experiences can be established, which assures that integral quality improvement plans are focused on the correct elements and enhances support to realize these improvements. ${ }^{11,12}$

Up until recently, experienced quality of care was mostly assessed with questionnaires, such as the CAHPS-NH. ${ }^{13}$ Research however has shown that whereas quantitative data is informative for some purposes, it misses the meaning behind a rating, providing insufficient information to determine what exactly is going well and what needs to be improve. ${ }^{14}$ Therefore, narrative methods have shown to be a powerful complementary method to discover what residents, families and nursing staff value, and to evaluate and improve care services based on their experiences. ${ }^{15,16}$ These narratives capture an experience by providing information about the caring relationships, explaining rationales and possessing emotions. ${ }^{17}$ Connecting Conversations is a narrative method that assesses experienced quality of care by performing separate conversations with the three actors in the care triad. ${ }^{18}$ It identifies similarities and discrepancies between residents', families' and nursing staffs' experienced quality of care and is based on the principles of relationship-centered care. In addition, appreciative inquiry is used to discover positive routines within nursing homes, i.e. what is going well. ${ }^{19}$

Whereas Connecting Conversations has shown to be feasible and valid to assess experienced quality of care in nursing homes, there is still a need to improve the usability of the narrative 
data for quality improvements. Merely assessing experienced quality of care is not sufficient as it is indispensable that the information can be used in practice for learning and improvement purposes. ${ }^{14}$ There is a need to discover how to use narrative data in practice, as the data are very rich and analysis is considered very time-intensive. ${ }^{20,21}$ Ideally, narratives are interpreted and classified into usable information to learn from and that can contribute towards improving quality of care. Therefore, this study aims to introduce a stepwise approach that enables the use of narrative data collected with Connecting Conversations to acquire an interpretation of the data that can assist with initiating quality improvements.

\section{METHODS}

\section{Study design}

In this cross-sectional mixed-methods study, qualitative data were collected with Connecting Conversations and quantified for analysis. Data was collected during autumn 2018 within the Living Lab in Aging and Long-Term Care in the south of the Netherlands. ${ }^{22}$

\section{Setting and participants}

Connecting Conversations was executed in 5 care organizations in the south of the Netherlands, including somatic wards, for older people with physical disabilities, and psychogeriatric wards, for older people with dementia ( 24 full care triads included). Random selection of residents on a ward was performed by generating a random sequence list of residents' room numbers of the ward and inviting the first five residents to participate. ${ }^{18}$ This ensured equal opportunity of participation for all residents on the ward, regardless of their diagnoses, capabilities and personalities. After a resident agreed to participate, a closely involved family member and a caregiver that provided care to the resident at least once a week were invited to participate as part of the care triad.

\section{Data collection}

Demographic characteristics were collected for the care triads (residents, family and professional caregivers) by the interviewer. For residents, age in years, sex, months living in the nursing home, activities of daily living (ADL) assessed with the ADL-scale (range from 0 independent to 6 fully dependent) and cognitive functioning assessed with the Cognitive Performance Scale (CPS, range from 0 full cognitive functioning to 6 extremely limited cognitive functioning) were collected. ${ }^{23}$ For family, age in years, sex, relationship to resident, and hours of weekly employment were collected. For caregivers, age in years, sex, and hours of weekly employment were collected.

Data were collected with the narrative assessment method 'Connecting Conversations', which assesses experienced quality of care in nursing homes as defined by the INDEXQUAL framework, by separately interviewing residents, family and nursing staff (care triad), 
adopting an appreciative inquiry approach. The Connecting Conversations' interview guide consisted of six questions to trigger respondents to share what matters to them. Questions 1 and 2 are about on the resident's quality of life and satisfaction with caregivers, asking to grade these and hereafter elaborating on what is needed to increase these grades. Hereafter, participants are asked to tell about the most positive experience in the nursing home, about an average day in the nursing home and about relationships between the resident, family and caregivers. Family and nursing staff were asked to answer the questions from the resident's perspective. The inclusion of three actors within a triad is considered a form of data triangulation. ${ }^{24}$ Interviewers were nursing staff employed at another nursing home. They received a three-day Connecting Conversations training in which they learned to perform separate interviews with residents, their family and professional caregivers. The interviews were audio recorded and summaries to each question were documented on a tablet. Full details on Connecting Conversations have previously been published. ${ }^{18}$

National experts in nursing home policy and practice $(n=11)$, provided advice on the content and format of the stepwise approach during two expert panel meetings, to enhance suitability for practice.

\section{Data analysis}

Data analysis was performed for all 24 fully completed care triads available with audiorecordings. ${ }^{18}$ Figure 1 presents the steps in analysis: listen (collecting data), look (understanding data), link (analyzing data) and learn (using data).

\begin{tabular}{|c|c|c|c|}
\hline $\begin{array}{l}\text { 1. Listen } \\
\text { Perform } \\
\text { Connecting } \\
\text { Conversations } \\
\text { Transcribing and } \\
\text { reading } \\
\text { transcripts }\end{array}$ & $\begin{array}{l}\text { 2. Look } \\
\text { Coding valence } \\
\text { ( } 24 \text { triads) and } \\
\text { subjectively } \\
\text { determining } \\
\text { valence for } \\
\text { validity } \\
\text { ( } 6 \text { triads) }\end{array}$ & $\begin{array}{l}\text { 3. Link } \\
\text { Comparing } \\
\text { resident-family- } \\
\text { nursing staff } \\
\text { transcripts in } \\
\text { triads }\end{array}$ & $\begin{array}{l}\text { 4. Learn } \\
\text { Visualizing and } \\
\text { interpreting } \\
\text { results }\end{array}$ \\
\hline
\end{tabular}

Figure 1. Analysis steps

As a first step to interpret the data as a quality rating, it was important to gain insight into what the conversations were truly about. Therefore, first, the interviews were transcribed verbatim by three members of the research team and read multiple times. Second, all 72 transcripts (24 triads) were coded with two codes: positive or negative. Coding was performed by one researcher and checked by another researcher. When disagreements occurred, a third researcher was consulted and coding was discussed until consensus was reached. Only pieces of text that were dependent on the process of care service delivery and the environment of the nursing home with a clear valence expressing a positive or negative experience were coded (hereafter called segments). For example, "I like the food here" or "the resident enjoys family visits" were coded as positive, as these aspects were made 
possible by the nursing home and the words like and enjoy express a positive valence. Descriptions of the relationship between the resident and family, such as "I have a good relationship with my daughter" or about the who the resident is "She is lucky she can still walk and is not in a wheelchair" were not coded, because these are not directly related to the service delivered by the nursing home. In addition, neutral segments without a valence expressing if someone was positive (satisfied) or negative (dissatisfied) were not coded, such as "I get showered twice a week". To validate the coding with positive and negative segments, for 6 triads (25\%) the researchers determined if the transcripts were overall considered positive or negative as a comparison to the coding. The research team also explored how to translate the ratio of positive/negative valences into a valence score, defined as a score ranging from a transcript being very negative to very positive, based on the amount of coded segments. Third, the research team explored possibilities to determine a level of agreement between the resident, family and nursing staff. Agreement was defined as the coherence between individual resident-family-nursing staff triads, dependent on the positive or negative valence score. Agreement did not take into consideration the content of each transcript, thus only the agreement between being negative or positive. As a final step, possibilities to visualize the analyzed data for interpretation and learning purposes were explored. Qualitative analyses were performed with the software package for qualitative data analysis MAXQDA v20.0.8 and quantitative data analysis were performed in MS Excel v2016. ${ }^{25,26}$

\section{Ethical considerations}

The Medical Ethics Committee of Zuyderland (17-N-86) approved the study protocol. Participants received information about the purpose of the study at least two weeks before the interview and submitted written informed consent. Participants could withdraw their voluntary participation at any moment. For residents living on psychogeriatric wards, the legal representative provided informed consent for their participation and during the interviews residents provided informed assent. To guarantee confidentiality of the interviews, no names or locations were documented.

\section{RESULTS}

In total, 24 triads were included for analysis, in 8 nursing homes, of which 8 psychogeriatric wards, 4 somatic wards and 1 acquired brain injury ward (Table 1 ). 
Table 1. Demographics care triads

\begin{tabular}{|c|c|c|c|}
\hline \multirow{5}{*}{ Resident $(\mathrm{N}=24)$} & \multicolumn{2}{|l|}{ Mean age in years $(\min -m a x)^{a}$} & $80(43-95)$ \\
\hline & \multicolumn{2}{|l|}{ Female (\%) } & $17(71 \%)$ \\
\hline & \multicolumn{2}{|c|}{ Mean months in nursing home $(\min -\max )^{\mathrm{b}}$} & $31(2-180)$ \\
\hline & \multicolumn{2}{|c|}{ Mean ADL (min-max) } & $3.1(0-6)$ \\
\hline & \multicolumn{2}{|l|}{ Mean CPS (min-max) } & $2.9(0-6)$ \\
\hline \multirow[t]{10}{*}{ Family $(\mathrm{N}=24)$} & \multirow[t]{3}{*}{ Age in years $(\%)^{b}$} & $45-54$ & $5(23 \%)$ \\
\hline & & $55-64$ & $11(50 \%)$ \\
\hline & & $\geq 65$ & $6(27 \%)$ \\
\hline & \multicolumn{2}{|l|}{ Female (\%) } & $16(67 \%)$ \\
\hline & \multicolumn{2}{|c|}{ Relationship to resident (\%) Child } & $16(67 \%)$ \\
\hline & & Parent & $3(12 \%)$ \\
\hline & & Partner & $2(8 \%)$ \\
\hline & & Niece & $2(8 \%)$ \\
\hline & & Sibling & $1(4 \%)$ \\
\hline & \multicolumn{2}{|c|}{ Mean employment hr/wk (min-max)c } & $11.5(0-40)$ \\
\hline \multirow{4}{*}{$\begin{array}{l}\text { Caregiver, } \\
\text { professional } \\
(\mathrm{N}=18)^{*}\end{array}$} & \multicolumn{2}{|l|}{ Mean age in years (min-max) } & $40(24-62)$ \\
\hline & \multicolumn{2}{|l|}{$\%$ Female } & $17(94 \%)$ \\
\hline & \multicolumn{2}{|c|}{ Mean employment hrs/wk (min-max) } & $29(24-36)$ \\
\hline & \multicolumn{2}{|c|}{ Mean years working in nursing home $(\min -\max )^{\mathrm{d}}$} & $12(1-31)$ \\
\hline
\end{tabular}

${ }^{\text {a }} \mathrm{N}=21,{ }^{\mathrm{b}} \mathrm{N}=22,{ }^{\mathrm{c}} \mathrm{N}=20,{ }^{\mathrm{d}} \mathrm{N}=17,{ }^{*}$ several caregivers were interviewed for multiple care triads

\section{Narratives collected with Connecting Conversations (listen)}

In each conversation, there were emotional and/or judgement words used, suggesting that care experiences are indeed expressed with positive and/or negative loaded words. In addition, similarities and/or differences between the valences of residents, families and staffs were recognized. To portray a better understanding of this, segments from four triads, which are each very different, are presented.

For care triad $\mathrm{C}$, there is clearly space for improvement. The resident misses home and believes the caregivers could gossip less and provide more gentle care. Her son experiences even more troubles with the caregivers and their communication. The caregiver does experience gratitude from the resident, however also experiences a challenging relationship with the resident's son.

"You can't do anything and here you sit in your chair and must stay seated. Every time you have to ask, can you do this for me? That is the worst." Resident (negative)

"The caregivers often do not know [if mum attended the activities], because the volunteer arranges that. And that is...the communication is sometimes...if something happened you will not hear of it." Son (negative)

"Family always wants to communicate with someone from management, while I really want to be there for their mum...I have actually never been part of all the conversations and I think that is a shame. I always ask why I 
am not invited and never get to hear anything about it [the conversations] or only later" Nurse (negative)

For care triad $F$, the resident wanted more attention, recognized by each actor. This triad portrays a clear discrepancy in the resident's needs and expectations versus what the caregiver believes they can offer with their available resources; and a daughter who is quite positive.

"And if I need them [the nurses] for something, I call and then they come somewhere next week...they are busy." Resident (negative)

"My contact with the caregivers is good. If they need me, they know where to find me. And if I need them, I will speak to them" Daughter (positive)

"If you are busy with the medication round in the morning, she will already be standing in the hallway. And then she actually expects you to come directly to her. And when we tell her we will first do our rounds, because otherwise we may make mistake with the medicines, then she gets angry." Nurse (negative)

Care triad $\mathrm{O}$ shows all actors touched upon the topic of dissatisfaction regarding the resident's participation in activities. On the one hand the resident wanted to be more active and on the other the resident did not want to participate when being offered the opportunity.

"Sometimes they take me to activities and sometimes they don't, because I fall asleep quickly... and it's a shame that they then don't wake me up [to join in]." Resident (negative)

"And you know we also had to force him a little bit to participate in the activities that are here. Because he is also quickly the type to say, no never mind. And we did not want to have that because he soon will be lonely." Niece (negative)

"He always says that he wants more activities and more physiotherapy, but when we ask him for things, he doesn't want to participate at all. But he always complains about this." Nurse (negative)

To the contrary, in care triad $\mathrm{V}$ all three actors were very positive about the nursing home in general. 
"Yes, I like to live here and I like to be here... it also gives me some security." Resident (positive)

"Because she is happy with her life at the moment. She likes to be here. She has some aches and pains, but overall, I'm happy for her to be here right now." Daughter (positive)

"From day one she felt like I feel at home and I don't want to go back." Nurse (positive)

\section{Valence scores for care triads (look)}

To gain understanding of how to interpret the transcripts, each transcript was coded with positive and negative coded segments and these codes were transferred into a valence score. First, the total number of positive coded segments was calculated as a percentage of the total number of negative + positive coded segments for each transcript, resulting in a socalled \%-positive per transcript. Second, to validate this scoring system, for 6 care triads these \%-positives were compared to the interpretation if a transcript was considered positive or negative according to the researchers. This showed a minimum of 5 coded segments was deemed necessary to determine a legit \%-positive that reflected the actual information from the transcript. Third, the valence score was calculated to reflect the mean \%-positive of the three actors in the care triad. This valence score was categorized as $0-25 \%$ (very negative), 26-50\% (quite negative), 51-75\% (quite positive) and 76-100\% (very positive). The results are presented in Table 2.

Table 2. Valence and agreement score for each triad

\begin{tabular}{lllllllll}
\hline \hline $\begin{array}{l}\text { Care } \\
\text { triad }\end{array}$ & $\begin{array}{l}\text { Resident } \\
\text { \%-pos }\end{array}$ & $\begin{array}{l}\text { Family } \\
\text { \%-pos }\end{array}$ & $\begin{array}{l}\text { Nursing } \\
\text { \%-pos }\end{array}$ & staff & Mean \%-positive score & Agreement score \\
\hline \hline A & $54 \%$ & $69 \%$ & $80 \%$ & $71 \%$ & Quite positive & 14 & Very low \\
\hline B & $71 \%$ & $87 \%$ & $91 \%$ & $83 \%$ & Very positive & 81 & Very high \\
\hline C & $20 \%$ & $42 \%$ & $56 \%$ & $44 \%$ & Quite negative & 11 & Very low \\
\hline D & $76 \%$ & $46 \%$ & $56 \%$ & $59 \%$ & Quite positive & 40 & Quite low \\
\hline E & $100 \%$ & $75 \%$ & $100 \%$ & $90 \%$ & Very positive & 75 & Very high \\
\hline F & $0 \%$ & $56 \%$ & $25 \%$ & $28 \%$ & Quite negative & 25 & Quite low \\
\hline G & n/a & $91 \%$ & $88 \%$ & $n / a$ & & n/a & \\
\hline H & n/a & $58 \%$ & $90 \%$ & $n / a$ & & n/a & \\
\hline I & $100 \%$ & $69 \%$ & $53 \%$ & $72 \%$ & Quite positive & 9 & Very low \\
\hline J & $46 \%$ & $80 \%$ & $75 \%$ & $68 \%$ & Quite positive & 45 & Quite low \\
\hline K & $50 \%$ & $100 \%$ & $64 \%$ & $72 \%$ & Quite positive & 36 & Quite low \\
\hline L & $50 \%$ & $43 \%$ & $69 \%$ & $53 \%$ & Quite positive & 68 & Quite high
\end{tabular}




\begin{tabular}{llllllll}
$\mathrm{M}$ & $\mathrm{n} / \mathrm{a}$ & $88 \%$ & $69 \%$ & $\mathrm{n} / \mathrm{a}$ & & $\mathrm{n} / \mathrm{a}$ & \\
\hline $\mathrm{N}$ & $90 \%$ & $100 \%$ & $81 \%$ & $89 \%$ & Very positive & 81 & Very high \\
\hline $\mathrm{O}$ & $47 \%$ & $40 \%$ & $40 \%$ & $42 \%$ & Quite negative & 93 & Very high \\
\hline $\mathrm{P}$ & $67 \%$ & $41 \%$ & $71 \%$ & $53 \%$ & Quite positive & 70 & Quite high \\
\hline $\mathrm{Q}$ & $80 \%$ & $56 \%$ & $69 \%$ & $67 \%$ & Quite positive & 76 & Very high \\
\hline $\mathrm{R}$ & $50 \%$ & $33 \%$ & $70 \%$ & $57 \%$ & Quite positive & 58 & Quite high \\
\hline $\mathrm{S}$ & $41 \%$ & $50 \%$ & $67 \%$ & $51 \%$ & Quite negative & 75 & Very high \\
\hline $\mathrm{T}$ & $30 \%$ & $90 \%$ & $75 \%$ & $64 \%$ & Quite positive & 35 & Quite low \\
\hline $\mathrm{U}$ & $100 \%$ & $100 \%$ & $92 \%$ & $97 \%$ & Very positive & 92 & Very high \\
\hline $\mathrm{V}$ & $100 \%$ & $82 \%$ & $100 \%$ & $92 \%$ & Very positive & 82 & Very high \\
\hline $\mathrm{W}$ & $57 \%$ & $46 \%$ & $72 \%$ & $61 \%$ & Quite positive & 64 & Quite high \\
\hline $\mathrm{X}$ & $38 \%$ & $38 \%$ & $65 \%$ & $50 \%$ & Quite negative & 24 & Very low \\
\hline
\end{tabular}

n/a: less than 5 segments coded as positive/negative and therefore insufficient to calculate \%positive

\section{Agreement scores for care triads (link)}

To gain understanding of how the resident, family and nursing staff transcripts relate to each other, the \%-positives were used as the basis for determining a level of agreement (agreement score) between the three actors. In a preliminary version, this score was calculated without making a distinction between the importance of the three actors. However, when presenting this intermittent version to the panel of experts, they determined that the resident's perspective should weigh heavier than the families', and that the lowest level of agreement is when the nursing staffs' views (the service providers) differ from the residents' (the service receivers). The reason for this is that nursing staff and residents have a continuous relationship in the nursing home founded on providing and receiving care, whereas family has a supportive role in this service encounter. This resulted in the calculation of an agreement score based on the mean \%-positive, with a hierarchy of combinations between actors as presented in Table 3 . The starting point was that a difference of $\leq 25 \%$ positive between actors was considered a high level of agreement, and a difference of $>25 \%$ positive between actors was considered as disagreement. The agreement level is selected based on the largest \%-positive difference between two actors. This resulted in four categories: 1) resident \& caregiver \& family agree (very high agreement level), 2) caregiver \& family disagree (quite high agreement level); 3) resident \& family disagree (quite low agreement level); and 4) resident \& caregiver disagree (very low agreement level). For all care triads, the agreement scores are presented in Table 2. 
Table 3. Calculation and interpretation of agreement level and scores

\begin{tabular}{lll}
\hline \hline Agreement level & Agreement outcome & Agreement score \\
\hline \hline Very high & $\begin{array}{l}\text { Resident-family-staff agree } \\
(\Delta \% \text {-pos } \leq 25 \%)\end{array}$ & $100-$ (largest $\Delta \%$-pos) \\
\hline Quite high & $\begin{array}{l}\text { Caregiver and family disagree most } \\
(\Delta \% \text {-pos }>25 \%)\end{array}$ & $75-$ (smallest $\Delta \%$-pos) \\
\hline Quite low & $\begin{array}{l}\text { Resident and family disagree most } \\
(\Delta \% \text {-pos }>25 \%)\end{array}$ & $50-$ (smallest $\Delta \%$-pos $)$ \\
\hline Very low & $\begin{array}{l}\text { Resident and caregiver disagree most } \\
(\Delta \% \text {-pos }>25 \%)\end{array}$ & $25-$ (smallest $\Delta \%$-pos) \\
\hline \hline
\end{tabular}

\section{Combination of valence and agreement scores for care triads (learn)}

The valence and agreement scores allowed for a visual representation in a graph. Figure 2 present the valence and agreement scores of 21 out of the 24 triads plotted into a graph. The $x$-axis presents the agreement level (from very low to very high) and the $y$-axis the valence (from very negative to very positive). Triads $G, H, M$ had insufficient data from the resident to calculate a \%-positive and have therefore not been plotted. The graph can be divided into 8 sections, which can help to interpret the placement of triads in the graph as presented in Figure 3. The positioning of a triad in the graph reflects the narrative data from the Connecting Conversations. For example, the positive triad $V$ is plotted in the right top of the graph, whereas the negative triad $\mathrm{O}$ is plotted in the right bottom. Figure 4 provides an example for the listen-look-link-learn steps for care triad 4. 


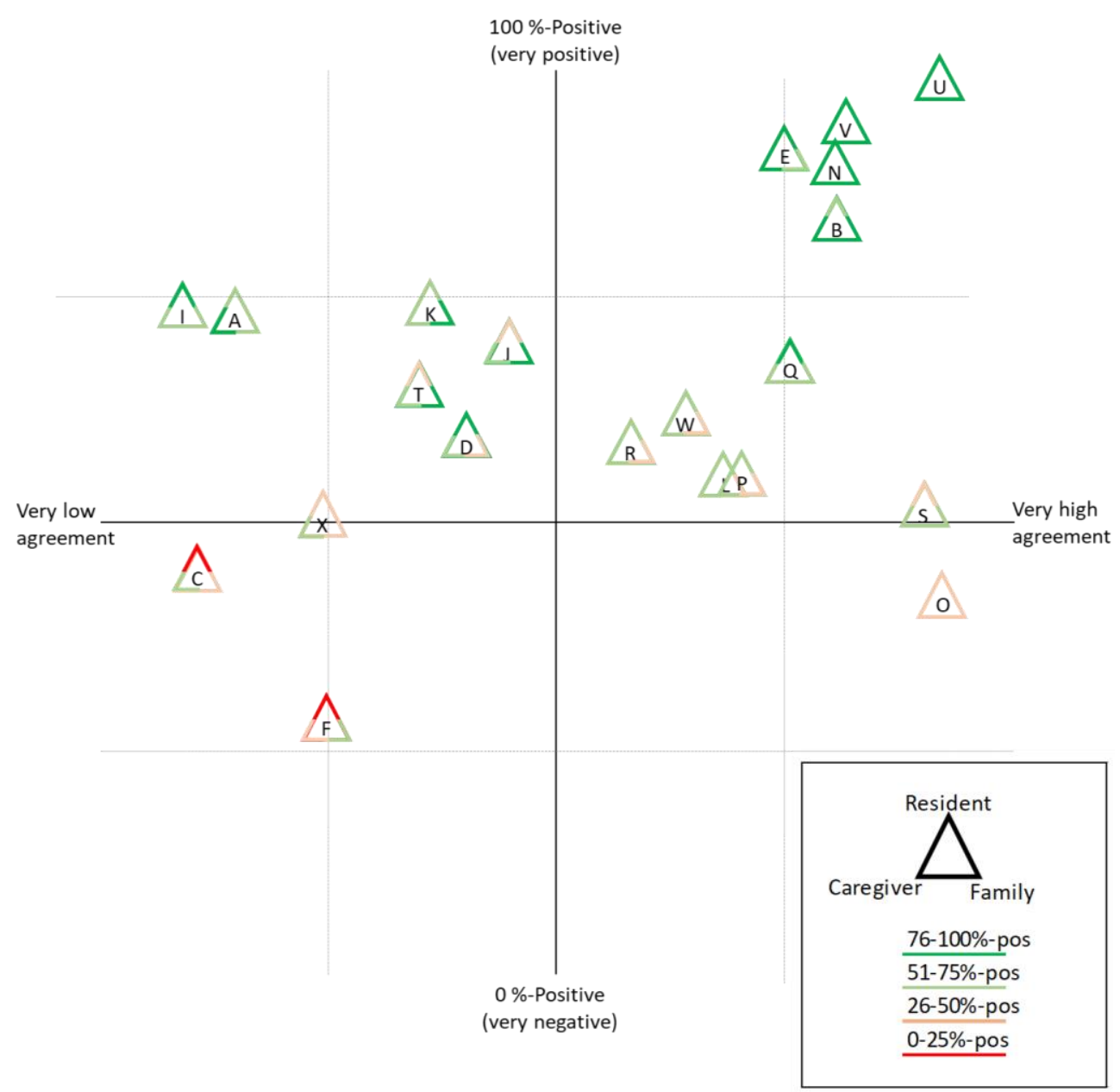

Figure 2. Quadrant-graph of agreement and valence scores for each triad 


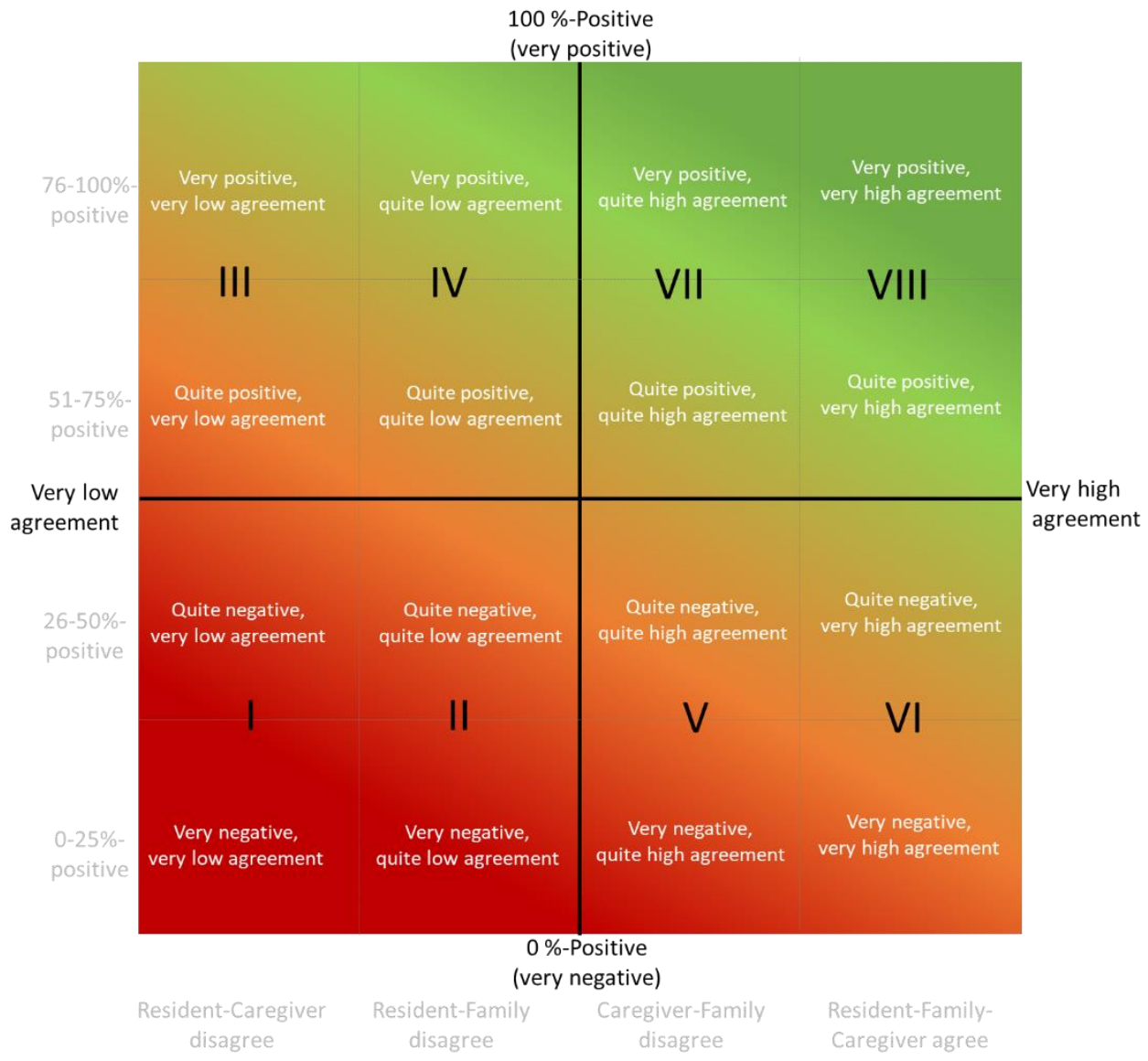

Figure 3. Interpretation of agreement and valence scores

\begin{tabular}{|c|c|c|c|}
\hline 1. Listen & 2. Look & 3. Link & 4. Learn \\
\hline $\begin{array}{l}\text { Resident wants more } \\
\text { attention (negative) }\end{array}$ & $\begin{array}{l}\text { Valence } \\
\text { score: }\end{array}$ & $\begin{array}{l}\text { Agreement } \\
\text { score: } 14\end{array}$ & \\
\hline Family is satisfied (positive) & $28 \%$ & Very low & \\
\hline $\begin{array}{l}\text { Caregiver experiences resident } \\
\text { as demanding (negative) }\end{array}$ & $\begin{array}{l}\text { Quite } \\
\text { negative }\end{array}$ & & $\begin{array}{l}\text { Quadrant I: } \\
\text { Quite negative } \\
\text { Very low }\end{array}$ \\
\hline
\end{tabular}

Figure 4. An example of how to use narrative Connecting Conversations data (care triad F) 


\section{DISCUSSION}

The aim of this study was to introduce an approach that enables the analysis of narrative data collected with Connecting Conversations for quality improvements. Results indicate that narrative Connecting Conversations' data (listen) can be quantified into a valence score based on positive/negative segment coding (look), and an agreement score can be deducted from this (link). In addition, these scores can be positioned in a graph portraying the level of agreement between the resident, family and nursing staff (x-axis), and the mean \%-positive of the triad (y-axis). The positioning in the graph can be interpreted into 8 categories ranging from very negative with very low agreement to very positive with very high agreement (learn).

Findings show that narrative data can be used to detect similarities and differences between residents, families and nursing staffs' experienced quality of care. Different actors contribute towards and benefit from creating added value to an experience. ${ }^{27,28}$ Nursing homes strive to create a balance between the resident's, families', staffs' and organizations' needs (balanced centricity), which can also enhance their effectivity and performance. ${ }^{29}$ Nursing staff have expressed their desire to collaborate more to find solutions and implement sustainable improvements, however, undertaking action together with families and residents does not occur automatically. ${ }^{30,31}$ To improve this, a learning climate is needed in which a care organization aims at improvement by stimulating, facilitating and rewarding learning and development. ${ }^{32}$ A successful learning climate positively influences organizational commitment and job satisfaction by providing space for decision-making, initiative and innovation, support and help from management, and support from and teamwork with colleagues. ${ }^{33}$

Our analysis show narrative data collected with Connecting Conversations can be interpreted as a valence and agreement score. One might argue this defeats the purpose of using narrative data, as eventually only a quality rating is plotted in the graph whilst the story behind the rating is considered most meaningful. However, the graph of plotted triads should not be considered the final outcome, but a first impression of how a nursing home is performing. Based on this, a better understanding of the conversations can be achieved. Taking into consideration the desire for a more learning culture, it would be beneficial to provide care teams with the responsibility to reflect on and learn from narrative quality data together with residents and family. This provides care teams with more voice and responsibility in their quality reporting and improvement initiatives, which is a response to a recent Dutch advice pleading for a change in bureaucratic quality reporting. ${ }^{34}$

To support nursing staff to reflect on and learn from narrative quality data together with families and residents on an operational and tactical level, the 4-D cycle of appreciative inquiry can be used as a starting point as portrayed in Figure 5: discover and appreciate what 
is, dream and envision results, design and co-construct, and sustain destiny. ${ }^{35}$ To achieve this, it is recommended to assign a representative group with the responsibility of addressing the $4 D^{\prime}$ s, consisting of nursing staff working on the participating ward, family, and residents living on the ward (hereafter called the quality team). ${ }^{11}$ The members of the quality team are assigned as champions, which could increase the chance of successful quality improvements. ${ }^{36}$ Together the quality team can identify what is going well and what could be improved on the ward based on the Connecting Conversations data. They can do this by first discussing the findings in the graph (discover) and hereafter relating the positioning of the triads to the raw narratives elaborating on these scores (dream). In addition, they are responsible for providing the scores and narrative stories back to the care triads in order for the actors to discuss and align their differences and similarities (design). Especially for care triads with discrepancies between actors, it is recommended to have a meeting together aimed at discovering why there are discrepancies and what needs to be improved. Hereafter, learning objectives are formulated that can be applied in future care provision, focused both on what is going well and defining bite-sized improvement plans, keeping them achievable in the busy care routines (destiny). ${ }^{37}$ On a strategic level, the quality team can report the valence-agreement graph with accompanied improvement plans back to management for transparency and accountability purposes. This operationalization of the 4D framework should be tested in practice.

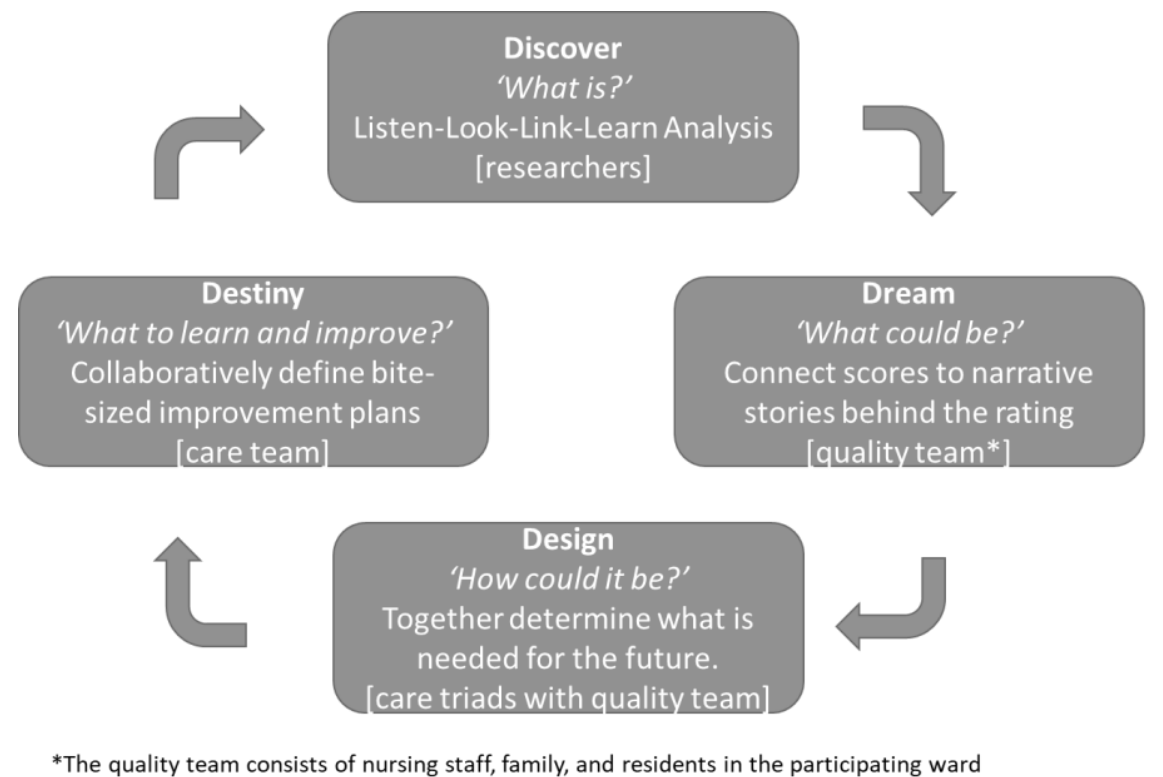

Figure 5. The 4-D cycle to learn from and use narrative quality data for quality improvements

For this study, several methodological considerations need to be addressed First, Connecting Conversations is an assessment method adopting an appreciative inquiry 
(positive) approach. Questions asked are for example "what is the most positive experience in the nursing home?" and not the most negative experience. One might expect this enhances positive results. However, when adopting an appreciative inquiry approach, the negative is also addressed, yet respondents tend to dwell less in this and think more in sustainable opportunities. ${ }^{38}$ Second, the cut-off for \%-positive of $25 \%$ increments was manufactured. Henceforth, a resident with a $49 \%$ positive would be considered quite negative, whereas a resident with $51 \%$ positive would be considered quite positive. Therefore, it is important to no solely look at the \%-positive, but also look at the relative difference in \%-positive between the resident-family-caregiver in the triad. Third, coding \%positive and plotting the graph is a time-consuming process prone to researcher's subjectivity. It is not expected that nursing staff performs the look-listen-link-learn analysis steps. Therefore, it is desirable to explore opportunities to automate this process with for example text-mining and sentiment analysis. ${ }^{39,40}$ In addition, this would allow for more distinction between words used. As now, "it is great" and "it is quite good" are both coded with the same weight of positive, whereas sentiment analysis could correct for intensities of words and word combinations being used, providing a more actual representation of the narratives.

In conclusion, narrative stories collected with Connecting Conversations contain useful information for care triads and teams to reflect on, learn from and improve with. It would be beneficial to embed Connecting Conversations into a total quality management cycle of nursing homes and create a learning climate. Future research should however first focus on testing the use of valence and agreement scores in practice with the 4-D cycle. 


\section{REFERENCES}

1. van Stenis AR, van Wingerden J, Kolkhuis Tanke I. The Changing Role of Health Care Professionals in Nursing Homes: A Systematic Literature Review of a Decade of Change. Frontiers in Psychology. 2017;8(2008).

2. Pew-Fetzer Task Force \& Tresolini CP. Health professions education and relationship-centered care : report: Pew Health Professions Commission, UCSF Center for the Health Professions; 1994.

3. Nolan MR, Davies S, Brown J, Keady J, Nolan J. Beyond person-centred care: a new vision for gerontological nursing. Journal of clinical nursing. 2004;13(3a):45-53.

4. Sion KYJ, Haex R, Verbeek H, Zwakhalen SMG, Odekerken-Schröder G, Schols JMGA, et al. Experienced Quality of Post-Acute and Long-Term Care From the Care Recipient's Perspective-A Conceptual Framework. Journal of the American Medical Directors Association. 2019;20(11):138690.e1.

5. Robertson S, Cooper C, Hoe J, Lord K, Rapaport P, Livingston G. Why do staff and family think differently about quality of life in dementia? A qualitative study exploring perspectives in care homes. Int J Geriatr Psychiatry. 2019;34(12):1784-91.

6. Crespo M, Bernaldo de Quiros M, Gomez MM, Hornillos C. Quality of life of nursing home residents with dementia: a comparison of perspectives of residents, family, and staff. Gerontologist. 2012;52(1):56-65.

7. Sion KYJ, Verbeek H, Zwakhalen SMG, Odekerken-Schröder G, Schols JMGA, Hamers JPH. Themes Related to Experienced Quality of Care in Nursing Homes from the Resident's Perspective: A Systematic Literature Review and Thematic Synthesis. Gerontol Geriatr Med. 2020; [Accepted for publication].

8. Milte R, Ratcliffe J, Chen G, Crotty M. What Characteristics of Nursing Homes Are Most Valued by Consumers? A Discrete Choice Experiment with Residents and Family Members. Value Health. 2018;21(7):843-9.

9. van Zadelhoff E, Verbeek H, Widdershoven G, van Rossum E, Abma T. Good care in group home living for people with dementia. Experiences of residents, family and nursing staff. J Clin Nurs. 2011;20(17-18):2490-500.

10. van Beek AP, Gerritsen DL. The relationship between organizational culture of nursing staff and quality of care for residents with dementia: questionnaire surveys and systematic observations in nursing homes. Int J Nurs Stud. 2010;47(10):1274-82.

11. Adams T, Gardiner P. Communication and interaction within dementia care triads:Developing a theory for relationship-centred care. Dementia. 2005;4(2):185-205.

12. Johnsson A, Wagman P, Boman $\AA$, Pennbrant S. Striving to establish a care relationship-Mission possible or impossible?-Triad encounters between patients, relatives and nurses. Health Expect. 2019;22(6):1304-13.

13. Sangl J, Buchanan J, Cosenza C, Bernard S, Keller S, Mitchell N, et al. The development of a CAHPS instrument for Nursing Home Residents (NHCAHPS). J Aging Soc Policy. 2007;19(2):63-82.

14. Schlesinger M, Grob R, Shaller D, Martino SC, Parker AM, Finucane ML, et al. Taking Patients' Narratives about Clinicians from Anecdote to Science. New England Journal of Medicine. 2015;373(7):675-9.

15. Heliker DM. A Narrative Approach to Quality Care in Long-Term Care Facilities. Journal of Holistic Nursing. 1997;15(1):68-81.

16. Hsu MY, McCormack B. Using narrative inquiry with older people to inform practice and service developments. J Clin Nurs. 2012;21(5-6):841-9. 
17. Finucane ML, Martino SC, Parker AM, Schlesinger M, Grob R, Cerully JL, et al. A framework for conceptualizing how narratives from health-care consumers might improve or impede the use of information about provider quality. Patient Experience Journal. 2018;5(1):15-26.

18. Sion K, Verbeek H, de Vries E, Zwakhalen S, Odekerken-Schröder G, Schols J, et al. The Feasibility of Connecting Conversations: A Narrative Method to Assess Experienced Quality of Care in Nursing Homes from the Resident's Perspective. Int J Environ Res Public Health. 2020;17(14).

19. Cooperrider D, Srivastva S. Appreciative Inquiry in Organizational Life. Research in Organizational Change and Development. 1987;1:129-69.

20. Ubels GM. Narrative accountability and quality awareness: Learning about (re)presenting narrative care. Journal of Aging Studies. 2015;34:190-8.

21. Anderson C. Presenting and evaluating qualitative research. American journal of pharmaceutical education. 2010;74(8):141-.

22. Verbeek H, Zwakhalen SMG, Schols J, Kempen G, Hamers JPH. The Living Lab In Ageing and LongTerm Care: A Sustainable Model for Translational Research Improving Quality of Life, Quality of Care and Quality of Work. J Nutr Health Aging. 2020;24(1):43-7.

23. Gerritsen D, Ooms M, Steverink N, Frijters D, Bezemer D, Ribbe M. [Three new observational scales for use in Dutch nursing homes: scales from the Resident Assessment Instrument for Activities of Daily Living, cognition and depression]. Tijdschr Gerontol Geriatr. 2004;35(2):55-64.

24. Sim J, Sharp K. A critical appraisal of the role of triangulation in nursing research. Int J Nurs Stud. 1998;35(1-2):23-31.

25. MAXQDA, software for qualitative data analysis. Berlin: VERBI Software - Consult - Sozialforschung $\mathrm{GmbH} ; 1989-2020$.

26. Microsoft Corporation. Microsoft Excel. . 2016.

27. Čaić M, Odekerken-Schröder G, Mahr D. Service robots: value co-creation and co-destruction in elderly care networks. Journal of Service Management. 2018;29(2):178-205.

28. Odekerken-Schröder G. Are you being Served? Maastricht: Maastricht University; 2011.

29. Hillebrand B, Driessen PH, Koll O. Stakeholder marketing: Theoretical foundations and required capabilities. Journal of the Academy of Marketing Science. 2015;43(4):411-28.

30. Haesler E, Bauer M, Nay R. Recent evidence on the development and maintenance of constructive staff-family relationships in the care of older people--a report on a systematic review update. Int J Evid Based Healthc. 2010;8(2):45-74.

31. Verbeek H. Inclusion and Support of Family Members in Nursing Homes. In: Schüssler S, Lohrmann C, editors. Dementia in Nursing Homes. Cham: Springer International Publishing; 2017. p. 67-76.

32. Nikolova I, Van Ruysseveldt J, De Witte H, Van Dam K. Learning climate scale: Construction, reliability and initial validity evidence. Journal of Vocational Behavior. 2014;85(3):258-65.

33. Kyndt E, Dochy F. Antecedenten van een succesvolle organisatieontwikkeling en hun relatie met het leerklimaat van de organisatie: Een mixed method studie. Gedrag en Organisatie. 2013;26(4):357-78.

34. Raad Volksgezondheid en Samenleving. Blijk van vertrouwen: anders verantwoorden van goede zorg. Den Haag: Raad voor Volksgezondheid en Samenleving, , 2019.

35. Cooperrider DL, Whitney DK, Stavros JM. Appreciative Inquiry Handbook: Lakeshore Communications; 2003.

36. Woo K, Milworm G, Dowding D. Characteristics of quality improvement champions in nursing homes: A systematic review with implications for evidence-based practice. Worldviews on Evidence-Based Nursing. 2017;14(6):440-6. 
37. Mills WL, Pimentel CB, Palmer JA, Snow AL, Wewiorski NJ, Allen RS, et al. Applying a theory-driven framework to guide quality improvement efforts in nursing homes: The LOCK model. Gerontologist. 2018;58(3):598-605.

38. Bushe G. Appreciative inquiry is not about the positive. OD practitioner. 2007;39(4):33-8.

39. Mohammad SM, Turney PD. Crowdsourcing a word-emotion association lexicon. Computational Intelligence. 2013;29(3):436-65.

40. Usai A, Pironti M, Mital M, Mejri CA. Knowledge discovery out of text data: a systematic review via text mining. Journal of Knowledge Management. 2018. 



\section{CHAPTER 8}

General Discussion 
The aim of this dissertation was to develop a method to assess quality of care in nursing homes from the resident's perspective. The steps undertaken to develop this assessment method were based on the five steps to develop a measurement instrument: defining the construct, development of items and response options, pilot-testing, field-testing, and evaluation of measurement properties. ${ }^{1,2}$ More specifically, this dissertation consisted of three parts. Part 1 (chapters 2 to 4 ) aimed to identify what to assess, how to assess this and by whom this should be done (defining the construct, and item and response options). Part 2 (chapter 5) used this information to develop the narrative assessment method 'Connecting Conversations' and test its feasibility (pilot-testing and field-testing). Part 3 (chapters 6 and 7) aimed to test and evaluate Connecting Conversations regarding its validity and value (evaluation). In this final chapter, the main findings of the research in this dissertation are discussed, a reflection on the methodological and theoretical considerations is provided, and recommendations for future practice and research are formulated.

\section{MAIN FINDINGS}

This dissertation resulted in two main results: a new definition of experienced quality of longterm care and an innovative narrative method to assess experienced quality of care in nursing homes.

We created an interdisciplinary, innovative framework defining quality of care from the resident's perspective. The Individually Experienced Quality of Post-Acute and Long-Term Care (INDEXQUAL) framework portrays experienced quality of care as a process within a context consisting of expectations before the care experience, interactions during, and an assessment of the care experience afterwards in terms of what happened and how it happened (perceived care services), how this influenced the resident's health status (perceived care outcomes) and how this made someone feel (satisfaction). This definition adopts the relationship-centred care view and enhances the importance of including residents, their family and their professional caregivers (care triads), as their interactions directly influence the care experience. Residents consider maintaining their personhood, social engagement and the nursing home environment important aspects contributing towards their experienced quality of care.

Based on the INDEXQUAL framework, we developed the feasible, valid and valuable method Connecting Conversations in co-creation with residents and their representatives, nursing staff, policy-makers and national stakeholders. Connecting Conversations is a narrative method that assesses experienced quality of care in nursing homes from the resident's perspective by conducting separate conversations with a resident, family member and professional caregiver of that resident. Key elements of the method are that it assesses experienced quality of care as defined in the INDEXQUAL framework; it includes the residentfamily-caregiver care triad (relationship-centred care); it adopts a positive appreciative inquiry approach, and it creates a learning network for nursing home staff (interviewers 
perform conversations in each other's care organisations). Additionally, a supportive app for tablets has been developed, in which conversations can be documented (text and audio) and viewed. In two rounds of field-testing, 275 conversations were performed by 35 trained interviewers. Findings revealed the conversations indeed cover the elements of experienced quality of care (content validity) and it is feasible to perform Connecting Conversations in nursing homes within the learning network. The principles that Connecting Conversations is based on are presented in Figure 1.

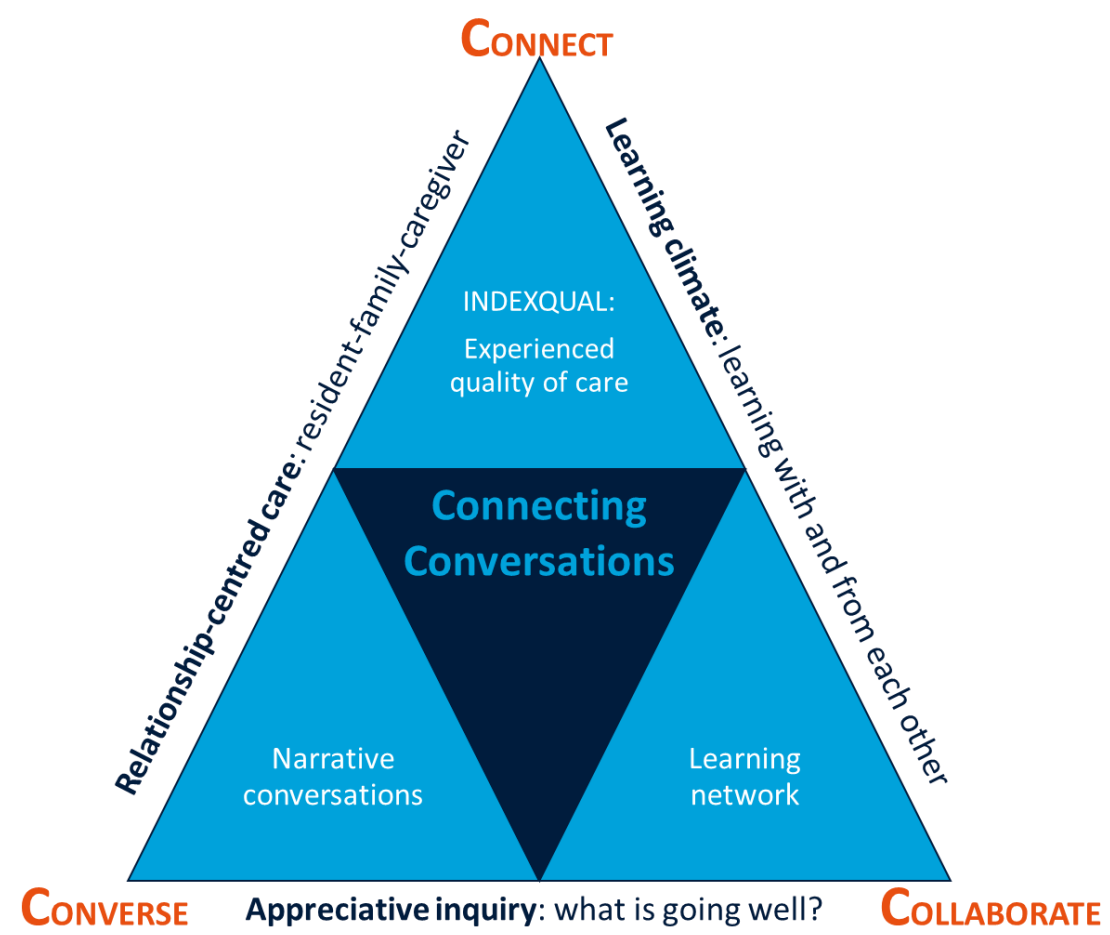

Figure 1. 'Connecting Conversations: in the nursing home everybody matters'

\section{METHODOLOGICAL CONSIDERATIONS}

Whereas each separate chapter has reflected on specific strengths and limitations of each study, this section will reflect on the overall methodological considerations of this dissertation, regarding the study population, innovative forms of study design and data collection, and the evaluation of reliability and validity.

\section{Study population}

For Connecting Conversations, the decision was made to focus on the actors in the care triad: resident-family-caregiver. By selecting the three actors in the care triad - which are also the starting point of relationship-centred care - a full view on experienced quality of care was 
believed to be captured whilst remaining feasible. Our findings showed that the inclusion of three perspectives was deemed suitable to capture the core of experienced quality of care as found in the validity study. Stories could partially be validated by comparing the stories from residents, their families and caregivers to each other, known as data triangulation. ${ }^{3}$ In addition, findings confirmed that actors can experience the same care event quite differently. The residents themselves portray who they are, what they experience and what they desire. Family can contribute by placing the stories into the context of who the resident used to be prior to living in the nursing home and what they experience themselves, and the caregiver sees the resident on a regular base whilst living in the nursing home. However, the resident's network does go far beyond the care triad, including amongst others volunteers, other medical staff, and supportive staff working in the nursing home. Future studies could consider including other actors beyond the direct actors in the care triad for robustness checks of the findings.

Findings in the studies of this dissertation included a wide variety of residents. The risk of selection bias of care triads was decreased by generating a random sequence list of residents who were invited to participate on a ward. The contact person of the ward was responsible for inviting residents to participate. There is a small chance that the contact person, subconsciously or not, influenced residents' decision to participate in the conversation, because for example a resident has challenges to verbally communicate or is known to be extremely negative. Therefore it is important to provide the contact person with clear instructions and emphasize that all residents are equally relevant.

An inclusive approach was adopted when testing Connecting Conversations and all residents were included in the random selection. No distinction was made between residents living in psychogeriatric wards with lesser cognitive functioning or in somatic wards with lesser physical functioning. Regardless of their health status, a conversation was attempted with all randomly selected residents. This was considered very important, as residents living in nursing homes are often too quickly excluded from studies when they have been diagnosed with a certain degree of dementia or other cognitive declines. ${ }^{4-7}$ Residents' inclusion can be further enhanced by applying creatives techniques, as this can contribute towards decreasing inequalities in relationships between people with dementia and others, and it allows for a better understanding of their experiences and views. ${ }^{8}$ This could further enhance the feasibility and validity of their quality assessments. ${ }^{8-10}$

\section{Study design and data collection}

Our research focused on developing a qualitative method for quality assessments, because a qualitative approach is deemed most suitable when wanting to gain a better and in-depth understanding of a phenomenon (experienced quality of care) and it empowers individuals. ${ }^{12}$ Whereas there is a group of researchers that believes the development of a qualitative method (e.g. interviews) fundamentally differs from the development of a quantitative 
method (e.g. surveys), we have discovered the development is quite similar. For both it is important to define the construct to be measured, develop item and response options, pilotand field test, and evaluate the measurement properties. Therefore, to develop this narrative assessment method, the five steps to develop a measurement instrument by De Vet, $2011^{1}$ were used. These steps are mostly used to develop quantitative instruments, and to our knowledge have not often been applied to develop a narrative assessment method. For narrative research it is more common to use qualitative frameworks, however this dissertation shows the five steps are a suitable alternative when wanting to develop a qualitative assessment method. ${ }^{3}$

The studies in this dissertation combined views from multiple experts and disciplines, including health sciences, service sciences, gerontology, psychology, and information technology. This interdisciplinary approach was deemed indispensable for the major societal issue under study and has resulted in a significant contribution to scientific innovation, indepth and broader knowledge in individual disciplines, and new cross-disciplinary knowledge. ${ }^{13}$ This approach was supported by adopting different creative techniques to collect data such as the world café method, the use of photo elicitation and appreciative inquiry. The use of innovate methods to collect data enhanced the richness of the data, as participants were triggered to think beyond the surface. ${ }^{14-16}$ Main stakeholders' views were incorporated throughout the research by means of co-creation of the assessment method, which resulted in an assessment method that is widely accepted by its stakeholders, as it is aligned to their needs.

A challenge when assessing experienced quality of care is that there is always the risk of receiving socially desirable answers, because people living in nursing homes are in a care dependent position and residents' families rely on the care that residents receive. One may not dare to be fully honest about the experienced quality of care, especially when negative, as they may fear for repercussions in the delivered care. For Connecting Conversations, social desirability was minimized in two ways: (1) the interviewer was not employed in the care organization and was henceforth considered neutral, and (2) every participant was asked if the stories could be reported back to the nursing home retraceable to them as individuals, or only anonymously on a ward level. Furthermore, residents' physical and cognitive capabilities can hinder correct answering of the questions, due to misunderstanding of questions or incorrectly remembering past experiences. ${ }^{17,18}$ For residents, a lower feasibility of the method was detected in some cases compared to families and caregivers. However, perhaps it should not necessarily be about the facts they share, but the emotions accompanying their stories.

In addition, an innovative component and strength of Connecting Conversations is that nursing home staff is expected to take ownership when collecting the data. This enhances its usability in practice. Several steps were undertaken to decrease the risk of bias accompanied 
by this approach. Firstly, the risk of interviewer bias was decreased by providing staff members nine hours of interviewer training. Our feasibility findings confirm most interviewers were sufficiently skilled after the training, however this was not the case for all, as interviewing remains a skill that not everyone is equally good at. ${ }^{19}$ Intermittent feedback on conversations might help interviewers continue improving their skills after the training. Secondly, the risk for reporting bias was decreased by not just summarising, but also audiorecording all conversations with the app. This allowed the performed analyses in this dissertation to be based on transcripts instead of summaries. Future research should explore the reliability of the documented answers. Whereas many attempts were undertaken to decrease the aforementioned risks of bias, one might argue they could be decreased even further by using professional interviewers. The added value of the learning network however outweighs this by far, because it provides staff the opportunity to learn from and with each other and provides nursing homes themselves with the responsibility of collecting quality of care data, instead of an external company.

\section{Evaluation of reliability and validity}

The five steps to develop a measurement instrument which was used to ensure Connecting Conversations is of high quality, recommends evaluating measurement properties, known as reliability (is it free from measurement error?) and validity (does it measure the construct it purports to measure?) in quantitative research..$^{1,20}$ It is uncommon for qualitative research to evaluate reliability and validity, as evaluations usually focus on the four key components of trustworthiness: credibility, transferability, dependability and conformability. ${ }^{3}$ The research in this dissertation introduced how the more traditional concepts of reliability and validity (face, content and construct) can be used. ${ }^{20}$ This is in line with our approach that quantitative and qualitative instrument development are similar in many aspects. These findings have contributed to the credibility of the quality of care data, which are being used in daily practice. However, two main challenges should be addressed.

The first challenge was that reliability analyses are usually focused on the outcome of the assessment method in terms of consistency, stability and repeatability. ${ }^{1}$ For quantitative assessment methods, it is more straightforward to obtain similar outcomes, as these are numerical. For qualitative assessment methods it is more demanding and difficult to achieve similar outcomes, as the data are in a subjective and narrative form. ${ }^{21}$ The research team had multiple discussions about performing duplicate interviews and comparing these with an agreement analysis, as was done for the analysis of the narrative data (two coders). Eventually, the decision was made to not do this, for two main reasons. First, the interviewers were nursing staff member who performed the interviews during working hours within the learning network. Each hour spent on the conversations, could not be spent performing care duties. Therefore, in collaboration with stakeholders, it was considered unreasonable to ask interviewers to perform double the amount of work in these times of staff shortages and 
high workload, outweighing the benefits of the analysis. Alternatively, it was considered to have a researcher perform a duplicate conversation, however this was still considered too demanding to ask from the participants in the care triads. Second, as the conversations are of a qualitative nature, it is not as straightforward to calculate a \%-agreement for both conversations. It is expected that no two conversations are going to be the exact same, however a similar rating of quality is expected. This requires the development of a new type of formula to determine an agreement score, going beyond the scope of this dissertation.

The second challenge was that for validity analysis, quantitative statistical analyses are most commonly performed. As no numerical data were available for Connecting Conversations, content and construct validity required new forms of analyses. For content analysis, the themes from the INDEXQUAL framework were used to code the data collected with Connecting Conversations. Connecting Conversations was developed based on this framework, however the six broad-ended questions do not explicitly ask about each INDEXQUAL theme to enhance space for the respondents to share their stories. For construct analysis, the qualitative data collected with Connecting Conversations were translated into numerical values (\%-positive). Whereas findings show this was deemed a promising approach, it is challenging to determine which positive and negative words to count. The power of providing people with a limitless amount of words to share their stories, also means that not all words reflect the construct being measured. For example, a resident may talk a significant amount of the conversation about how upsetting his childhood was. The numerous amounts of negative words used in the conversation, may bias the \%-positive reflecting a poor result for the nursing home, whereas these words are not related to the care provided in the nursing home. Therefore, it is important to remain critical when interpreting narrative data and positioning words into their context. In addition, some interviewees may use a higher amount of 'valence' words to describe a situation than others would do to describe the same situation. Thus, one needs to be cautious when merely counting positive/negative words, as this might bias the interpretation of the results and the stories behind the quantification need to remain accessible to provide context. This innovative method can however support the interpretation and classification of narrative quality of care data.

\section{THEORETICAL CONSIDERATIONS}

This section will reflect on some theoretical considerations of this dissertation, regarding quality of care, providing high quality of care and using narratives to learn from in practice.

\section{Quality of care}

A strong theoretical foundation is an important prerequisite for any study, as the choice of framework can influence the decisions made and results acquired in any research. In this dissertation, theories from the health sciences and service sciences literature were 
combined. Due to the unique setting of the nursing home, accompanied by a complex customer journey and limited choice, adopting the definition of quality as traditionally used in either health sciences or service sciences were both deemed insufficient. Therefore, this dissertation resulted in the interdisciplinary INDEXQUAL framework founded on the principles of relationship-centred care. INDEXQUAL has defined the concept of quality of care in nursing homes from the resident's perspective as a process consisting of expectations before, interactions during, and an assessment of the experience afterwards within a certain context. This framework provides a new view towards quality of care, as it steps away from standard quality indicators and it allows for the complexity, interactions and continuity that care experiences possess, and that differ for each individual. In addition, whereas the starting point of this dissertation was to approach quality assessments from the resident's perspective, the INDEXQUAL framework denotes that the resident's perspective is not an alone-standing perspective, as it is highly influenced by relationships. This has resulted in a new approach towards quality of care from the resident's perspective, which can be used in research and practice.

Residents, family and professional caregivers consider three main elements that contribute towards high experienced quality of care, of which the content may differ for each individual: (1) value the resident as a person, (2) maintain strong relationships and (3) provide an appropriate nursing home environment. This confirms nursing home practice should go a step beyond person-centred care, and recognise the importance of relationship-centred care and the environment more. In relationship-centered care, residents, family and professional caregivers are each acknowledged, each contribute towards creating added value to an experience, and each benefit from this. ${ }^{22-25}$ These relationships incorporate performing physical work, interacting with each other, and knowing each other, which highly influences how a care encounter is experienced. ${ }^{26}$ In addition, relationships can positively influence residents' psychosocial outcomes and therefore nursing home regulations should enhance opportunities for meaningful relationships. ${ }^{27}$ Now is the time to put this theory into practice. To achieve this, an overarching and interdisciplinary approach is crucial, including all stakeholders and combining insights from health sciences (what is good care?), service sciences (what adds value for residents-families-professional caregivers?), environmental sciences (how can the caring environment enhance quality of care?) and human rights (how can people's rights for autonomy and dignity be enhanced in the nursing home?) amongst others. This will result in a better fit for practice, enhancing each disciplines' strengths and capabilities that are expected to lead to a more sustainable change.

\section{Providing high quality of care: the impact of COVID-19}

The COVID-19 pandemic is a clear example of the need for relationship-centred care. While research and policy have been focused on residents being included in decision-making, care centred on their needs, and making the nursing home feel like a home; the pandemic 
rigorously redirected policy-makers and management to safety and the medical perspective in which the only aim was to protect residents from obtaining the virus. In the Netherlands, and many other countries, this resulted in a full lock down for nursing homes, meaning residents were not allowed to leave their wards or have any visitors. Now almost a year later, research has shown this was not the right decision. Whereas everyone living at home could choose how to cope with the COVID-19 restrictions, in nursing homes neither residents, family or nursing staff got a say in this. ${ }^{29}$ Depriving residents from all social contact has high repercussions and one might argue the risk of getting COVID-19 during social interactions outweighs the negative effects of social isolation. ${ }^{30}$ For family it was upsetting not to be allowed to visit their loved ones in the nursing home, and nursing staff experienced a high work burden, whilst seeing residents suffer. ${ }^{31}$ Nursing staff were continuously confronted with the dilemma of on the one hand adhering to the rules and on the other hand wanting to provide high quality of care. ${ }^{32}$ Whereas there was understanding for abrupt changes and business of nursing staff, not feeling heard and a lack of choice were considered devastating. 32 In addition, there are many alternative options between a full lock down versus no additional safety measures. Visits can be regulated to enhance safety by means of for example a limited number of visitors at a time, mandatory hand hygiene and face coverage, and screening of visitors prior to entry. ${ }^{33}$ It is unrealistic to believe that during a pandemic, all of a sudden a one-size-fits-all approach is suitable. By collaborating with residents, family and nursing staff, safe guidelines can be developed for individuals that balance everyone's needs. This can help achieve a higher experienced quality of care, even in times of crisis. The pandemic confirmed that relationships and people's stories are precisely the core of what is considered important and what truly matters. ${ }^{34}$ This current example counters all the principles that Connecting Conversations is founded on. In line with the research in this dissertation, we preach for the inclusion of residents, family and staff in future life-invading decision-making in nursing homes, to ensure living in the nursing home remains a life worth living.

\section{Using narratives to learn from and improve quality of care}

It is in our human nature to want to compare to others and be the best. ${ }^{34}$ The effect of competition in nursing homes is increasing, due to an increase in transparency of quality assessments (for example Zorgkaart Nederland). ${ }^{35,36}$ Quality assessments are frequently quantified and placed into rankings, to enhance transparency and provide people support when selecting a nursing home. However, rankings don't provide organisations insight into what and how to improve or remain on top. In addition, rankings can be dangerous, as people tend to focus on the ranking (the outcome) instead of on what is actually happening in the nursing home (the process). If a nursing home is focussed on being ranked highest, there is the chance that a distorted image is presented during assessments and success stories are embellished. In a learning culture in which a nursing home is keen to learn and improve, lesser achievements and mistakes are actually used to reflect on and guide improvement 
initiatives. ${ }^{37}$ This raises the question whether it is desirable, and possible, to place a quality rating on narrative data.

Connecting Conversations has shown it is possible to classify narrative data with a valence score (degree to which a conversation is positive) and an agreement score (degree to which the resident-family-caregiver agree or disagree with each other). However, a balance is needed between classifying the narrative data into more easy interpretable results on the one hand and staying close to the rich stories on the other. Combining both may provide a promising foundation for future usability of the method, as this narrative quality of care data can be used to learn from and improve with within a learning climate. Informal learning at the workplace has shown to be more effective for this as opposed to traditional forms of learning, such as schooling. ${ }^{38,39}$ It connects the gap between theory and practice, and allows nursing staff to approach residents as individuals. ${ }^{40,41}$ From a relationship-centred care approach, it is also recommended that nursing staff collaborate more with residents and families, to improve quality of care, even though research has shown it costs much effort to create and maintain these collaborations. ${ }^{42,43}$

Eventually, it should not be a matter of 'ranking as the best', but of being part of a learning climate focused on continuous interacting, reflecting, learning and improving together. To achieve this, support from management is crucial. Managers should stimulate staff to continuously reflect on and develop their competences, include them in organisation-wide decision-making, and provide them space to actively participate in service delivery processes and innovations. ${ }^{44}$ By incorporating these collaborations in a learning climate, personal development and learning are stimulated, facilitated and rewarded; and decision-making and innovations are enhanced. ${ }^{45,46}$

\section{FUTURE DIRECTIONS}

The results of this dissertation have several implications for future practice and research in nursing homes. It would be beneficial for both practice and research to strive towards achieving a shift from nursing homes as person-centred, problem-solving and accountable organizations, towards relationship-centred, generative and learning organizations.

\section{Practice}

Ideally, in the future, nursing homes and other long-term care settings will approach quality of care as a broad concept consisting of experienced quality of care, (medical) safety, and employee satisfaction balanced with financial investments. The principles that Connecting Conversations is based on, can serve as the foundation for this and support long-term care organizations to continuously monitor and improve their quality of care, quality of life and quality of work together with residents, families and staff. To achieve this, we have formulated several recommendations for practice. 
Whereas the nursing home culture is evolving rapidly, there is a need for a further culture change. Policy-makers should stimulate nursing homes to distance themselves from the oneway approach towards residents (person-centeredness), overload of administration, and standardized strictly regulated approach, towards a dynamic culture of balance (relationshipcenteredness), openness and a learning climate. Although the concept of relationshipcentred care has been applied in health care, up to recently person-centred care has prevailed in most nursing homes. ${ }^{24}$ Striving to achieve this so-called balanced centricity between the needs of all involved actors (residents, family and caregivers, but also management and the inspectorate) can contribute to the performance of nursing homes. ${ }^{47}$ More specifically, this means management and policy-makers should support nursing homes to adopt a relationship-centred care approach and to embed conversations with residents, family and caregivers about quality of care in their daily work routines. By adopting an appreciative culture in nursing homes, focus can shift from problem-solving to generativity, aimed at achieving transformational change together. ${ }^{48}$ It is important that a learning climate is in place for this, in which caregivers can openly learn together from and with each other, residents and their families. The foundations of Connecting Conversations can assist with this and help to better understand experienced quality of care.

For educational program directors responsible for the nursing curricula, it would be beneficial to create space in the curriculum on quality of care to introduce the foundations of Connecting Conversations. This will make it easier for future staff to adapt to this new way of working, enhancing the change towards a balanced, interactive, and learning culture. Frequently, nursing education still has the medical knowledge at the core of its education. Based on the principles of Connecting Conversations, it would be beneficial to introduce the concepts of relationship-centred care, appreciative inquiry and the INDEXQUAL framework to student nurses. This foundation can help future nurses to better understand residents' needs and henceforth provide more tailored care, and it shows nurses that their stories and experiences also matter. Teachers will need to undergo a train-the-trainer program, in order to successfully be able to teach these principles to their students. In addition other disciplines, including physicians, paramedical staff and supportive staff, can also be taught the principles of Connecting Conversations and apply these in practice. Thinking beyond the care setting, the principles of Connecting Conversations can also be applied in other settings, for example in education. Students are asked to rate their teachers; however teachers barely get the opportunity to rate the process of their interactions with students, except when officially grading them. By providing time for these appreciative conversations, better understanding between teacher-student relationships can be accomplished, resulting in improved experienced quality of education.

For staff in nursing homes, three recommendations regarding how to approach experienced quality of care in nursing homes emerged from the research in this dissertation. (1) Take time to listen to residents, families and colleagues, without interrupting or prematurely 
finishing other people's sentences. This provides people the space to share their story. The lack of time and staff shortages often compromise in taking the time for conversations, whereas this has shown to contribute towards higher experienced quality of care and work. (2) Focus on what is going well and learn from this. Whatever one focusses on grows and henceforth, it is valuable to also focus on the best in people, nursing homes and their contexts, and to acknowledge and celebrate successes, as this can contribute towards a positive working climate. ${ }^{49,50}$ (3) Learn with and from each other. Create time to collaborate with colleagues within and outside of the care organization, as this will provide valuable insights for daily work practices and can help to become aware of and break through negative routines. In addition, collaborate with residents and their families, as this has shown to enhance mutual understanding and improve tailored care experiences.

In the Netherlands, national developments are occurring that fit the Connecting Conversations' principles of investing time in conversations, involving care triads and adopting a positive approach for quality assessments. A group of national stakeholders and care organizations (Radicale Vernieuwing) has collaborated in the battle against less administration obligations, to create more time that can be invested in the care relationships. ${ }^{51}$ In line with this, a recent report published by the Council for Health and Society (Raad voor Volksgezondheid en Samenleving) advised to provide care providers with more space to take initiatives concerning accountability, allowing them to form learning networks and include the residents and family as well. ${ }^{52}$ To truly achieve these changes, health insurance companies will need to change their criteria for care procurement; the inspectorate will need to continue adjusting their way of evaluating care organizations, and national policy needs to stay close to the principles in the new quality framework and not diverge back towards ratings and rankings.

\section{Research}

The main findings in this dissertation have resulted in the need for further research. First, there has been an ongoing demand from care organisations to further enrol Connecting Conversations and make it nationally available. One of the principles of Connecting Conversations is that care organizations can perform the quality assessments themselves and incorporate them into the regular care routines. As research has shown, many newly developed innovations often do not make it to practice because knowledge is lacking about cost-effective, sustainable implementation processes. ${ }^{53}$ Therefore, the first need is to gain insight into the conditions under which a sustainable national implementation of Connecting Conversations is practically feasible and cost-effective. This includes answering questions such as how to facilitate the learning network; where to provide the training; who will manage the app, randomisation and scheduling of the conversations; who is responsible for reporting back the results; and which investments are needed. The completion of a business case for Connecting Conversations prepared through the business model canvas can help to 
answer these questions and prepare for implementation. ${ }^{54}$ Once national implementation is a success, translation to international settings could also be further explored and established. This would include adaptations to the setting and culture, linguistic translation, and adaptation to the local policies and regulations.

Second, findings show that whereas many residents are capable of having a conversation, there is a need for a complementary method to further enhance inclusion of all residents when assessing experienced quality of care. An adapted conversation protocol should be developed together with residents-family-staff, to simplify questions and enhance their understanding of the questions. This could include the use of visual aids, a photo function in the app and sub-questions simplifying the main questions. Additionally, a complementary observational tool could be an alternative approach to capture the resident's story when he or she is unable to engage in the conversation. Whereas in the past four years some smallscale attempts of observations have been tested, more research is needed to develop a more suitable method of observation which could be introduced into the learning network.

Third, currently it is still challenging to provide narrative quality data back to care organisations in a user-friendly and usable format. More research is needed to determine how Connecting Conversations' data can be best presented back to nursing homes. Considering the learning network, it would be beneficial to experiment if the raw data from Connecting Conversations could be given back to the ward. The care team would receive the responsibility to analyse the results together with residents and family, and in collaboration decide what actions need to be taken. The team would then receive responsibility to present the results to the nursing home board. This urges teams to actively engage in the quality data and learn and improve with this data, enhancing a learning culture, instead of providing standard reports that are often not looked at. In addition, it would be interesting to explore possibilities to enhance automated narrative data analysis. Text-mining and sentiment analysis could contribute to this, however these techniques need to be further developed specifically towards the language used in the Dutch nursing home setting. Additionally, as audio-recordings are available for all conversations, the development of an automated audio-to-word software would save a lot of time in documenting and transcribing the conversations.

Fourth, on a larger scale, more research is needed on how nursing homes can use quality of care data to learn from and improve with. Often quality of care data are merely used for accountability purposes, whereas this information is very valuable to improve care for individual residents as well. Quality of care is a broad concept consisting of experienced quality of care, (medical) safety and employee satisfaction balanced with financial investments. Henceforth, for total quality management, a mixed-method approach is recommended. Future research should explore the possibilities to combine these different outcomes of quality of care to determine a full quality assessment and improvement cycle. 
Eventually, it should not be about the assessments themselves, but how the collected quality of care data are used to enhance high quality of care in nursing homes.

\section{CONCLUSION}

In conclusion, Connecting Conversations is a feasible, valid and valuable narrative method to assess experienced quality of care in nursing homes from the resident's perspective. It has been developed in co-creation with stakeholders in nursing homes and assesses experienced quality of care as defined by the INDEXQUAL framework, by means of narrative conversations within a learning network. By performing resident-family-caregiver conversations, connecting these and collaborating together, in an appreciative form, a promising step towards a more learning climate in nursing homes can be achieved. 


\section{REFERENCES}

1. De Vet HCW, Terwee CB, Mokkink LB, Knol DL. Measurement in Medicine: A Practical Guide. Cambridge: Cambridge University Press; 2011.

2. Altheide DL, Johnson JM. Criteria for assessing interpretive validity in qualitative research. Handbook of qualitative research. Thousand Oaks, CA, US: Sage Publications, Inc; 1994. p. 485-99.

3. Lincoln YS, Guba YSLEG, Guba EG. Naturalistic Inquiry: SAGE Publications; 1985.

4. Chang SJ. Lived Experiences of Nursing Home Residents in Korea. Asian Nursing Research. 2013;7(2):83-90.

5. Chuang YH, Abbey JA, Yeh YC, Tseng IJ, Liu MF. As they see it: A qualitative study of how older residents in nursing homes perceive their care needs. Collegian. 2015;22(1):43-51.

6. Drageset J, Haugan G, Tranvag O. Crucial aspects promoting meaning and purpose in life: perceptions of nursing home residents. BMC Geriatr. 2017;17(1):254.

7. Walker $\mathrm{H}$, Paliadelis P. Older peoples' experiences of living in a residential aged care facility in Australia. Australasian Journal on Ageing. 2016;35(3):E6-E10.

8. Wilkinson H, Downs M, Bruce E, Clarke C, Bowes A. 1. Including people with dementia in research: methods and motivations. The Perspectives of People with Dementia: Research Methods and Motivations: Jessica Kingsley Publishers; 2001.

9. Stans SE, Dalemans R, de Witte L, Beurskens A. Challenges in the communication between 'communication vulnerable' people and their social environment: an exploratory qualitative study. Patient Educ Couns. 2013;92(3):302-12.

10. Curyto KJ, Van Haitsma K, Vriesman DK. Direct observation of behavior: a review of current measures for use with older adults with dementia. Res Gerontol Nurs. 2008;1(1):52-76.

11. Klassen AC, Smith KC, Meissner HI, Clark VLP, Creswell JW, Behavioral NloHOo, et al. Best Practices for Mixed Methods Research in the Health Sciences: The Office; 2011.

12. Creswell JW. Qualitative Inquiry and Research Design: Choosing Among Five Approaches: SAGE Publications; 2012.

13. Evers AWM, Jensen LE, Paul H. Grensverleggend: kansen en belemmeringen voor interdisciplinair onderzoek: Amsterdam: De Jonge Akademie; 2015.

14. Brown J. The World Café: A Resource Guide for Hosting Conversations That Matter. . Mill Valley, CA: Whole Systems Associates; 2002.

15. Harper D. Talking about pictures: A case for photo elicitation. Visual Studies. 2002;17(1):13-26.

16. Dewar B. Editorial: Appreciative inquiry. Int J Older People Nurs. 2010;5(4):290-1.

17. Applebaum R, Uman C, Straker J. Capturing the voices of consumers in long-term care: If you ask them they will tell. Consumer voice and choice in long-term care. 2006:127-40.

18. Bedard M, Squire L, Minthorn-Biggs M-B, Molloy DW, Dubois S, O'Donnell M, et al. Validity of SelfReports in Dementia Research. Clinical Gerontologist. 2003;26(3-4):155-63.

19. Stiegler A, Biedinger N. Interviewer Skills and Training. 2016.

20. Mokkink LB, Terwee CB, Patrick DL, Alonso J, Stratford PW, Knol DL, et al. The COSMIN study reached international consensus on taxonomy, terminology, and definitions of measurement properties for health-related patient-reported outcomes. Journal of clinical epidemiology. 2010;63(7):737-45.

21. Zohrabi M. Mixed Method Research: Instruments, Validity, Reliability and Reporting Findings. Theory \& practice in language studies. 2013;3(2).

22. Čaić M, Odekerken-Schröder G, Mahr D. Service robots: value co-creation and co-destruction in elderly care networks. Journal of Service Management. 2018;29(2):178-205.

23. Odekerken-Schröder G. Are you being Served? Maastricht: Maastricht University; 2011. 
24. McCormack B, Roberts T, Meyer J, Morgan D, Boscart V. Appreciating the 'person' in long-term care. Int J Older People Nurs. 2012;7(4):284-94.

25. Pew-Fetzer Task Force \& Tresolini CP. Health professions education and relationship-centered care : report: Pew Health Professions Commission, UCSF Center for the Health Professions; 1994.

26. Duffy JR, Hoskins LM. The Quality-Caring Model: blending dual paradigms. ANS Adv Nurs Sci. 2003;26(1):77-88.

27. Kang B, Scales K, McConnell ES, Song Y, Lepore M, Corazzini K. Nursing home residents' perspectives on their social relationships. Journal of clinical nursing. 2020;29(7-8):1162-74.

28. Boekel LV, Stoop A, Luijkx KG. [COVID-19 outbreak in nursing homes: what can be learned from the literature about other disasters or crisis situations?]. Tijdschr Gerontol Geriatr. 2020;51(3).

29. Cocuzzo B, Wrench A, O'Malley C. Balancing Protection from COVID-19 and the Need for Human Touch in Nursing Homes. J Am Geriatr Soc.n/a(n/a).

30. Simard J, Volicer L. Loneliness and Isolation in Long-term Care and the COVID-19 Pandemic. Journal of the American Medical Directors Association. 2020;21(7):966-7.

31. Begerow A, Gaidys U. COVID-19 Pflege Studie-Erfahrungen von Pflegenden während der Pandemie-erste Teilergebnisse. Pflegewissenschaft, Sonderausgabe: Die Corona-Pandemie April 2020. 2020:33-5.

32. Kusmaul N. COVID-19 and Nursing Home Residents' Rights. Journal of the American Medical Directors Association. 2020:S1525-8610(20)30660-5.

33. Verbeek H, Gerritsen DL, Backhaus R, de Boer BS, Koopmans RTCM, Hamers JPH. Allowing visitors back in the nursing home during the COVID-19 crisis - A Dutch national study into first experiences and impact on well-being. Journal of the American Medical Directors Association. 2020.

34. Festinger L. A Theory of Social Comparison Processes. Human Relations. 1954;7(2):117-40.

35. Zhao X. Competition, information, and quality: Evidence from nursing homes. Journal of Health Economics. 2016;49:136-52.

36. Patiëntenfederatie Nederland. 70.000 verpleeghuisbewners aan het word: eindrapportage waarderingen binnen de verpleeghuiszorg 2015-2018. Utrecht, Nederland: 2018.

37. Smith K. A learning organisation. Elderly care. 1999;11(9):28.

38. Skule S. Learning conditions at work: a framework to understand and assess informal learning in the workplace. International Journal of Training and Development. 2004;8(1):8-20.

39. McGuire D, Gubbins C. The Slow Death of Formal Learning: A Polemic. Human Resource Development Review. 2010;9(3):249-65.

40. Field DE. Moving from novice to expert - the value of learning in clinical practice: a literature review. Nurse Education Today. 2004;24(7):560-5.

41. Henderson A, Cooke M, Creedy DK, Walker R. Nursing students' perceptions of learning in practice environments: A review. Nurse Education Today. 2012;32(3):299-302.

42. Haesler E, Bauer M, Nay R. Recent evidence on the development and maintenance of constructive staff-family relationships in the care of older people--a report on a systematic review update. Int J Evid Based Healthc. 2010;8(2):45-74.

43. Verbeek H. Inclusion and Support of Family Members in Nursing Homes. In: Schüssler S, Lohrmann C, editors. Dementia in Nursing Homes. Cham: Springer International Publishing; 2017. p. 67-76.

44. Anvik C, Vedeler JS, Wegener C, Sletteb $\varnothing \AA$, $\varnothing$ degård A. Practice-based learning and innovation in nursing homes. Journal of Workplace Learning. 2020.

45. Nikolova I, Van Ruysseveldt J, De Witte H, Van Dam K. Learning climate scale: Construction, reliability and initial validity evidence. Journal of Vocational Behavior. 2014;85(3):258-65. 
46. Kyndt E, Dochy F. Antecedenten van een succesvolle organisatieontwikkeling en hun relatie met het leerklimaat van de organisatie: Een mixed method studie. Gedrag en Organisatie. 2013;26(4):357-78.

47. Hillebrand B, Driessen PH, Koll O. Stakeholder marketing: Theoretical foundations and required capabilities. Journal of the Academy of Marketing Science. 2015;43(4):411-28.

48. Bushe G. Appreciative inquiry is not about the positive. OD practitioner. 2007;39(4):33-8.

49. Carter B. 'One expertise among many' - working appreciatively to make miracles instead of finding problems: Using appreciative inquiry as a way of reframing research. Journal of Research in Nursing. 2006;11(1):48-63.

50. van der Haar D, Hosking DM. Evaluating Appreciative Inquiry: A Relational Constructionist Perspective. Human Relations. 2004;57(8):1017-36.

51. LOC Waardevolle Zorg. Radicale vernieuwing verpleeghuiszorg, van regels naar relaties 2015-2020 [28 May 2020]. Available from: https://www.radicalevernieuwing.nl/.

52. Raad Volksgezondheid en Samenleving. Blijk van vertrouwen: anders verantwoorden van goede zorg. Den Haag: Raad voor Volksgezondheid en Samenleving, , 2019.

53. Christie HL, Martin JL, Connor J, Tange HJ, Verhey FRJ, de Vugt ME, et al. eHealth interventions to support caregivers of people with dementia may be proven effective, but are they implementationready? Internet Interventions. 2019;18:100260.

54. Osterwalder A, Pigneur Y. Business model generation: a handbook for visionaries, game changers, and challengers: John Wiley \& Sons; 2010. 

SUMMARY 

The assessment of quality of care in nursing homes is important to improve on an individual level, learn on a team level and be accountable for on an organizational level. It is however challenging to define what to assess and how to assess this, in order to achieve these purposes. In 2017, a new quality framework on how to maintain and improve quality of care in nursing homes was published in the Netherlands. This framework recommends that residents should be included in evaluations about the quality of care they receive. The aim of this dissertation was to develop an innovative method to assess quality of care in nursing homes from the resident's perspective. The steps undertaken to develop this method were based on the five steps to develop a measurement instrument: defining the construct, developing items and response options, pilot- and field-testing, and evaluating measurement properties.

This dissertation resulted in the introduction of a feasible, valid and valuable assessment method: Connecting Conversations. Connecting Conversations is a narrative method that assesses experienced quality of care in nursing homes from the resident's perspective by conducting separate conversations with a resident, family member and professional caregiver of that resident. Key elements of the method are that it approaches experienced quality of care as a dynamic process influenced by expectations and interactions within a context (the INDEXQUAL framework); it includes the resident-family-caregiver care triad (relationship-centred care); it adopts a positive approach (appreciative inquiry), and interviewers are nursing home staff members who perform conversations with an app in each other's care organizations after having received a training (learning network).

Connecting Conversations is valuable for many different stakeholders. Residents, their families and professional caregivers are provided with a method that supports conversations are about what is going well; connects their stories; and can contribute towards quality improvements that are considered important to them. In addition, these narratives provide client council members with rich information that they can use to lobby for their residents' needs. Team managers can use the stories to learn from and improve with on a team level; and higher management can gain insight into how their care organizations are truly being experienced. For national stakeholders, the stories can contribute towards providing information about the experienced quality of care of care organizations. This information can be used to purchase high quality of care (health insurance companies), monitor and ensure high quality of care (the Health and Youth Care Inspectorate) and stimulate continuous quality improvements founded on these narratives (the National Health Care Institute). In addition, for education, both the new view on quality of care and the value of narrative quality assessments can be introduced to students to broaden their view on quality of care. Henceforth, Connecting Conversations steps away from ratings and rankings, towards the stories behind them. Each chapter in this dissertation has contributed towards the 
development of Connecting Conversations, as described in more detail in the remainder of this summary.

Chapter one introduces the main concepts of this dissertation: nursing homes, quality of care and the assessment of quality of care in nursing homes. In addition, a comparison is made between the similarities and differences of quality of care provision and quality of other service encounters. The chapter ends by presenting the aims and outline of this dissertation.

Chapter two presents a systematic literature review and thematic synthesis on residents' experiences in nursing homes. This resulted in three main themes and six sub-themes that residents consider important: (1) the nursing home environment, consisting of the physical environment and caring environment; (2) individual aspects of living in the nursing home, consisting of personhood and coping with change; and (3) social engagement consisting of meaningful relationships and care provision. Including residents' care experiences in quality management can contribute towards achieving higher experienced quality of care in nursing homes.

In order to develop an assessment method, the construct to be assessed was defined in chapter three. The conceptual framework, INDEXQUAL, defines experienced quality of care from the resident's perspective. This research is founded on service sciences and health sciences literature, and supported by expert options. The INDEXQUAL framework presents experienced quality of long-term care as a continuous process within a context, in which expectations are formed before, experiences occur during and an assessment of that experience is given afterwards. Expectations are based on personal needs, word-of-mouth and past experiences. Experiences occur within interactions between the care recipient (resident), professional caregiver and informal caregiver (family). This is in line with the concept of relationship-centred care that depicts that not only residents, but also their relationships have needs and influence their experiences. Hereafter, an assessment is made regarding what happened and how it happened (perceived care services), how this influenced the care recipient's health status (perceived care outcomes) and how this made the care recipient feel (satisfaction). The INDEXQUAL framework can serve as a starting point for quality monitoring, improvement and transparency from the resident's perspective.

A qualitative study consisting of two homogenous focus groups and a heterogeneous world café was performed and presented in chapter four. This study aimed to identify how quality of care in nursing homes should be assessed according to client council representatives, informal caregivers, and nursing home staff. Results confirmed that experienced quality of care occurs within the interactions between residents, family and staff, highlighting the impact of relationships. According to participants, quality assessments should focus on three aspects: (1) knowledge about the resident, (2) a responsive approach, and (3) a caring environment. Assessments should be performed by having conversations with residents, 
their families and nursing staff, and by observing residents in their living environments. Two prerequisites for this are sufficient time and sufficient resources. In addition, the person performing the quality assessments needs to possess certain communication and empathy skills.

Chapter five presents the content and feasibility of the narrative method 'Connecting Conversations' that assesses experienced quality of care in nursing homes. This method was developed in co-creation in iterative steps. It is based on the principles of INDEXQUAL, relationship-centred care, appreciative inquiry, and learning networks. Three separate conversations are conducted with a resident, family member and professional caregiver of that resident by a trained interviewer. Interviewers are staff employed in another nursing home than where the conversations are performed, to enhance a learning network. The conversations are supported by an app that can be used to document both audio and typed summaries. During two rounds of field-testing, 35 interviewers were trained and performed 275 conversations of which 68 full triads and 34 dyads (family or resident unwilling or unable to perform the conversations). Median duration of the conversations was 17 minutes. Completeness findings were $76 \%$ of all planned conversations and protocol adherence was high with family and caregiver conversations, and slightly lower in the resident conversations. Interviewers were overall very positive about the training and conducting the conversations, however sometimes experienced challenges with scheduling.

The face, content and construct validity of Connecting Conversations have been assessed in chapter six. Face validity results show that experts deemed the narrative assessment method appropriate and complete to assess experienced quality of care in nursing homes. Content validity was assessed by analysing if the elements from the INDEXQUAL framework were present in the answers provided by respondents in the conversations with directed content analysis. Findings confirmed that the questions asked appeared to capture the full construct of experienced quality of care. Additionally, exploratory construct validity analyses revealed there was a range in how positive conversations were and indicated that a nursing home scoring higher on satisfaction had more positive conversations. The innovative approach of analysing validity of narrative data needs to be further validated in practice. This study showed promising results to use Connecting Conversations as a valid narrative method to assess experienced quality of care.

Chapter seven introduces how narrative data collected with Connecting Conversations can be classified and interpreted. Findings resulted in a stepwise approach for the use of narrative quality data consisting of four steps: (1) perform and transcribe the conversations (listen); (2) calculate a valence sore, defined as the mean \%-positive coded segments within a triad (look); (3) calculate an agreement score, defined as the level of agreement between resident-family-staff (link); and (4) plot the agreement score ( $x$-axis) and valence score ( $y$ axis) into a graph for interpretation and learning purposes (learn). To incorporate Connecting 
Conversations into a continuous quality cycle, it is important that these plotted scores are related to the raw qualitative data to gain a rich understanding of what is going well and what needs to be improved.

In chapter eight the main findings of all studies are summarized followed by methodical and theoretical considerations, resulting in recommendations for further research and practice. By performing appreciative resident-family-caregiver conversations, connecting these and collaborating together, a more learning climate in nursing homes can be achieved. 
SAMENVATTING 

Het meten van de kwaliteit van de verpleeghuiszorg is belangrijk om op individueel niveau te verbeteren, op teamniveau te leren en op organisatieniveau te verantwoorden. Het is echter uitdagend om te definiëren wat gemeten moet worden en op welke manier, om daadwerkelijk deze doelstellingen te bereiken. In 2017 is het Kwaliteitskader Verpleeghuiszorg gepubliceerd in Nederland, met als doel het monitoren en verbeteren van de kwaliteit van de verpleeghuiszorg. Dit kwaliteitskader erkent onder andere het belang van het betrekken van bewoners binnen kwaliteitsevaluaties. Het doel van dit proefschrift is om een innovatieve methode te ontwikkelen die kwaliteit van de verpleeghuiszorg meet vanuit het perspectief van de bewoner. Hiervoor zijn vijf algemeen erkende stappen gevolgd: 1) het definiëren van het construct, 2) het ontwikkelen van items en antwoordmogelijkheden, 3) pilotonderzoek, 4) veldonderzoek en 5) het evalueren van meeteigenschappen.

Dit proefschrift heeft geleid tot de haalbare, valide en waardevolle narratieve meetmethode Ruimte voor Zorg (Connecting Conversations). Ruimte voor Zorg meet de ervaren kwaliteit van verpleeghuiszorg vanuit het perspectief van de bewoner, door aparte gesprekken te voeren met de bewoner, een familielid en een dagelijks betrokken zorgverlener van die bewoner. Kernelementen van de methode zijn dat 1) de ervaren kwaliteit wordt gezien als een dynamisch proces dat wordt beïnvloed door verwachtingen en interacties binnen een context (het INDEXQUAL raamwerk); 2) de diriehoek bewoner-familie-zorgverlener (relatiegerichte zorg) centraal staat; 3) een positieve benadering (appreciative inquiry) wordt gebruikt; en 4) interviewers getrainde verpleeghuismedewerkers zijn, die met een ondersteunende app in elkaars zorgorganisaties gesprekken voeren (lerend netwerk).

Ruimte voor Zorg is waardevol voor verschillende belanghebbenden. Voor bewoners, hun familie en zorgverleners biedt het waardevolle handvatten om het gesprek aan te gaan over wat men belangrijk vindt in de dagelijkse zorg. Dit draagt bij aan directe kwaliteitsverbetering. Bovendien bieden de verhalen aan cliëntenraden rijke informatie die zij kunnen gebruiken om de behoeften van de bewoners in kaart te brengen. Teammanagers gebruiken de verhalen om op teamniveau te leren en te verbeteren; en hoger management krijgt inzicht in hoe hun zorgorganisaties daadwerkelijk worden ervaren. Voor landelijke stakeholders dragen de verhalen bij aan het verkrijgen van informatie over de ervaren kwaliteit van zorgorganisaties. Deze informatie kan bijvoorbeeld gebruikt worden voor het inkopen van hoge zorgkwaliteit (zorgverzekeraars), het waarborgen van zorg van hoge zorgkwaliteit (Inspectie Gezondheidszorg en Jeugd) en het stimuleren van kwaliteitsverbeteringen (Zorginstituut). Daarnaast kan zowel de nieuwe kijk op kwaliteit als het gebruik van narratieve kwaliteitsmetingen een meerwaarde hebben binnen het onderwijs om de opvattingen van studenten over kwaliteit van zorg te verbreden.

Ruimte voor Zorg biedt een nieuw perspectief op kwaliteit van leven en zorg in het verpleeghuis, direct vanuit het dagelijks leven en vanuit de verschillende perspectieven. Het maakt een verdiepingsslag door te kijken naar de verhalen achter de cijfers. leder hoofdstuk 
in dit proefschrift heeft bijgedragen aan de ontwikkeling van Ruimte voor Zorg, zoals nader wordt beschreven in deze samenvatting.

Hoofdstuk één introduceert de belangrijkste concepten van dit proefschrift: verpleeghuizen, kwaliteit van zorg en de beoordeling van kwaliteit van zorg in verpleeghuizen. Daarnaast wordt er een vergelijking gemaakt tussen kwaliteit van zorgverlening en kwaliteit van andere vormen van dienstverlening. Het hoofdstuk eindigt met een overzicht van de doelstellingen en opbouw van dit proefschrift.

Hoofdstuk twee presenteert een systematisch literatuuronderzoek en thematische synthese over de ervaringen van bewoners in verpleeghuizen. Dit resulteerde in drie hoofdthema's en zes sub thema's die bewoners belangrijk vinden: (1) de verpleeghuisomgeving, bestaande uit de fysieke omgeving en de zorgomgeving; (2) individuele aspecten van het wonen in het verpleeghuis, bestaande uit persoonlijkheid en het omgaan met verandering; en (3) sociale betrokkenheid, bestaande uit zinvolle relaties en zorgverlening. Het meenemen van zorgervaringen van bewoners in kwaliteitsmanagement kan bijdragen aan het bereiken van een hogere ervaren kwaliteit van zorg in verpleeghuizen.

In hoofdstuk drie is het kern construct 'ervaren kwaliteit' gedefinieerd. Deze studie is gebaseerd op literatuur uit de wetenschap van de dienstverlening en de gezondheidswetenschappen en wordt tevens ondersteund door experts. Het conceptuele kader, INDEXQUAL, presenteert ervaren kwaliteit van de langdurige zorg als een continu proces binnen een context, waarin verwachtingen vooraf worden gevormd, ervaringen tijdens de zorg optreden en een evaluatie van die ervaring achteraf wordt gegeven. De verwachtingen worden gevormd door persoonlijke behoeften, mond-tot-mondreclame en voorgaande ervaringen. Ervaringen doen zich voor binnen de interacties tussen de zorgvrager (bewoner), zorgverlener en de mantelzorger (familie). Dit sluit aan bij het concept van relatiegerichte zorg, dat laat zien dat niet alleen bewoners, maar ook hun relaties behoeften hebben en ervaringen beïnvloeden. Op basis daarvan wordt beoordeeld wat er is gebeurd en hoe dit is gebeurd (ervaren zorgdiensten), hoe dit de gezondheidstoestand van de zorgvrager beïnvloed heeft (ervaren zorguitkomsten) en hoe de zorgvrager zich hierbij voelde (tevredenheid). INDEXQUAL kan als uitgangspunt dienen voor monitoring, verbetering en transparantie van kwaliteit van de verpleeghuiszorg vanuit het perspectief van de bewoner.

In hoofdstuk vier wordt een kwalitatieve studie beschreven bestaande uit twee homogene focusgroepen en een heterogeen wereldcafé. Het doel van deze studie was om te achterhalen hoe de kwaliteit van zorg in verpleeghuizen gemeten zou moeten worden volgens cliëntenraadsleden, familie en verpleeghuismedewerkers. De resultaten bevestigden dat ervaren kwaliteit van zorg plaatsvindt binnen de interacties en relaties tussen bewoners, familie en zorgverleners. Deelnemers gaven aan dat kwaliteitsmetingen zich moeten richten 
op drie aspecten: (1) kennis over de bewoner, (2) een interactieve benadering en (3) een zorgzame omgeving. Dit moet worden gemeten door gesprekken te voeren met bewoners, hun families en zorgverleners; en door bewoners in hun eigen leefomgeving te observeren. Hiervoor zijn twee randvoorwaarden van belang, te weten voldoende tijd en voldoende middelen. Bovendien moet degene die de gesprekken voert beschikken over specifieke communicatieve en empathische vaardigheden.

Hoofdstuk vijf presenteert de inhoud en haalbaarheid van de narratieve methode Ruimte voor Zorg, die de ervaren kwaliteit van verpleeghuiszorg meet. Deze methode is iteratief ontwikkeld in co-creatie. Ruimte voor Zorg is gebaseerd op de principes van INDEXQUAL, relatiegerichte zorg, de waarderende benadering en lerende netwerken. Er worden drie aparte gesprekken gevoerd door een getrainde interviewer met respectievelijk een bewoner, een familielid en een zorgverlener van die bewoner. Interviewers zijn medewerkers die werkzaam zijn in een ander verpleeghuis dan waar de gesprekken worden gevoerd, om op die wijze een lerend netwerk te creëren. De gesprekken worden ondersteund door een app die wordt gebruikt om zowel audio als getypte samenvattingen vast te leggen. Tijdens twee meetrondes zijn 35 interviewers getraind die samen 275 gesprekken hebben gevoerd, waarvan 68 volledige driehoeken en 34 tweehoeken (bewoner of familie kon of wilde het gesprek niet voeren). De duur van de gesprekken was 17 minuten (mediaan). 76\% van alle geplande gesprekken werden uitgevoerd en correcte naleving van het protocol was hoog bij de familie en zorgverleners en iets lager bij de bewoners. Interviewers waren over het algemeen erg positief over de training en het voeren van de gesprekken, maar ondervonden soms problemen met de planning.

De validiteit van Ruimte voor Zorg is beoordeeld in hoofdstuk zes. De validiteit op het eerste gezicht (face) laat zien dat experts de narratieve methode geschikt en compleet vinden om de ervaren kwaliteit van verpleeghuiszorg te meten. De inhoudsvaliditeit (content) is beoordeeld door te analyseren of de elementen uit het INDEXQUAL raamwerk aanwezig waren in de antwoorden van de respondenten middels kwalitatieve data-analyse. De resultaten bevestigen dat de gestelde vragen het volledig construct 'ervaren kwaliteit' meten. Exploratieve analyses inzake de begripsvaliditeit (construct) laten zien dat er een variatie is in hoe positief gesprekken zijn. Verder heeft een verpleeghuis dat hoger scoort op tevredenheid gemeten met de Net Promotor Score, positievere Ruimte voor Zorg gesprekken. Deze studie laat veelbelovende resultaten zien om Ruimte voor Zorg te kunnen gebruiken als valide narratieve methode om de ervaren kwaliteit van verpleeghuiszorg te meten.

Hoofdstuk zeven introduceert hoe narratieve Ruimte voor Zorg data kunnen worden geclassificeerd en geïnterpreteerd. Dit heeft geresulteerd in een stapsgewijze aanpak voor het gebruik van narratieve kwaliteitsdata middels een grafiek met verschillende segmenten. Deze aanpak bestaat uit vier stappen: (1) het voeren en transcriberen van gesprekken 
(listen); (2) het berekenen van een valentiescore, gedefinieerd als het gemiddelde \%-positief gecodeerde segmenten binnen een driehoek (look); (3) het berekenen van een overeenkomstscore, gedefinieerd als de mate van overeenstemming tussen de bewonerfamilie-zorgverlener (link); en (4) het plotten van de overeenkomstscore ( $x$-as) en de valentiescore ( $y$-as) in een grafiek voor interpretatie- en leerdoeleinden (learn). Om Ruimte voor Zorg op te nemen in een continue kwaliteitscyclus, is het belangrijk dat deze scores worden gekoppeld aan de ruwe narratieve data om een volledig beeld te krijgen van wat goed gaat en wat verbeterd kan worden.

In hoofdstuk acht worden de belangrijkste bevindingen van alle onderzoeken samengevat, gevolgd door methodologische en theoretische overwegingen, resulterend in aanbevelingen voor de praktijk en verder onderzoek. Het waarderend voeren, verbinden en samen leren van bewoner-familie-zorgverlener gespreken draagt bij aan het verlenen van hoge kwaliteit van verpleeghuiszorg. 
IMPACT 

"As an interviewer, I enjoyed having the time to really listen. For example, a nurse proudly told me that she adjusted her morning routine to the residents' wishes and she always let Mr. Johnson sleep in. Mr. Johnson however told me it bothered him that he is always cared for so late in the morning, because he has aches and pains when staying in bed so long. Identifying these discrepancies, that is what Connecting Conversations is about." This chapter reflects on the societal and scientific impact, the dissemination and the future of the results in this dissertation.

\section{SOCIETAL IMPACT}

This dissertation has introduced a new view on quality of long-term care. Experienced quality of care in nursing homes is an interactive process, highly influenced by relationships between residents, their families and professional caregivers. This broader view on quality of care also requires a different way of assessing this, henceforth requiring not just quantitative data but also additional narrative data on residents' and families experiences. Connecting Conversations is a narrative method that assesses experienced quality of care. Unlike standard questionnaires, it monitors the relationships between and experiences of residents, their families and their professional caregivers, helps to identify what is going well and helps to initiate improvements where needed by collecting and connecting stories. Since the introduction of the new quality framework for nursing homes in 2017 in the Netherlands, ${ }^{1}$ nursing homes have been struggling to find a proper way to assess their quality of care from the resident's perspective. Connecting Conversations fills this gap and creates space for what really matters: the needs and experiences of residents and their relationships. It has been developed in co-creation with key stakeholders in the nursing home setting, to assure support and a good fit for practice.

The most important groups of people that can and should benefit from Connecting Conversations are residents, their families and their professional caregivers in everyday practice. The method actually creates time for them to share their stories and express what is considered important to them. Three key elements that make Connecting Conversations valuable for them are that: (1) Conversations are about what is going well; (2) Connections are made between resident-family-caregiver stories; and, (3) Collaborations are built with each other, and include the resident-family-caregiver triad in quality improvements.

Client councils have also expressed their gratitude for this new way of assessing quality of care. As representatives for residents, they find it important to have insight into a nursing homes' experienced quality of care. The stories collected and connected with Connecting Conversations provide them with valuable information that they can use to lobby for the residents' needs. In the future, possibilities to train client council members as Connecting Conversations interviewers will also be explored, based on their initiative. 
For team management, the stories can provide insight into how their wards and nursing homes are being experienced, including what is going well, what could be improved and what lessons can be learned. Unlike average numbers retrieved from questionnaires, Connecting Conversations provides rich data that care teams can use to learn from and improve with. For higher management, Connecting Conversations also provides insight into how their care organization is being experienced. In addition, the method meets the requirements that an assessment method for quality of care from the resident's perspective needs to fulfil, defined by the Dutch government. ${ }^{2}$ This adds to its value and appeal for nursing homes, as it also fulfils the national requirement of needing to assess these aspects.

Health insurance companies have the responsibility to purchase high quality care for nursing homes. They strive to purchase high quality of care and enter into negotiations and discussions about this with local care providers. Since recently, health insurance companies value the resident's perspective on quality of care more in their decision-making process. For this, stories collected with Connecting Conversations can contribute towards providing information about the experienced quality of care of a care organization.

The Health and Youth Care Inspectorate has the responsibility to ensure high quality care in their supervisory role. Since the new quality framework, their way of supervision has shifted from evaluation documentations towards more visits and observations on wards and conversations with different members of staff, families and residents. The stories collected with Connecting Conversations can also contribute to this new way of working and provide the Inspectorate with valuable insight into nursing homes' experienced quality of care.

The National Health Care Institute stimulates continuous quality improvements by for example supporting nursing homes to adhere to the new quality framework. They support the added value of narrative quality assessments in nursing homes and recommend the use of this additional form of quality assessments. Connecting Conversations can be included as a narrative method that care organization can select for their narrative quality assessments.

For education, the new view on quality of care and value of narrative quality assessments should be introduced to students. By introducing the concepts of relationship-centred care, appreciative inquiry and the INDEXQUAL framework to them, they will learn quality of care is a wider concept than just the clinical aspects. Henceforth, they will learn how to provide more individualised care. This is firstly recommended for nursing students on all levels, however is also recommended for other disciplines such as paramedical studies, medicine, social work and health sciences, as all these disciplines are integrated in long-term care.

Connecting Conversations contributes to the needs of many different stakeholders. Ideally, this method and its principles can support a shift in the nursing home culture, in which mandatory registrations, tasks and checklists make more room for conversations, 
relationships and a learning culture. This can contribute towards achieving a higher quality of care, quality of life and quality of work for residents, family and staff in nursing homes.

\section{SCIENTIFIC IMPACT}

The studies in this dissertation have added to scientific knowledge regarding the assessment of quality of care in nursing homes in multiple innovative ways. First, a new view on quality of long-term care was created, which has been highly accepted by national and international researchers and stakeholders. The INDEXQUAL framework presents experienced quality of long-term care as a dynamic process consisting of expectations before, interactions during and an assessment of the experience afterwards. The interdisciplinary nature of this framework was achieved by approaching care provision as a service being delivered to consumers within the complex context of long-term care. Service sciences has taught us to acknowledge that different actors contribute towards and benefit from creating added value to an experience. ${ }^{3,4}$ Whereas this view has been used in health care, known as relationshipcentred care, up to recently person-centred care has prevailed in most long-term care settings. ${ }^{5}$ Striving to achieve a 'balanced centricity' between the needs of all involved actors (residents, family, caregivers, management, inspectorate) can contribute to the performance of care organizations. ${ }^{6}$ By adopting this new definition of experienced quality of long-term care, a new perspective on what is considered important and what should be improved can be adopted, bringing theory and practice closer together.

Second, there is a continuous scientific debate regarding the evaluation of reliability and validity in qualitative research. Some deem these concepts unsuitable for the nature of the qualitative research; whereas others argue reliability and validity are the foundation of good research. A novel approach was developed to evaluate the validity of a narrative assessment method. By translating the concepts of content and construct validity to the assessment method under study, it is deemed plausible to use the concepts of validity for this. This provides for an increased use of qualitative methods to assess complex constructs in a proven reliable and valid manner.

Third, it is known that qualitative data analysis is very time-consuming, amongst others due to transcribing, coding, collaborating and continuously adjusting analysis in iterative steps. This dissertation explored with a new approach towards analysing qualitative data, by means of translating text into a percentage positive text segments. The quantification of narrative data provides new possibilities for the classification and interpretation of narratives for assessment purposes, even though the raw stories should always be attached to these quantifications. 


\section{DISSEMINATION OF FINDINGS}

Various channels have been used to disseminate the findings of this research to residents, families, caregivers, care organizations, researchers, policy makers, students, national stakeholders and other relevant stakeholders. Of the six articles in this dissertation, five have been published in international, peer-reviewed journals, and the sixth article has been submitted for publication as well. Four of these articles have been published open access, meaning that they are accessible free-of-charge. Additionally, the findings of these articles have been presented at various national and international conferences, including amongst others twice at the international Gerontological Society of America meetings and at the national Gerontology conference. Since 2019, a collaboration has also been set up between the universities of Tilburg, Leiden, Twente and Maastricht, in which knowledge is exchanged about using narratives to assess quality of long-term care. Together this group also advocates the importance of using narratives in nursing homes for quality assessments and improvements by e.g. collaborating at scientific and societal conferences.

The above-mentioned channels are used mainly to reach researchers. Therefore, other channels have also been used to disseminate findings to society. Residents, families and caregivers participating in any of the research activities or Connecting Conversations themselves received the opportunity to sign up for a newsletter about Connecting Conversations' advancements. The Living Lab in Ageing and Long-Term Care disseminated multiple findings through the large reach within their network. Amongst others, Connecting Conversations was an item in multiple newsletters, on social media, and it was a topic in the special edition '20-year Living Lab jubilee magazine', which was distributed during a symposium with 1000+ attendees (including many caregivers and families). Additionally, several care organizations have published items about Connecting Conversations in their own internal magazines, which are distributed to employees, families and residents; and multiple small-scale presentations have been given at nursing homes. At least once a year the advisory board for older people (Ouderen Adviesraad) was consulted about the progress of the research and disseminated findings to their peers in e.g. client councils. In education, the INDEXQUAL framework has become part of the curriculum for the second year of the Health Sciences track in the course 'quality of care' and in the master's of Healthcare Policy, Innovation and Management in the course 'quality and innovation management'. These students are the policy makers of the future.

This whole research trajectory has been supported by a national steering committee, consisting of representatives from the Ministry of Health, the National Health Care Institute, the National Client Council, the Professional Association of Nurses, the Health and Youth Care Inspectorate and the Board of Nursing Home Organizations. Once or twice a year, the committee was consulted, to monitor and reflect on Connecting Conversations' suitability for practice. The committee also disseminated the latest information of the study to their 
networks. Furthermore, an item on Connecting Conversations was published by the national governmental website of 'Waardigheid en Trots', aimed at presenting innovations and current events in the Dutch nursing home sector. In addition, Connecting Conversations was on the meeting agenda of the network of radical renewal of nursing home care (Radicale Vernieuwing), aimed at achieving a shift from rules to relationships in nursing homes. To enhance the national reach further, an article in Dutch describing how Connecting Conversations works, has been published in a journal for professionals working in gerontology.

\section{CONNECTING CONVERSATIONS IN THE FUTURE}

The promising results of the studies in this dissertation have led to the demand to further disseminate and research Connecting Conversations. To ensure Connecting Conversations remains available beyond the borders of the research described in this dissertation, multiple steps have been undertaken. Currently, four other research projects within the Living Lab in Ageing and Long-Term Care are using Connecting Conversations to some extent in their research. One research project is developing a narrative assessment method for the home care setting. This method has also been based on the INDEXQUAL framework. In the future, it may be possible to link this method to Connecting Conversations in order to support a more smooth transition from home to the nursing home. The second research project, 'LEEV', aims to discover how nursing homes can use Connecting Conversations' data to learn from and improve with within care teams. The third research project, 'text-mining', explores how automated text analysis, by means of for example sentiment analysis, can be used to analyse narrative data more efficiently. Once the coding for these analyses is fully developed, opportunities to embed these automated analyses into the Connecting Conversations' app can be explored. The last research project, 'quality of care in nursing homes', combines the more quantitative quality indicators (National Prevalence Measure of Quality of Care), with narrative experienced quality of care (Connecting Conversations), to create a more sustainable and complete view on quality of care for nursing homes.

In addition, there is a need to perform further research on Connecting Conversations, including (1) optimizing its usability of the findings and inclusion of all residents, (2) serving its large-scale availability and implementation with a sustainable business model, and (3) securing its theoretical foundations in education. These objectives are of a large-scale and will need to be achieved in iterative steps. The research team is planning on applying for additional research funding for this, which will be prepared, planned and executed together with representatives of residents, families, caregivers and education, to ensure everyone's needs continue to be met.

In conclusion, Connecting Conversations has shown to be a valuable assessment method for nursing home practice. It steps away from ratings and rankings and can facilitate identifying residents-families-caregivers' needs and detect learning and improvement points. The 
studies in this dissertation have provided a next step towards achieving a culture shift in nursing homes from a more medical and person-centred environment, towards a relationship-centred, generative and learning climate. This means we need to acknowledge everyone involved in interactive care experiences and focus should not be on short-term problem-solving, but on long-term generativity in which resident-family-caregiver can discover together what is going well and what needs to be improved.

'Connect-Converse - Collaborate' 


\section{REFERENCES}

1. Zorginstituut Nederland. Kwaliteitskader Verpleeghuiszorg Samen leren en verbeteren.: Zorginstituut Nederland; 2017. p1-41.

2. Actiz. Instrumenten Cliëntervaringsonderzoek: geen waaier, wel set van eisen 2018 [5 August 2020]. Available from: https://www.actiz.nl/nieuws/web/ouderenzorg/open/2018/04/instrumentenclientervaringsonderzoek-geen-waaier-wel-set-van-eisen.

3. Čaić M, Odekerken-Schröder G, Mahr D. Service robots: value co-creation and co-destruction in elderly care networks. Journal of Service Management. 2018;29(2):178-205.

4. Odekerken-Schröder G. Are you being Served? Maastricht: Maastricht University; 2011.

5. Pew-Fetzer TaskForce. Relationship-centered care: San Francisco: Pew Health Professions Commission; 1994.

6. Hillebrand B, Driessen PH, Koll O. Stakeholder marketing: Theoretical foundations and required capabilities. Journal of the Academy of Marketing Science. 2015;43(4):411-28. 

DANKWOORD 

Today is the tomorrow you worried about yesterday, and all is well'. Nu het inhoudelijke gedeelte van het proefschrift is afgerond, kan de focus verlegd worden naar het belangrijkste hoofdstuk: het dankwoord. Een van de leukste dingen aan mijn werk vind ik de samenwerking met anderen en hier wil ik graag mijn waardering voor uiten, dus dit hoofdstuk is minstens zo belangrijk als de rest. Om te beginnen wil ik iedereen hartelijk bedanken die direct of indirect heeft bijgedragen aan de totstandkoming van dit proefschrift. Er zijn een aantal mensen die ik in het bijzonder wil benoemen. Dit betekent echter niet dat als ik je naam niet heb uitgeschreven, dat je niet van waarde bent geweest.

Dit onderzoek was niet mogelijk geweest zonder alle deelnemende zorgorganisaties binnen de Academische Werkplaats Ouderenzorg Zuid-Limburg (AWO-ZL): MeanderGroep ZuidLimburg, Sevagram, Envida, Cicero Zorggroep, Zuyderland, Mosae Zorggroep en Vivantes. Bewoners, familieleden, zorgmedewerkers, beleidsmedewerkers, cliëntenraden en overige stafleden: van harte bedankt voor jullie nauwe betrokkenheid bij dit uitdagende onderzoek. In het bijzonder wil ik de Ruimte voor Zorg interviewers bedanken. We hebben jullie soms wellicht in het diepe hebben gegooid, maar jullie inzet en motivatie waren blijvend. Ruimte voor Zorg is mede door jullie inzet tot stand gekomen en mijn dank daarvoor is groot!

Zoals tijdens ieder promotietraject, ben ook ik de afgelopen vier jaar begeleid door een fantastisch sterk en divers team. Ik denk dat maar weinigen kunnen zeggen dat ze zijn begeleid door vijf hoogleraren, met ieder hun eigen visies, talenten en voorkeuren. Ik wil jullie als team bedanken voor de onvoorwaardelijke support en jullie vertrouwen in mij.

Jan, jij bent een voorbeeld van hoe een gedegen onderzoeker de brug slaat tussen wetenschap en praktijk, zonder daarin zichzelf te verliezen. Ik bewonder je standvastigheid in je visie, loyaliteit naar je collega's en leiderschap binnen de AWO-ZL. De eerste promotieoverleggen vond ik erg spannend, maar al gauw werd het duidelijk dat jij alleen maar wilde dat ik het meeste uit mezelf en mijn onderzoek zou halen. Je feedback was altijd waardevol, al was het soms even puzzelen om je handschrift te ontcijferen. Bedankt voor je vertrouwen in ons onderzoek. Ik ben trots op wat wij samen met het team bereikt hebben en dit was nooit gelukt zonder jouw begeleiding en onvoorwaardelijke vertrouwen in onze methode. Ik verheug me op onze verdere samenwerking!

Gaby, ik ben zo blij dat jij bent aangesloten bij mijn promotieteam. Het was even aftasten, want onderzoek binnen SBE is toch wel anders dan binnen de AWO-ZL, maar wat heb ik veel van jou geleerd. Je openheid, betrokkenheid en oprechte interesse in het onderwerp en in mij als persoon, maken jou een fantastische promotor. Jij hebt mij geleerd dat 'drama' ook iets positiefs kan zijn en dat visualiseren van onderzoek complexe vraagstukken kan verhelderen. Ik hoop dat wij in de toekomst zullen blijven samenwerken!

Jos, als jij de kamer inloopt neem je altijd zoveel energie mee naar binnen. Ik heb je feedback op mijn stukken altijd ontvangen nog voordat ik op de verzendknop kon klikken en - ondanks je drukke agenda - ben je altijd nauw betrokken geweest. Bedankt voor je positieve en 
motiverende woorden de afgelopen vier jaar. Ik wens je veel plezier met het toewerken naar je welverdiende pensioen!

Hilde, wij kenden elkaar al van mijn masterscriptie in 2013. Terugkijkend ben ik blij dat ik niet meteen bij jullie ben gebleven om te promoveren, maar eerst elders werkervaring heb opgedaan. Bedankt dat jij iets in mij hebt gezien destijds en mij vier jaar na mijn afstuderen alsnog de kans hebt gegeven om binnen de AWO-ZL te kunnen promoveren. Ik ken weinig mensen zoals jij, zo bevlogen in je werk, een heldere visie en zoveel doorzettingsvermogen. Ik schrok in het begin van je drukke agenda en je aanpak om mij in het diepe te gooien, maar achteraf gezien wil ik jou hiervoor bedanken. Je pragmatische aanpak heeft mij geleerd dat gedegen onderzoek niet altijd volledig te plannen is in de praktijk. Je kritische blik heeft ervoor gezorgd dat ik altijd nog dat beetje extra kon geven. En, je drukke agenda stond nooit in de weg als ik je écht nodig had. Bedankt voor de begeleiding de afgelopen vier jaar, en gefeliciteerd met je benoeming tot hoogleraar!

Sandra, je bent officieel gezien geen lid van mijn promotieteam, maar dat is alleen maar omdat een vijfde lid écht niet mocht. Ook wij hebben elkaar al leren kennen tijdens mijn masterscriptie. Ik ben je erg dankbaar dat jij de afgelopen vier jaar betrokken bent gebleven bij mijn onderzoek en vroeg mij soms af of jij hier wel echt de tijd voor had. Tijdens promotieoverleggen had ik altijd het gevoel dat jij mij begreep en ik heb me ook altijd echt gesteund gevoeld door jou. Bedankt voor al je feedback en betrokkenheid als bonus-teamlid!

Graag wil ik de leden van de beoordelingscommissie, prof. dr. Verhey, prof. dr. Mahr, prof. dr. Schols, en prof. dr. Westerhof in het bijzonder bedanken voor het lezen en beoordelen van dit proefschrift. A special thank you to prof. dr. Spilsbury for your willingness to be part of the assessment committee.

Daarnaast wil ik graag bedanken Marthijn Laterveer (LOC), Charlotte de Winter (IGJ), Noor Heim, Jacqueline Sonneveld en Margje Mahler (ZIN), Caro Verlaan (CZ), Petra Schout en Christina Woudhuizen (V\&VN), Brigitte Verhage en Pieter Roelfsema (VWS), Kina Koster en Ellen Leers (Cicero Zorggroep) en Roger Ruitjers en Jan Maarten Nuijens (Envida) als leden van de landelijke stuurgroep. Vanaf het begin zijn jullie betrokken geweest in dit onderzoek. De bijeenkomsten vormden voor mij steeds een belangrijk ijkpunt, vanuit waar ik mij naar 'het volgende level' van mijn onderzoek kon tillen. De Ouderen Adviesraad van de AWO-ZL heeft tevens een enorme steun geleverd aan mijn onderzoek. Jullie hebben gewaarborgd dat het bewonersperspectief altijd centraal is blijven staan en hebben een waardevolle rol gespeeld in de vertaalslag van wetenschappelijke theorie naar de praktijk, bedankt hiervoor!

Ook wil ik alle studenten die hebben geholpen met het verzamelen en verwerken van data bedanken voor hun tijd en inzet. Hun tijd en inzet zijn van grote hulp geweest. 
Een andere belangrijke partij die Ruimte voor Zorg tot een succes heeft gemaakt is UMIO. Gordon, Damian, Dominik, Daria en Linda, bedankt voor de fijne samenwerking. Ik hoop dat wij in de toekomst samen verder mogen bouwen aan Ruimte voor Zorg.

Duco, Robbert en Hans, ook jullie wil ik bedanken. Jullie bedrijf CodeArt BV heeft alle elementen die zorgen voor een aangename samenwerking. Ik heb van jullie geleerd hoe de complexiteit van de app-wereld soms best eenvoudig in lekentaal kan worden uitgelegd en mijn vragen werden jullie nooit te veel. Bedankt voor het ontwikkelen van onze mooie app en de fijne samenwerking! Marc, ook jou wil ik in het bijzonder bedanken voor je inzet met het testen en waarborgen van de gebruiksvriendelijkheid van de app.

Desiree, Stefanie, Karla, Angèle en Elke, jullie wil ik bedanken voor de nauwe samenwerking rondom de subsidieaanvraag om Ruimte voor Zorg te kunnen doorontwikkelen. Tevens zou ik een paar andere onderzoeksgroepen in het land willen bedanken, namelijk de groep van prof. Katrien Luijkx in Tilburg (TRANZO), de groep van prof. Gerben Westerhof in Enschede (TU) en de groep van prof. Joris Slaets in Leiden (Leyden Academy). Onze kennisuitwisseling is een mooi voorbeeld hoe wetenschap zou moeten gaan over het grotere geheel. Ik hoop dat wij in de toekomst samen het belang van narratieven in de langdurige zorg kunnen blijven behartigen.

Zonder mijn collega's waren de afgelopen vier jaren nooit zo leuk geweest. ledereen weet dat ik het (verplicht) thuiswerken van 2020 niet erg vond vanwege de gewonnen reistijd en de concentratie om te kunnen schrijven, maar toch heb ik mijn collega's gemist!

Erica, zonder jou was dit proefschrift nooit geworden wat het is. Ik grap soms dat jouw naam ook wel op de kaft van dit boekje had mogen staan, maar ik meen wel echt dat jij een waanzinnig grote bijdrage hebt geleverd. Onze sparringsessies, je kritische blik op mijn grammatica, je actieve rol in de verpleeghuizen, je flexibiliteit, je gezelligheid en ga zo maar door. Ik ben niet alleen een waardevolle collega rijker, maar heb er ook een vriendschap bijgekregen!

Linda, ook wij hebben een hechte vriendschap opgebouwd de afgelopen jaren, en zelfs met onze mannen samen. Bedankt voor al je steun de afgelopen jaren. Onze conferentiebezoekjes naar Rome, Boston en Austin zal ik nooit vergeten (Lydia Koek, dessert in een vissenkom op je verjaardag, cocktails in Austin, Hook 'em Horns en ga zo maar door). Ondertussen ben je gesetteld in Enschede met je gezin, een gemis voor Eindhoven, maar het is je zo gegund! Dankjewel dat je altijd achter mij staat, nu zelfs letterlijk als mijn paranimf.

Theresa, wij kennen elkaar alweer een hele tijd en ik vind het zo leuk dat we collega's zijn geworden vier jaar geleden. Ik heb veel bewondering voor hoe je bent als vriendin, collega en moeder van je twee jongens. Je weet altijd de kalmte te bewaren, tijd te maken voor wie je nodig heeft en je hebt je prioriteiten op de juiste plaats - een echt voorbeeld! Dankjewel dat jij mijn paranimf wilt zijn. 
Angela, we zijn pas het laatste jaar kamergenoten geworden, maar wat een succesverhaal is het geweest! Onze gedeelde passies voor reizen en eten hebben altijd gezorgd voor de leukste gesprekken. Ook ben je er altijd voor mij geweest als uitlaatklep en heb ik altijd zoveel gelachen tijdens de lunch, op onze kamer en tegenwoordig via zoom. Ik ben blij dat je bij de OU zo op je plek zit. Aan jou hebben ze echt een goede, zowel voor het onderwijs en de wetenschap, als voor de gezelligheid. Roy, wij zijn al sinds jouw eerste dag kamergenoten, en wat een geluk is dat geweest! Wij verschillen ontzettend van elkaar en daarom zijn het juist zulke leuke jaren geweest. Onze gesprekken - die varieerden van onderwerpen als huizen kopen, verbouwen, financiën en dialect tot aan samen stoom afblazen, sparren en successen vieren - hebben de afgelopen vier jaren stukken leuker gemaakt. Ik hoop dat we contact zullen houden als jij klaar bent! Ruth, wat was het gezellig toen jij naar onze kamer verhuisde. Je hebt elke kamer op DUB30 uitgetest, en ik hoop dat 0.050 je favoriet is geworden. Wat heb jij toch een bruisende persoonlijkheid! Altijd als je er was, gaf je me weer energie en je had altijd tijd voor een praatje. De ene keer wat serieuzer dan de andere, maar altijd gezellig. Ondertussen ben jij aan de slag met je nieuwe baan die volgens mij perfect bij je past. Hopelijk kunnen we gauw eens een keertje gaan borrelen en proosten op het feit dat onze boekjes af zijn! Mirre, ook wij zijn lang kamergenootjes geweest. Je hebt mij geleerd dat promoveren meer is dan hard werken. Dankzij jou heb ik altijd tijd genomen voor een lunchpauze, een kopje thee of een wandeling. Je hebt me geleerd hoe alles op DUB30 werkt. Ondertussen ben je alweer een tijdje weg, en getrouwd en gesetteld in het 'noorden' van het land, maar 0.050 mist je nog altijd.

Johanna, ik heb nog niet vaak een nieuwe promovendus gezien die zo snel alles onder de knie heeft als jij. Onze samenwerking vind ik superfijn en de gezellige gespreken eveneens. Jij bent een van de weinige collega's die ik bijna dagelijks heb gesproken sinds het thuiswerken in maart, en dit heeft elke werkdag toch echt een stuk leuker gemaakt! Ik hoop dat we nog lange tijd collega's mogen zijn. Svenja, wat hebben wij veel over wereldcafés en systematic reviews gepraat, haha. Gelukkig gingen deze gesprekken altijd gepaard met veel gezelligheid en andere gespreksonderwerpen. Ons reisje naar Austin was echt fantastisch, en ik hoop dat we samen in de toekomst nog meer leuke congressen mogen bezoeken! Annick, ik wilde laten weten dat je trots op jezelf mag zijn en dat DUB30 je mist. Je was echt een superfijne collega, die de werkvloer altijd net dat beetje gezelliger wist te maken! Sil, toen jij bij ons kwam werken, werd je meteen in het diepe gegooid in mijn onderzoek. We moesten samen even zoeken hoe we het beste alles konden organiseren en ik denk dat we ondertussen een fijne samenwerking hebben gevonden. Je bent een toevoeging voor de afdeling! Audrey, ook jou wil ik bedanken voor je inzet voor Ruimte voor Zorg. Je bent een fijne collega die graag wil helpen waar mogelijk en openstaat om nieuwe dingen te leren. Bedankt voor al je hulp! Bram, jij kreeg de taak van Hilde om de begeleiding van mijn onderzoek over te nemen vanwege haar zwangerschapsverlof. Jouw pragmatische aanpak heeft mij geholpen om mijn eerste data-verzameling in het verpleeghuis gewoon te gaan doen. Bedankt voor al je advies en support de afgelopen jaren. 
Ook wil ik mijn dank en waardering uiten aan de ondersteunende stafleden, die mij hebben geholpen met elke vraag, zo gek als je ze maar kan bedanken. Ik heb er veel bewondering voor hoe jullie alle ballen en agenda's hooghouden! Bedankt Brigitte, Bernike, Joanna, Ine, Willy-Anne, Suus, Janet, Dennis en Arnold. Er zijn nog heel veel andere collega's die ik zou willen bedanken, maar volgens mij is het de bedoeling dat het dankwoord korter is dan de overige hoofdstukken in dit proefschrift. Dus als je je naam hier niet tussen ziet staan en je hebt me wel geholpen of ondersteund, dan ook naar jou een woord van dank. Bedankt allemaal voor de gezellige tijd.

Zonder mijn lieve familie en vrienden, had ik vast nooit de stap durven zetten om van baan te wisselen en terug naar Maastricht te gaan om te promoveren. Inge, Marinke, Cindy en Theresa, wij hebben elkaar leren kennen tijdens de bachelor Gezondheidswetenschappen. Ik weet dat ik niet altijd de perfecte studiegenoot was, maar ik vond het een hele gezellige tijd met jullie. Ik ben blij dat we al die jaren contact hebben gehouden.

Justus, Loek, Marloes en Joep, het is altijd weer een genot als jullie langskomen voor een biertje, dartpijltjes gooien of gewoon een goed gesprek. Die gezellige avonden hebben er altijd voor gezorgd dat ik even kon afschakelen van werk om vervolgens weer te knallen. Ik begrijp waarom jullie zo belangrijk voor Simon zijn en ben blij dat ik jullie ook als vrienden erbij heb gekregen!

Miriam, jij hebt mij laten zien dat werk en vriendschap prima samengaan en dankzij jou was werken bij Mapi absoluut geen straf. Ik heb nog niet vaak iemand ontmoet met wie ik zoveel gelijkenissen deel, van gedachtespinsels, woordgrappen en dezelfde zorgen, tot aan kledingstijl en liefde voor lekker eten. Afscheid nemen van jou als collega was een van de moeilijkste dingen in de transitie naar mijn PhD. Ik ben blij dat - ongeacht de afstand - onze vriendschap stand heeft gehouden! We zien elkaar wellicht minder dan vroeger, maar weet dat onze vriendschap mij heel dierbaar is.

Daphne, wij kennen elkaar ondertussen alweer langer dan 18 jaar en zijn echt samen opgegroeid tot 'volwassenen'. We hebben van alles meegemaakt in die tijd, waaronder grote successen zoals ons eerste reisje naar Londen samen, maar ook diepe dalen zoals het verlies van dierbaren. We zijn beiden heel verschillend, maar dat is juist ook de kracht van onze vriendschap. Ik verheug me op nog vele etentjes, (slechte) films en nostalgische momenten. Bedankt dat je er altijd voor me bent!

Femke, er zijn weinig mensen die zo sterk zijn als jij. We wonen dan wellicht niet (meer) in dezelfde stad, toch zijn we altijd op de hoogte van elkaars levens. Onze koffietjes en etentjes zijn altijd heel waardevol voor mij geweest om even te reflecteren op hoe alles gaat en om met iemand het lief en leed dat promoveren heet te kunnen delen. Laten we dat erin houden! 
Lieve TGIFJES, where to begin. Het begon allemaal in Maastricht...vrouwen met klote(n). Als je ons eenmaal kent, dan weet je dat daar maar weinig van waar is, maar toppers zijn jullie zeker. Ik weet niet hoe ik de afgelopen vier jaar zonder jullie was doorgekomen. En ook jullie tones beschouw ik ondertussen als goede vrienden! Mijn hoop is nog altijd dat er een dag komt dat heel TGIF zich in Eindhoven zal settlen. Lizzie, je luisterend oor en steun zijn zoveel waard, ik ken weinig mensen die zo lief zijn als jij. Ik ben trots op je dat je een stap in het diepe neemt en ben benieuwd naar je volgende avonturen. Renee, mijn mede gezondheidswetenschapper in de groep, je nuchterheid, openheid en betrokkenheid zijn je kracht. Het congres waar we samen heen mochten zal ik nooit vergeten; er is niks zo leuk als met een goede vriendin naar je werk te gaan. Succes met het afronden van je eigen PhD! Cécile, ik bewonder je passie voor de geneeskunde en het onderzoek, maar nog meer je crazy gezelligheid. Ongeacht hoe druk je het hebt, je maakt altijd tijd voor je vrienden, en ik vind het altijd weer zo leuk als je langskomt! Laura, ik ben zo blij dat jullie in Eindhoven zijn komen wonen. Onze spontane dinertjes, koffietjes, boulderen en borrelavonden hebben de stres van het promoveren weten te verzachten. Ik bewonder hoe stabiel je in het leven staat en je droom om huisarts te worden werkelijkheid hebt gemaakt. Es, we hebben veel lief en leed samen gedeeld, en ik bewonder het hoe jij je dromen najaagt. Jij hebt mij geleerd om lekker te koken, voor mijzelf op te komen en soms een risico te nemen. Ik mis de tijden dat we elkaar dagelijks in Maastricht zagen voor koffie, kaas, drank en dutjes; maar ben zo blij dat je lekker gesetteld bent in Utrecht. Just remember, KaEs is going nowhere! Lieve, toen jij besloot naar Zweden te verhuizen moest ik wel even slikken, maar de dapperheid om de stap te nemen siert je! We begrijpen elkaar altijd zo goed, zelfs zonder woorden te gebruiken. Je mag trots zijn op waar je nu staat, en ik hoop dat de afronding van je PhD vlot zal verlopen! Dionne, mijn partner in crime, het begon al toen we 16 waren. Ik vind het zo leuk hoe we beiden steeds onze eigen weg kiezen en uiteindelijk toch weer in dezelfde stad belanden. Jouw loyaliteit, gezelligheid, mafheid en betrokkenheid maken je zo een fijn persoon. Ik ben blij dat we al zoveel hilarische dingen samen hebben meegemaakt en verheug me op many more to come. Subje faal, we've got this!

Ook mijn lieve schoonfamilie wil ik bedanken. Ik ken maar weinig families die zo hecht zijn en zoveel onvoorwaardelijke steun geven aan elkaar, en ben dan ook trots dat ik sinds 2019 ook een Bergje ben! René en Katinka, ik beschouw jullie als mijn extra ouders en ik vind het heel fijn dat jullie altijd voor ons klaar staan. Reggy en Ingrid, voor jullie geldt eigenlijk precies hetzelfde. Roos, David, Jack en Liv, ik bewonder jullie als gezin; ik geniet altijd van onze gesprekken en ben dol op de kids. Marijn en Eva, onze gedeelde liefde voor reizen en kerstmis zorgt ervoor dat het altijd gezellig is als wij elkaar zien! Marijn, ik vind het heel bijzonder dat jij de kaft van mijn proefschrift hebt ontworpen. Nogmaals: superbedankt daarvoor! Maarten, helaas heb ik jou nooit leren kennen, maar van alle verhalen die ik heb gehoord weet ik zeker dat jij voor mij de ideale schoonbroer was geweest. 
Marleen en Patrick, ik beschouw jullie als mijn tante en oom. Elke keer als wij elkaar zien is het ontzettend gezellig, en wij prijzen onszelf gelukkig dat mama zulke lieve, warme, oprechte en genereuze vrienden heeft.

Ben, wij moesten even aan elkaar wennen, maar ik ben heel blij dat mama en jij gelukkig zijn samen. Bedankt voor alle goede gesprekken en lekkere drankjes elke keer als wij langskomen.

Oma, jij bent het perfecte voorbeeld hoe ik oud wil worden: lekker met de tablet op de bank, genietend van goed eten en vele potjes scrabble. Ik verheug mij op nog vele jaren gevuld met gezelligheid.

Felix, Carlien en Josephine, ik ben zo blij dat jullie het geluk in Heerlen hebben gevonden en ik word altijd zo gelukkig als ik weer een foto van jullie voorbij zie komen. Carlien, bedankt dat jij er altijd voor de Sions bent! Josephine, ik kan niet wachten om je te zien opgroeien, ik ben zo trots om jouw tante te zijn. Felix, wij zeggen het altijd, maar wij zien elkaar te weinig. Daartegenover staat dat als wij elkaar zien, het altijd zo ontzettend gezellig is! Jij begrijpt mij als geen ander, en je bent de beste grote broer die ik mij ooit had kunnen wensen.

Daddy, you gave me the courage to believe in myself. Unfortunately, you never got the chance to see how Felix and I grew up; however, people have told us you would be proud. Your wisdom, life stance, and unconditional love for your family made me who I am today. I still miss you and want to thank you for being the best Daddy in the world!

Mama, voor mij ben jij een powervrouw. Ik weet niet hoe ik jou ooit zou kunnen bedanken. Waarschijnlijk had jij vroeger ook nooit gedacht dat je dochter in je voetsporen zou treden, maar ook ik ben gezwicht voor de wetenschap. Met de dag zie ik meer hoe ik op je lijk en daar ben ik trots op. Bedankt voor je steun in alle keuzes die ik tot nu toe in mijn leven heb gemaakt. Ik hoop net zo een goede moeder te worden als jij!

Simon, you are the love of my life and together it's us! You inspire me every single day. I admire your dedication, caring nature and unconditional love for the people around you. When I started my PhD, I had many doubts and felt insecure, thrown in the deep and completely lost. If it wasn't for you, who knows what I would be doing right now, but you encouraged me to push through and supported me all along. Thank you for being my rock! I look forward to an amazing future with you filled with funnies, adventures, our own little family and lots of love. I love you! 

ABOUT THE AUTHOR 

Katya Sion was born on June 6, 1990 in Heerlen, the Netherlands. In 2008, she completed secondary school at 'Bernardinuscollege' and in 2012 she received her Bachelor's degree in Health Sciences at Maastricht University, specializing in policy and management. Additionally, she participated in the Erasmus exchange program at Karolinska Institutet (Sweden) attending classes in nutrition and physical activity. In 2013, Katya received her Master's degree in Healthcare Policy, Innovation and Management at Maastricht University. Alongside her studies, she was a research assistant supporting data collection for multiple studies at MUMC+. In 2014, Katya started her professional career as a junior research associate within the department of Health Economics and Outcomes Research at Mapi B.V. (currently known as ICON). She grew into the position of analyst and became a senior analyst in 2016 leading multiple project teams and specializing in systematic literature reviews, network meta-analyses and market access development for pharmaceutical products. In 2017, Katya started working as a PhD-candidate within the 'Living-Lab in Ageing and LongTerm Care' at the department of Health Services Research at Maastricht University. During her PhD she developed the narrative method 'Connecting Conversations' that assesses experienced quality of care in nursing homes from the resident's perspective. Katya will continue working at Maastricht University as a post-doc, during which she will pursue her scientific research on improving quality of long-term care. She aims to bring theory and practice closer together by adopting a theory-based practice-applied approach in co-creation with all relevant stakeholders. 

SCIENTIFIC PUBLICATIONS 



\section{INTERNATIONAL PUBLICATIONS}

Sion KYJ, Rutten JER, Verbeek H, De Vries E, Zwakhalen SMG, Odekerken-Schröder GJ, Schols JMGA, Hamers JPH. Listen, Look, Link and Learn: a stepwise approach to analyze narrative quality data within resident-family-nursing staff triads in nursing homes. Submitted

Sion KYJ, Verbeek H, Aarts S, Zwakhalen SMG, Odekerken-Schröder GJ, Schols JMGA, Hamers $\mathrm{JPH}$. The Validity of Connecting Conversations: A Narrative Method to Assess Experienced Quality of Care in Nursing Homes from the Resident's Perspective. International Journal of Environmental Research and Public Health, 2020; 17(14):5100

Sion KYJ, Verbeek H, De Vries E, Zwakhalen SMG, Odekerken-Schröder GJ, Schols JMGA, Hamers JPH. The Feasibility of Connecting Conversations: A Narrative Method to Assess Experienced Quality of Care in Nursing Homes from the Resident's Perspective. International Journal of Environmental Research and Public Health, 2020; 17(14):5118

Sion KYJ, Verbeek H, De Boer B, Zwakhalen SMG, Odekerken-Schröder GJ, Schols JMGA, Hamers JPH. How to assess experienced quality of care in nursing homes from the client's perspective: results of a qualitative study. BMC Geriatrics, 2020; 20(67):1-12

Sion KYJ, Verbeek H, Zwakhalen SMG, Odekerken-Schröder GJ, Schols JMGA, Hamers JPH. Themes Related to Experienced Quality of Care in Nursing Homes from the Resident's Perspective: A Systematic Literature Review and Thematic Synthesis. Gerontology \& Geriatric Medicine, 2020; 5:1-16

Sion KYJ, Haex R, Verbeek H, Zwakhalen SMG, Odekerken-Schröder GJ, Schols JMGA, Hamers $\mathrm{JPH}$. Experienced Quality of Post-Acute and Long-Term Care from the Care Recipient's Perspective-A Conceptual Framework. JAMDA, 2019; 20(11):1386-1390

Sion KYJ, Huisman EL, Punekar YP, Naya I, Ismaila AS. A Network Meta-Analysis of Long-Acting Muscarinic Antagonist (LAMA) and Long-Acting $\beta 2$-Agonist (LABA) Combinations in COPD. Pulmonary Therapy, 2017; 3:297-316

Gaultney J, Benucci M, lannazzo S, Nappi C, Sion KYJ, Sabater FJ. Trial-based costeffectiveness of abatacept for rheumatoid arthritis patients in Italy. Expert Review of Pharmacoeconomics \& Outcomes Research, 2016; 16(3):409-417

\section{NATIONAL PUBLICATIONS}

Sion KYJ, Verbeek H, De Vries E, Zwakhalen SMG, Odekerken-Schröder GJ, Schols JMGA, Hamers JPH. Ruimte voor Zorg Meet Ervaren Kwaliteit in Verpleeghuizen door Verhalen te Verbinden. SENIOR, 2020; 1(4):3-9 


\section{CONFERENCE CONTRIBUTIONS}

Sion, KYJ, Verbeek, H, Zwakhalen, SMG, Odekerken-Schröder, G, Schols, JMGA, Hamers, JPH. Assessing Experienced Quality of Care in Nursing Homes; a Narrative Approach. [Oral presentation scheduled on 20 June 2020, Nursing Home Research Meeting 2020, Leiden, NL - cancelled due to COVID-19]

Sion, KYJ, Verbeek, H, Zwakhalen, SMG, Odekerken-Schröder, G, Schols, JMGA, Hamers, JPH. Connecting Conversations to Assess Experienced Quality of Care in Nursing Homes from the Resident Perspective. [Oral presentation scheduled on 8 May 2020, International Conference of the German Society of Nursing Science, Berlin, DE - cancelled due to COVID-19]

Sion, KYJ, Verbeek, H, Aarts, S, Zwakhalen, SMG, Odekerken-Schröder, G, Schols, JMGA, Hamers, JPH. Ruimte voor Zorg: het verhaal van de bewoner, familie en zorgverlener verbinden. 2020. [Oral Presentation, Geriatriedagen 2020, Den Bosch, NL]

Sion, KYJ, Verbeek, H, Zwakhalen, SMG, Odekerken-Schröder, G, Schols, JMGA, Hamers, JPH. Facilitating Care: A Narrative Approach to Assess Experienced Quality of Care. Innovation in Aging, 2019; 4(suppl_1):S73 [Oral Presentation, Gerontological Society of America Conference (GSA) 2019, Austin, USA]

Sion, KYJ, Verbeek, H, Aarts, S, Zwakhalen, SMG, Odekerken-Schröder, G, Schols, JMGA, Hamers, JPH. (2019). Ruimte voor Zorg: De Ontwikkeling van een Narratieve Methode om Ervaren Kwaliteit te Meten. Tijdschrift voor Gerontologie en Geriatrie, 2019; S4.1 [Oral Presentation, Gerontologiecongres 2019, Ede, NL]

Sion, KYJ, Haex, R, Verbeek, H, De Boer, B, Zwakhalen, SMG, Odekerken-Schröder, G, Schols, JMGA, Hamers, JPH. INDEXQUAL: a Conceptual Model of Individually Experienced Quality of Long-term Care. Innovation in Aging, 2018; 2(suppl_1):723-724 [Poster Presentation, Gerontological Society of America Conference (GSA) 2018, Boston, USA].

Sion, KYJ, Verbeek, H, De Boer, B, Zwakhalen, SMG, Odekerken-Schröder, G, Schols, JMGA, Hamers, JPH. Developing a Method to measure Experienced Quality of Care in Nursing Homes. Innovation in Aging, 2018; 2(suppl_1):421-422 [Oral Presentation, Gerontological Society of America Conference (GSA) 2018, Boston, USA]

Sion, KYJ, Verbeek, H, De Boer, B, Zwakhalen, SMG, Odekerken-Schröder, G, Schols, JMGA, Hamers, JPH. Policy Makers', Caregivers' and Client Representatives' Views on How Quality of Care in Nursing Homes Should be measured from the Resident's Perspective: a Qualitative Needs Assessment. The Journal of Nursing Home Research Sciences, 2018; 4:S22. [Poster Presentation, Nursing Home Research Meeting 2018, Rome, IT]

Sion, KYJ, Verbeek, H, De Boer, B, Zwakhalen, SMG, Odekerken-Schröder, G, Schols, JMGA, Hamers, JPH. The Development of a Method that Measures Quality of Care in Nursing Homes: A Relationship-Centered Care Approach. 2018 [Oral Presentation, European Doctoral Conference in Nursing Science 2018, Maastricht, NL] 


\section{LIVING LAB IN AGEING AND LONG-TERM CARE}





\section{LIVING LAB IN AGEING AND LONG-TERM CARE}

This thesis is part of the Living Lab in Ageing and Long-Term Care, a formal and structural multidisciplinary network consisting of Maastricht University, nine longterm care organizations (MeanderGroep Zuid-Limburg, Sevagram, Envida, Cicero Zorggroep, Zuyderland, Vivantes, De Zorggroep, Land van Horne \& Proteion), Intermediate Vocational Training Institutes Gilde and VISTA college and Zuyd University of Applied Sciences, all located in the southern part of the Netherlands. In the Living Lab we aim to improve quality of care and life for older people and quality of work for staff employed in long-term care via a structural multidisciplinary collaboration between research, policy, education and practice. Practitioners (such as nurses, physicians, psychologists, physio- and occupational therapists), work together with managers, researchers, students, teachers and older people themselves to develop and test innovations in long-term care.

\section{ACADEMISCHE WERKPLAATS OUDERENZORG LIMBURG}

Dit proefschrift is onderdeel van de Academische Werkplaats Ouderenzorg Limburg, een structureel, multidisciplinair samenwerkingsverband tussen de Universiteit Maastricht, negen zorgorganisaties (MeanderGroep Zuid-Limburg, Sevagram, Envida, Cicero Zorggroep, Zuyderland, Vivantes, De Zorggroep, Land van Horne \& Proteion), Gilde Zorgcollege, VISTA college en Zuyd Hogeschool. In de werkplaats draait het om het verbeteren van de kwaliteit van leven en zorg voor ouderen en de kwaliteit van werk voor iedereen die in de ouderenzorg werkt. Zorgverleners (zoals verpleegkundigen, verzorgenden, artsen, psychologen, fysio- en ergotherapeuten), beleidsmakers, onderzoekers, studenten en ouderen zelf wisselen kennis en ervaring uit. Daarnaast evalueren we vernieuwingen in de dagelijkse zorg. Praktijk, beleid, onderzoek en onderwijs gaan hierbij hand in hand. 


\section{PHD-THESES LIVING LAB IN AGEING AND LONG-TERM CARE/ PROEFSCHRIFTEN ACADEMISCHE WERKPLAATS OUDERENZORG LIMBURG}

Katya Sion. Connecting Conversations. Experienced quality of care from the resident's perspective: a narrative method for nursing homes. 2021

Linda Hoek. Change begins with choice. Supporting the autonomy of nursing home residents with dementia through partnership. 2020

Mirre den Ouden. Every step counts. Daily activities of nursing home residents and the role of nursing staff. 2018

Theresa Thoma-Lürken. Innovating long-term care for older people. Development and evaluation of a decision support app for formal caregivers in community-based dementia care. 2018

Eveline van Velthuijsen. Delirium in older hospitalised patients: diagnosis and management in daily practice. 2018

Bram de Boer. Living at a green care farm. An innovative alternative for regular care in nursing homes for people with dementia. 2017

Nienke Kuk. Moving forward in nursing home practice. Supporting nursing staff in implementing innovations. 2017

Irma Everink. Geriatric rehabilitation. Development, implementation and evaluation of an integrated care pathway for older patients with complex health problems. 2017 Ramona Backhaus. Thinking beyond numbers. Nursing staff and quality of care in nursing homes. 2017

Martin Van Leen. Prevention of pressure ulcers in nursing homes, a big challenge. 2017

Mariëlle Daamen-Van der Velden. Heart failure in nursing home residents. Prevalence, diagnosis and treatment. 2016

Armand Rondas. Prevalence and assessment of (infected) chronic wounds. 2016

Hanneke Beerens. Adding life to years. Quality of life of people with dementia receiving long-term care. 2016 (Cum Laude)

Donja Mijnarends. Sarcopenia: a rising geriatric giant. Health and economic outcomes of community-dwelling older adults with sarcopenia. 2016 
Tanja Dorresteijn. A home-based program to manage concerns about falls. Feasibility, effects and costs of a cognitive behavioral approach in community-dwelling, frail older people. 2016

Basema Afram. From home towards the nursing home in dementia. Informal caregivers' perspectives on why admission happens and what they need. 2015

Noemi Van Nie-Visser. Malnutrition in nursing home residents in the Netherlands, Germany and Austria. Exploring and comparing influencing factors. 2014

Esther Meesterberends. Pressure ulcer care in the Netherlands versus Germany 0-1. What makes the difference? 2013

Math Gulpers. EXBELT: expelling belt restraints from psychogeriatric nursing homes. 2013

Hilde Verbeek. Redesigning dementia care. An evaluation of small-scale homelike care environments. 2011

Judith Meijers. Awareness of malnutrition in health care, the Dutch perspective. 2009 Ans Bouman. A home visiting program for older people with poor health. 2009 Monique Du Moulin. Urinary incontinence in primary care, diagnosis and interventions. 2008

Anna Huizing. Towards restraint free care for psychogeriatric nursing home residents. 2008

Pascalle Van Bilsen. Care for the elderly, an exploration of perceived needs, demands and service use. 2008

Rixt Zijlstra. Managing concerns about falls. Fear of falling and avoidance of activity in older people. 2007

Sandra Zwakhalen. Pain assessment in nursing home residents with dementia. 2007 